$$
\text { DOE/ET/51013--T249 }
$$

FY97-FY98 WORK PROPOSAL

MARCH 1996

Submitted to

OFFICE OF FUSION ENERGY

U.S. DEPARTMENT OF ENERGY

WASHINGTON, D.C. 20545

\title{
ALCATOR DIVISION
}

I.H. Putth -

Ian H. Hutchinson

Alcator Division Head

Milllos Polvolab

Miklos Porkolab

Director, Plasma Fusion Center
Julie T. Norris

Director

- Office of Sponsored Programs 
$\because \quad \therefore \quad \therefore \%$ 


\section{DOE CONFINEMENT DIVISION FY97-98 TASK PROPOSAL}

\section{TABLE OF CONTENTS}

PAGE

\section{ALCATOR C-MOD}

1. Alcator C-Mod Executive Summary $\ldots \ldots \ldots \ldots \ldots \ldots \ldots \ldots \ldots$

2. Alcator C-Mod Research $\ldots \ldots \ldots \ldots \ldots \ldots \ldots \ldots \ldots \ldots \ldots$

2.1 Alcator C-Mod Transport $\ldots \ldots \ldots \ldots \ldots \ldots \ldots \ldots \ldots \ldots, 9$

2.2 Alcator C-Mod Divertor Physics ................. 15

2.3 Alcator C-Mod MHD, Control \& Plasma Physics Operations .. 23

2.4 Alcator C-Mod RF and Current Drive ................ 26

2.5 Advanced Tokamak Physics Research ................ 34

3. Alcator C-Mod Engineering Operations $\ldots \ldots \ldots \ldots \ldots \ldots \ldots .41$

4. Alcator C-Mod Publications Summary ................ 49

Budgets $\ldots \ldots \ldots \ldots \ldots \ldots \ldots \ldots \ldots \ldots \ldots \ldots \ldots \ldots \ldots \ldots, 51$

Appendix A: Detailed Publications $\ldots \ldots \ldots \ldots \ldots \ldots \ldots \ldots \ldots \ldots$ A -1

Appendix B: Collaborations $\ldots \ldots \ldots \ldots \ldots \ldots \ldots \ldots \ldots \ldots \ldots \ldots \ldots \ldots \ldots \ldots \ldots \ldots$

\section{DISCLAIMER}

This report was prepared as an account of work sponsored by an agency of the United States Government. Neither the United States Government nor any agency thereof, nor any of their employees, makes any warranty, express or implied, or assumes any legal liability or responsibility for the accuracy, completeness, or usefulness of any information, apparatus, product, or process disclosed, or represents that its use would not infringe privately owned rights. Reference herein to any specific commercial product, process, or service by trade name, trademark, manufacturer, or otherwise does not necessarily constitute or imply its endorsement, recommendation, or favoring by the United States Government or any agency thereof. The views and opinions of authors expressed herein do not necessarily state or reflect those of the United States Government or any agency thereof: 

U.S. DEPARTMENT OF ENERGY

FELD WORK PACKAGE PROPOSALAGREEMENT

\begin{tabular}{|c|c|c|c|c|c|}
\hline 1.WORKPACKAGE NUMBER & 2. REVISION NO. & \multicolumn{2}{|c|}{ 3. CONTRACTORNO. } & \multicolumn{2}{|l|}{$\begin{array}{r}\text { 4. DATE PREPARED } \\
3 / 18 / 96 \\
\end{array}$} \\
\hline \multicolumn{4}{|l|}{ 5.WORK PACKAGE TITLE } & \multicolumn{2}{|l|}{ 6.BUDGETAND REPORTNGCODE } \\
\hline $\begin{array}{l}\text { 7. CONTRACT NUMBER } \\
\text { DE-AC02-78ET-51013 }\end{array}$ & 8. PHASE & \begin{tabular}{rr|} 
9. PROJECT NUMBER & \\
& 1
\end{tabular} & $\begin{array}{l}10 . \mathrm{CC} \\
\text { Begin } \\
1 / 1\end{array}$ & \multicolumn{2}{|l|}{$\begin{array}{l}\text { End : }(\mathrm{mm} \text { dd } y y) \\
\qquad 12 / 31 / 97\end{array}$} \\
\hline $\begin{array}{lc}11 . \text { WORK PACKAGE TERM } & \\
\text { Begin : }(\mathrm{mm} \text { dd } \mathrm{w}) & \text { End : }(\mathrm{mm} \text { dd } \mathrm{y} \\
10 / 1 / 95 & 9 / 30 / 98\end{array}$ & $\begin{array}{l}\text { 12. Does this work package } \\
\text { any management service } \\
\text { N/A }\end{array}$ & $\begin{array}{l}\text { include []YES } \\
\text { e efforts }\{] \text { NO }\end{array}$ & & $\begin{array}{l}\text { his work package included in the } \\
\text { itutional Plan? } \\
\text { N/A }\end{array}$ & $\begin{array}{l}\text { [] YES } \\
\text { [] NO }\end{array}$ \\
\hline \multicolumn{2}{|l|}{$\begin{array}{l}\text { 14. NAME (Last First, MI) } \\
\text { HEADQUARTERS PROGRAM MANAGER: } \\
\text { Priester, Donald }\end{array}$} & \multirow{2}{*}{\multicolumn{3}{|c|}{$\begin{array}{l}\text { 17. HEADQUARTERS ORGANIZATION: } \\
\text { Department of Energy } \\
\text { Office of Fusion Energy } \\
\text { 18. OPERATIONS OFFICE: } \\
\text { Chicago Operations Office }\end{array}$}} & $\begin{array}{l}\text { DOE ORGANIZATION } \\
\text { COOE }\end{array}$ \\
\hline \multicolumn{2}{|c|}{$\begin{array}{l}\text { 15. OPERATONSOFFICEAW WORK PACKAGE MANAGER: } \\
\text { Wice, L. Mark }\end{array}$} & & & & $\begin{array}{l}\text { DOE ORGANLATION } \\
\text { CODE }\end{array}$ \\
\hline $\begin{array}{l}\text { 16. CONTRACTOR WORK PACKAGE MANAGEF } \\
\text { Hutchinson, Ian } \mathrm{H} \text {. }\end{array}$ & & \multicolumn{3}{|c|}{$\begin{array}{l}\text { 19. CONTRACTOR NAME: } \\
\text { Massachusetts Institute of Technology }\end{array}$} & CODE (See instructions) \\
\hline \multicolumn{6}{|c|}{ 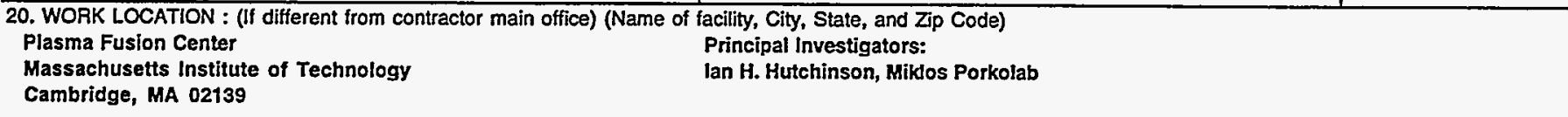 } \\
\hline
\end{tabular}

21. WORK PACKAGE DESCRIPTION (Approach, anticipated benefit in 200 words or less:)

See Attachment

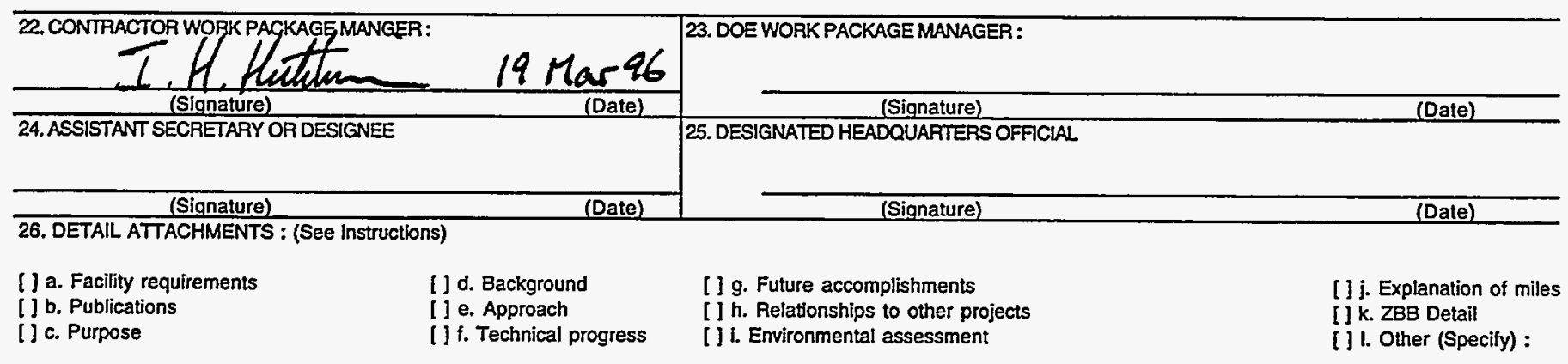




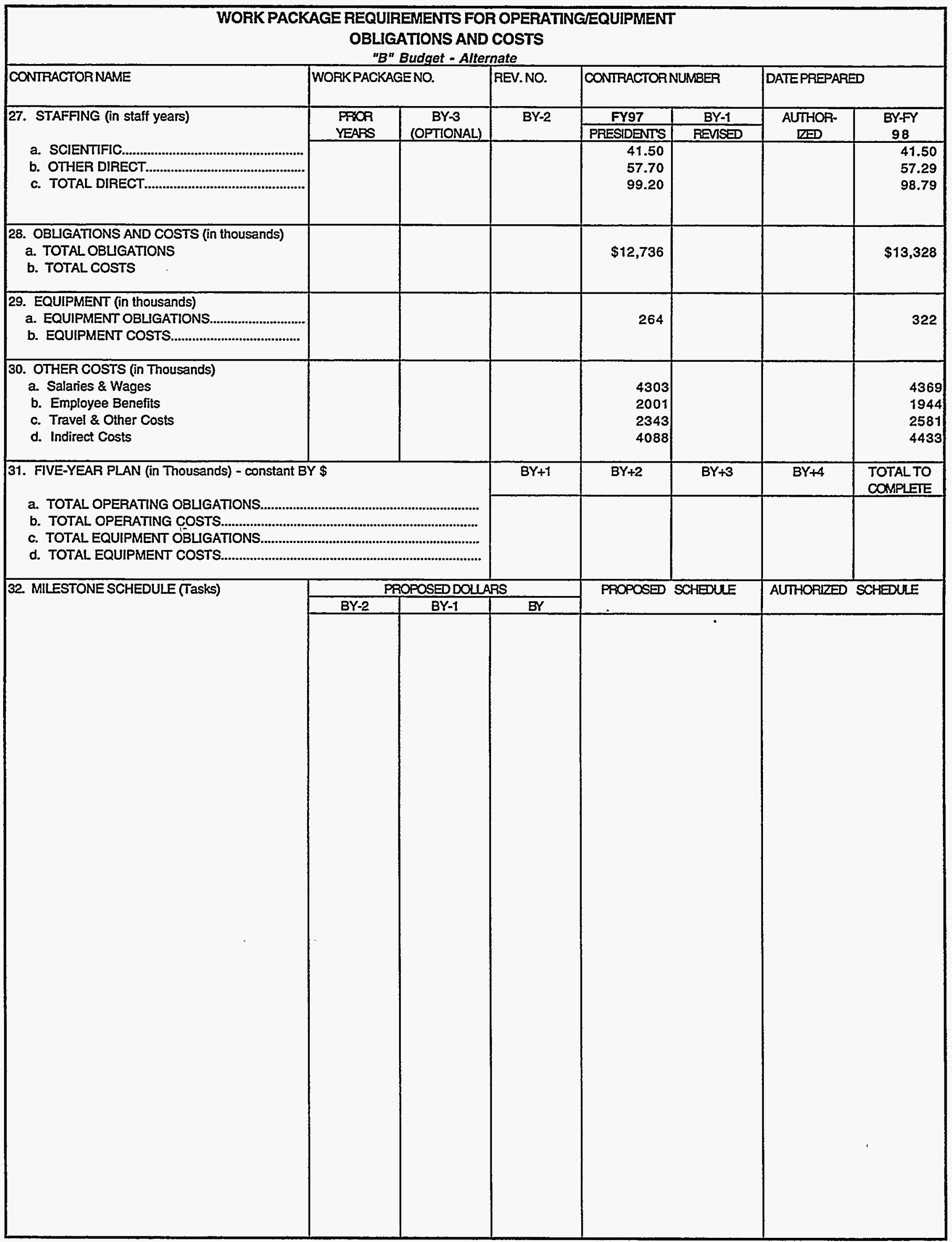




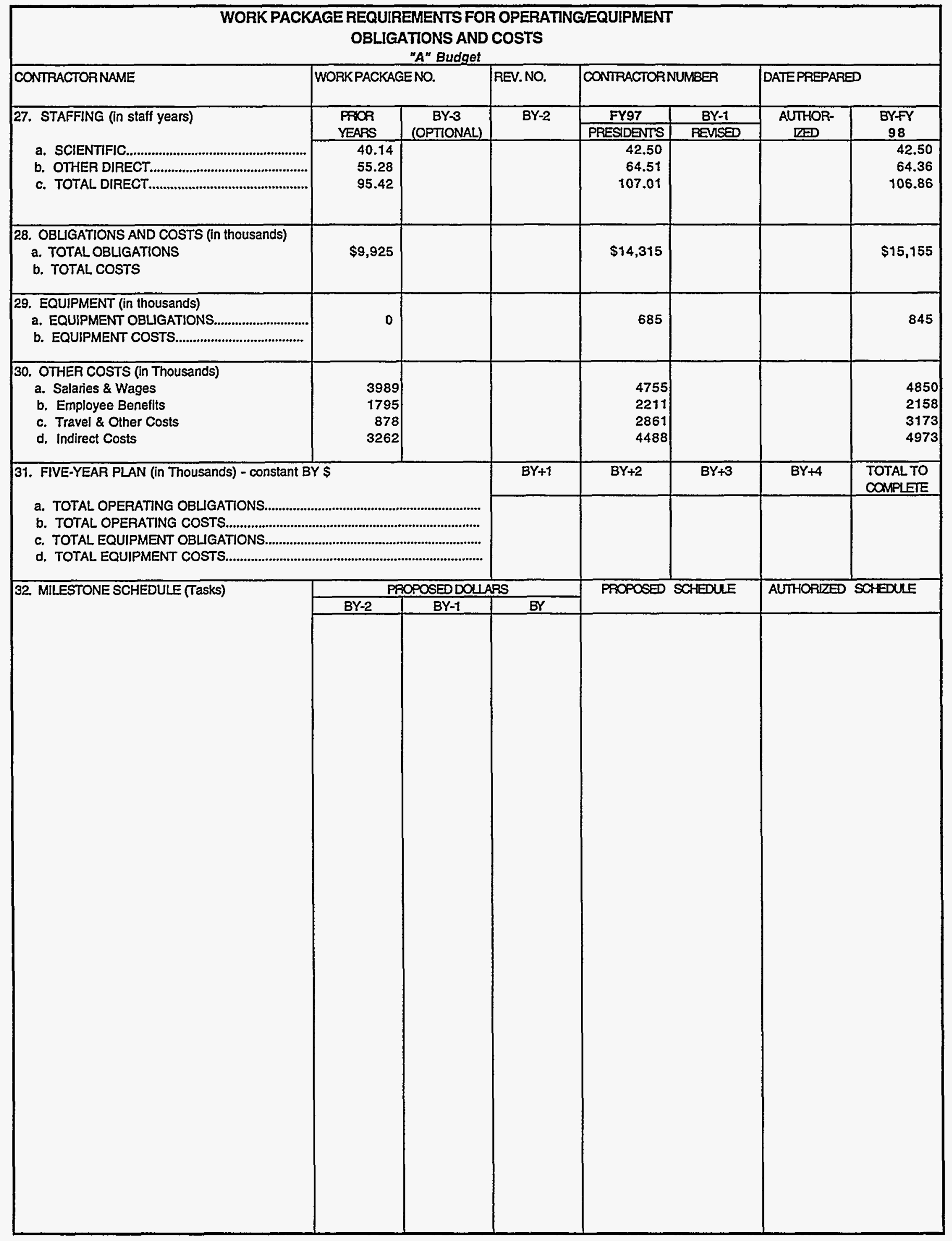




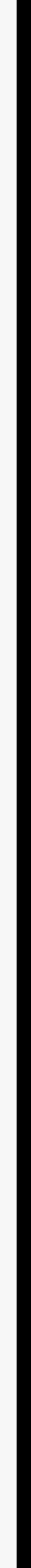




\section{ALCATOR C-MOD EXECUTIVE SUMMARY}

Alcator C-Mod is the high-field, high-density divertor tokamak in the world fusion program, see figure 1-1. It is one of five divertor experiments capable of plasma currents exceeding one megamp. Of these, JET and JT60-U, are the flagships of their national programs, and DIIID and ASDEX Upgrade are intermediate size and field devices. The current density in Alcator C-Mod, for example, is about eight times that in DIIID and JET. This positioning provides an overall theme to the Alcator program:

Compact high-performance divertor tokamak research to establish the plasma physics and plasma engineering necessary for an ignited tokamak experiment and for attractive fusion reactors.

Because of its compact dimensions, Alcator C-Mod investigates an essential area in parameter space, which complements the world's larger experiments, in establishing the tokamak physics database.

Three key areas of investigation have been called out in which Alcator C-Mod has a vital role to play.

- Divertor research on C-Mod takes advantage of the advanced divertor shaping, the very high scrape-off-layer power density, unique abilities in impurity diagnosis, and the High-Z metal wall, to advance the physics understanding of this critical topic.

- In transport studies, C-Mod is making critical tests of both empirical scalings and theoretically based interpretations of tokamak transport, at dimensional parameters that are unique but dimensionless parameters often comparable to those in much larger experiments.

- In the area of Advanced Tokamak research, so important to concept optimization, the high-field design of the device also provides long pulse length, compared to resistive skin time, which provides an outstanding opportunity to investigate the extent to which enhanced confinement and stability can be sustained in steady-state, using active profile control

In addition to these main programmatic emphases, important enabling research is being performed in MHD stability and control, which has great significance for the immediate design of ITER, and in the physics and engineering of ICRF, which is the main auxiliary heating method on C-Mod. 
Figure 1-1

\section{Alcator C-Mod Tokamak}

Mo First Wall

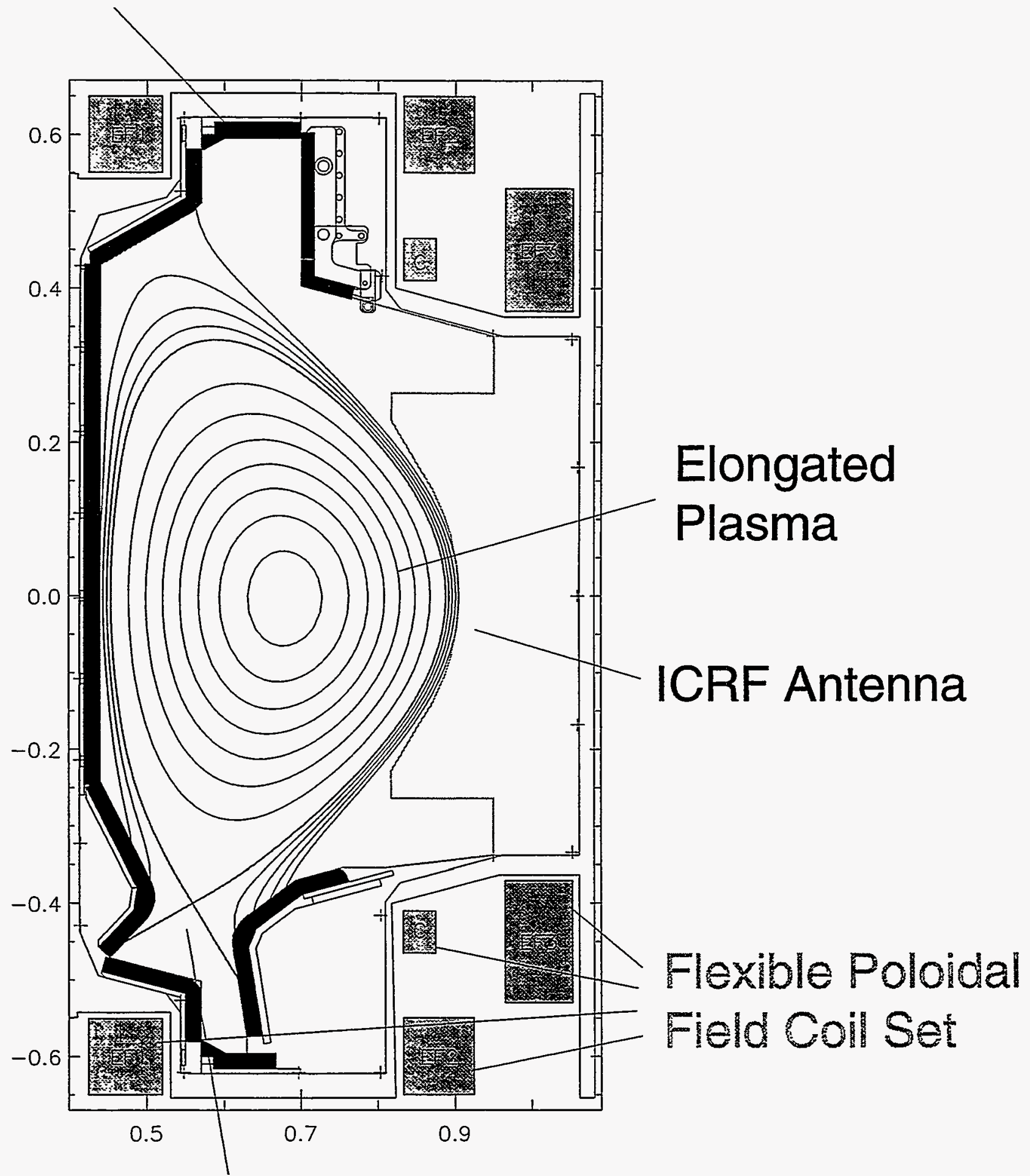

Closed Shaped Divertor 


\section{Budget and Schedule}

The field work proposal described here addresses two different budget assumptions. The reference budget for the proposal assumes $\$ 15 \mathrm{M}$ funding in FY97, which we interpret to be "consistent with the Fusion Energy Advisory Committee recommendations". We have assumed a mostly cost-of-living increase to $\$ 16 \mathrm{M}$ in FY98, and refer to these levels in FY97 and FY98 as the "\$15M case". (MIT has previously submitted detailed plans, in its contract renewal proposal of June 95, under which the budget rises to $\$ 22 \mathrm{M}$ in FY98.) The alternate budget addresses levels of $\$ 13 \mathrm{M}$, and $\$ 13.6 \mathrm{M}$ in FY97 and FY98 respectively, which we take to be representative of a $15 \%$ cut. We have indicated those elements of the program that are cancelled or delayed under the reduced budgets.

This proposal assumes that major collaborative efforts on Alcator C-Mod are funded in addition to the $\$ 15 \mathrm{M}$ or $\$ 13 \mathrm{M}$ funding at MIT. In particular, we are assuming two major collaborations, the first with PPPL emphasizing ICRF heating and current drive and divertor Thomson scattering, and the second with the University of Texas at Austin, emphasizing fluctuations and transport, and involving the installation on C-Mod of a diagnostic neutral beam (DNB). The additional funding at the collaborating institutions is assumed to be at the level of about $\$ 1 \mathrm{M}$ per year for each of these major collaborations. Various ongoing collaborations of smaller scale, on diagnostics and so on, are assumed to be continuing at least at the FY96 level.

Figures 1-2 and 1-3 show the program schedule and the facilities schedule under the $\$ 15 \mathrm{M}$ case. We anticipate that the tokamak would operate for a total of about 22 weeks in FY97 and FY98. On \$13M, operation time would be cut to approximately 15 weeks. In the remainder of this section the scientific plans are summarized very briefly. Much more detail is provided in the succeeding sections which are organized by topic.

\section{Divertor and Edge Physics}

Alcator C-Mod's lower divertor is extensively diagnosed. For example, probes embedded in the divertor plates, together with the reciprocating probe in the upstream scrapeoff-layer provide greater detail in diagnosis of the dynamics of the divertor than probably any other current experiment, and the spectroscopic and bolometric diagnosis of radiation from the divertor is second to none. Another unique aspect of Alcator C-Mod is the use of molybdenum divertor plates and plasma facing components. This provides urgently needed information concering the feasibility of using materials in future experiments that will resist the erosion predicted for carbon and berylium. 


\section{Alcator C-Mod Schedule}

\begin{tabular}{|l|l|l|l|l|l|l|l|}
\hline \multicolumn{2}{|c|}{ CY95 } & \multicolumn{2}{c|}{ CY96 } & CY97 & CY98 & CY99 & CY00 \\
\hline FY95 & FY96 & FY97 & FY98 & FY99 & FY00 \\
\hline
\end{tabular}

$\mathrm{B} \leq 8 \mathrm{~T}$

$\mathrm{I} \leq 1.5 \mathrm{MA}$

$\kappa \leq 1.7$

$\mathrm{B} \leq 9 \mathrm{~T}$

$\mathrm{I} \leq 2 \mathrm{MA}$

$\mathrm{ICH} \leq 8 \mathrm{MW}$

$\mathrm{ICH} / \mathrm{CD} \leq 8 \mathrm{MW}$

$\mathrm{ICH} \leq 4 \mathrm{MW}$

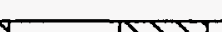
$\mathrm{LH} \leq 2 \mathrm{MW}$

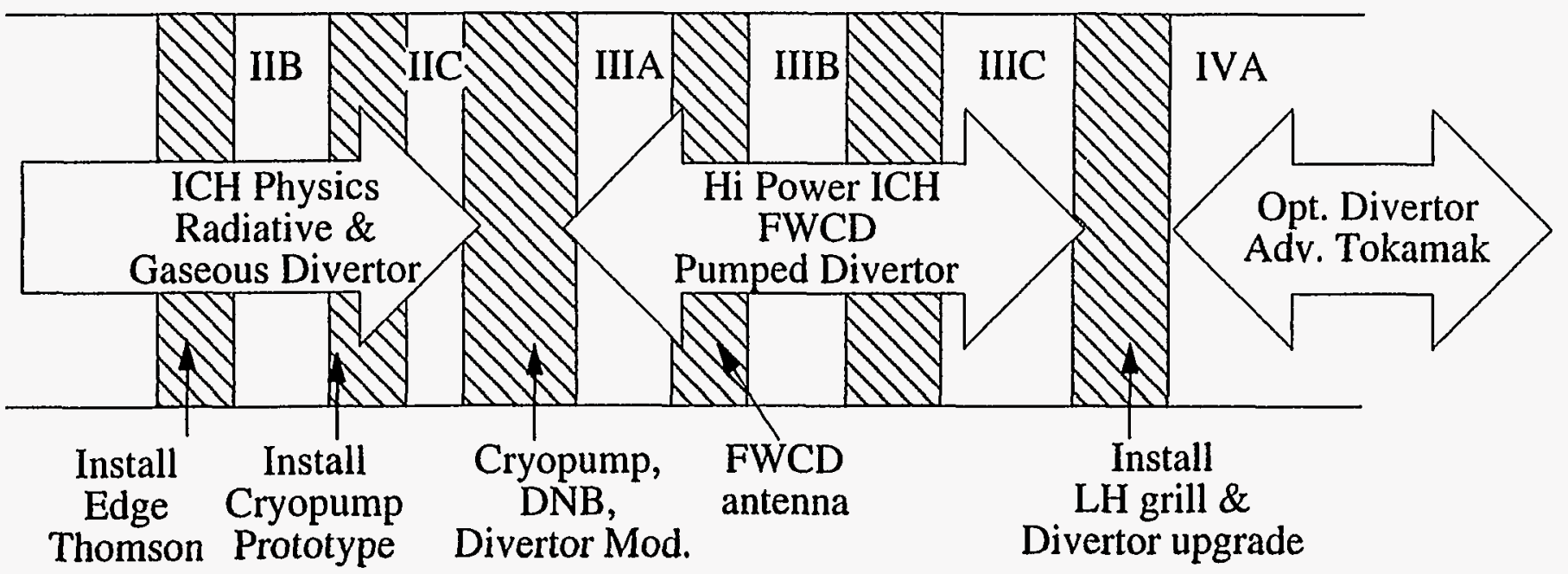

Radiative \&

Gaseous Divertor,

Power loading char.,

Compare open \&

closed divertors,

ICH physics,

Transport scalings,

L\&H-mode studies
ICRF Physics Hi-power/Pumped divertor,

Fast-wave Current Drive, High Density H-mode,

$\beta$-limit studies, Disruption studies, Initial AT studies
Optimized divertor, Advanced Tokamak Studies with profile control, High $\beta_{p} \&$ Bootstrap fraction. Quasi-steady state ops. with divertor cooling + pumping. 


\section{nemex tos \\ Alcator C-Mod Facilities Schedule \\ Moderately Constrained Budget}

\begin{tabular}{|l|l|l|l|l|l|l|l|l|}
\hline 1996 & 1997 & 1998 & 1999 & 2000 & 2001 & 2002 & 2003 & 2004 \\
\hline
\end{tabular}

Phase \begin{tabular}{|lllll} 
Divertor High Power & FWCD & LHCD & Advanced Tokamak
\end{tabular}

Tokamak $1.5 \mathrm{MA} \longrightarrow 2 \mathrm{MA}$

Divertor $\square$ Cryopump Design/Fab Upgrade Operate Upgrade

u

Power Alternator Inspection Alternator Inspection

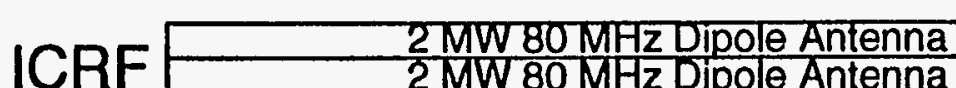

$4 \mathrm{MW}$ 40-80 MHz FWCD plus Antenna

Lower Hybrid

Preparations

$2 M W$

$4 \mathrm{MW} 4.6 \mathrm{GHz}$ Current Drive

ECRH

Preparations

$1 \mathrm{MW} 170 \mathrm{GHz}$

Diagnostics Div Thomson Divertor Upgrade

DNB $j(r)$ Fluctuations

Current Drive 
Recent achievements in divertor research include: the demonstration of detached divertor operation with high confinement quality $\mathrm{H}$-mode; investigation of the radiating processes at the x-point; discovery of the high albedo of the plasma to divertor neutrals, and demonstration of record ratios of neutral pressure in the divertor to pressure in the main chamber; detailed investigation of the cross-field drifts and important consequent divertor asymmetries; and the demonstration, in comparison with fluid modelling, that neutral neutral collisions are vital to divertor physics.

Key questions that we are proposing to address in FY97 and FY98 include: what determines the width of the power channel in the scrape-off-layer? what determines the maximum radiation rate that can be achieved in the divertor? what determines the impurity transport from the divertor back into the confined plasma? and what is the role of neutrals in the scrape-off-layer and divertor?

Major near-term initiatives in the divertor area include:

- Edge Thomson Scattering. This new diagnostic is expected to reach full operation in early FY97.

- Divertor Cryopump. Is scheduled for installation in FY97 under the $\$ 15 \mathrm{M}$ case but not till FY98 at the earliest under the $\$ 13 \mathrm{M}$ case.

- Redesign of Inner Divertor. Planned to give more flexible shaping and divertor configurations, for installation in FY97 under the $\$ 15 \mathrm{M}$ case, probably not till FY98 under the $\$ 13 \mathrm{M}$.

- Various Divertor and SOL Diagnostics. Notably the omegatron ion mass spectrometer and the high resolution spectroscopy for $T_{i}$ and flow measurement.

\section{Transport}

Confinement and transport studies benefit from the high power densities characteristic of Alcator C-Mod's compact design. The flexible shaping over elongations from 0.9 to 1.8 has been used and exploration of a range of triangularity has begun. We have both lithium and deuterium pellets for density profile modification, and the localized deposition of ICRF power is available for temperature profile modification, and perturbative transport experiments.

Alcator C-Mod has seen excellent progress in the past year in obtaining and controlling $\mathrm{H}$-modes on a routine basis with ICRF heating. H-factors to 2.5 have been obtained and steady-state $\mathrm{H}$-modes with confinement enhancements of approximately 1.8. The 
threshold for entering $\mathrm{H}$-mode is lower than previous scalings might suggest and important detailed edge profile physics has begun to emerge. Pellet injection has achieved the high performance behavior first observed as $\mathrm{P}$-modes on Alcator $\mathrm{C}$, and detailed studies have indicated that in the C-Mod plasmas, the magnetic shear is reversed, as was the case for JET's PEP modes. Systematic dimensionless scaling comparisons with DIIID have begun, and substantial data has been contributed to the ITER transport databases. Alcator's results clearly invalidate the 92 and $93 \mathrm{H}$-mode scalings as fits to more compact tokamaks.

The main thrust in FY97 and FY98 in the transport area is to obtain more detailed profile and fluctuation measurements so as to address the transport physics more directly.

- The diagnostic neutral beam is extremely important to this end. It will provide higher resolution ion temperature and velocity profiles (CXRS), and beam emission fluctuation measurements (BES), which are the responsibility of $\mathrm{U} T \mathrm{~T}$, and motional Stark effect (MSE) measurements of current density profiles. At the $\$ 15 \mathrm{M}$ budget level, the beam can be commissioned in FY97 and the major harware development of the associated diagnostics undertaken. However, at the $\$ 13 \mathrm{M}$ level, the beam commissioning is expected to extend into FY98 and the MSE cannot be begun, nor can major MIT funds be devoted to the CXRS and BES hardware until FY98.

\section{RF and Advanced Tokamak Research}

Major progress has been made in ICRF heating during the past year, including the demonstration of efficient minority heating at 5-6 $\mathrm{T}$, and $8 \mathrm{~T}$. These are the key bulkheating modes that support the transport and divertor programs. In addition, the novel mode-conversion direct-electron heating (both on and off axis) has been demonstrated. These achievements pave the way for current drive, and current profile control, and lead to the future advanced tokamak program we have planned.

- The upgrade of the 3rd and 4th FMIT units as 40-80 MHz transmitters has begun and will be completed in FY97. This will broaden even further our ICRF options.

- The fast-wave current-drive antenna, being designed by PPPL is scheduled for installation early in FY98. Prior to that installation, scoping current-drive investigations will be undertaken with the existing antennas.

- The longer-term lower-hybrid system refurbishment begins at a low level in FY97 and more substantially in FY98 on the $\$ 15 \mathrm{M}$ budget. At the $\$ 13 \mathrm{M}$ level, little progress on the lower hybrid can be made in either year.

Long-pulse advanced tokamak scenarios for Alcator C-Mod have been studied using 
the ACCOME/PEST codes. They indicate that, for example, $0.8 \mathrm{MA}$ of plasma current can be sustained with reversed shear and bootstrap fraction of $75 \%$ and would be stable at $\beta_{N}$ of 3 without a conducting wall. This exciting level of performance awaits the completion of the current-drive upgrades.

\section{MHD, Control and Operations}

In addition to providing the equilibrium and shape control required for the rest of the program, C-Mod MHD research is addressing some high-profile tasks in support of ITER needs, especially respecting disruptions. The halo-current measurements on CMod are uniquely complete, and have shown some fascinating results on asymmetries that are important both to ITER design and to the develoment of a basic understanding of disruption processes. The networked control system of C-Mod has proven its strength in terms of accurate and flexible plasma shape control. The remote operation of C-Mod from California demonstrated the feasibility of a remote control room for ITER and attracted a surprising level of interest from the press. Substantial upgrades of power supplies and other facilities were undertaken during the past year. Boronization, operational since January 1995, has proven to be an important tool for impurity control even in our molybdenum machine.

Future MHD research will continue to study the science and the scaling of halo currents as well as disruption mitigation techniques such as "killer pellets". Detailed investigation of ELMs will be undertaken, and promises to be particularly rewarding on C-Mod since several new phenomena have been observed. The continued extension of operational space to higher currents and densities will call for efforts in control and equilibrium development. 


\section{ALCATOR C-MOD RESEARCH}

\subsection{Alcator C-Mod Transport}

\section{Background and Technical Progress}

Because of its unique parameters, C-Mod provides critical tests for comparisons with theory and for global scaling exercises. In particular, we greatly expand the world database in the variables $n_{e}, B_{t}$, and provide data at small $\mathrm{R}$ with very high performance. In addition to these engineering parameters, C-Mod operates in unique regimes in several other respects. Because of its high density, $T_{e} / T_{i} \sim 1$ for virtually all of our operating conditions. This parameter is important in the standard drift wave turbulence theories of transport and also reflects the regime in which a fusion reactor would operate. Our auxiliary heating scheme, ICRF, has neither strong torques associated with it nor particle source nor current drive. Most machines rely on neutral beam heating, which have all three.

Work in the last year has emphasized transport in $\mathrm{L}$ and $\mathrm{H}$ mode with strong ICRF heating. Confinement studies have been carried out in hydrogen and deuterium plasmas with $0.23<I_{p}(M A)<1.2 ; 2.6<B_{T}(T)<8.0 ; 0.24<n_{e}\left(10^{20} m^{-3}\right)<4.4 ; .94<\kappa<$ $1.85 ; .26<P_{\text {input }}(M W)<4.4$. A full set of plasma diagnostics allow calculation of stored energy by integrating kinetic profiles or by computing the plasma equilibrium; these are generally in good agreement. To calculate local transport quantities we have used the TRANSP code (courtesy PPPL). This code uses measured plasma profiles as inputs then calculates the electron and ion heat balance, particle balance, and magnetic diffusion with a fixed boundary equilibrium. For ICRF heated plasmas, the full wave SPRUCE code linked to the Fokker-Planck solver FPPRF is used to calculate the heating power to ions and electrons.

A fairly complete data set for $\mathrm{L}$ mode plasmas in C-Mod is now available. Confinement in this regime is in good agreement with ITER89P though it is fitted just as well by $\tau_{E}=.05 I p / P^{0.5}$. About 200 records have been contributed to the ITER $L$ mode database. Local analysis indicates that at low densities, the electron channel is the dominant loss mechanism while the ion channel may dominate at higher densities. Most of our ohmic data

is also consistent with an $\mathrm{L}$ mode confinement law, however a form of neo-alcator scaling (but not consistent with Alcator $\mathrm{C}$ results) was recovered at very low densities. Impurity confinement was measured for $\mathrm{L}$ mode plasmas and found to be somewhat smaller than 
the energy confinement time with somewhat similar dependences. Transient transport experiments with modulated ICRF have been carried out and detailed analysis is underway.

$\mathrm{H}$ mode is easily achieved with ohmic or ICRF heating. Global scaling of the power threshold has been carried out and compared to results from other tokamaks. We observe threshold $\mathrm{P} / \mathrm{S} \sim \mathrm{nB}$ scaling, though with a lower coefficient than lower field, low density devices. As a result, new scaling laws have been proposed which have weaker density and size dependence. Recent boronization of C-Mod has not dramatically changed our threshold power. Measurements of the edge temperature at the L-H transition offer better hope of making contact with $\mathrm{H}$ mode theory. In our normal configuration, with grad(B) ion drifts toward a single null divertor, we transit to $\mathrm{H}$ mode when the edge temperature reaches about $150 \mathrm{eV}$. This threshold temperature is apparently independent of density but increases with plasma current, suggesting a role for rho-poloidal in triggering the transition. With grad(B) drifts away from the divertor, the power threshold and critical edge temperature are both about a factor of two higher. This suggests important direct interaction with the SOL plasma which is greatly affected by the drift direction.

Following boronization of first wall surfaces, the quality of $\mathrm{H}$ modes achieved in C-Mod have been greatly improved. This can probably be attributed to a decrease in radiated power. Molydenum radiation as measured by X-ray and XUV spectrometers (including one provided as part of a collaboration with Johns Hopkins Univ.) has decreased dramatically. Confinement enhancement over ITER89 scaling range up to 2.4 and is systematically above the predictions of the various ITER $H$ mode scalings. Confinement is also about a factor of 2 above JET-DIIID scaling suggesting important dependencies on $\mathrm{n}$ or $B_{t}$ or a different dependence on size. Both ELMy and ELMfree discharges are produced, though the ELMS are of much different character than the standard "type 1" ELMs typically seen on other devices. None the less, a very large edge pedestal is present with pressure gradients which are at or above the predicted ideal ballooning limit. Impurity particle confinement has been measured for these $\mathrm{H}$ mode plasmas and found to be more than 10 times the confinement in $\mathrm{L}$ mode. About 200 records have been contributed to the ITER $H$ mode threshold database and about 60 to the $\mathrm{H}$ mode confinement database (in support of ITER needs $4.1,4.2,4.5)$.

Dimensionless identity experiments have been carried out in coordination with the DIII-D group. In these experiments all dimensionless variables (beta, rhostar, nustar, epsilon, kappa, delta, q, etc.) are kept the same for two machines with very different physical sizes. The aim is to validate the dimensionless scaling approach which is used for predicting confinement in the ITER device. Detailed profile analysis of data from this 
experiment is underway. Single device, rhostar scans have also recently been carried out in C-Mod. Global results suggest Bohm-like scaling in L mode and gyro-bohm in $\mathrm{H}$ mode but analysis of this data has just begun.

With pellet fueling, PEP/P modes have been achieved. These have highly peaked density and pressure profiles and greatly improved core confinement. The current profile of these discharges has been determined by measuring the tilt angle of the ablation cloud of injected $\mathrm{Li}$ pellets. These measurements show that a reversed shear configuration develops in the core of PEP discharges but only well after the improved confinement regime has been established. TRANSP calculations indicate the reversed shear is the result of bootstrap currents driven by the strong pressure gradient which exists after the reheat of the peaked density profile produced by the injection.

\section{Future Accomplishments}

While transport studies will be carried out in many different areas, we will continue to stress those where C-Mode makes unique contributions. We believe that progress can only come from a better understanding of the physics which underlies the phenomena that we study. We note that plasmas with C-Mod's unique parameters provide a critical test for theories and we will make every attempt to involve the theoretical community in the design and interpretation of our transport experiments. We will also keep in close contact with the physics team from ITER and help them in putting that project on the firmest possible basis.

During the 97-98 run periods, new tools and facilities will provide exciting opportunities in the transport area. The PPPL collaboration will provide additional ICRF heating power with tuneable sources, allowing us to extend our accessible parameter range, particularly to higher plasma betas. A major collaboration with UTx, will enhance our profile measurements with a diagnostic neutral beam (DNB) and its associated diagnostics and provide much needed fluctuation measurements. Modification of the inner divertor will enable us to produce plasmas with higher triangularity. Finally, a divertor cryo-pump will allow active particle control and help illuminate the role of neutrals in the L-H transition and the dynamics of gas fueling.

We will continue to make contributions to the global database for $\mathrm{H}$ mode threshold in support of ITER (urgent need 3.1). The additional heating power will allow us to extend the range over which we can achieve $\mathrm{H}$ modes and the tunable sources will enable operation at a wider variety of magnetic fields. We will characterize the low density limit seen in the power threshold and studies of the threshold for the back transition ( $H$ to $\mathrm{L}$ ) will be 
carried out. We can test theoretical predictions which suggest that the H-L transition should be slower than the L-H. An important initiative will be the careful measurement of local edge parameters taken at the $\mathrm{L}-\mathrm{H}$ transition. These hold out hope for putting the transition physics on a firm physical basis and for better extrapolation to future machines. We will continue with our measurements of edge $T_{e}$ and extend the studies to density profile, using X-mode reflectometry and a tangential interferometer system, and to $T_{i}$, $\mathrm{V}_{\phi}$, and $\mathrm{V}_{\theta}$ with a charge exchange recombination (CXR) diagnostic. We will look for appropriate physics quantities (such as $\rho_{\mathrm{i}}$ poloidal) and associated dimensionless variables. Inter-machine comparisons will be carried out to verify such dependencies. To obtain true predictive power, we will also need to study the dependence of the edge parameters on controllable global quantities (like $n_{e}, B_{t}, I_{p}$, Power, etc). We also begin systematic investigations concerning the relationship of the plasma inside and outside the separatrix and the consequent effect on the $\mathrm{H}$ mode threshold. The study of the role of neutrals in the threshold may be aided by the capability for active particle control provided by cryo-pumping or lithiumization in combination with pellet fueling.

The improvements we are planning in our diagnostics will be a tremendous help in studies of $\mathrm{H}$ mode confinement. Our existing set with upgrades combined with those from UTx, will allow measurements of $T_{e}, T_{i}, n_{e}, V_{\phi}, V_{\theta}$, and $\mathrm{j}$ in the edge and core with excellent spatial and temporal resolution. We should be able to make good measurements of the transport barrier profiles and evolution. Direct comparison of the transport barrier characteristics with those from other devices should be particularly helpful in understanding the underlying physics. An important topic for research will be the relationship between the edge barrier and the improvement seen in core confinement. Our initiatives in particle control may allow us to hold down the density rise in $\mathrm{H}$ mode and thus produce lower density, higher temperature plasmas. This would greatly increase the range of plasma conditions that we can achieve in particular changing the temperature and density gradients and providing a very stringent test for drift wave turbulent theories of plasma transport. We will compare measured profiles to the critical gradients calculated for ITG modes and, in collaboration with modeling groups, undertake detailed comparisons between our measurements and various theory-based or semi-empirical transport models. We will study the relationship between energy, particle, and impurity confinement improvements in the $\mathrm{H}$-mode. We will continue our studies of ELMs and their impact on confinement with emphasis on the role of plasma shaping on ELM characteristics. Our contributions to the global scaling and profile database will continue, including data from the improved diagnostic set discussed above. 
Core density fluctuation measurements will be made via beam emission spectroscopy (BES) viewing the DNB, phase contrast interferometry, reflectometry, and possibly a shearing interferometer being built by a collaborator from Science Research Labs (SRL) under an SBIR. A heterodyne ECE system will provide measurements of core $T_{e}$ fluctuations. Spectra from these diagnostics can be compared to predictions from theories for turbulence driven transport. We will be able to perform a wide variety of perturbation experiments relevant to testing of transport theories. We can modify the density profile by pellet injection or gas puffing. The temperature profile can be perturbed by modulating ICRF heating power or by cooling the edge with injected impurities. We can inject impurities by puffing impurity gas, laser blow-off, with the impurity pellet injector, or by doping deuterium pellets with neon. Each leads to a different source function for the impurities.

The additional ICRF power will allow us to extend our operating range to higher values of plasma beta. This can be accomplished by doubling available power at $5.3 \mathrm{~T}$, increasing $\beta_{N}$ to around 2 . The tunable sources will also provide $4 \mathrm{MW}$ of source power for minority heating at $2.6 \mathrm{~T}$ where higher betas are easier to achieve. Both of these scenarios can be used to produce ITER "demonstration" discharges. These have the same shape, beta, and nustar as ITER and differ only in rhostar (size). By comparing our results to those from larger machines like DIII-D and JET, it is hoped that a clear scaling law for rhostar will emerge, leading to reliable scaling to ITER conditions (ITER need 3.2). We will also be completing work on the dimensionless identity experiments discussed above and extend them to include analogous experiments with ASDEX Upgrade.

With the modification of the inner divertor, a greater range of plasma shapes will be available to us. In particular, we should be able to increase triangularity, look for the suppression of ELMs and attempt to access the VH confinement mode. We can test current ideas that suggest beam driven currents are an essential ingredient in achieving VH mode (driving $q_{0}$ above 1 and suppressing sawtooth activity). We operate in a regime with higher collisionality and pressure gradients than DIII-D, JET, or JT-60U so the amount and distribution of bootstrap current (also thought to be important) will be different. Since, at our high fields we can be reasonably certain of avoiding beta limit effects, we should be able to decouple high beta stability issues from others. We will continue our studies of PEP/P mode, investigating the roles of $\operatorname{grad}(\mathrm{n}), \operatorname{grad}(\mathrm{p}), \operatorname{grad}(\mathrm{q})$, and $\operatorname{grad}(\mathrm{v})$ in the improved core confinement which is observed. We will attempt to access the ERS/NCS regime by a combination of fast current ramp and ICRF heating. These are typically achieved with neutral beam heating, where the central particle source aids greatly in achieving high central pressure gradients (very similar to those in PEP/P mode). Experiments with 
ICRF alone may shed light on the role of central fueling in these regimes. Since modes with internal transport barriers are often seen to have high power thresholds, the additional $R F$ power that we will have available may be essential. 


\subsection{Alcator C-Mod Divertor Physics}

\section{Technical progress}

During the past year experiments have been carried out over a range of divertor geometries, including slot, flat plate and the standard vertical plate C-Mod geometry which is now the ITER design. The power density flowing along field lines in the divertor Scrape-Off Layer (SOL) has been increased to $\sim 500 \mathrm{MW} \mathrm{m}^{-2}$ using ICRF heating. This is the highest power density so far achieved in the international fusion program and close to the design value of ITER. A significant improvement in the quality of ICRF heated $\mathrm{H}$-Modes has been obtained.

One of the most important features of the high power conditions is that the scrape-of layer narrows as the power density rises, fig. 2.2-1. This is partly due to the narrowing of the SOL as a result of the formation of the H-mode, but other effects contribute, including faster parallel transport as a result of higher edge temperatures and smaller cross field transport even in L-mode conditions. A surprising result is that the cross-field transport is significantly reduced after boronization. A series of experiments has been undertaken with impurity gas injection at the higher power density to try and obtain the high radiated power density and low plasma temperature which enables plasma detachment from the target to be achieved. While radiative conditions have been achieved this becomes significantly harder as the power density is increased. Nonetheless injection of $N_{2}$ was successful in allowing divertor detachment in high power/high confinement discharges $(\mathrm{H}$ factor $=\sim$ 1.7) with $\mathrm{Z}_{\text {eff }} \sim 0.6$

Detailed studies of the power radiated from different impurities have been made both in the core plasma and at the $x$-point. It has been found that before boronization the radiation at the $\mathrm{x}$-point is dominated by low $\mathrm{Z}$ impurities and has roughly equal contributions from $\mathrm{C}, \mathrm{O}, \mathrm{F}$ and $\mathrm{Ar}$. Mo is not an important radiator in the divertor. In the high recycling and detached regimes cx neutrals play a significant role in the power balance. Impurity transport has been studied with both recycling and non-recycling injected impurities. With the non-recycling impurities screening has been shown to depend on the poloidal position of injection

Important new physics results have also come from the studies of neutrals in the divertor. It has been found that it was not possible to model either the neutral pressure measurements or the experimental distribution of $\mathrm{H}_{\alpha}$ radiation using existing neutral codes (DEGAS). Investigation into this result led to the conclusion that at the high densities 
Figure 2.2-1

Reactor Relevant Parallel Heat Fluxes in the Alcator C-Mod SOL

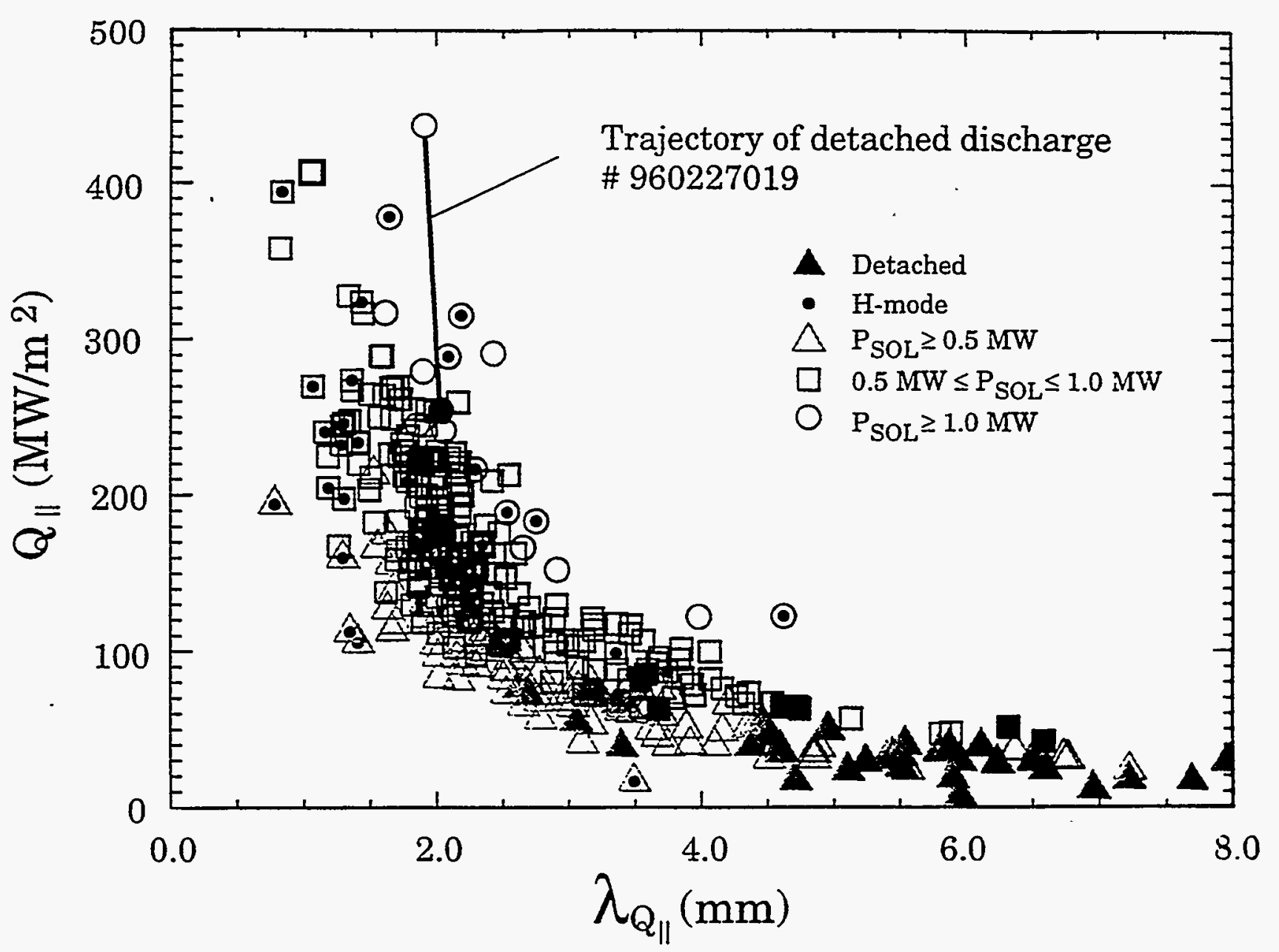

- Data shown above from the edge database is primarily from ohmic plasmas. This calculation of $Q_{\|}$is conservative $(\sim x 2)$. Even so the values of $Q_{\|}$are similar to that predicted for ITER. Recent results with RF have increased $Q_{\|}$by $50-75 \%$.

- Note that as $\mathrm{Q}_{\|}$increases, the corresponding e-folding length decreases further exacerbating the already difficult divertor heat load problems. 
which exist in C-Mod (and which will exist in ITER), neutral-neutral collisions play an important role. Analytic modeling has shown that in high recycling conditions, with low plasma temperature, there is high probability of neutrals being backscattered from the plasma, leading to effective plasma plugging. The main source of neutral gas in the main chamber was shown to be leakage through the divertor structure. By physically blocking this path during the fall ' 95 maintenance period the divertor compression has been increased from a maximum of 60 to over 300 . These are the highest values of compression achieved so far on any tokamak.

A new neutral fluid model has now been introduced into the UEDGE plasma code which gives significantly better agreement with experiment than earlier versions. However further development of the treatment of neutrals to cover both low and high collisionality is necessary

Experimental data for a range of divertor operating conditions has been distributed to a number of collaborating modeling groups both within the US and internationally (MIT, INEL, PPPL, JET and the University of Toronto.) C-Mod has a unique role to play in the international fusion program having magnetic field, particle and power densities at the high end of the range of parameters envisaged for ITER. Data from C-Mod thus provide a stringent test of divertor models. Encouraging results have been achieved in comparing codes to experiment and the existing codes have been validated for some conditions. This is considered an essential part of obtaining the tools required for extrapolating to ITER conditions.

\section{Future Program}

The future divertor program will continue to elucidate the relevant physics of high density/high power SOL and divertor plasmas. This includes the continued study of the role of neutral particles, the transport of particles and energy and the dissipative capabilities of various divertor regimes and geometries. In addition, a number of new diagnostics and an additional $4 \mathrm{MW}$ of ICRF power from new antennas and transmitters (in collaboration with PPPL) is planned. The increase in heating power will enable the power across the separatrix to be increased, resulting in parallel heat fluxes to the target $\sim 1 \mathrm{GW} \mathrm{m}^{-2}$, which is well into the range planned for ITER. We have already shown that increased heating power has a marked effect on the thickness of the SOL and makes it more difficult to reach the highly radiating conditions necessary for safely dissipating power. There is the possibility that fundamental atomic physics rates will prevent radiative power dissipation at the rate required. It is thus critically important that experimental data be obtained 
which demonstrates whether or not it is possible to radiate sufficient power. At present it is expected that the extra ICRF antennas and power supplies will be installed by the end of fiscal '97.

An Edge Transport Database has been set up and is being updated routinely during the C-Mod operation. This database has already proved invaluable in understanding trends in the data and in testing theoretical models. Data will continue to be added as C-Mod edge parameters are extended to regions of higher density, higher power levels and extended $\mathrm{H}$-mode conditions.

The new hardware and the program to which it will contribute in '97 are discussed below:

1. Edge Thomson Scattering Diagnostic.

Detailed measurements of the plasma parameters in the divertor are critical to understanding the physical mechanisms of momentum transfer from ions to neutrals and the general phenomena of high radiation and detachment. Existing measurements with probes have allowed us to map out the sheath limited, conduction limited and detached conditions over a range of operating parameters. They have led to the conclusion that parallel heat transport cannot be simply described by conduction, but that convection and energy transfer to neutrals play important roles. To understand the physics of these processes it is necessary to have more detailed $n_{e}$ and $T_{e}$ profiles along field lines. These will be provided by an edge Thomson scattering system which has been designed in collaboration with Princeton PPL and Princeton Scientific Instruments under a SBIR contract. The design and construction have been completed and the optical head was installed in the divertor under the outer divertor target module in fall '95. Testing of the Nd-YAG laser has been completed, the spectrometer is at present being calibrated and the data acquisition is undergoing test at PPPL: the system is due for delivery to MIT in April. Preliminary operation will start in the summer campaign and full operation should start in fiscal '97.

\section{Divertor Cryopump}

In order to control the plasma density and the impurity flux in the SOL it is necessary to have an independent means of pumping the divertor. At present there is adequate wall pumping to control density in L-mode discharges for $1 \mathrm{~s}$. For longer pulses and high densities it is clear that the walls are saturating. Moreover in long pulse H-Mode discharges it is at present difficult to control the plasma density. A cryopump has been designed consisting of 10 individual units which will be distributed toroidally around the machine under the outer divertor. A prototype has been built which will be installed spring 
'96 (fig. 2.2-2). Its performance will be evaluated in the summer campaign. It would then be possible to build the remaining units for installation in '97. However this will not be possible on a $\$ 13 \mathrm{M}$ fiscal ' 97 budget.

\section{Redesign of Inner Divertor.}

While the present design of divertor has been very satisfactory from the point of view of heat dispersion and minimizing impurities, it restricts the possible magnetic configurations necessary to optimize the triangularity required for Advanced Tokamak (AT) performance. Redesign of the inner target has begun to allow the triangularity to be increased. The planned configuration is shown in fig. 2.2-3. In addition to allowing more flexibility of the magnetic geometry it will reduce the recycling occurring close to the separatrix. Further development of the divertor using a Gas Box design similar to one of the early ITER designs is being considered for the longer term program.

\section{Omegatron.}

The impurity density and the charge state distribution in the SOL are important parameters for understanding impurity transport and for code validation but are difficult to measure spectroscopically. An alternative approach is to use a probe which is mass and charge sensitive. A novel design based on the omegatron (cyclotron) principle has been designed and built. The hardware for this probe has been installed in the upper divertor but the data acquisition has still to be completed. Preliminary tests will be undertaken this summer and full operation is planned for the fiscal ' 97 program. It is intended that measurements will be made of the mass/charge spectrum leading to the identification and quantification of the charge states of the impurities. In addition the probe will have a retarding field analyzer which will allow measurements of the ion energy distribution to be made.

\section{Diagnostic Neutral Beam.}

A major new proposal is being put forward for a Diagnostic Neutral Beam in collaboration with the University of Texas (see section $x x x x$ ). Such a beam will allow measurement of ion temperatures near the separatrix at the midplane. These measurements are important to estimate the ratio of the power crossing the separatrix in the ion and electron channels. The data is necessary as an input to the 2-D fluid models. In addition it is planned to use Beam Emission Spectroscopy to measure fluctuation levels in the edge in order to obtain further understanding of the physics of cross field transport under the high density, high power conditions typical of ITER. If approved it is planned that the beam will be commissioned by the end of Fiscal ' 97 , coming into full operation in ' 98 . 


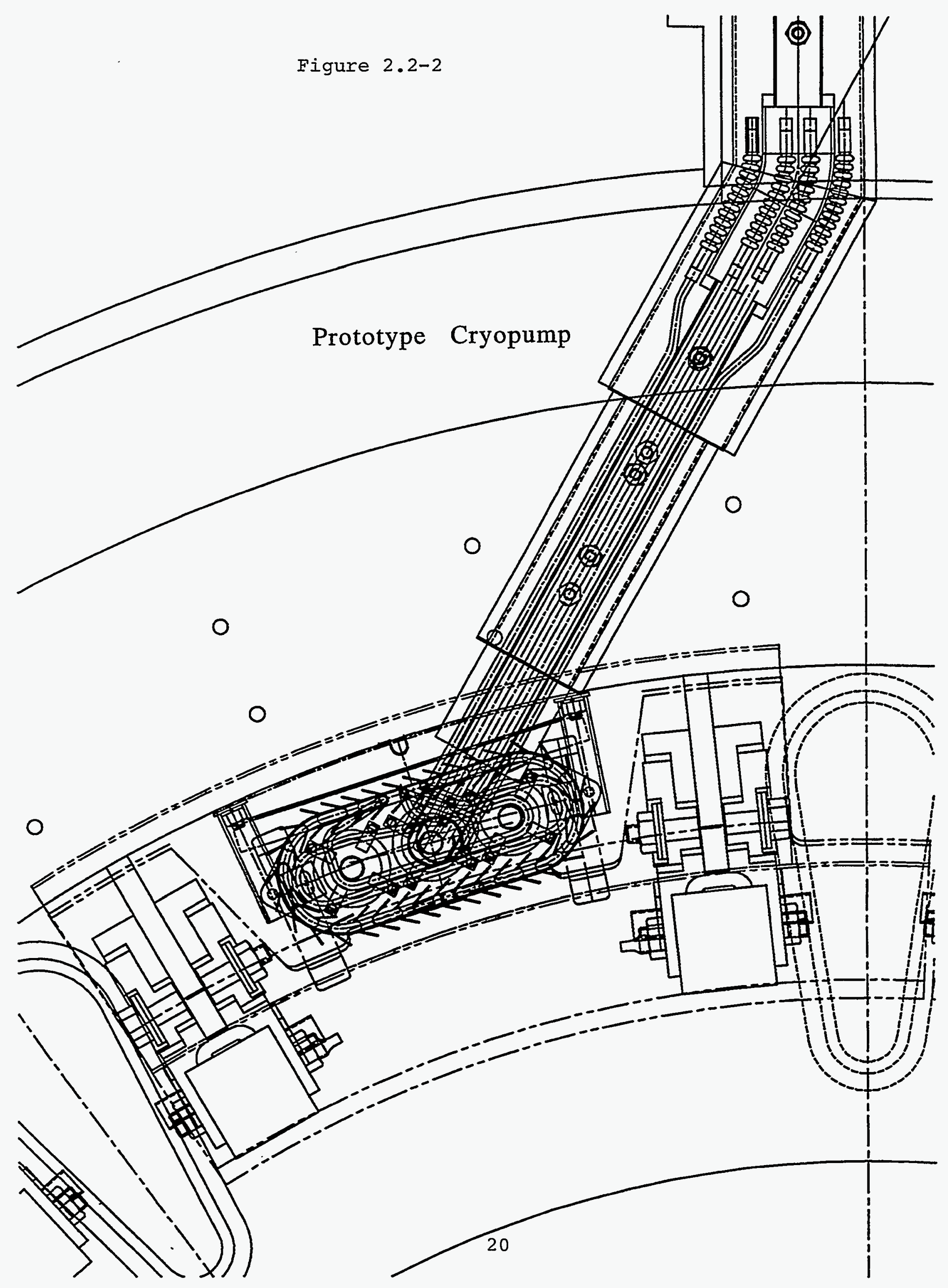



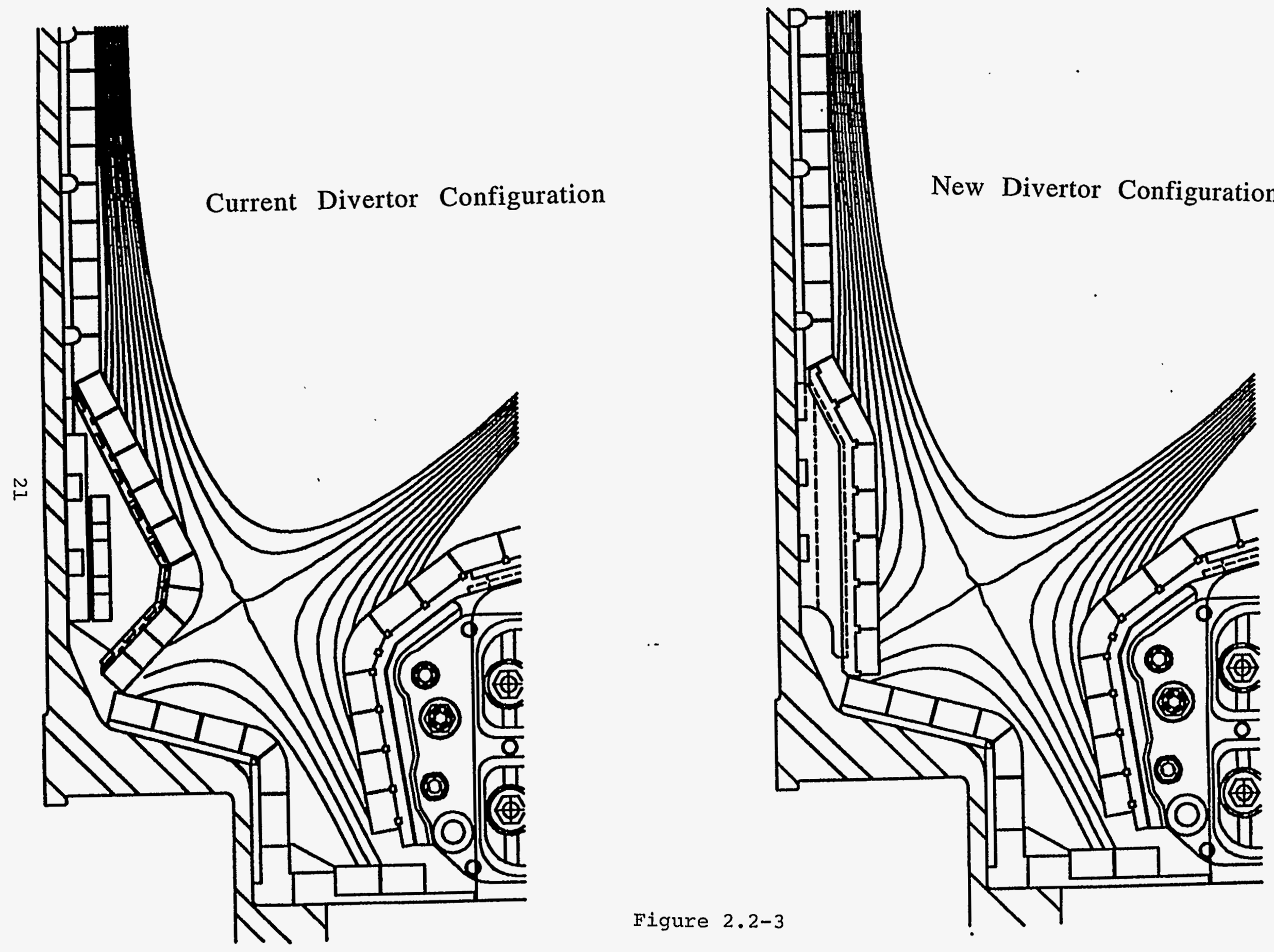


\section{Divertor Spectroscopy.}

A number of spectroscopic views of the divertor chamber and hardware presently exist. These views are being used by various visible and uv diagnostics. High resolution instruments, built and operated by collaborators ( $U$ of Maryland and PPPL) will measure directional flows and line emission shapes to obtain ion temperatures. In addition an instrument observing resonance lines in the $10 \mathrm{~nm}$ range with the same line of sight as the Edge Thomson Scattering system is to be built and installed on C-Mod by the John Hopkins University. 


\subsection{Alcator C-Mod MHD, Control \& Plasma Physics Operatoins}

\section{Technical Progress}

A large fraction of the MHD research effort during the past year has been devoted to studying the halo currents associated with disruptions. An additional array of ten current sensors has been installed to measure the toroidal distribution of halo current flowing through the outboard divertor modules. Analysis of the toroidal distribution provides timeresolved information on the 'peaking factor', which is important for determining maximum local $J \times B$ forces on the vessel wall and other conducting structures. Typical instantaneous peaking factors during C-Mod disruptions are $\sim 2$. However, we have found that for all of the extreme outlier cases in our database (about a dozen) the peaking factors are very low. This information is of great interest to the ITER program. In addition, we have transferred data on over 1400 disruptions to the ITER disruption database. In fact, the C-Mod cases comprise most of the ITER database.

Experiments have also been carried out with killer pellet termination of VDEs. Initially we tried lithium pellets doped with $200 \mu \mathrm{g}$ of gold, and quickly dissipated the plasma thermal energy. Since $W_{p}$ is only about $10 \%$ of the total stored energy in C-Mod plasmas, these initial experiments had little effect on the current quench. Recently, we have been able to fabricate plastic pellets doped with $2.5 \mathrm{mg}$ of silver, which in principle can radiate at an order of magnitude higher power (of order a gigawatt)-enough to dissipate all of the plasma thermal and magnetic energy in a millisecond. Recent experiments with these new killer pellets have yielded at least one case where the VDE was successfully terminated much faster than normal, and halo currents were reduced considerably.

In the area of MHD operations, feedback control of the plasma-antenna gap has been successfully implemented and is now in routine use. With the present ICRF power level of 3-3.5 MW, H-modes with $\beta_{N}$ up to 1.5 have been achieved. The large pressure gradients that build up near the edge of these plasmas result in bootstrap current densities of about $30 \%$ of the local $J$ at $r / a \sim 0.9$, and $I_{\mathrm{BS}} / I_{p} \sim 0.1$. Calculations using Glasser's DCON code show that the edge region of these plasmas are often ballooning unstable, possibly leading to the observed ELM behavior. We have also begun running higher triangularity plasma shapes, with noticeable effects on the ELMs. Much more operation at 8 tesla has been done, with good ICRF heating.

Equilibrium analysis of PEP modes produced by lithium pellet injection and RF heating indicates that $q$-profiles exhibiting central shear reversal have been obtained. This 
analysis uses measurements of $B_{p}(R)$ from the tilt of lithium ablation clouds to constrain the $p^{\prime}$ and $F F^{\prime}$ functions in EFIT code calculations.

\section{Future Accomplishments}

Expanding our operating parameter space is always a major objective, and during the next two years we intend to raise the plasma current from 1.2 to $1.5 \mathrm{MA}$, and eventually to 2.0 MA. This should further improve both energy confinement and the $\beta$ limit. Most of this higher current operation will be carried out at 8 tesla so as to have reasonable $q$ values. High-triangularity operation and its effects on $\mathrm{H}$-modes, ELMs, and the $\beta$ limit will also continue to be pursued.

Several MHD research topics in FY97 and 98 will be carried out directly in support of the ITER program. Recently ITER has expressed concerns about changes in plasma and control system responses when edge current density builds up after the $\mathrm{L}-\mathrm{H}$ transition. This edge $J$ is the bootstrap current produced by the high $\nabla p$ which develops after the transport barrier forms. ITER is concerned that if this happens on a timescale faster than the control system can respond to, the $x$-point location would move, and possibly hit the divertor 'dome'. A cursory examination of C-Mod data shows that we may be seeing such an effect, and much more detailed analysis is needed to determine the amplitude as a function of plasma parameters, and the control system response.

A substantial part of the MHD research effort will continue to be focussed on studies of disruptions, halo currents, and avoidance/amelioration (i.e. killer pellets), particularly as we increase the plasma current. If the $I_{p}^{2} / B_{\phi}$ (or $I_{p} / q_{95}$ ) scaling obtained during the previous year continues to hold at higher $I_{p}$, large halo current fractions will be seen. Studies of the toroidal peaking factor and its scaling with halo current are providing important information to ITER, and analysis of the new gusset Rogowski data should expand on that. Additional Rogowski current sensors will be inserted in the new inner divertor modules when they are installed next year, allowing us to determine more precisely the path of halo current flow. In addition, we will study how this modification of the divertor shape changes the magnitude and/or behavior of halo currents. As a first step in trying to understand the $n=1$ helical nature of the halo currents observed on C-Mod, modeling of a plasma with a non-axisymmetric MHD instability in contact with conducting walls is just beginning to be pursued by Steve Jardin, of PPPL and the ITER home team, and will continue.

Measurements of stresses in the vessel wall and other conducting structures during disruptions is highly desirable, in order to confirm engineering calculations currently being 
carried out. During FY97 we are planning to use strain gauges on the inner wall, and possibly on divertor modules as well, to directly determine disruption forces. It may be possible to reduce the disruption forces on the divertor hardware using the killer pellet scheme proposed by ITER. Additional experiments with killer pellets are planned, possibly with frozen neon or krypton, as well as the metallic-doped pellets we have used to date.

With the anticipated addition of 4 more megawatts of ICRF power, along with the installation of the new 4-strap antenna from PPPL, we expect to raise further the plasma $\beta_{N}$. As $\beta_{N}$ increases, stability issues will become more of a concern, both in the plasma core, and at the edge (i.e. ELMs). Through a collaboration with the MIT-PFC Theory Division, kink and ballooning stability analyses of C-MOD plasmas are being carried out using the Lausanne-Keldysh codes. In addition, we will continue to use Glasser's DCON code to provide simple stable/unstable characterization of these discharges. All of these issues concerning high $\beta_{N}$ apply to our PEP-mode studies as well.

Research programs on advanced tokamak concepts are expected to become a major programmatic focus, and are discussed in detail in section 2.5. A crucial part of the AT research will be the measurement of current profiles using a new MSE diagnostic, development of which will be in FY97 and 98. This assumes that the diagnostic neutral beam is obtained in the planned collaboration with $U$. of $T$., and that an additional scientist is added to our MIT staff. As with the lithium pellet technique, the $B_{p}(R)$ data from the MSE measurements will be used to constrain EFIT reconstructions of $q(\psi)$ and $J(R, Z)$. TRANSP will be used the analyze the bootstrap profiles and fractions. 


\subsection{Alcator C-Mod RF and Current Drive}

\section{Technical Progress}

The RF program provides the means to heat, drive current, and control the pressure and current density profiles in support of major program elements: Divertor, Transport, and Advanced Tokamak (Tokamak Improvement). In particular, development of advanced tokamak scenarios, such as the reversed shear mode, relies heavily on understanding of RF physics since RF heating and current drive are the main knobs for controlling the temperature and current density profiles in C-Mod.

The 4MW $80 \mathrm{MHz}$ ICRF system has been fully operational since January 1995. The RF system operates routinely up to an antenna power density of $10 \mathrm{MW} / \mathrm{m}^{2}$ and a peak $R F$ voltages of $40 \mathrm{kV}$. Up to $3.5 \mathrm{MW}$ of $R F$ power has been coupled into the plasma into I-mode, $\mathrm{H}$-mode, and PEP mode plasmas, over a wide range of operating parameters $\left(B \leq 8 \mathrm{~T}, I \leq 1.2 \mathrm{MA}, \bar{n}_{\mathrm{e}} \leq 4 \times 10^{20} \mathrm{~m}^{-3}\right)$. H-mode operation over essentially the entire range of operating parameters (except at the extreme low end of density range $\bar{n}_{e} \lesssim 1 \times$ $10^{20} \mathrm{~m}^{-3}$ ) became possible with ICRF heating. A high-power, high-density ICRF heated $\mathrm{H}$-mode is shown in Fig. 2.4-1. Extremely high power densities of $5 \mathrm{MW} / \mathrm{m}^{3}$ (averaged over the plasma volume) and $0.6 \mathrm{MW} / \mathrm{m}^{2}$ (averaged over the plasma surface area) have been achieved. Through operational improvements such as plasma position feedback and RF power feedback, we are able to maintain constant RF power through load changes such as $\mathrm{L}-\mathrm{H}$ transitions and ELMs.

RF power absorption, determined from the discontinuity in slope of the stored energy at RF power transitions, was found to be near perfect ( $280 \%)$ in high single-pass absorption scenarios such as the $\mathrm{D}(\mathrm{H})$ heating at $5.3 \mathrm{~T}$ (the minority ion species is indicated in parenthesis). In low single-pass absorption scenarios such as the $\mathrm{D}\left({ }^{3} \mathrm{He}\right)$ heating at $7.9 \mathrm{~T}$, lower RF power absorption ( $\lesssim 70 \%$ ) is observed. It was found that L-mode plasmas follow the ITER89-P L-mode scaling regardless of the radiated power fraction. In contrast, $\mathrm{H}$ mode performance is improved markedly after boronization. This is believed to be due to substantial reduction in the radiated power from the main plasma. A PEP/P mode was 


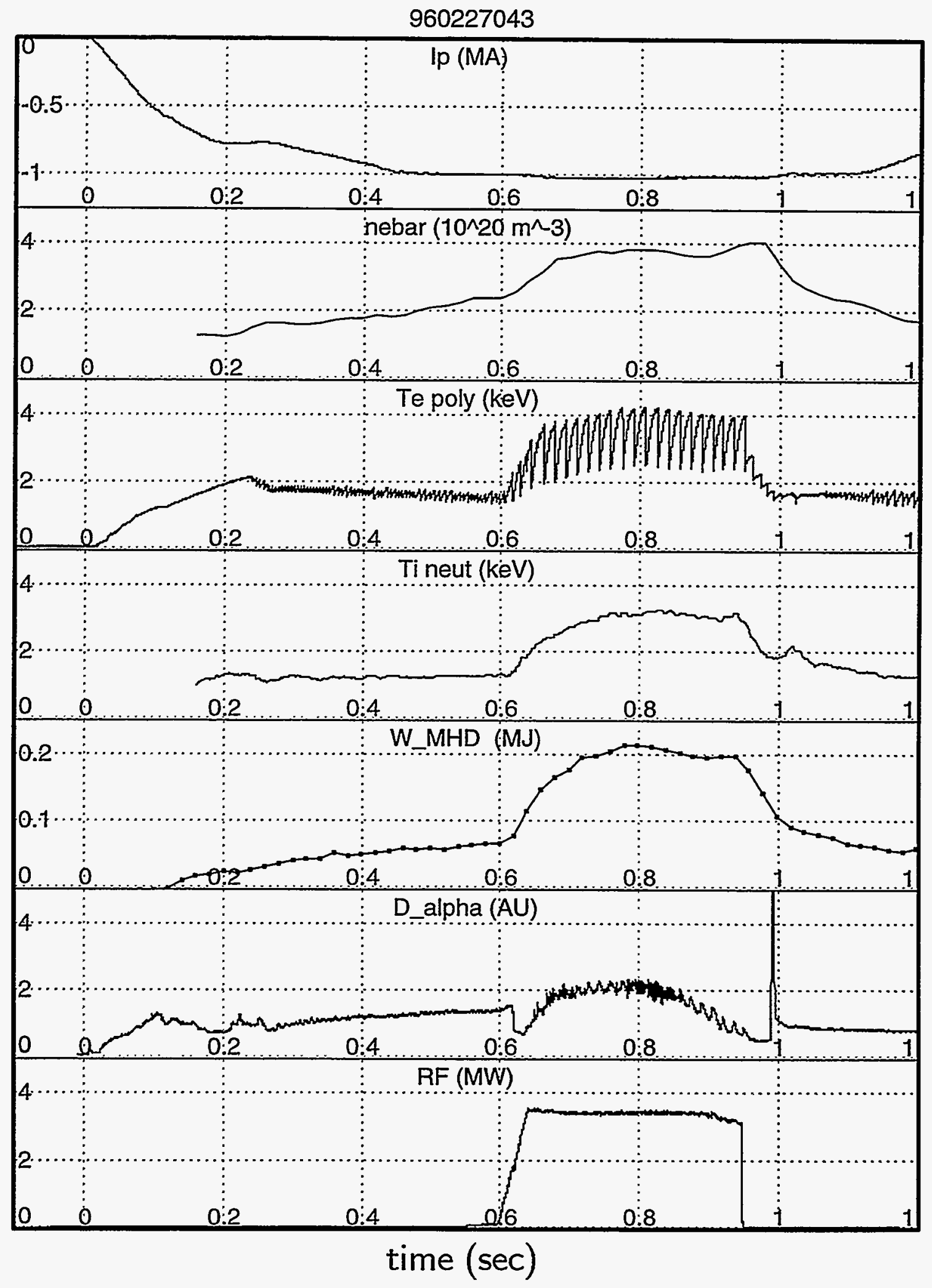

Fig. 2.4-1. High power ICRF heated H-mode at 5.3 T. 
observed with central ICRF heating following a $\mathrm{Li}$ pellet injection. A greatly enhanced ion temperature (a factor of 2 ) and fusion neutron rate (an order of magnitude) over L-mode, as well as very high pressure in the plasma core $\left(p_{0}>8 \mathrm{~atm}\right)$ were observed. Efficient off-axis $\mathrm{D}(\mathrm{H})$ minority heating was demonstrated with the minority resonance at least out to $r / a=0.5$ (outside the sawtooth inversion radius), as shown in Fig. 2.42.

Off-axis direct electron heating was demonstrated using the mode converted ion Bernstein wave (IBW). As shown in Fig. 2.4-3, well localized off-axis electron heating was observed using the $\mathrm{D}-{ }^{3} \mathrm{He}$ mode conversion scenario, which will be used in advanced tokamak studies. Off-axis current drive will become possible starting in FY 1997 with directional wave launch. Evaluation of off-axis heating and off-axis current drive will be an important part of the RF physics program in FY 1997 to prepare the profile control tools to be used for the advanced tokamak research program. From FY 1998 the program focus will shift toward demonstrating advanced tokamak modes using the profile control tools developed earlier. C-Mod has a unique high field capability, which allows attainment of high plasma pressures comfortably below MHD stability limits. More importantly, the compact size of C-Mod offers a unique capability in the world to sustain advanced tokamak plasmas for durations well in excess of the current profile relaxation time scale at "moderate" fields $(B \lesssim 5 \mathrm{~T})$.

FISIC/FELICE (full-wave RF codes) and FPPRF/SPRUCE (Fokker-Planck/full wave code) are used extensively to understand the RF power deposition and power balance. Significant progress has been made in the development of a model (ACCOME/PEST) for the prediction and MHD stability analysis of self-consistent tokamak equilibria in the presence of noninductive current profile control sources (LHCD, FWCD, bootstrap current, etc.), and further improvements will continue in the future.

\section{Expected progress}

Optimization of heating at high field ( $8 \mathrm{~T})$ and high current (1.5 MA) and a more complete characterization of the RF power absorption in low single-pass absorption schemes will be the primary focus of the RF physics program during the remainder of FY 1996- 


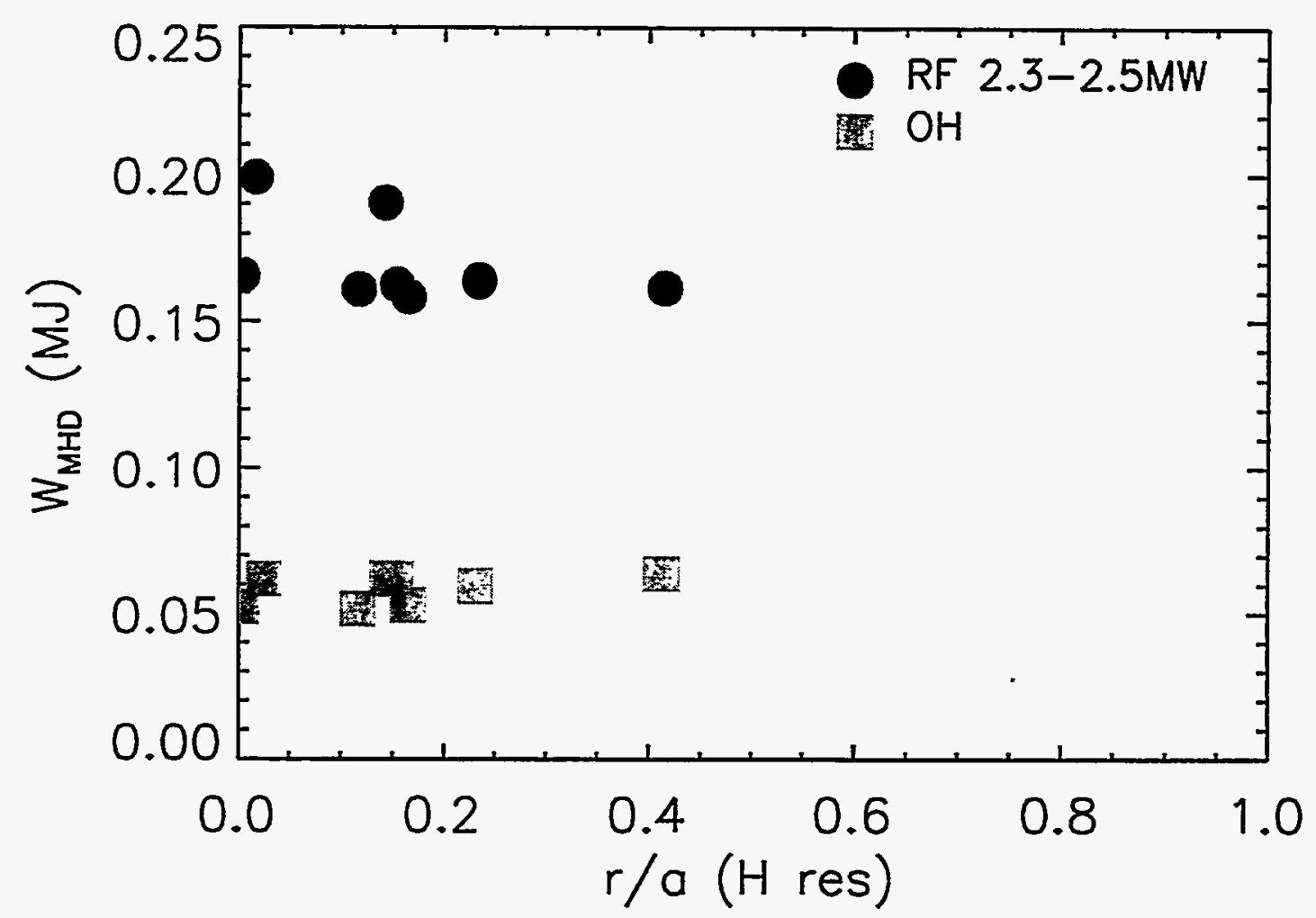

Fig. 2.4-2. Off-axis $\mathrm{D}(\mathrm{H})$ minority heating is almost as efficient as on-axis heating. The horizontal axis is the normalized minor radius of the $\mathrm{H}$ minority resonance, $\mathrm{B}=5.3-6.2 \mathrm{~T}$. 


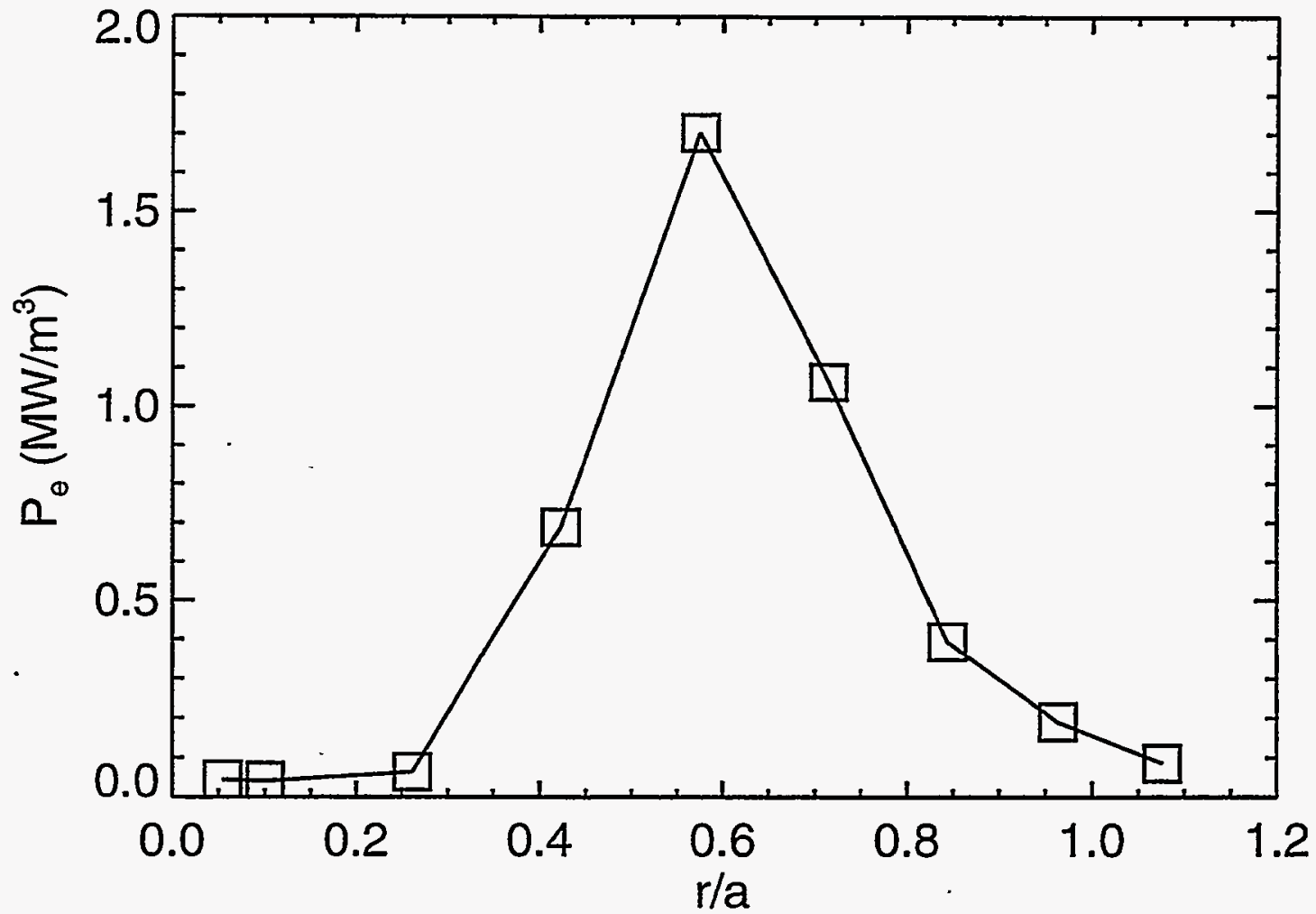

Fig. 2.4-3. Electron heating profile for off-axis $\mathrm{D}^{3} \mathrm{He}$ mode conversion heating at $\mathrm{B}=7.9 \mathrm{~T}$. 
7. Investigation of off-axis heating will continue to assess its usefulness in developing different scenarios for advanced tokamak modes. A phase contrast imaging system will become operational in FY 1996. This diagnostic will offer unique capability in the world to study RF waves in detail, combined with stationary RF probes at several locations and a reciprocating $R F$ probe.

We are currently in the process of installing additional $4 \mathrm{MW}$ of $40-80 \mathrm{MHz}$ ICRF power in collaboration with the PPPL RF Group. Implementation of this additional capability will proceed in two steps (see Sec. 3 for details). The $40-80 \mathrm{MHz}$ ICRF system will become operational, and will be connected to the existing MIT antennas in current drive configuration at $40 \mathrm{MHz}$ in FY 1997. Preliminary current drive studies will be carried out and the efficacy of off-axis current drive will be evaluated. Flexibility in plasma shaping (especially high triangularity) will be greatly enhanced with the modification of the inner divertor. Effects of shaping on confinement and stability will be investigated. $40 \mathrm{MHz}$ operation will also enable $\mathrm{D}(\mathrm{H})$ minority heating at $2.6 \mathrm{~T}$, well suited for high beta $\mathrm{MHD}$ stability studies and magnetic field (and $\rho^{*}$ ) scaling studies.

A 4-strap antenna capable of variable toroidal phasing (FWCD/MCCD antenna) will be fabricated by PPPL in FY 1997 and will be installed in J-port in early FY 1998. PPPL physicists will begin to participate in RF experiments on C-Mod. Both $80 \mathrm{MHz}$ and $40-80 \mathrm{MHz}$ power will become available for tokamak improvement studies. Addition of these sources will greatly enhance the flexibility in conducting longer pulse experiments at lower fields, such as the $\mathrm{D}-{ }^{3} \mathrm{He}$ reversed shear advanced tokamak regime in the field range 4-5.5 $\mathrm{T}$, with off-axis mode conversion current drive around $r / a \simeq 0.5$ [see Sec. 2.5 for details]. Experimental simulations of ITER fast wave current drive scenarios $(60 \mathrm{MHz}$ at $5.3 \mathrm{~T}, 40 \mathrm{MHz}$ at $5.3-5.7 \mathrm{~T}$ ) will also become possible. A simulation of one such fully noninductive current drive scenario $[\mathrm{D}(\mathrm{H})$ plasma at $5.3 \mathrm{~T}$ with $60 \mathrm{MHz}$ FWCD and $80 \mathrm{MHz}$ heating, $\left.n_{\mathrm{e} 0}=1.3 \times 10^{20} \mathrm{~m}^{-3}, T_{\mathrm{e} 0}=6 \mathrm{keV}, I=0.41 \mathrm{MA}, I_{\mathrm{BS}} / I=0.44\right]$ is shown in Fig. 2.4-4. In addition, $8 \mathrm{MW}$ of $\mathrm{RF}$ heating power will be available for high heat load divertor studies and high power transport studies (including the ITER demonstration discharge). Long-pulse (longer than the current profile relaxation time) current profile 


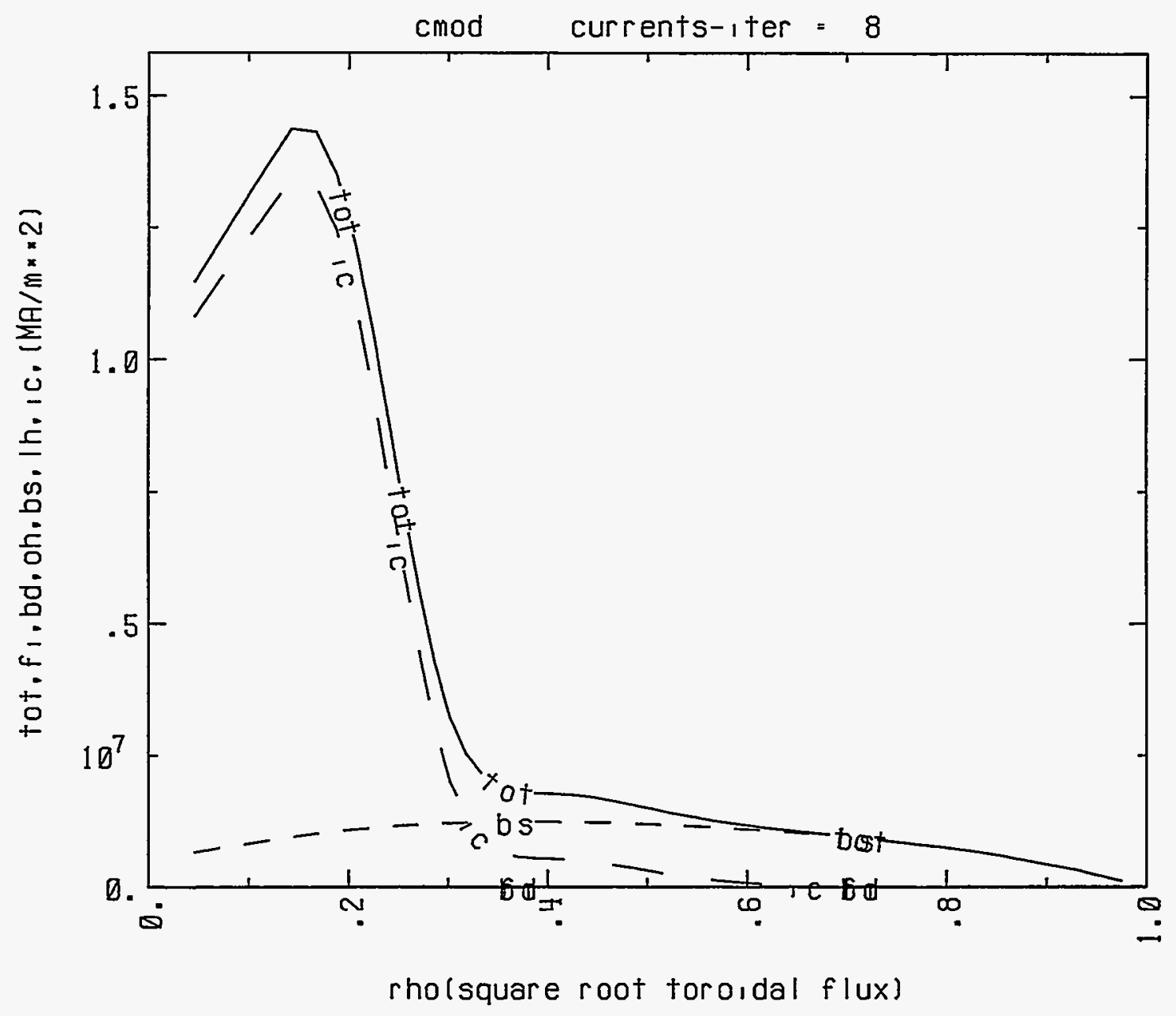

138

Fig. 2.4-4. A simulation of the $60 \mathrm{MHz}$ ITER FWCD scenario that can be tested in C-Mod. $\mathrm{D}(\mathrm{H})$ plasma at $\mathrm{B}=5.3 \mathrm{~T}$ with $60 \mathrm{MHz}$ FWCD and $80 \mathrm{MHz}$ heating. 
control experiments will begin in FY 1998 and continue into FY 1999.

A longer term upgrade includes installation of a $4 \mathrm{MW} 4.6 \mathrm{GHz}$ Lower Hybrid Current Drive (LHCD) system, which will start in FY 1997 and complete in FY 2000 (see Sec. 3 for details). In combination with ICRF heating, the lower hybrid system will provide a unique capability to study fully noninductive current driven reversed shear plasmas with advanced shaping for durations much longer than the current profile relaxation time scale. Shear flow control with directly launched IBW is not in the present plan, but is possible (requires a new IBW antenna). 


\subsection{Advanced Tokamak Physics Research}

\section{Background and Past Research}

The Alcator C-Mod device offers the possibility of demonstrating quasi-steady-state maintenance of advanced tokamak (AT) operating modes at high magnetic field ( $\mathrm{B}_{\mathrm{o}}=$ 3.5-5.5 T) near the $\beta$-limit. In this respect, C-Mod is unique in the US and international fusion program. The C-Mod magnets have a pulse length capability of up to 7 seconds at magnetic fields up to $5 \mathrm{~T}$. A typical skin time $t_{\text {skin }}$ in C-Mod at $\mathrm{T}_{\mathrm{e}}=5.0 \mathrm{keV}$ and $\mathrm{Z}_{\text {eff }}=1.5$ is $t_{\text {skin }}=1.0 \mathrm{sec}$. Thus with non-inductive current drive capability, C-Mod can explore the enhanced reverse shear (ERS) mode for time scales that exceed a full current relaxation and poloidal flux diffusion time $\left[\tau_{L / R} \simeq(3-4) t_{\text {skin }}\right]$. Detailed modelling studies indicate that with a confinement enhancement factor of $\mathrm{H}=3.5$, C-Mod can operate at $\beta_{\mathrm{N}} \geq 3.0$ with a bootstrap current fraction of 0.74 .

An important ingredient of accessing AT operating modes is the achievement of current density profiles with reverse shear. A reverse shear profile has already been demonstrated in a transitory fashion during pellet enhanced performance (PEP) modes in C-Mod using a combination of $\mathrm{Li}$-pellet injection and central ICRF heating. These PEP modes have been observed during hydrogen $(\mathrm{H})$ minority heating at $5.3 \mathrm{~T}$ and during ${ }^{3} \mathrm{He}$ minority heating at $7.9 \mathrm{~T}$. An example of the current density and q-profiles for a $5.3 \mathrm{~T}$ PEP mode at 0.8 $\mathrm{MA}$ and $\mathrm{P}_{\mathrm{RF}}=1 \mathrm{MW}$ are shown in Fig. 2.5-1. These profiles result from an EFIT analysis using external magnetics measurements and internal field line pitch angle measurements. The reversed shear profile is maintained in this discharge for less than $100 \mathrm{msec}$.

A key element in maintaining reverse shear current profiles in steady state is the use of off-axis current profile control methods. Off-axis electron heating has been demonstrated in C-Mod using a D-( $\left.{ }^{3} \mathrm{He}\right)$ mode conversion scheme at $7.9 \mathrm{~T}$ and high ${ }^{3} \mathrm{He}$ concentration $\left(\mathrm{n}_{\mathrm{s}_{\mathrm{He}}} / \mathrm{n}_{\mathrm{e}} \geq 0.15\right.$ ), as shown in Fig. 2.5-3. The existence of this electron heating and the threshold ${ }^{3} \mathrm{He}$ concentration for significant mode conversion to ion Bernstein waves (IBW) has been corroborated by 1-D full wave ICRF calculations from the FELICE code. The implication of this mode conversion scheme for current profile control is that if an antenna with unidirectional launch was employed, off-axis if current generation could be achieved.

\section{Future Research (FY1997 and FY1998)}

During FY1997 current drive experiments at $40 \mathrm{MHz}$ will become possible. Off-axis mode conversion current drive (MCCD) will be tested at $B_{\circ}=3.5 \mathrm{~T}$ and $f_{\circ}=40 \mathrm{MHz}$, in $\mathrm{D}-\left({ }^{3} \mathrm{He}\right)$ plasmas. The fundamental ${ }^{3} \mathrm{He}$ cyclotron resonance layer is approximately 

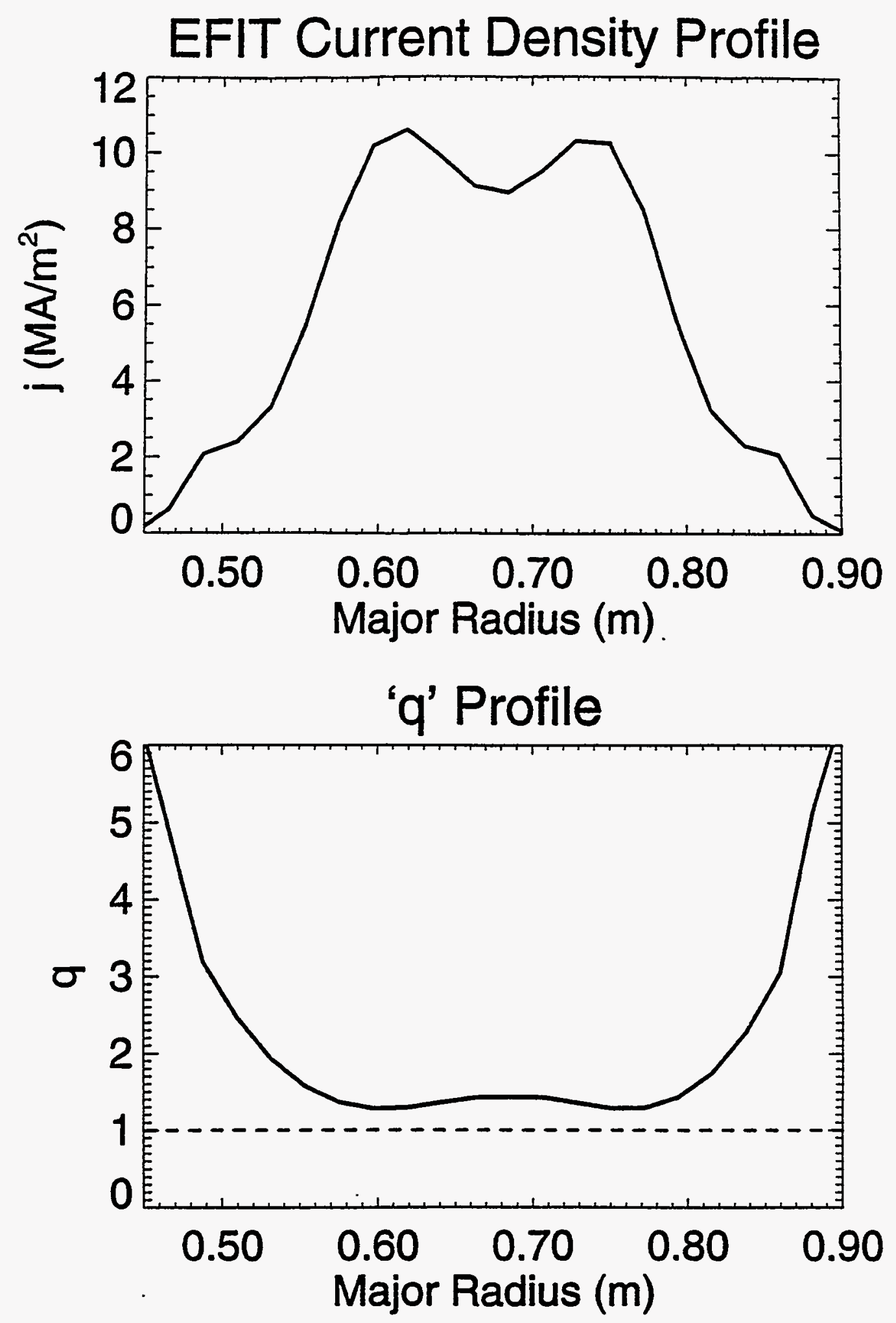

Figure 2.5-1: EFIT reconstruction for PEP mode shot $950427014\left(\mathrm{~B}_{\mathrm{o}}=5.3 \mathrm{~T}, \mathrm{I}_{\mathrm{p}}=\right.$ $0.8 \mathrm{MA}$, and $\mathrm{P}_{\mathrm{RF}} \simeq 1.0 \mathrm{MW}$ ). (a) Current density ( $\mathrm{MA} / \mathrm{m}^{2}$ ) versus major radius $(\mathrm{m})$. (b) Safety factor (q) versus major radius (m). 
(7-8) $\mathrm{cm}$ to the high field side (HFS) in this case. Mode conversion current drive at 3.5 $\mathrm{T}$ is attractive because the fundamental deuterium and hydrogen cyclotron resonance layers fall outside the plasma on the high and low field sides respectively. Thus parasitic absorption of the ICRF power via edge cyclotron damping is not a concern. Analysis of this MCCD scenario using the FELICE code indicates that at $n_{3} \mathrm{He} / n_{e} \geq 0.20,84 \%$ of the incident power is predicted to be absorbed via electron Landau damping (mostly on the mode converted IBW). About $15 \%$ of the RF power is absorbed via cyclotron damping at the fundamental ${ }^{3} \mathrm{He}$ cyclotron resonance layer. Other parameters used in this case were $\mathrm{n}_{\mathrm{e}}(0)=1.5 \times 10^{20} \mathrm{~m}^{-3}$ and $\mathrm{T}_{\mathrm{e}}(0)=\mathrm{T}_{\mathrm{d}}(0)=2.5 \mathrm{keV}$.

During FY1998 multiple frequency operation using the $80 \mathrm{MHz}$ and (40-80) $\mathrm{MHz}$ sources will become possible. Mode conversion current drive would be done at higher field (5.3 T) in D- $\left({ }^{3} \mathrm{He}\right.$ ) plasmas using $55 \mathrm{MHz}$. The $80 \mathrm{MHz}$ MIT sources (3 MW coupled power) would be used for on-axis plasma heating with a small fraction of $(\mathrm{H})$ minority ions. Preliminary studies using the FELICE code indicate that (75-80)\% absorption via electron Landau damping can be obtained at $\mathrm{n}_{3} \mathrm{He} / \mathrm{n}_{\mathrm{e}} \geq 0.15, \mathrm{n}_{\mathrm{e}}(0)=1.5 \times 10^{20} \mathrm{~m}^{-3}$, and $\mathrm{T}_{\mathrm{e}}(0)=$ $\mathrm{T}_{\mathrm{d}}(0)=2.5 \mathrm{keV}$. An example of the MCCD at $55 \mathrm{MHz}$ and $\mathrm{n}_{3 \mathrm{He}} / \mathrm{n}_{\mathrm{e}}=0.20$ is shown in Fig. 2.5-2. About $81 \%$ of the incident power is absorbed via electron Landau damping (mostly on the mode converted IBW). Parasitic absorption of the mode converted IBW at the deuterium cyclotron resonance (HFS) is evident in Fig. 2.5-2. Mode conversion current drive experiments at $55 \mathrm{MHz}$ in C-Mod will provide valuable information concerning the importance of this parasitic absorption.

The $80 \mathrm{MHz}$ sources could also be used for plasma heating in the D- $\left({ }^{3} \mathrm{He}\right) \mathrm{MCCD}$ scenario at $40 \mathrm{MHz}$. Absorption of the $40 \mathrm{MHz}$ ICRF power (fundamental ${ }^{3} \mathrm{He}$ cyclotron damping) would result in a more energetic distribution of ${ }^{3} \mathrm{He}$ ions, leading to increased absorption of the $80 \mathrm{MHz}$ heating power at $2 \Omega_{\mathrm{c}_{\mathrm{He}}}$.

A second key ingredient in the achievement of high $\beta$ and high confinement regimes in C-Mod will be plasma shaping, in particular high triangularity $\left(\delta_{\mathrm{x}} \geq 0.5\right)$. During FY1997, modifications to the inner divertor on C-Mod will be undertaken, thus enabling operation with highly shaped plasma configurations $\left(\kappa_{x} \simeq 1.8\right.$ and $\delta_{x} \simeq 0.8$ ). Effects of plasma shaping on confinement and MHD stability will be investigated.

In FY2000, lower hybrid current drive capability at $4.6 \mathrm{GHz}$ will be added to C-Mod. This will enable fully noninductive current driven operation with reverse shear profiles for long pulse $\left(t \simeq \tau_{\mathrm{L} / \mathrm{R}}\right)$. We have carried out detailed current profile control and ideal MHD stability studies for this long pulse operation using the combined ACCOME/PEST 

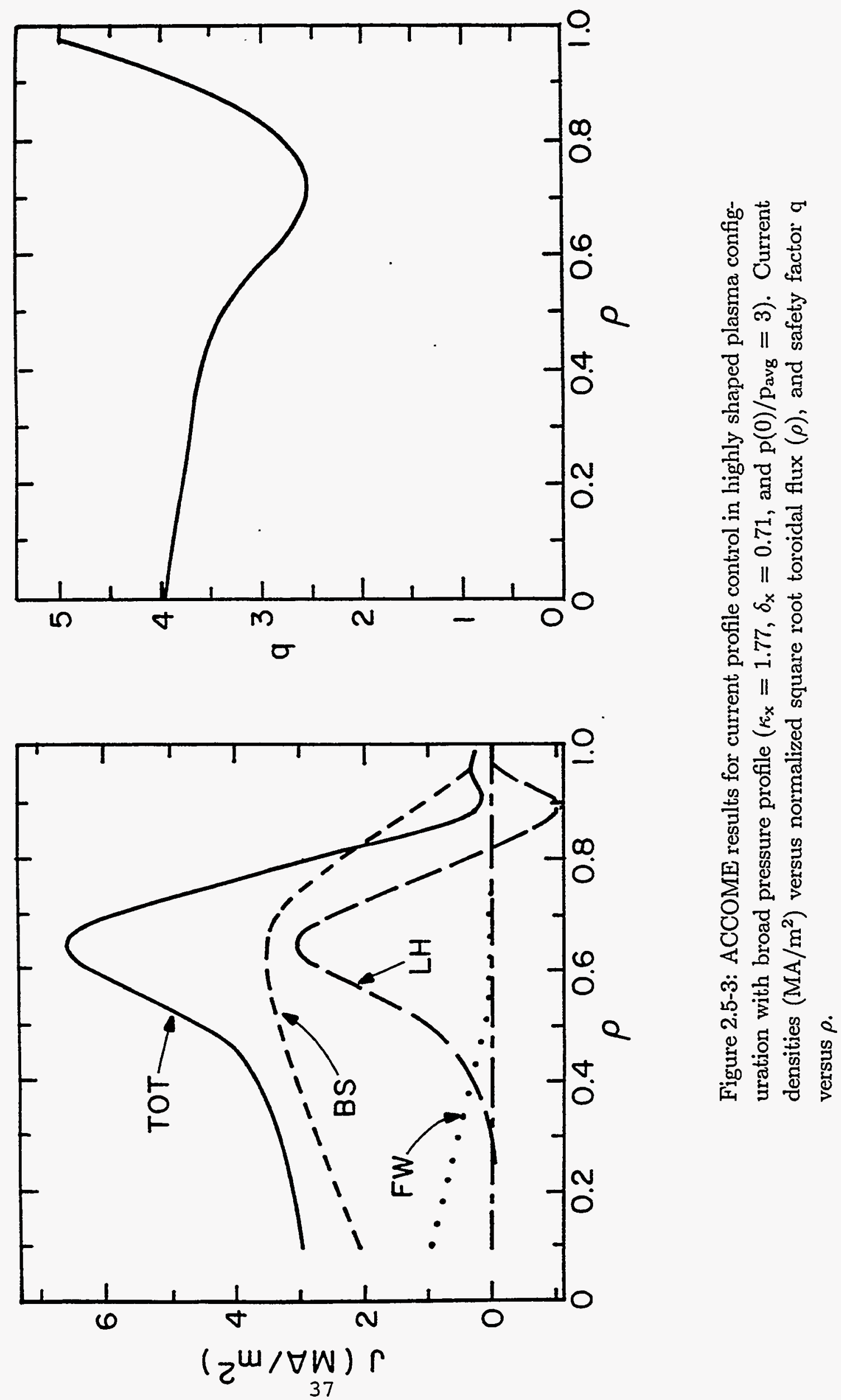
simulation model. An example of the current profile control results for a highly shaped C-Mod configuration are shown in Fig. 2.5-3 and the corresponding stability analysis is summarized in Fig. 2.5-4. The parameters used in this case were $B_{o}=4.0 \mathrm{~T}, \mathrm{~T}_{\mathrm{e}}(0)=$ $\mathrm{T}_{\mathrm{d}}(0)=7.5 \mathrm{keV}, \mathrm{a}=0.23 \mathrm{~m}, \mathrm{R}_{\mathrm{o}}=0.665 \mathrm{~m}, \mathrm{p}(\psi)=\mathrm{p}(0)(1-\psi)^{2}, \mathrm{~T}(\psi)=\mathrm{T}(0)\left[\frac{2}{3}(1-\right.$ $\left.\psi)^{7 / 2}+\frac{1}{3}\left(1-\psi^{8}\right)^{3 / 2}\right], \mathrm{n}(\psi)=\mathrm{p}(\psi) / \mathrm{T}(\psi), \mathrm{n}_{\mathrm{e}}(0)=2.0 \times 10^{20} \mathrm{~m}^{-3}$, and the plasma gas is deuterium. The off-axis current profile control is provided by $3 \mathrm{MW}$ of LHRF power at $4.6 \mathrm{GHz}$ and the central seed current density is provided by $(0.15-0.65) \mathrm{MW}$ of ICRF fast wave power at $40 \mathrm{MHz}$. The parallel refractive index of the LH waves was varied in the range $2.9 \leq n_{\|} \leq 3.55$ and the toroidal mode number of the ICRF waves was set at $n_{\phi}=4$.

The case shown in Fig. 2.5-3 corresponds to a plasma configuration with $\kappa_{x}=1.77$ and $\delta_{x}=0.71$. The total plasma current is $\mathrm{I}_{\mathrm{p}}=807 \mathrm{kA}$ with bootstrap current fraction $f_{\mathrm{BS}}=0.74$, and $I_{\mathrm{FW}}=9 \mathrm{kA}$. The profiles of the bootstrap current, lower hybrid current, central fast wave seed current and the total current are shown in Fig. 2.5-3. The central value of the safety factor is $\mathrm{q}_{0}=3.95$ with $\mathrm{q}_{\min }=2.65$, $\mathrm{q}_{95}=6.35$, and internal inductance $\ell_{\mathrm{i}}(3)=0.65$. The radius of shear reversal in this case is at a normalized square root of the toroidal flux of $\rho \approx 0.71$. The volume average toroidal beta is $\beta_{\mathrm{t}}=2.60 \%$ with a pressure peaking factor of $\mathrm{p}(0) / \mathrm{p}_{\text {avg }}=2.90$, where $p_{\text {avg }}$ stands for the volume averaged pressure.. The normalized beta is $\beta_{\mathrm{N}}=\beta_{\mathrm{t}} /\left(\mathrm{I}_{\mathrm{p}} / \mathrm{aB}_{\mathrm{o}}\right)=2.96(\%-\mathrm{mT} / \mathrm{MA})$. This equilibrium is found to be stable to all the ideal MHD modes $(n=1,2,3, \infty)$ without a conducting wall. Figure 2.5-4 is a stability diagram generated from the a scaling of the ACCOME equilibrium, using the PEST-II code. The marginal stability boundary is shown as a solid line and the ACCOME equilibrium is indicated by a triangle. The critical $\beta_{\mathrm{N}}$ for marginal stability at $\mathrm{q}_{\min } \simeq 2.6$ is $\beta_{\mathrm{N}} \simeq 2.9-3.0$. Thus the simulation shown in Fig. 2.5-3 is very close to the $\beta$-limit. The effect of plasma shaping on ideal MHD stability (and in particular, the effect of high triangularity) has been investigated for this case. It is found that for almost identical pressure and current profiles, the critical value of $\beta_{\mathrm{N}}$ is reduced from 3.7 to (2.0$2.2)$ as the triangularity is reduced from 0.7 to 0 . These predicted effects of triangularity will be compared with experimental results for MHD stability. 


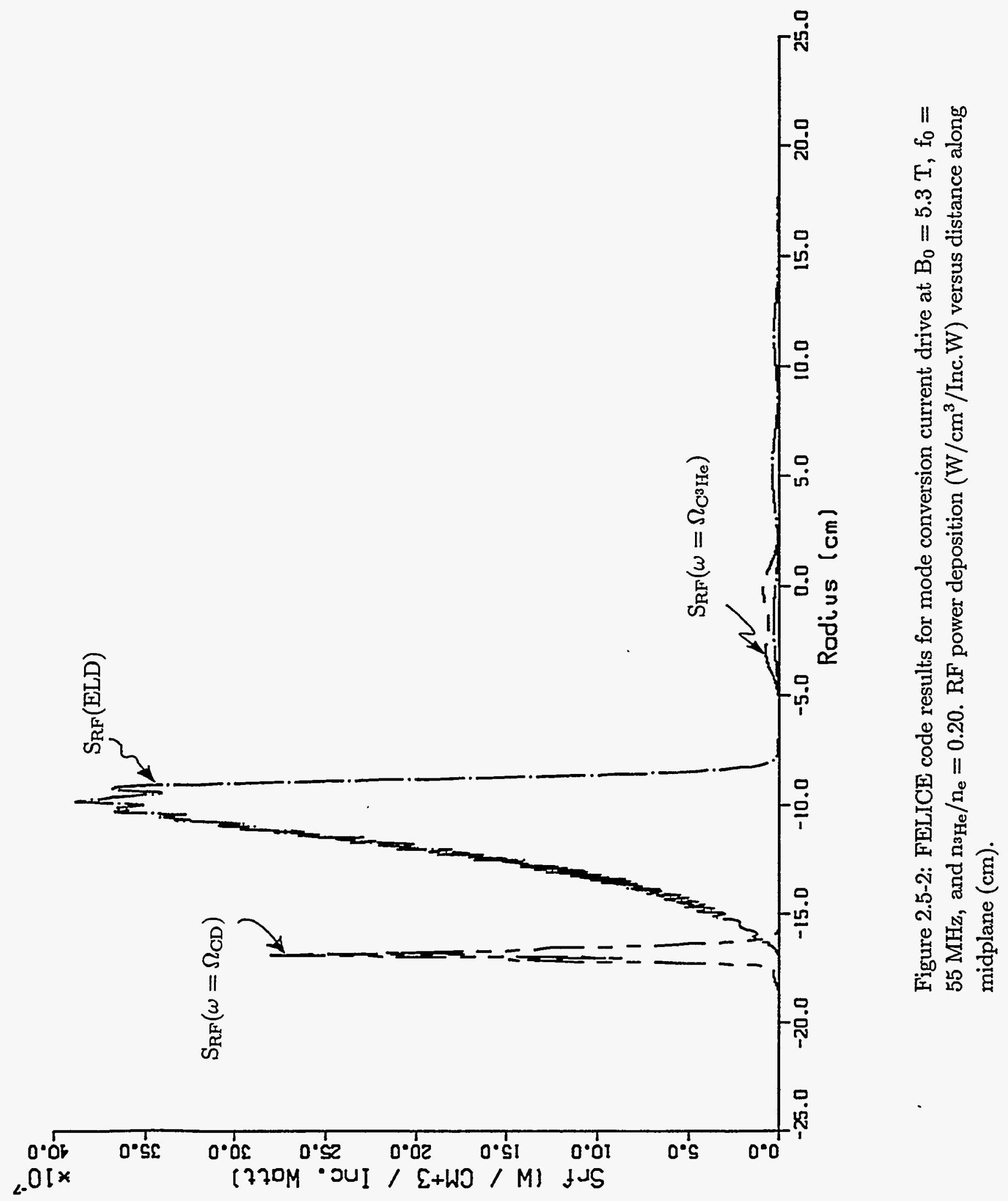




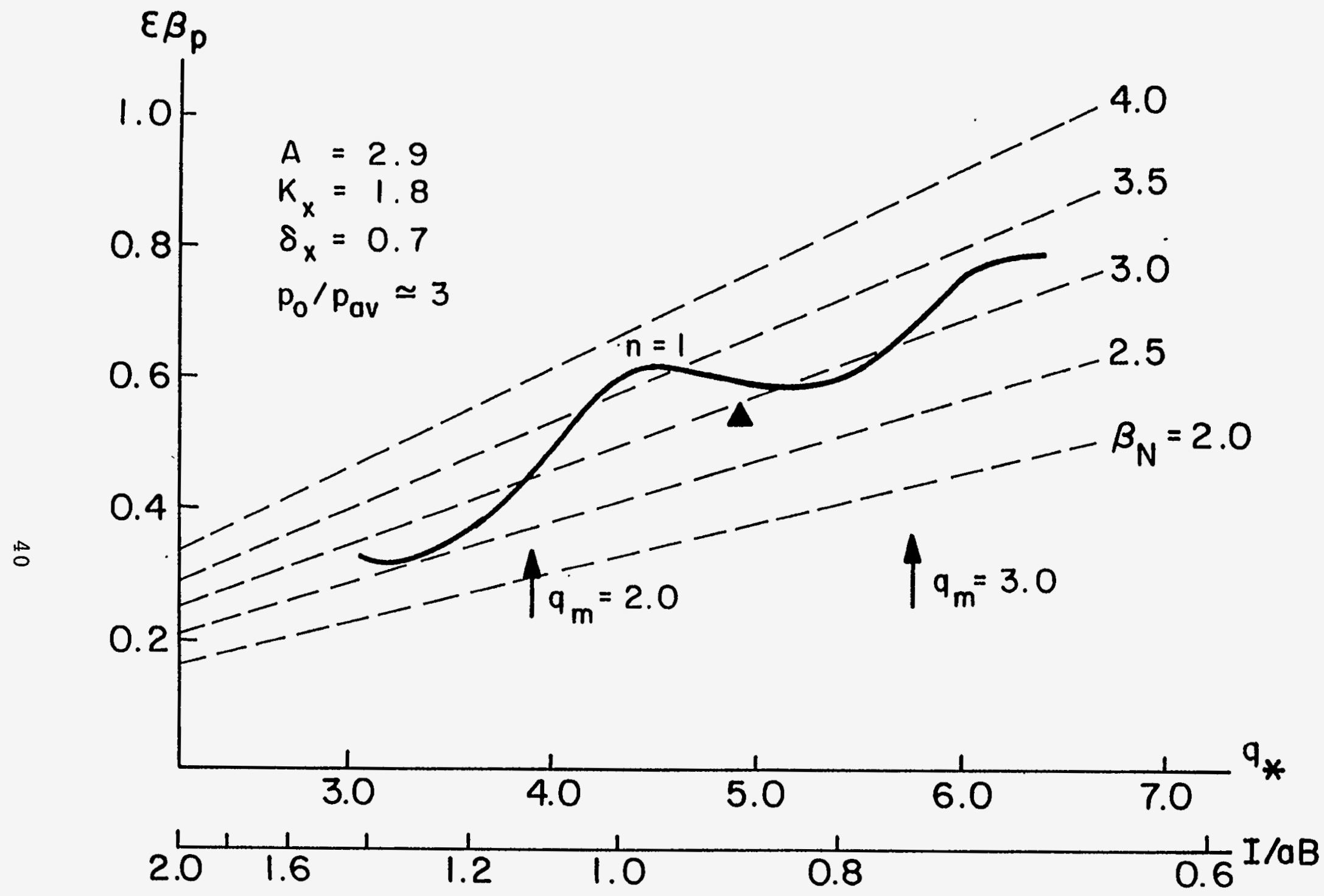

Figure 2.5-4: PEST-II results for stability limit against the $\mathrm{n}=1$ external mode in the absence of conducting walls, in an $\epsilon \beta_{\mathrm{p}}$ vs. $\mathrm{q}_{*}$ space spanned by scaling the highly shaped ACCOME equlibrium with broad pressure profile (Fig. 2.5-3). The location of the original equilibrium is indicated by the black triangle and the stable domain is below the curve. Mode resonant values of $q_{\min }$ along the marginal stability curve are indicated by arrows. 


\section{Alcator C-Mod: Engineering Operations}

\section{FY96 Progress:}

During FY96 Alcator C-Mod ran reliably at toroidal fields of up to 8.1 Tesla, and plasma currents of 1.2 MA. RF powers of up to $3.5 \mathrm{MW}$ were coupled to the plasma, with plasma position feedback used to maintain proper loading at the antennas. New circuits in the alternator feedback loop maintained a more stable voltage source for the power supplies, even during the high field operation. Engineering instrumentation upgrades allowed us for the first time to record alternator rotation speeds and voltages, TF sliding joint resistances, hi-yard currents and voltages, and $\mathrm{OH}$ coax resistances, temperatures, and accelerations. Upgrades to the EF4 supply increased its current capability by a factor of three. The EF1 primary transformer was replaced and its voltage capability enhanced with a resulting decrease in the number of VDE events. Additional halo current Rogowski measurements were added to the outer divertor and results from these measurements are now being integrated into detailed models of the outer divertor stresses. Our divertor cryopump preprototype was finished and tested. It cooled down below $6 \mathrm{~K}$, with 30 minute hold times, and a pumping speed for D2 for greater than $1000 \mathrm{l} / \mathrm{s}$. The prototype is now in house and will be installed during the current up-to-air. The LN2 and LHe transfer lines for the pump are nearly complete. A lower divertor mockup was also built to aid in construction of the cryopump. A great deal of work has been done on the new RF systems. The HVDC power supplies have been reconditioned and installed in the hi-yard. Power and control conduits have been installed, high voltage cables have been run, AC switchgear acquired and reconditioned, water cooling systems nearly completed, and CAMAC and PLC control interface wiring has begun. In addition the drivers have been installed in the power room, and the power crowbar units are well underway. The edge Thomson scattering head was installed in-vessel, and the required modifications to the divertor were made so that beam and viewing dumps could be installed. Finally, a complete boronization system was brought into operation, including the PLC gas control system, vents, pumps, and

extensive monitoring/safety diagnostics. Deposition rates of about 100 Angstroms/hour were achieved, with much enhanced plasma performance resulting.

\section{Future Accomplishments}

During FY97 and FY98 the engineering group will be concentrating primarily on a set of upgrades, most of which are essential to the progress of the physics program. Listed below are the upgrades and estimates of completion times at two budget levels. 
Divertor Cryopump: The divertor cryopump upgrade consists of ten liquid helium cooled cryopump modules installed below the lower-outer divertor modules. The total pumping speed will be in the $10000-20000 \mathrm{l} / \mathrm{s}$ range. A prototype module has been built, and will be installed and tested in C-Mod before the full cryopump is installed. At a $\$ 13 \mathrm{M}$ funding level, this activity would be delayed well into FY98. At a $\$ 15 \mathrm{M}$ funding level, we would expect to complete the installation on schedule in late FY97.

Divertor Upgrade: The lower divertor upgrade consists primarily of modifications to the inner divertor which will allow for better plasma shape control. An upgrade to the upper divertor is also planned to add a gas box and sufficient instrumentation to diagnostic this region. We are currently completing the design phase of our inner divertor modification. In addition, halo and eddy current modelling is about to begin. Because of the importance of this upgrade to the future of the project, we would push to complete the lower-inner divertor upgrade in FY97 at either budget level.

Diagnostic Neutral Beam: We are currently planning to install the UTx DNB hardware on C-Mod. We have sent engineers to UTx to look over the equipment so that detailed planning of the installation on C-Mod can begin. In addition, scientists from UTx have visited MIT so that questions about the beam itself together with the various diagnostics we expect to use with the beam could be addressed. At a $\$ 15 \mathrm{M}$ budget level we hope to have the DNB hardware installed during FY97, even with the large uncertainly in the amount of help we can expect for UTx. At a $\$ 13 \mathrm{M}$ level we would expect installation to extend well into FY98. Note that we are discussing the DNB hardware only and not the diagnostics required to make it useful. We discuss the support diagnostics below.

ICRF: The ICRF upgrade consists of the commissioning of two variable frequency (40-80MHz) transmitters, and the transmission lines, decoupler, controls, and antenna required to deliver power to the plasma. These new power sources in combination with the existing transmitters will provide C-Mod with approximately $8 \mathrm{MW}$ of RF heating power. In addition, as the new transmitters come on line in FY97, we will have the ability to drive our current antennas at the proper frequency and phasing to allow FWCD experiments to begin. We plan to push this upgrade to completion in FY98 at either funding scenario.

Lower Hybrid: The lower hybrid upgrade consists of site prep, installation of new HVDC supplies, developing a control system, commissioning the klystrons both at MIT and PPPL, recommisioning the modulator system, and designing, fabricating, and installing a launcher and associated waveguide. 
The lower hybrid upgrade is currently planned to be complete by the end of FY00. This upgrade will be done in collaboration with PPPL, who would commission the modulator equipment and design and procure the launcher. We are just beginning the planning phase of this upgrade. We have begun to consider what site modifications will be required, what HVDC power supply upgrades will be needed, and what work will be required to get the klystrons now at MIT operational. We would expect to have the system operational on schedule at the $\$ 15 \mathrm{M}$ level. At the $\$ 13 \mathrm{M}$ level we would expect the upgrade to be delayed well into fy01.

\section{Diagnostic Upgrades}

Alcator C-Mod has a very good set of core diagnostics, and an excellent set of divertor diagnostics. Table 3.1 summarizes the capabilities and features of the presently operational diagnostic complement on the tokamak. In both the core and divertor areas, we envision a number of important enhancements to the diagnostics which will allow for more detailed physics studies of many of the key scientific issues to be addressed on C-Mod over the next several years. Tables 3.2 and 3.3 list the core and divertor/edge diagnostic upgrades, respectively, along with status and planned availability, assuming the $\$ 15 \mathrm{M}$ at MIT baseline budget case.

For the core plasma, the key scientific issues include: H-mode dynamics; internal transport barrier formation and evolution; MHD and disruptions; and ICRH physics. With the implementation of the planned diagnostic additions and upgrades, measurement capabilities will be improved in the following areas: electron density profiles (especially spatial resolution near the edge); fluctuations, both near the edge and into the core; plasma rotation, both poloidal and toroidal; ion temperature profiles (improved spatial resolution); and current density profile (time evolution and edge spatial resolution). The last four in this list rely heavily on diagnostics which will work in conjunction with the DNB.

The improvements to edge/divertor diagnostics are aimed at increased understanding of: impurity sources and screening; momentum and energy balance; ELM physics; hydrogenic recycling; parallel and perpendicular energy and particle transport; plasma flows; and neutral dynamics. The planned systems will upgrade our capabilities as follows: temperature and density profiles (increased coverage, spatial resolution); impurity dynamics, including increased spatial coverage for source measurements, additional impurity species mix measurements; fluctuations (increased probe coverage); time resolved power flows to surfaces; and low energy neutral outflux.

The effects on the diagnostic upgrades, of decreasing the budget to $\$ 13 \mathrm{M}$ at MIT in 
FY97, are as follows: DNB related diagnostics are delayed (CXRS and BES, 8 months, MSE 1 year); completion of the core Thomson scattering system is delayed until FY99; the tangential interferometer array delayed 12 months; the collimated neutron detector array and the tangential XUV photodiode array are deferred indefinitely. 
Table 3.1

Installed C-Mod Diagnostic Systems

Diagnostic Technique

Magnetic loops

Internal Rogowskis

Nd:YAG Thomson Scattering

Two Color

Interferometer

Electron Cyclotron Emission

Fast Scanning Michelson

Polychromator

Neutral Particle Energy

Analysis

Neutron Diagnostics

Uranium fission detectors

${ }^{3} \mathrm{He}$ Bank

Visible and UV Spectroscopy

a) 2.2 Meter Grazing Incidence Time Resolving Spectrograph

b) 2.2 Meter High Resolution UV-Vis

c) Fabry-Perot

d) 1.0 Meter Normal Incidence Time Resolving Spectrograph

e) Visible continuum

f) Mo Monitor

g) Periscopes $\underline{\text { Parameters }}$

$\mathrm{I}_{p} ; \mathrm{B}_{\theta} ;$ flux

Halo currents

$\mathrm{T}_{e}(\mathrm{r}, \theta, \mathrm{t}) ; \mathrm{n}_{e}(\mathrm{r}, \theta, \mathrm{t})$

$\mathrm{n}_{e}(\mathrm{r}, \mathrm{t})$

$\mathrm{T}_{e}(\mathrm{r}, \mathrm{t})$

$\mathrm{T}_{e}(\mathrm{r}, \mathrm{t})$

$\mathrm{T}_{i}(\mathrm{r}, \mathrm{t})$; Ion distribution function; $H / D$ ratio

Neutron rate; $T_{i}(t)$

Neutron rate; $T_{i}(t)$

Line emission

Doppler shifts and widths

$\mathrm{H} / \mathrm{D}$ ratio,

Neutral energy distribution

Current density profile

$n_{e}{ }^{2} \times Z_{e f f} / \sqrt{\left(T_{e}\right)}$

Mo line emission

Tangential view

in visible light

views of inner and

outer divertor
Features

Internal to vacuum vessel

2 total current

10 azimuthal

4 vertical

10 toroidal segments

$50 \mathrm{~Hz}$ rep. rate,

Ten chord, CW

operation. Able easily

to follow density

rise with pellet

injection.

Complete Spectra, $50 \mathrm{~Hz}$

Nine channels with

fast frequency response

Two systems: one

perpendicular, one tangential

Dynamic range $>10^{4}$

Fast time response

Covers any $40 \AA$ slice between $18 \AA$ and $600 \AA$ with $4 \mathrm{msec}$ time and $0.2 \AA$ spectral resolution

Spatial and spectral imaging

$1200 \AA<\lambda<8000 \AA$

LPI polarimetry

One 30 channel tangential array, plus a single chord system. MLM Polychromator multiple systems 


\author{
h) $\mathrm{H}_{\alpha}$ \\ i) Impurity Radiation \\ j) 2-d Visible Spectrograph \\ Reflectometer \\ Lithium Pellet Injector \\ X-ray Diagnostics \\ a) Compact Curved Crystal \\ Time Resolving Spectro- \\ graph Arrays (HIREX) \\ b) Broad Band Soft X-Ray \\ Arrays
}

Bolometry

Langmuir Probes

Pneumatic probes

Thermocouples

Laser Blow-Off Impurity Injector

Neutral pressure gauges

Collimated Charged

Particle Detector

RF Probes
Particle sources

Impurity sources

Edge density profiles

Current density profile; Impurity transport

$\mathrm{T}_{i}(\mathrm{r}, \mathrm{t}) ; \mathrm{T}_{e}(\mathrm{r}, \mathrm{t})$;

$\mathrm{n}_{\mathrm{o}}(\mathrm{r}, \mathrm{t})$; Impurity

Densities \& evolution

Plasma position and shape; MHD activity; impurity transport

Total radiated plus charge exchange power from core plasma Divertor radiated power plus $\mathrm{C}$-X $2 \pi$ XUV photodiode

Edge $\mathrm{n}_{e}, \mathrm{~T}_{e}, \phi$; fluctuations

Edge $\mathrm{n}_{e}, \mathrm{~T}_{e}, \phi$; fluctuations; edge $R F$ fields $(B, \phi)$ Limiter/divertor tile bulk temperatures

Impurity transport, Confinement

$\mathrm{n}_{0}$ at edge/divertor

Production rate and confinement of D-D fusion produced $3 \mathrm{MeV}$ protons

Edge RF fields $(B, \phi)$
Video cameras, pol. arrays Video cameras, pol. arrays 14 Fiber views

5 frequencies

multiple pellets per shot

$1.5 \mathrm{keV}<h \nu<5 \mathrm{keV}$, Measures doppler broadening of impurity lines. Fully two-dimensional tomographic reconstructions.

Tangential array

Poloidal arrays

Wide angle view monitors total radiated power

Dense poloidal coverage with multi-probe arrays.

Scan SOL up to last closed flux surface.

modified ion gauges

Capacitance Manometers

Multiple toroidal and poloidal locations 
Table 3.2 Core Diagnostic Upgrades

\begin{tabular}{|c|c|c|c|}
\hline $\begin{array}{l}\text { Diagnostic } \\
\text { system }\end{array}$ & $\begin{array}{l}\text { Measured } \\
\text { Parameters }\end{array}$ & Status & Availability \\
\hline ECE Radiometer & $\begin{array}{l}\text { Core temperature } \\
\text { fluctuations }\end{array}$ & Collaboration with Texas; add to existing ECE system & July, 96 \\
\hline $\begin{array}{l}\text { Core Thomson } \\
\text { Scattering }\end{array}$ & $\begin{array}{l}\mathrm{n}_{\mathrm{e}}(\mathrm{r}, \mathrm{t}), \mathrm{T}_{\mathrm{e}}(\mathrm{r}, \mathrm{t}) ; \text { additional } \\
\text { spatial points. }\end{array}$ & $\begin{array}{l}6 \text { spectrometers operational; add } 5 \text { more to complete } \\
\text { system }\end{array}$ & $\begin{array}{l}2 \text { in FY97 } \\
3 \text { in FY98 }\end{array}$ \\
\hline Reflectometer & $\begin{array}{l}\text { Density profiles, } \\
\text { fluctuations; higher } \\
\text { density capability }\end{array}$ & $\begin{array}{l}\text { New antennas will allow X-Mode and O-Mode } \\
\text { operation - operate to much higher } \mathrm{n}_{\mathrm{e}} \text { with present } \\
\text { frequencies }\end{array}$ & July, 96 \\
\hline $\begin{array}{l}\text { Tangential } \\
\text { Interferometer }\end{array}$ & $\begin{array}{l}\text { Density profiles; } \\
\text { improved spatial } \\
\text { resolution }\end{array}$ & $\begin{array}{l}\text { Single chord prototype will be tested in FY96; } \\
\text { multi-chord array being designed }\end{array}$ & March, 97 \\
\hline $\begin{array}{l}\text { Collimated Neutron } \\
\text { Detector Array }\end{array}$ & Ion temperature profile & preliminary design and prototype testing in FY96 & January, 98 \\
\hline $\begin{array}{l}\text { Phase contrast } \\
\text { imaging }\end{array}$ & $\begin{array}{l}\text { RF waves, d ensity } \\
\text { fluctuations }\end{array}$ & $\begin{array}{l}\text { designed and most hardware at MIT; student thesis } \\
\text { project }\end{array}$ & Sept, 96 \\
\hline $\begin{array}{l}\text { "Sieve" Fluctuation } \\
\text { diagnostic }\end{array}$ & density fluctuations & $\begin{array}{l}\text { SBIR project in collaboration with Science Research } \\
\text { Laboratory }\end{array}$ & July, 96 \\
\hline $\begin{array}{l}\text { Tangential XUV } \\
\text { photodiode array }\end{array}$ & $\begin{array}{l}\text { Core radiated power } \\
\text { profiles }\end{array}$ & improved time resolution relative to bolometers & January, 98 \\
\hline $\begin{array}{l}\text { Charge exch. } \\
\text { recomb. spectr. }\end{array}$ & $\begin{array}{l}\mathrm{T}_{\mathrm{i}}(\mathrm{r}, \mathrm{t}) \text {, impurity density } \\
\text { profiles, rotation }\end{array}$ & needs DNB. Collaboration with Texas & July, 97 \\
\hline BES & density fluctuations & with DNB, Texas collaboration & July, 97 \\
\hline MSE & current density profile & with DNB, Texas collaboration & January, 98 \\
\hline
\end{tabular}


Table 3.3 Edge/Divertor Diagnostic Upgrades

\begin{tabular}{|c|c|c|c|}
\hline $\begin{array}{l}\text { Diagnostic } \\
\text { system }\end{array}$ & Measured Parameters & Status & Availability \\
\hline $\begin{array}{l}\text { Edge Thomson } \\
\text { Scattering }\end{array}$ & $\begin{array}{l}\text { SOL temperature and density } \\
\text { profiles }\end{array}$ & $\begin{array}{l}\text { Collaboration with PPPL/PSI; } \\
\text { in-vessel optics installed; rest of } \\
\text { system in final test at PPPL, }\end{array}$ & July, 96 \\
\hline Divertor RGA & $\begin{array}{l}\text { Impurity mix from private flux } \\
\text { region }\end{array}$ & System designed & July, 96 \\
\hline $\begin{array}{l}\text { Omegatron mass } \\
\text { analyzer }\end{array}$ & $\begin{array}{l}\text { charge to mass spectrum, ion } \\
\text { energy distribution }\end{array}$ & $\begin{array}{l}\text { Hardware installed; student thesis } \\
\text { project }\end{array}$ & July, 96 \\
\hline Infrared Imaging & $\begin{array}{l}\text { Surface temperature; divertor } \\
\text { loading; disruption dynamics }\end{array}$ & Collaboration with LANL & July, 96 \\
\hline $\begin{array}{l}\text { Visible/UV fiber } \\
\text { views (interface to } \\
\text { spectrographs) }\end{array}$ & $\begin{array}{l}\text { Impurity source, rotation } \\
\text { (added views) }\end{array}$ & Hardware at MIT & July, 96 \\
\hline Probes & $\begin{array}{l}\text { density and temperature, } \\
\text { fluctuations }\end{array}$ & $\begin{array}{l}\text { Texas collaboration (increased } \\
\text { emphasis on fluctuations) }\end{array}$ & March, 97 \\
\hline $\begin{array}{l}\text { X-Point Multi- } \\
\text { Layer- Mirror } \\
\text { spectrograph }\end{array}$ & nitrogen line emission & Johns Hopkins collaboration & March, 97 \\
\hline
\end{tabular}




\section{ALCATOR C-MOD PUBLICATIONS SUMMARY}

Papers Published in Refereed Journals

12

Papers to be Published in Refereed Journals 8

MIT Plasma Fusion Center Research Reports 21

Conference Presentations $\quad 12$

APS Posters $\quad 40$

APS Oral Presentations $\quad 10$

Invited Papers 5

Workshop Presentations 6

Other Presentations 16

See Appendix A for detailed publications list. 
TASK 1 : ALCATOR CMOD FIELD WORK PROPOSAL

DE-AC02-78ET-51013

B\&R\# AT-10-10-14F

\begin{tabular}{|c|c|c|c|c|c|}
\hline \multirow{2}{*}{$\begin{array}{l}\text { COST SUMMARY } \\
\text { (dollars in } \mathrm{K} \text { with overhead) }\end{array}$} & \multicolumn{3}{|c|}{ "A" BUDGET } & \multicolumn{2}{|c|}{$\begin{array}{l}\text { "B" BUDGET } \\
\text { ALTERNATE }\end{array}$} \\
\hline & FY 96 & FY97 & FY98 & FY97 & FY98 \\
\hline Personnel & $\$ 8,713$ & $\$ 10,548$ & $\$ 10,994$ & $\$ 9,538$ & $\$ 9,917$ \\
\hline Materials \& Services & 1,006 & 3,485 & 3,856 & 2,955 & 3,147 \\
\hline Travel & 206 & 282 & 305 & 243 & 264 \\
\hline Subtotal Operating Funds & $\$ 9,925$ & $\$ 14,315$ & $\$ 15,155$ & $\$ 12,736$ & $\$ 13,328$ \\
\hline Capital Equipment & 0 & 685 & 845 & 264 & 322 \\
\hline TOTAL COSTS & $\$ 9,925$ & $\$ 15,000$ & $\$ 16,000$ & $\$ 13,000$ & $\$ 13,650$ \\
\hline
\end{tabular}

\begin{tabular}{|c|c|c|c|c|c|}
\hline \multirow[t]{2}{*}{ FTE SUMMARY } & \multicolumn{3}{|c|}{ "A" BUDGET } & \multicolumn{2}{|c|}{$\begin{array}{l}\text { "B" BUDGET } \\
\text { ALTERNATE }\end{array}$} \\
\hline & FY 96 & FY97 & FY98 & FY97 & FY98 \\
\hline Scientific & 18.14 & 20.50 & 20.50 & 19.50 & 19.50 \\
\hline Technical \& Drafters & 24.50 & 28.95 & 28.95 & 25.50 & 25.50 \\
\hline Engineering \& Computing & 20.12 & 22.35 & 22.35 & 19.96 & 19.96 \\
\hline Students & 22.00 & 22.00 & 22.00 & 22.00 & 22.00 \\
\hline Administrative \& Other Support & 10.66 & 13.21 & 13.06 & 12.24 & 11.83 \\
\hline TOTAL MAN YEARS & 95.42 & 107.01 & 106.86 & 99.20 & 98.79 \\
\hline
\end{tabular}


COST PROFILE BY FISCAL YEAR

October 01, 1995 - September 30, 1998

Dollars in Thousands

\section{OPERATIONS}

Personnel Costs

M\&S

Travel

Capital Equipment

SUBTOTAL .

11. EXPERIMENT GROUP

Personnel Costs

$M$ \& $S$

Travel

Capital Equipment

SUBTOTAL

III. RF GROUP

Personnel Costs

$M$ \& S

Travel

Capital Equipment

SUBTOTAL

IV. PLASMA GROUP

Personnel Costs

M \& S

Travel

Capital Equipment

SUBTOTAL

V. DIVISION GROUP

Personnel Costs

$M$ \& S

Travel

SUBTOTAL

\section{COLLABORATION}

Personnel Costs

$M \& S$

Travel

SUBTOTAL

\section{SUMMARY}

Personnel Costs

$M \& S$

Travel

Total Operating Funds

Capital Equipment

FY 97

3,779

3,485

1,006

206

0

4,114

685

8,231

2,708

2,311

0

0

0

2,311

2,708

2,732

$$
\begin{array}{r}
4,026 \\
3,856 \\
305 \\
845 \\
\hline
\end{array}
$$

9,032

2,732

0

0

$\begin{array}{rr}2,311 & 2,708 \\ & \\ 1,003 & 1,49 \\ 0 & 0 \\ 0 & 0 \\ 0 & 0\end{array}$

1,003

1,496

1,561

0

0
0
0

1,561

1,493

$\begin{array}{rr}1,885 & 2,291 \\ 0 & 0 \\ 0 & 0 \\ 0 & 0\end{array}$

1,885

2,291

2,383

2,266

2,510

$\begin{array}{lr}0 & 2,383 \\ 0 & 0 \\ 0 & 0\end{array}$

1,8

$\begin{array}{rr}266 & 274 \\ 0 & 0 \\ 0 & 0\end{array}$

266

274

292

292

0

0

2,383

2,266

2,510

\begin{tabular}{rr}
266 & 274 \\
346 \\
0 \\
0 \\
\hline
\end{tabular}

346

0
0
0

0

0

0

0

274

0

0

274

292

\begin{tabular}{rrrrr|}
\hline 346 & 0 & 0 & 0 & 0 \\
\hline & & & & \\
8,713 & 10,548 & 10,994 & 9,538 & 9,917 \\
1,006 & 3,485 & 3,856 & 2,955 & 3,147 \\
206 & 282 & 305 & 243 & 264 \\
\hline 9,925 & 14,315 & 15,155 & 12,736 & 13,328 \\
0 & 685 & 845 & 264 & 322 \\
\hline \hline & & & & 13,000 \\
\hline
\end{tabular}


DOE PRIME CONTRACT \# DE-AC02-78ET-51013 : B\&R \# AT-10-10-14F

TASK 01 : ALCATOR CMOD : Field Work Proposal

October 01, 1995 - September 30, 1998

SUMMARY OF COSTS

\section{SALARIES \& WAGES}

FACULTY \& RESEARCH STAFF

RESEARCH ASSISTANTS

COMPUTERSTAFF

ENGINEERS

TECHNICIANS

DRAFTERS

ADMINISTRATIVE STAFF

PROJECT SUPPORT STAFF

PFCCOMP SUPPORT

ADMINISTRATIVE SUPPORT

\section{SUBTOTAL SALARIES \& WAGES}

EMPLOYEEBENEFITS

OFF CAMPUS EB

ON CAMPUS TRAVEL (See attached)

OFF CAMPUS TRAVEL (See attached)

RASTIPENDS

RA TUITION

M\&S (See attached)

TOTAL DIRECT COSTS

"OVERHEAD OFF CAMPUS

OVERHEAD

TOTAL EST. OPERATIONS

CAPITAL EQUIPMENT (See Attached)

TOTAL ESTIMATED COSTS

\begin{tabular}{|c|c|c|c|c|}
\hline FY 96 & FY 97 & FY 98 & $\begin{array}{c}\text { Alternate } \\
\text { FY97 }\end{array}$ & $\begin{array}{c}\text { Alternate } \\
\text { FY98 }\end{array}$ \\
\hline$\$ 1,141,382$ & $\$ 1,336,512$ & $\$ 1,389,974$ & $\$ 1,276,828$ & $\$ 1,327,902$ \\
\hline 349,934 & 364,848 & 284,581 & 364,848 & 284,581 \\
\hline 240,223 & 249,347 & 259,320 & 249,347 & 259,320 \\
\hline 865,102 & $1,027,040$ & $1,068,123$ & 888,935 & 924,492 \\
\hline $\begin{array}{r}902,038 \\
81,350\end{array}$ & $\begin{array}{r}1,166,217 \\
83,013\end{array}$ & $\begin{array}{r}1,218,697 \\
86,333\end{array}$ & $\begin{array}{r}952,216 \\
83,013\end{array}$ & $\begin{array}{r}995,066 \\
86,333\end{array}$ \\
\hline 31,291 & 32,486 & 33,786 & 32,486 & 33,786 \\
\hline $\begin{array}{r}28,578 \\
9,607\end{array}$ & $\begin{array}{r}29,136 \\
9,966\end{array}$ & $\begin{array}{l}30,418 \\
10,364\end{array}$ & $\begin{array}{r}29,136 \\
9,966\end{array}$ & $\begin{array}{l}30,418 \\
10,364\end{array}$ \\
\hline 339,875 & 456,092 & 468,769 & 416,507 & 417,111 \\
\hline$\$ 3,989,380$ & $\$ 4,754,657$ & $\$ 4,850,365$ & $\$ 4,303,282$ & $\$ 4,369,373$ \\
\hline $1,795,223$ & $2,210,914$ & $2,158,413$ & $2,001,026$ & $1,944,372$ \\
\hline 0 & 0 & 0 & 0 & 0 \\
\hline 122,096 & 163,151 & 171,310 & 141,086 & 148,142 \\
\hline 0 & 0 & 0 & 0 & 0 \\
\hline 0 & 0 & 94,860 & 0 & 94,860 \\
\hline 0 & 0 & 98,956 & 0 & 98,956 \\
\hline 755,966 & $2,697,868$ & $2,808,264$ & $2,202,139$ & $2,239,218$ \\
\hline$\$ 6,662,665$ & $\$ 9,826,590$ & $\$ 10,182,168$ & $\$ 8,647,533$ & $\$ 8,894,921$ \\
\hline 0 & 0 & 0 & 0 & 0 \\
\hline $3,262,335$ & $4,488,410$ & $4,972,832$ & $4,088,467$ & $4,433,079$ \\
\hline$\$ 9,925,000$ & $\$ 14,315,000$ & $\$ 15,155,000$ & $\$ 12,736,000$ & $\$ 13,328,000$ \\
\hline 0 & 685,000 & 845,000 & 264,000 & 322,000 \\
\hline$\$ 9,925,000$ & $\$ 15,000,000$ & $\$ 16,000,000$ & $\$ 13,000,000$ & $\$ 13,650,000$ \\
\hline
\end{tabular}


Exclusions from Overhead:

Administratlve Support

EB on Administrative Support

Allocated Expense

RA Tuition

Equipment Rental

Subcontracts $>\$ 25 \mathrm{~K}$ (incl. Alternator)

Cambridge Electric, Airco (BOC)

Fabrications/Upgrades

\begin{tabular}{rrrrr}
$\$ 339,875$ & $\$ 456,092$ & $\$ 468,769$ & $\$ 416,507$ & $\$ 417,111$ \\
152,945 & 212,082 & 208,602 & 193,676 & 185,615 \\
116,160 & 155,880 & 160,213 & 142,350 & 142,557 \\
0 & 0 & 98,956 & 0 & 98,956 \\
20,100 & 35,400 & 37,170 & 35,400 & 37,170 \\
0 & 200,000 & 210,000 & 200,000 & 210,000 \\
0 & 400,000 & 420,000 & 270,000 & 270,000 \\
89,100 & 595,000 & 600,000 & 310,000 & 400,000 \\
\hline$\$ 718,180$ & $\$ 2,054,454$ & $\$ 2,203,710$ & $\$ 1,567,933$ & $\$ 1,761,409$ \\
\hline
\end{tabular}


DOE PRIME CONTRACT \# DE-AC02-78ET-51013 : B\&R \# AT-10-10-14F

TASK 01 : ALCATOR CMOD : Fleld Work Proposal

October 01, 1995 - September 30, 1998

SUMMARY OF MAN-YEARS

\begin{tabular}{rrrrr} 
& & & Alternate & Alternate \\
FY 96 & FY 97 & FY 98 & FY97 & FY98 \\
\hline
\end{tabular}

SCIENTFIC

FACULTY

OTHERACADEMIC STAFF

SCIENTIFIC RESEARCHSTAFF

RESEARCH ASSISTANTS

SUBTOTAL SCIENTIFIC

TECHNICAL \& ENGINEERING

COMPUTERSTAFF

ENGINEERING RESEARCHSTAFF

TECHNICIANS

DRAFTERS

SUBTOTAL ENGINEERING \& TECH.

OTHER SUPPORT

ADMINISTRATIVE STAFF

PROJECT SUPPORT STAFF

PFC COMP SUPPORT

ADMINISTRATIVE SUPPORT

SUBTOTAL OTHER

\begin{tabular}{rrrrr}
0.77 & 0.74 & 0.74 & 0.74 & 0.74 \\
1.36 & 1.36 & 1.36 & 1.36 & 1.36 \\
16.01 & 18.40 & 18.40 & 17.40 & 17.40 \\
22.00 & 22.00 & 22.00 & 22.00 & 22.00 \\
\hline & & & & \\
40.14 & 42.50 & 42.50 & 41.50 & 41.50 \\
\hline
\end{tabular}

\begin{tabular}{rrrrr}
4.00 & 4.00 & 4.00 & 4.00 & 4.00 \\
16.12 & 18.35 & 18.35 & 15.96 & 15.96 \\
22.47 & 26.95 & 26.95 & 23.50 & 23.50 \\
2.03 & 2.00 & 2.00 & 2.00 & 2.00 \\
\hline & & & & \\
44.62 & 51.30 & 51.30 & 45.46 & 45.46 \\
\hline
\end{tabular}

\begin{tabular}{rrrrr} 
& & & & \\
0.80 & 0.80 & 0.80 & 0.80 & 0.80 \\
1.00 & 1.00 & 1.00 & 1.00 & 1.00 \\
0.15 & 0.15 & 0.15 & 0.15 & 0.15 \\
8.71 & 11.26 & 11.11 & 10.29 & 9.88 \\
\hline & & & & \\
10.66 & 13.21 & 13.06 & 12.24 & 11.83 \\
\hline
\end{tabular}

TOTAL MAN-YEAAS

95.42

107.01

106.86

99.20

98.79 
DOE PRIME CONTRACT \# DE-AC02-78ET-51013 : B\&R \# AT-10-10-14F

DETAIL OF MAN-YEARS

\begin{tabular}{|c|c|c|c|c|}
\hline FY 96 & FY 97 & FY 98 & $\begin{array}{r}\text { Alternate } \\
\text { FY97 } \\
\end{array}$ & $\begin{array}{r}\text { Alternate } \\
\text { FY98 } \\
\end{array}$ \\
\hline $42 \%$ & $39 \%$ & $39 \%$ & $39 \%$ & $39 \%$ \\
\hline $35 \%$ & $35 \%$ & $35 \%$ & $35 \%$ & $35 \%$ \\
\hline $0 \%$ & $0 \%$ & $0 \%$ & $0 \%$ & $0 \%$ \\
\hline 0.77 & 0.74 & 0.74 & 0.74 & 0.74 \\
\hline $100 \%$ & $100 \%$ & $100 \%$ & $100 \%$ & $100 \%$ \\
\hline $36 \%$ & $36 \%$ & $36 \%$ & $36 \%$ & $36 \%$ \\
\hline $0 \%$ & $0 \%$ & $0 \%$ & $0 \%$ & $0 \%$ \\
\hline $100 \%$ & $100 \%$ & $100 \%$ & $100 \%$ & $100 \%$ \\
\hline $55 \%$ & $100 \%$ & $100 \%$ & $100 \%$ & $100 \%$ \\
\hline $50 \%$ & $50 \%$ & $50 \%$ & $50 \%$ & $50 \%$ \\
\hline $100 \%$ & $100 \%$ & $100 \%$ & $100 \%$ & $100 \%$ \\
\hline $41 \%$ & $0 \%$ & $0 \%$ & $0 \%$ & $0 \%$ \\
\hline $100 \%$ & $100 \%$ & $100 \%$ & $100 \%$ & $100 \%$ \\
\hline $90 \%$ & $90 \%$ & $90 \%$ & $90 \%$ & $90 \%$ \\
\hline $17 \%$ & $0 \%$ & $0 \%$ & $0 \%$ & $0 \%$ \\
\hline $100 \%$ & $100 \%$ & $100 \%$ & $100 \%$ & $100 \%$ \\
\hline $100 \%$ & $100 \%$ & $100 \%$ & $100 \%$ & $100 \%$ \\
\hline $100 \%$ & $100 \%$ & $100 \%$ & $100 \%$ & $100 \%$ \\
\hline $43 \%$ & $0 \%$ & $0 \%$ & $0 \%$ & $0 \%$ \\
\hline $100 \%$ & $100 \%$ & $100 \%$ & $100 \%$ & $100 \%$ \\
\hline $75 \%$ & $0 \%$ & $0 \%$ & $0 \%$ & $0 \%$ \\
\hline $0 \%$ & $0 \%$ & $0 \%$ & $0 \%$ & $0 \%$ \\
\hline $100 \%$ & $100 \%$ & $100 \%$ & $100 \%$ & $100 \%$ \\
\hline $100 \%$ & $100 \%$ & $100 \%$ & $100 \%$ & $100 \%$ \\
\hline $100 \%$ & $100 \%$ & $100 \%$ & $100 \%$ & $100 \%$ \\
\hline $100 \%$ & $100 \%$ & $100 \%$ & $100 \%$ & $100 \%$ \\
\hline $30 \%$ & $0 \%$ & $0 \%$ & $0 \%$ & $0 \%$ \\
\hline $100 \%$ & $100 \%$ & $100 \%$ & $100 \%$ & $100 \%$ \\
\hline $0 \%$ & $100 \%$ & $100 \%$ & $100 \%$ & $100 \%$ \\
\hline $0 \%$ & $100 \%$ & $100 \%$ & $100 \%$ & $100 \%$ \\
\hline $0 \%$ & $100 \%$ & $100 \%$ & $0 \%$ & $0 \%$ \\
\hline $0 \%$ & $100 \%$ & $100 \%$ & $100 \%$ & $100 \%$ \\
\hline 17.37 & 19.76 & 19.76 & 18.76 & 18.76 \\
\hline
\end{tabular}

$$
\begin{aligned}
& \text { I. Hutchinson } \\
& \text { M. Porkolab (N/C eff } 2 / 1 / 95) \\
& \text { A. Bers }
\end{aligned}
$$

TOTAL FACULTY

\section{RESEARCH STAFF - OTHER ACADEMIC}

E. Marmar

J. Kesner

D. Sigmar

SCIENTIFIC RESEAACH STAFF

R. Boivin

P. Bonoli

C. Fiore

J. Goetz

S. Golovato

R. Granetz

M. Greenwald

S. Horne

A. Hubbard

J. Irby

B. LaBombard

P. Linsay

B. Lipschultz

G. MoCracken

A. Ram

J. Rice

J. Snipes

Y. Takase

J. Terry

R. Watterson

S. Wolfe

Divertor

Thomson Scattering

H

TOTAL SCIENTIFIC RES. STAFF 
DOE PRIME CONTRACT \# DE-AC02-78ET-51013 : B\&R \# AT-10-10-14F

DETAIL OF MAN-YEARS

ENGINEERS
W. Beck
H. Becker
V. Bertolino
J. Bosco
W. Burke
W. Byford
E. Byrne
R. Childs
J. Daigle
S. Fairfax
E. Fitzgerald
M. Fridberg
D. Gwinn
A. Helander
I. Mastovsky
J. Paranay
C. Park
W. Parkin
N. Plerce
R. Pillsbury
C. Reddy
J. Rosatl
F. Sabelli
F. Silva
F. Tambinl
E. Thibeault
X. Zhong
New - RF
New - Cryo
TOTAL. ENGiNEERS

\section{COMPUTER STAFF}

H. Bergler

T. Fredian

F. Kreisel

D. Nelson

J. Stillerman

New

TOTAL COMPUTER STAFF

\begin{tabular}{|c|c|c|c|c|}
\hline FY 96 & FY 97 & FY 98 & $\begin{array}{r}\text { Alternate } \\
\text { FY97 } \\
\end{array}$ & $\begin{array}{r}\text { Alternate } \\
\text { FY98 } \\
\end{array}$ \\
\hline $25 \%$ & $0 \%$ & $0 \%$ & $0 \%$ & $0 \%$ \\
\hline $100 \%$ & $100 \%$ & $100 \%$ & $100 \%$ & $100 \%$ \\
\hline $100 \%$ & $100 \%$ & $100 \%$ & $100 \%$ & $100 \%$ \\
\hline $100 \%$ & $100 \%$ & $100 \%$ & $100 \%$ & $100 \%$ \\
\hline $100 \%$ & $100 \%$ & $100 \%$ & $100 \%$ & $100 \%$ \\
\hline $41 \%$ & $50 \%$ & $50 \%$ & $50 \%$ & $50 \%$ \\
\hline $0 \%$ & $0 \%$ & $0 \%$ & $0 \%$ & $0 \%$ \\
\hline $100 \%$ & $100 \%$ & $100 \%$ & $100 \%$ & $100 \%$ \\
\hline $100 \%$ & $100 \%$ & $100 \%$ & $100 \%$ & $100 \%$ \\
\hline $0 \%$ & $0 \%$ & $0 \%$ & $0 \%$ & $0 \%$ \\
\hline $100 \%$ & $90 \%$ & $90 \%$ & $100 \%$ & $100 \%$ \\
\hline $100 \%$ & $100 \%$ & $100 \%$ & $100 \%$ & $100 \%$ \\
\hline $64 \%$ & $100 \%$ & $100 \%$ & $64 \%$ & $64 \%$ \\
\hline $11 \%$ & $0 \%$ & $0 \%$ & $0 \%$ & $0 \%$ \\
\hline $50 \%$ & $100 \%$ & $100 \%$ & $50 \%$ & $50 \%$ \\
\hline $21 \%$ & $0 \%$ & $0 \%$ & $0 \%$ & $0 \%$ \\
\hline $50 \%$ & $0 \%$ & $0 \%$ & $0 \%$ & $0 \%$ \\
\hline $100 \%$ & $100 \%$ & $100 \%$ & $100 \%$ & $100 \%$ \\
\hline $0 \%$ & $0 \%$ & $0 \%$ & $0 \%$ & $0 \%$ \\
\hline $0 \%$ & $0 \%$ & $0 \%$ & $0 \%$ & $0 \%$ \\
\hline $100 \%$ & $100 \%$ & $100 \%$ & $100 \%$ & $100 \%$ \\
\hline $64 \%$ & $100 \%$ & $100 \%$ & $64 \%$ & $64 \%$ \\
\hline $9 \%$ & $0 \%$ & $0 \%$ & $0 \%$ & $0 \%$ \\
\hline $100 \%$ & $100 \%$ & $100 \%$ & $100 \%$ & $100 \%$ \\
\hline $95 \%$ & $95 \%$ & $95 \%$ & $95 \%$ & $95 \%$ \\
\hline $73 \%$ & $100 \%$ & $100 \%$ & $73 \%$ & $73 \%$ \\
\hline $9 \%$ & $0 \%$ & $0 \%$ & $0 \%$ & $0 \%$ \\
\hline $0 \%$ & $100 \%$ & $100 \%$ & $100 \%$ & $100 \%$ \\
\hline $0 \%$ & $100 \%$ & $100 \%$ & $0 \%$ & $0 \%$ \\
\hline 16.12 & 18.35 & 18.35 & 15.96 & 15.96 \\
\hline $50 \%$ & $50 \%$ & $50 \%$ & $50 \%$ & $50 \%$ \\
\hline $100 \%$ & $100 \%$ & $100 \%$ & $100 \%$ & $100 \%$ \\
\hline $100 \%$ & $100 \%$ & $100 \%$ & $100 \%$ & $100 \%$ \\
\hline $50 \%$ & $50 \%$ & $50 \%$ & $50 \%$ & $50 \%$ \\
\hline $100 \%$ & $100 \%$ & $100 \%$ & $100 \%$ & $100 \%$ \\
\hline $0 \%$ & $0 \%$ & $0 \%$ & $0 \%$ & $0 \%$ \\
\hline 4.00 & 4.00 & 4.00 & 4.00 & 4.00 \\
\hline
\end{tabular}


DOE PRIME CONTRACT \# DE-AC02-78ET-51013 : B\&R \# AT-10-10-14F

DETAIL OF MAN-YEARS

\begin{tabular}{|c|c|c|c|c|}
\hline FY 96 & FY 97 & FY 98 & $\begin{array}{r}\text { Alternate } \\
\text { FY97 } \\
\end{array}$ & $\begin{array}{r}\text { Alternate } \\
\text { FY98 } \\
\end{array}$ \\
\hline $60 \%$ & $100 \%$ & $100 \%$ & $100 \%$ & $100 \%$ \\
\hline $81 \%$ & $100 \%$ & $100 \%$ & $100 \%$ & $100 \%$ \\
\hline $93 \%$ & $100 \%$ & $100 \%$ & $100 \%$ & $100 \%$ \\
\hline $78 \%$ & $100 \%$ & $100 \%$ & $100 \%$ & $100 \%$ \\
\hline $81 \%$ & $100 \%$ & $100 \%$ & $100 \%$ & $100 \%$ \\
\hline $92 \%$ & $100 \%$ & $100 \%$ & $100 \%$ & $100 \%$ \\
\hline $94 \%$ & $100 \%$ & $100 \%$ & $100 \%$ & $100 \%$ \\
\hline $77 \%$ & $100 \%$ & $100 \%$ & $100 \%$ & $100 \%$ \\
\hline $90 \%$ & $100 \%$ & $100 \%$ & $100 \%$ & $100 \%$ \\
\hline $14 \%$ & $0 \%$ & $0 \%$ & $0 \%$ & $0 \%$ \\
\hline $17 \%$ & $0 \%$ & $0 \%$ & $0 \%$ & $0 \%$ \\
\hline $94 \%$ & $100 \%$ & $100 \%$ & $100 \%$ & $100 \%$ \\
\hline $82 \%$ & $100 \%$ & $100 \%$ & $100 \%$ & $100 \%$ \\
\hline $71 \%$ & $100 \%$ & $100 \%$ & $100 \%$ & $100 \%$ \\
\hline $100 \%$ & $100 \%$ & $100 \%$ & $100 \%$ & $100 \%$ \\
\hline $100 \%$ & $100 \%$ & $100 \%$ & $100 \%$ & $100 \%$ \\
\hline $86 \%$ & $100 \%$ & $100 \%$ & $100 \%$ & $100 \%$ \\
\hline $97 \%$ & $100 \%$ & $100 \%$ & $100 \%$ & $100 \%$ \\
\hline $12 \%$ & $0 \%$ & $0 \%$ & $0 \%$ & $0 \%$ \\
\hline $92 \%$ & $100 \%$ & $100 \%$ & $100 \%$ & $100 \%$ \\
\hline $100 \%$ & $100 \%$ & $100 \%$ & $100 \%$ & $100 \%$ \\
\hline $78 \%$ & $100 \%$ & $100 \%$ & $100 \%$ & $100 \%$ \\
\hline $3 \%$ & $0 \%$ & $0 \%$ & $0 \%$ & $0 \%$ \\
\hline $76 \%$ & $100 \%$ & $100 \%$ & $100 \%$ & $100 \%$ \\
\hline $76 \%$ & $100 \%$ & $100 \%$ & $100 \%$ & $100 \%$ \\
\hline $94 \%$ & $100 \%$ & $100 \%$ & $100 \%$ & $100 \%$ \\
\hline $94 \%$ & $100 \%$ & $100 \%$ & $100 \%$ & $100 \%$ \\
\hline $50 \%$ & $50 \%$ & $50 \%$ & $50 \%$ & $50 \%$ \\
\hline $0 \%$ & $0 \%$ & $0 \%$ & $0 \%$ & $0 \%$ \\
\hline $165 \%$ & $345 \%$ & $345 \%$ & $0 \%$ & $0 \%$ \\
\hline 22.47 & 26.95 & 26.95 & 23.50 & 23.50 \\
\hline $100 \%$ & $100 \%$ & $100 \%$ & $100 \%$ & $100 \%$ \\
\hline $3 \%$ & $0 \%$ & $0 \%$ & $0 \%$ & $0 \%$ \\
\hline $100 \%$ & $100 \%$ & $100 \%$ & $100 \%$ & $100 \%$ \\
\hline $0 \%$ & $0 \%$ & $0 \%$ & $0 \%$ & $0 \%$ \\
\hline 2.03 & 2.00 & 2.00 & 2.00 & 2.00 \\
\hline
\end{tabular}


DOE PRIME CONTRACT \# DE-AC02-78ET-51013 : B\&R \# AT-10-10-14F

DETAIL OF MAN-YEARS

\begin{tabular}{rrrrr} 
FY 96 & FY 97 & FY 98 & Alternate & Alternate \\
\hline
\end{tabular}

ADMINISTRATIVE STAFF

V. Censabella

New

TOTAL ADMINISTRATIVE STAFF

SUPPORT STAFF

New

K. Johnson

C. Arlington

TOTAL SUPPORT

PFC COMPUTER SUPPORT

M. Greenwald

M. London

\begin{tabular}{rrrrr}
$80 \%$ & $80 \%$ & $80 \%$ & $80 \%$ & $80 \%$ \\
\hline $0 \%$ & $0 \%$ & $0 \%$ & $0 \%$ & $0 \%$ \\
\hline 0.80 & 0.80 & 0.80 & 0.80 & 0.80 \\
\hline
\end{tabular}

TOTAL PFC COMPUTER SUPPORT

\begin{tabular}{rrrrr}
$0 \%$ & & & & \\
$100 \%$ & $0 \%$ & $0 \%$ & $0 \%$ & $0 \%$ \\
\hline $0 \%$ & $100 \%$ & $100 \%$ & $100 \%$ & $100 \%$ \\
\hline 1.00 & 1.00 & $0 \%$ & $0 \%$ & $0 \%$ \\
\hline & & 1.00 & 1.00 & 1.00 \\
\hline $5 \%$ & $5 \%$ & & & \\
$10 \%$ & $10 \%$ & $10 \%$ & $5 \%$ & $5 \%$ \\
\hline & & & $10 \%$ & $10 \%$ \\
\hline & 0.15 & 0.15 & 0.15 & 0.15 \\
\hline
\end{tabular}


DOE PRIME CONTRACT \# DE-AC02-78ET-51013 : B\&R \# AT-10-10-14F DETAIL OF MAN-YEARS

\begin{tabular}{|c|c|c|c|c|}
\hline FY 96 & FY 97 & FY 98 & $\begin{array}{r}\text { Alternate } \\
\text { FY97 } \\
\end{array}$ & $\begin{array}{r}\text { Alternate } \\
\text { FY98 } \\
\end{array}$ \\
\hline $100 \%$ & $100 \%$ & $100 \%$ & $100 \%$ & $100 \%$ \\
\hline $100 \%$ & $100 \%$ & $100 \%$ & $100 \%$ & $100 \%$ \\
\hline $100 \%$ & $100 \%$ & $100 \%$ & $100 \%$ & $100 \%$ \\
\hline $100 \%$ & $100 \%$ & $100 \%$ & $100 \%$ & $100 \%$ \\
\hline $100 \%$ & $100 \%$ & $100 \%$ & $100 \%$ & $100 \%$ \\
\hline $71 \%$ & $100 \%$ & $100 \%$ & $100 \%$ & $100 \%$ \\
\hline $100 \%$ & $100 \%$ & $100 \%$ & $100 \%$ & $100 \%$ \\
\hline $100 \%$ & $100 \%$ & $100 \%$ & $100 \%$ & $100 \%$ \\
\hline $100 \%$ & $100 \%$ & $100 \%$ & $100 \%$ & $100 \%$ \\
\hline $29 \%$ & $0 \%$ & $0 \%$ & $0 \%$ & $0 \%$ \\
\hline $100 \%$ & $100 \%$ & $100 \%$ & $100 \%$ & $100 \%$ \\
\hline $100 \%$ & $100 \%$ & $100 \%$ & $100 \%$ & $100 \%$ \\
\hline $100 \%$ & $100 \%$ & $100 \%$ & $100 \%$ & $100 \%$ \\
\hline $100 \%$ & $100 \%$ & $100 \%$ & $100 \%$ & $100 \%$ \\
\hline $100 \%$ & $100 \%$ & $100 \%$ & $100 \%$ & $100 \%$ \\
\hline $100 \%$ & $100 \%$ & $100 \%$ & $100 \%$ & $100 \%$ \\
\hline $100 \%$ & $100 \%$ & $100 \%$ & $100 \%$ & $100 \%$ \\
\hline $100 \%$ & $100 \%$ & $100 \%$ & $100 \%$ & $100 \%$ \\
\hline $100 \%$ & $0 \%$ & $0 \%$ & $0 \%$ & $0 \%$ \\
\hline $100 \%$ & $100 \%$ & $100 \%$ & $100 \%$ & $100 \%$ \\
\hline $100 \%$ & $100 \%$ & $100 \%$ & $100 \%$ & $100 \%$ \\
\hline $100 \%$ & $100 \%$ & $100 \%$ & $100 \%$ & $100 \%$ \\
\hline $100 \%$ & $0 \%$ & $0 \%$ & $0 \%$ & $0 \%$ \\
\hline $0 \%$ & $100 \%$ & $100 \%$ & $100 \%$ & $100 \%$ \\
\hline $0 \%$ & $100 \%$ & $100 \%$ & $100 \%$ & $100 \%$ \\
\hline 22.00 & 22.00 & 22.00 & 22.00 & 22.00 \\
\hline 8.71 & 11.26 & 11.11 & 10.29 & 9.88 \\
\hline 95.42 & 107.01 & 106.86 & 99.20 & 98.79 \\
\hline
\end{tabular}


"RA effort (man-years) reflects the entire year. However, salary is for the period 1 January - 30 June; effective 1 July, RA stipends and tuition are included in operating expenses and shown below:

\section{DETAIL OF RESEARCH ASSISTANT COSTS}

For the 6 Months Subsequent to July 1, 1998

Prior to July 1, 1998 the tuition of graduate research assistants was charged to the employee benefits pool. At the request of the government, effective July 1,1998 RA tuition will be charged directly to the research project on which the RA works. The following assumptions were used in calculating the anticipated changes to the budget:

No EB on RA Stipends. Stipends will be subject to $\mathrm{OH}$.

No $\mathrm{OH}$ on Tuition.

$55 \%$ of RA tuition will be charged to the research accounts; MIT will subsidize the remaining $45 \%$.

EB drops 8 points.

RA Summer appointments span the period June-August. Therefore, June RA salary is shown in the salary portion of the budget, whil the stipends and tuition for July forward are reflected in the figures below. However, for clarity, RA effort (man-years) for the full year is recorded above.

RA STIPENDS

NoEB

RA TUITION

No overhead

TOTAL RA COSTS

\begin{tabular}{rrrrr} 
FY 96 & FY 97 & FY 98 & $\begin{array}{r}\text { Alternate } \\
\text { FY97 }\end{array}$ & $\begin{array}{r}\text { Alternate } \\
\text { FY98 }\end{array}$ \\
\hline 0.00 & 0.00 & 94,860 & 0 & 94,860 \\
& & & & \\
0.00 & 0.00 & 98,956 & 0 & 98,956 \\
\hline & & & & \\
0.00 & 0.00 & 193,816 & 0 & 193,816 \\
\hline \hline
\end{tabular}


DOE PRIME CONTRACT \# DE-AC02-78ET-51013 : B\&R \# AT-10-10-14F

TASK 01 : ALCATOR CMOD : Field Work Proposal

October 01, 1995 - September 30, 1998

\section{DETAIL OF MATERIALS \& SERVICES}

Telephones

Catalogues, Journals, Books, etc.

Publications

Graphic Arts

Xerox Expense

Equipment Rental (no OH)

Office \& Drafting Supplies

Postage \& Shipping

Comp. Hardware Maintenance

Computer Software

Computer Supplies

PFC Computer Contribution

AIRCO ; LN2 (No Overhead)

Camb. Electric (No Overhead)

Industrial Subcontracts

Alternator Maintenance

Gases

Radiology \& Safety

Machinists

Cryogenic Materials

Electrical/Electronic Components

Mechanical Components

Optical Components

Vacuum Components

Raw Materials

Electronic Assemblies

Tools

Materials \& Services

Allocated Expense

\begin{tabular}{|c|c|c|c|c|}
\hline FY 96 & FY 97 & FY 98 & $\begin{array}{r}\text { Alternate } \\
\text { FY97 } \\
\end{array}$ & $\begin{array}{r}\text { Alternate } \\
\text { FY98 } \\
\end{array}$ \\
\hline 0.00 & 0.00 & 0.00 & 0 & 0 \\
\hline 17,000 & 29,350 & 30,820 & 29,350 & 30,820 \\
\hline 3,400 & 2,500 & 2,630 & 2,500 & 2,630 \\
\hline 11,500 & 13,200 & 13,860 & 13,200 & 13,860 \\
\hline 1,100 & 1,700 & 1,790 & 1,700 & 1,790 \\
\hline 8,500 & 11,000 & 11,550 & 11,000 & 11,550 \\
\hline 20,100 & 35,400 & 37,170 & 35,400 & 37,170 \\
\hline 18,300 & 25,450 & 26,720 & 25,450 & 26,720 \\
\hline 7,500 & 11,400 & 11,970 & 11,400 & 11,970 \\
\hline 23,500 & 44,530 & 46,760 & 44,530 & 46,760 \\
\hline 33,000 & 56,090 & 58,890 & 56,090 & 58,890 \\
\hline 14,500 & 26,120 & 27,430 & 26,120 & 27,430 \\
\hline 12,900 & 23,260 & 24,420 & 23,260 & 24,420 \\
\hline 0 & 300,000 & 315,000 & 200,000 & 200,000 \\
\hline 0 & 100,000 & 105,000 & 70,000 & 70,000 \\
\hline 0 & 200,000 & 210,000 & 200,000 & 210,000 \\
\hline 0 & 0 & 0 & 0 & 0 \\
\hline 23,000 & 28,780 & 41,810 & 28,780 & 30,220 \\
\hline 24,000 & 40,955 & 59,490 & 40,955 & 43,000 \\
\hline 14,000 & 23,850 & 34,650 & 23,850 & 25,040 \\
\hline 9,000 & 11,840 & 17,200 & 11,840 & 12,430 \\
\hline 60,000 & 278,470 & 304,510 & 278,470 & 292,390 \\
\hline 55,000 & 144,740 & 210,260 & 144,740 & 151,980 \\
\hline 12,500 & 27,775 & 40,350 & 27,775 & 29,160 \\
\hline 25,000 & 69,645 & 101,180 & 69,645 & 73,130 \\
\hline 11,500 & 26,295 & 38,210 & 26,295 & 27,610 \\
\hline 37,500 & 112,320 & 163,160 & 112,320 & 117,940 \\
\hline 2,200 & 5,465 & 7,940 & 5,465 & 5,740 \\
\hline 171,426 & 371,348 & 180,251 & 301,557 & 186,288 \\
\hline 116,160 & 155,880 & 160,213 & 142,350 & 142,557 \\
\hline
\end{tabular}


DOE PRIME CONTRACT \# DE-AC02-78ET-51013 : B\&R \# AT-10-10-14F

TASK 01 : ALCATOR CMOD : Field Work Proposal

October 01, 1995 - September 30, 1998

DETAIL OF MATERIALS \& SERVICES

\begin{tabular}{|c|c|c|c|c|}
\hline FY 96 & FY 97 & FY 98 & $\begin{array}{r}\text { Alternate } \\
\text { FY97 }\end{array}$ & $\begin{array}{r}\text { Alternate } \\
\text { FY98 } \\
\end{array}$ \\
\hline 1,100 & 0 & 0 & 0 & 0 \\
\hline 18,500 & 0 & 0 & 0 & 0 \\
\hline 0 & 150,000 & 50,000 & 150,000 & 0 \\
\hline 0 & 50,000 & 200,000 & 0 & 200,000 \\
\hline 0 & 0 & 0 & 0 & 0 \\
\hline 0 & 0 & 0 & 0 & 0 \\
\hline 43,500 & 50,000 & 20,000 & 50,000 & 20,000 \\
\hline 2,000 & 0 & 0 & 0 & 0 \\
\hline 0 & 0 & 0 & 0 & 0 \\
\hline 800 & 0 & 0 & 0 & 0 \\
\hline 6,200 & 265,000 & 0 & 30,000 & 50,000 \\
\hline 0 & 0 & 200,000 & 0 & 0 \\
\hline 0 & 0 & 0 & 0 & 0 \\
\hline 0 & 20,000 & 30,000 & 20,000 & 30,000 \\
\hline 2,600 & 20,000 & 10,000 & 20,000 & 10,000 \\
\hline 11,650 & 20,000 & 20,000 & 20,000 & 20,000 \\
\hline 0 & 0 & 50,000 & 0 & 50,000 \\
\hline 2,750 & 20,000 & 20,000 & 20,000 & 20,000 \\
\hline 821,686 & $2,772,363$ & $2,883,234$ & $\begin{array}{r}0 \\
2,274,042 \\
\end{array}$ & $2,311,495$ \\
\hline
\end{tabular}

SUBSYSTEM FABSNUPGRADES (NO OH)

$X$-ray Tomography System Fab

Magnetic Diagnostics Fab

First-Wall Upgrade

LHH/LHCD Fab

LH Antenna Fab

LH Instrumentation \& Control Fab

ICRF Tunable Transmitter Fab

Edge Thomson Scattering

EFC Magnet Power Supply Upgrade

Control System Upgrade

Cryopump Fab

DIvertor Upgrade

ICRF Antenna

ICRF Matching System

ICRF Transmitter Upgrade

ICRF Instrumentation \& Control

LH Transmission Line Fab

ICRF Diagnostics

821,686

772,363

TOTAL ESTIMATED M\&S 
DOE PRIME CONTRACT \# DE-AC02-78ET-51013 : B\&R \# AT-10-10-14F

TASK 01 : ALCATOR CMOD : Field Work Proposal

October 01, 1995 - September 30, 1998

DETAIL OFESTIMATED TRAVEL NEEDS

\begin{tabular}{|c|c|c|c|c|}
\hline FY 96 & FY 97 & FY 98 & $\begin{array}{r}\text { Alternate } \\
\text { FY97 } \\
\end{array}$ & $\begin{array}{r}\text { Alternate } \\
\text { FY98 } \\
\end{array}$ \\
\hline 13,125 & 12,838 & 13,482 & 10,087 & 10,593 \\
\hline 12,795 & 18,600 & 19,540 & 14,880 & 15,632 \\
\hline 5,376 & 5,784 & 6,072 & 4,338 & 4,554 \\
\hline 1,200 & 0 & 0 & 0 & 0 \\
\hline 12,032 & 29,268 & 30,726 & 24,390 & 25,605 \\
\hline 2,640 & 2,854 & 2,996 & 2,854 & 2,996 \\
\hline 0 & 2,120 & 2,226 & 2,120 & 2,226 \\
\hline 6,628 & 0 & 0 & 0 & 0 \\
\hline 22,000 & 38,625 & 40,550 & 29,355 & 30,818 \\
\hline 0 & 0 & 0 & 0 & 0 \\
\hline 4,500 & 1,582 & 1,662 & 1,582 & 1,662 \\
\hline 4,800 & 1,700 & 1,785 & 1,700 & 1,785 \\
\hline 12,000 & 10,800 & 11,340 & 10,800 & 11,340 \\
\hline 6,000 & 5,200 & 5,460 & 5,200 & 5,460 \\
\hline 5,000 & 7,050 & 7,404 & 7,050 & 7,404 \\
\hline 3,500 & 0 & 0 & 0 & 0 \\
\hline 0 & 2,430 & 2,552 & 2,430 & 2,552 \\
\hline 0 & 0 & 0 & 0 & 0 \\
\hline 0 & 7,500 & 7,875 & 7,500 & 7,875 \\
\hline 0 & 14,000 & 14,700 & 14,000 & 14,700 \\
\hline 10,500 & 0 & 0 & 0 & 0 \\
\hline 0 & 2,800 & 2,940 & 2,800 & 2,940 \\
\hline 122,096 & 163,151 & 171,310 & 141,086 & 148,142 \\
\hline
\end{tabular}

A. DOMESTIC:

Washington D.C.

Princeton, NJ

Texas

Sherwood Theory

California

New Mexico

Tennessee

RF/Diag Conference

APS

Canada

Canada

B. FOREIGN:

Japan

England

Germany

Russia

Switzerland

Netherlands

IAEA

EPS

France

Italy

TOTAL ON ESTIMATED TRAVEL 


\section{ALCATOR CMOD EQUIPMENT BREAKDOWN}

\section{DAC EQUIPMENT}

Crates \& Controllers

Enhanced Highway Drivers

CAMAC U-ports

CAMAC Digitizers

CAMAC Timing Modules

CAMAC Diagnostic/Maint. Module

CAMAC Modules: counters, TDC, Demod

CAMAC Prog. Amps.

\section{PLCS}

Mimic Panels, Displays

Maintenance/Calibration Instr.

\section{PLASMA CONTROL SYSTEM}

Hybrid Computer Upgrades

COMPUTER EQUIPMENT

Computer Peripherals

Computers, Personal

Computers, Workstations/Servers

Data Comm. Equipment

Data Terminals

Mass Storage, Magnetic

Mass Storage, Optical

Printers and Plotters

Network Test Equipment

Multi-media

FUELING/PEILTT EQUIPMENT

LPI

Diagnostic Neutral Beam FAB

MHD DIAGNOSTICS EQUIPMENT

MHD Colls

VIS. \& UV SPECTROSCOPY

MSEFAB

BES FAB

CXRSFAB

LASER SCATTERING

YAG Spectrometers \& Laser FAB

\begin{tabular}{rrrrr} 
FY 96 & FY 97 & FY 98 & Alternate & Alternate \\
\hline
\end{tabular}

0

0

0

0

0

0

0

0

0

0

7,000

10,000

3,000

20,000

5,000

2,000

10,000

8,000

24,000

0

5,000

5,000

15,000

10,000

20,000

10,000

2,000

5,000

5,000

15,000

5,000

5,000

10,000

10,000

15,000

10,000

10,000

10,000

0

5,000

10,000

20,000

20,000

70,000

20,000

10,000

25,000

65,000

5,000

10,000

0

0

0

40,000

0
45,000

0

0

2

$0 \quad 0$

10,000

0

2,000

5,000

3,000

15,000

0

5,000

5,000

2,000

5,000

0
0,000

5,000

5,000

0

0

3,000

0

$$
\begin{array}{r}
0 \\
5,000
\end{array}
$$

4,000

4,000
2,000

$$
2,000
$$

5,000

10,000

$$
4,000
$$

2,000

5,000

5,000

15,000

4,000

5,000

5,000

0

0
4,000

$$
\begin{array}{r}
000 \\
0
\end{array}
$$

60,000

13,000

12,000

2,000

2,000

2,000

12,000

40,000

10,000

10,000 
DOE PRIME CONTRACT \# DE-AC02-78ET-51013 : B\&R \# AT-10-10-14F DETAIL OF CAPITAL EQUIPMENT NEEDS

\begin{tabular}{|c|c|c|c|c|c|}
\hline & FY 96 & FY 97 & FY 98 & $\begin{array}{r}\text { Alternate } \\
\text { FY97 } \\
\end{array}$ & $\begin{array}{r}\text { Alternate } \\
\text { FY98 } \\
\end{array}$ \\
\hline \multicolumn{6}{|c|}{ ALCATOR CMOD EQUIPMENT BREAKDOWN (continued) } \\
\hline Calibration Source & 0 & 0 & 0 & 0 & 0 \\
\hline LASER SCATTERING & & 0 & 0 & 0 & \\
\hline Core Thomson Scattering (first 6 spec) & 0 & 0 & 0 & 0 & 0 \\
\hline Core Thomson Scattering (next 2 spec) & 0 & 0 & 0 & 0 & 0 \\
\hline Core Thomson Scattering (final 3 spec) & 0 & 0 & 0 & $0^{-}$ & 0 \\
\hline Toroldal Imaging (F side) & 0 & 0 & 0 & 0 & 0 \\
\hline Poloidal Imaging & 0 & 0 & 0 & 0 & 0 \\
\hline Visible Bremss Fluctuations Fab & 0 & 0 & 0 & 0 & 0 \\
\hline \multicolumn{6}{|l|}{ ECE } \\
\hline ECE Polychromator & 0 & 0 & 0 & 0 & 0 \\
\hline \multicolumn{6}{|l|}{ INTERFEROMETRY } \\
\hline TCI FAB & 0 & 0 & 0 & 0 & 0 \\
\hline Reflectometry FAB & 0 & 5,000 & 0 & 5,000 & 0 \\
\hline Tangential Interferometer & 0 & 30,000 & 5,000 & 5,000 & 0 \\
\hline \multicolumn{6}{|l|}{ X-RAY DIAGNOSTICS } \\
\hline HIREXFAB & 0 & 0 & 0 & 0 & 0 \\
\hline Pulse Height Analysis FAB & 0 & 0 & 0 & 0 & 0 \\
\hline \multicolumn{6}{|l|}{ BOLOMETRY } \\
\hline Bolometer Upgrade & 0 & 0 & 10,000 & 0 & 0 \\
\hline Tangential XUV Bolometer Array FAB & 0 & 10,000 & 0 & 0 & 0 \\
\hline Divertor Bolometer Arrays FAB & 0 & 0 & 0 & 0 & 0 \\
\hline \multicolumn{6}{|l|}{ NEUTRON DIAGNOSTICS } \\
\hline He3 Spectrometer FAB & 0 & 0 & 0 & 0 & 0 \\
\hline $\begin{array}{l}\text { Collimated Neutron Array FAB } \\
\text { NEUTRAL DIAGNOSTICS }\end{array}$ & 0 & 10,000 & 40,000 & 0 & 0 \\
\hline Fast Neutrals & 0 & 0 & 0 & 0 & 0 \\
\hline Single Channel Neutral Part & 0 & 0 & 0 & 0 & 0 \\
\hline Time of Flight & 0 & 10,000 & 0 & 10,000 & 0 \\
\hline \multicolumn{6}{|l|}{ FUSION PRODUCTS } \\
\hline Charged Fusion Part. Detector FAB & 0 & 0 & 0 & 0 & 0 \\
\hline New Charged Fusion & 0 & 0 & 0 & 0 & 0 \\
\hline \multicolumn{6}{|l|}{ EDGE } \\
\hline Neutral Pressure Diag. FAB & 0 & 0 & 0 & 0 & 0 \\
\hline Periscopes FAB & 0 & 0 & 0 & 0 & 0 \\
\hline IR Thermometry FAB & 0 & 5,000 & 0 & 5,000 & 0 \\
\hline Divertor Spectroscopy FAB & 0 & 10,000 & 1,000 & 1,000 & 1,000 \\
\hline Divertor Impurity Spectroscopy FAB & 0 & 5,000 & 2,000 & 1,000 & 1,000 \\
\hline Advanced Flush-Mount Probe FAB & 0 & 0 & 2,000 & 0 & 0 \\
\hline Fast Scanning Probe FAB & 0 & 5,000 & 0 & 0 & 0 \\
\hline X-Point MLM Spectrograph FAB & 0 & 10,000 & 0 & 10,000 & 0 \\
\hline Divertor Upgrade FAB & 0 & 0 & 125,000 & 0 & \\
\hline
\end{tabular}


DETAIL OF CAPITAL EQUIPMENT NEEDS

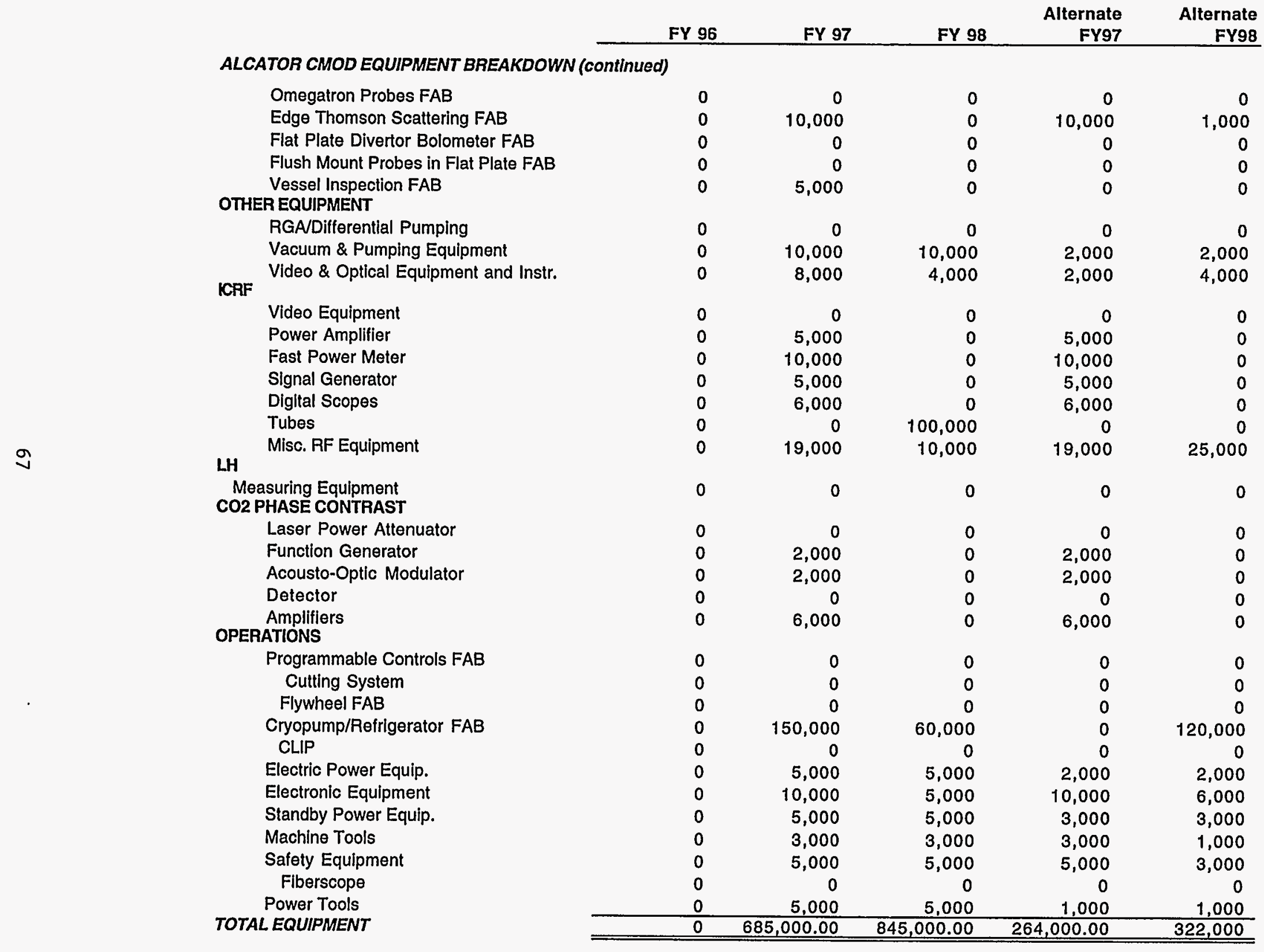


DOE PRIME CONTRACT \# DE-AC02-78ET-51013 : B\&R \# AT-10-10-14F

TASK 01 : ALCATOR CMOD : FY96 GROUP BREAKDOWN

October 01, 1995 - September 30, 1996

Fiscal Year 1996 Budget

SUMMARY OF COSTS

\begin{tabular}{|c|c|c|c|c|c|c|}
\hline $\begin{array}{l}\text { TOTAL } \\
\text { FY } 96\end{array}$ & $\begin{array}{c}\text { Operations } \\
\text { FY } 96\end{array}$ & $\begin{array}{c}\text { Experiment } \\
\text { FY } 96\end{array}$ & $\begin{array}{l}\text { RF } \\
\text { FY } 96\end{array}$ & $\begin{array}{c}\text { Plasma } \\
\text { FY } 96 \\
\end{array}$ & $\begin{array}{l}\text { Division } \\
\text { FY } 96 \\
\end{array}$ & $\begin{array}{c}\text { Collaboration } \\
\text { FY } 96 \\
\end{array}$ \\
\hline$\$ 1,141,382$ & $\$ 85,708$ & $\$ 527,746$ & $\$ 143,615$ & $\$ 281,403$ & $\$ 71,036$ & $\$ 31,874$ \\
\hline 349,934 & 15,211 & 222,553 & 47,086 & 65,084 & 0 & 0 \\
\hline 240,223 & 0 & 0 & 0 & 227,783 & 0 & 12,440 \\
\hline 865,102 & 539,883 & 58,355 & 114,181 & 115,143 & 8,911 & 28,629 \\
\hline $\begin{array}{r}902,038 \\
81,350\end{array}$ & $\begin{array}{r}515,489 \\
30,559\end{array}$ & $\begin{array}{r}155,067 \\
4,314\end{array}$ & $\begin{array}{r}104,247 \\
11,052\end{array}$ & $\begin{array}{r}90,558 \\
0\end{array}$ & $\begin{array}{l}0 \\
0\end{array}$ & $\begin{array}{l}36,677 \\
35,425\end{array}$ \\
\hline 31,291 & 0 & 0 & 0 & 0 & 31,291 & 0 \\
\hline $\begin{array}{r}28,578 \\
9,607\end{array}$ & $\begin{array}{r}28,578 \\
0\end{array}$ & $\begin{array}{l}0 \\
0\end{array}$ & $\begin{array}{l}0 \\
0\end{array}$ & $\begin{array}{r}0 \\
9,607\end{array}$ & $\begin{array}{l}0 \\
0\end{array}$ & $\begin{array}{l}0 \\
0\end{array}$ \\
\hline 339,875 & 147,582 & 76,475 & 33,194 & 62,377 & 8,788 & 11,459 \\
\hline$\$ 3,989,380$ & $\$ 1,363,010$ & $\$ 1,044,510$ & $\$ 453,375$ & $\$ 851,955$ & $\$ 120,026$ & $\$ 156,504$ \\
\hline $1,795,223$ & 613,355 & 470,030 & 204,019 & 383,380 & 54,012 & 70,427 \\
\hline 0 & 0 & 0 & 0 & 0 & 0 & 0 \\
\hline 122,096 & 122,096 & 0 & 0 & 0 & 0 & 0 \\
\hline 0 & 0 & 0 & 0 & 0 & 0 & 0 \\
\hline 0 & 0 & 0 & 0 & 0 & 0 & 0 \\
\hline 0 & 0 & 0 & 0 & 0 & 0 & 0 \\
\hline 755,966 & 755,966 & 0 & 0 & 0 & 0 & 0 \\
\hline$\$ 6,662,665$ & $\$ 2,854,427$ & $\$ 1,514,540$ & $\$ 657,394$ & $\$ 1,235,335$ & $\$ 174,038$ & $\$ 226,931$ \\
\hline & 0 & 0 & 0 & 0 & 0 & 0 \\
\hline $3,262,335$ & $1,361,460$ & 755,980 & 328,137 & 616,615 & 86,871 & 113,272 \\
\hline$\$ 9,925,000$ & $\$ 4,215,887$ & $\$ 2,270,520$ & $\$ 985,531$ & $\$ 1,851,950$ & $\$ 260,909$ & $\$ 340,203$ \\
\hline 0 & 0 & 0 & 0 & 0 & 0 & 0 \\
\hline
\end{tabular}

TOTAL ESTIMATED COSTS

\begin{tabular}{lllllll}
$\$ 9,925,000$ & $\$ 4,215,887$ & $\$ 2,270,520$ & $\$ 985,531$ & $\$ 1,851,950$ & $\$ 260,909$ & $\$ 340,203$ \\
\hline \hline
\end{tabular}

FY96 FUNDING :

EST FY96 BALANCE :

$9,925,000$ 
- A Composite Overhead Rate of $\mathbf{4 5 . 0 0 \%}$ (See "EB and OH Rates" Page attached to the Budget) is applied to the Modified Total Direct Costs (MTDC) Base which is comprised of Total Direct Costs less the following items, some of which are included in the M\&S Amount above and itemized on attached pages.

Administrative Support

$E B$ on Administrative Support

Allocated Expense

RA Tuition

Equipment Rental

Subcontracts $>\$ 25 \mathrm{~K}$ (incl. Alternator)

Cambridge Electric, Airco (BOC)

Fabricatlons/Upgrades

\begin{tabular}{rrrrrrr}
$\$ 339,875$ & $\$ 147,582$ & $\$ 76,475$ & $\$ 33,194$ & $\$ 62,377$ & $\$ 8,788$ & $\$ 11,459$ \\
152,945 & 66,412 & 34,414 & 14,937 & 28,070 & 3,955 & 5,157 \\
116,160 & 50,440 & 26,137 & 11,345 & 21,319 & 3,003 & 3,916 \\
0 & 0 & 0 & 0 & 0 & 0 & 0 \\
20,100 & 20,100 & 0 & 0 & 0 & 0 & 0 \\
0 & 0 & 0 & 0 & 0 & 0 & 0 \\
0 & 0 & 0 & 0 & 0 & 0 & 0 \\
89,100 & 89,100 & 0 & 0 & 0 & 0 & 0 \\
\hline$\$ 718,180$ & $\$ 373,634$ & $\$ 137,026$ & $\$ 59,476$ & $\$ 111,766$ & $\$ 15,746$ & $\$ 20,532$ \\
\hline \hline
\end{tabular}




\section{DOE PRIME CONTRACT \# DE-AC02-78ET-51013 : B\&R \# AT-10-10-14F}

TASK 01 : ALCATOR CMOD : FY96 GROUP BREAKDOWN

October 01, 1995 - September 30, 1996

Fiscal Year 1996 Budget

SUMMARY OF MAN-YEARS

\begin{tabular}{ccccccr}
$\begin{array}{c}\text { TOTAL } \\
\text { FY 96 }\end{array}$ & $\begin{array}{r}\text { Operations } \\
\text { FY 96 }\end{array}$ & $\begin{array}{r}\text { Experiment } \\
\text { FY 96 }\end{array}$ & $\begin{array}{c}\text { RF } \\
\text { FY 96 }\end{array}$ & $\begin{array}{r}\text { Plasma } \\
\text { FY 96 }\end{array}$ & $\begin{array}{r}\text { Division } \\
\text { FY 96 }\end{array}$ & $\begin{array}{r}\text { Collaboration } \\
\text { FY 96 }\end{array}$ \\
\hline 0.00 & 0.00 & 0.00 & 0.00 & 0.00 & 0.00 & 0.00
\end{tabular}

\section{SCIENTIFIC}

FACULTY

OTHER ACADEMIC STAFF

SCIENTIFIC RESEARCHSTAFF

RESEARCHASSISTANTS

\section{SUBTOTAL SCIENTIFIC}

TECHNICAL \& ENGINEERING

COMPUTER STAFF

ENGINEERING RESEARCHSTAFF

TECHNICIANS

DRAFTERS

SUBTOTAL ENGINEERING \& TECH.

OTHER SUPPORT

ADMINISTRATIVE STAFF

PROSECT SUPPORT STAFF

PFC COMPSUPPORT

ADMINISTRATIVE SUPPORT

SUBTOTAL OTHER

\begin{tabular}{|c|c|c|c|c|c|c|}
\hline 0.77 & 0.00 & 0.00 & 0.35 & 0.00 & 0.42 & 0.00 \\
\hline 1.36 & 0.00 & 0.80 & 0.00 & 0.36 & 0.10 & 0.10 \\
\hline 16.01 & 1.15 & 8.17 & 2.32 & 3.81 & 0.20 & 0.36 \\
\hline 22.00 & 1.00 & 14.00 & 3.00 & 4.00 & 0.00 & 0.00 \\
\hline 40.14 & 2.15 & 22.97 & 5.67 & 8.17 & 0.72 & 0.46 \\
\hline 4.00 & 0.00 & 0.00 & 0.00 & 3.80 & 0.00 & 0.20 \\
\hline 16.12 & 9.64 & 1.17 & 2.36 & 2.35 & 0.10 & 0.50 \\
\hline 22.47 & 12.73 & 3.87 & 2.67 & 2.25 & 0.00 & 0.95 \\
\hline 2.03 & 0.81 & 0.10 & 0.30 & 0.00 & 0.00 & 0.82 \\
\hline 44.62 & 23.18 & 5.14 & 5.33 & 8.40 & 0.10 & 2.47 \\
\hline 0.80 & 0.00 & 0.00 & 0.00 & 0.00 & 0.80 & 0.00 \\
\hline 1.00 & 1.00 & 0.00 & 0.00 & 0.00 & 0.00 & 0.00 \\
\hline 0.15 & 0.00 & 0.00 & 0.00 & 0.15 & 0.00 & 0.00 \\
\hline 8.71 & 3.78 & 1.96 & 0.85 & 1.60 & 0.23 & 0.29 \\
\hline 10.66 & 4.78 & 1.96 & 0.85 & 1.75 & 1.03 & 0.29 \\
\hline 95.42 & 30.11 & 30.07 & 11.85 & 18.32 & 1.85 & 3.22 \\
\hline
\end{tabular}

TOTAL MAN-YEARS 
DOE PRIME CONTRACT \# DE-AC02-78ET-51013 : B\&R \# AT-10-10-14F

DETAIL OF MAN-YEARS

\section{FACULTY}

I. Hutchinson

M. Porkolab (N/C off. 2/1)

A. Bers

\section{TOTAL FACULTY}

\section{RESEARCH STAFF - OTHER ACADEMIC}

\section{E. Marmar}

J. Kesner

D. Sigmar

SCIENTIFIC RESEARCH STAFF

R. Boivin

P. Bonoli

C. Fiore

J. Goetz

S. Golovato

R. Granetz

M. Greenwald

S. Horne

A. Hubbard

J. Irby

B. LaBombard

P. Linsay

B. Lipschultz

G. McCracken

A. Ram

J. Rice

J. Snipes

Y. Takase

J. Terry

R. Watterson

S. Wolfe

Divertor

Thomson Scattering

MSE

RF

TOTAL SCIENTIFIC RES. STAFF

\begin{tabular}{ccccccc}
$\begin{array}{c}\text { TOTAL } \\
\text { FY 96 }\end{array}$ & $\begin{array}{r}\text { Operations } \\
\text { FY 96 }\end{array}$ & $\begin{array}{r}\text { Experiment } \\
\text { FY 96 }\end{array}$ & $\begin{array}{c}\text { RF } \\
\text { FY 96 }\end{array}$ & $\begin{array}{r}\text { Plasma } \\
\text { FY 96 }\end{array}$ & $\begin{array}{r}\text { Division } \\
\text { FY 96 }\end{array}$ & $\begin{array}{r}\text { Collaboration } \\
\text { FY 96 }\end{array}$ \\
\hline 0.00 & 0.00 & 0.00 & 0.00 & 0.00 & 0.00 & 0.00 \\
& & & & & & \\
$42 \%$ & $0 \%$ & $0 \%$ & $0 \%$ & $0 \%$ & $42 \%$ & $0 \%$ \\
$35 \%$ & $0 \%$ & $0 \%$ & $35 \%$ & $0 \%$ & $0 \%$ & $0 \%$ \\
$0 \%$ & $0 \%$ & $0 \%$ & $0 \%$ & $0 \%$ & $0 \%$ & $0 \%$ \\
\hline
\end{tabular}

0.00

0.00

0.35

0.00

0.00

\begin{tabular}{|c|c|c|c|c|c|c|}
\hline $100 \%$ & $0 \%$ & $80 \%$ & $0 \%$ & $0 \%$ & $10 \%$ & $10 \%$ \\
\hline $36 \%$ & $0 \%$ & $0 \%$ & $0 \%$ & $36 \%$ & $0 \%$ & $0 \%$ \\
\hline $0 \%$ & $0 \%$ & $0 \%$ & $0 \%$ & $0 \%$ & $0 \%$ & $0 \%$ \\
\hline $100 \%$ & $0 \%$ & $100 \%$ & $0 \%$ & $0 \%$ & $0 \%$ & $0 \%$ \\
\hline $55 \%$ & $0 \%$ & $0 \%$ & $55 \%$ & $0 \%$ & $0 \%$ & $0 \%$ \\
\hline $50 \%$ & $25 \%$ & $25 \%$ & $0 \%$ & $0 \%$ & $0 \%$ & $0 \%$ \\
\hline $100 \%$ & $0 \%$ & $64 \%$ & $0 \%$ & $36 \%$ & $0 \%$ & $0 \%$ \\
\hline $41 \%$ & $0 \%$ & $0 \%$ & $37 \%$ & $0 \%$ & $0 \%$ & $4 \%$ \\
\hline $100 \%$ & $0 \%$ & $0 \%$ & $0 \%$ & $100 \%$ & $0 \%$ & $0 \%$ \\
\hline $90 \%$ & $0 \%$ & $0 \%$ & $0 \%$ & $90 \%$ & $0 \%$ & $0 \%$ \\
\hline $17 \%$ & $0 \%$ & $0 \%$ & $0 \%$ & $15 \%$ & $0 \%$ & $2 \%$ \\
\hline $100 \%$ & $0 \%$ & $0 \%$ & $50 \%$ & $50 \%$ & $0 \%$ & $0 \%$ \\
\hline $100 \%$ & $90 \%$ & $0 \%$ & $0 \%$ & $0 \%$ & $10 \%$ & $0 \%$ \\
\hline $100 \%$ & $0 \%$ & $100 \%$ & $0 \%$ & $0 \%$ & $0 \%$ & $0 \%$ \\
\hline $43 \%$ & $0 \%$ & $43 \%$ & $0 \%$ & $0 \%$ & $0 \%$ & $0 \%$ \\
\hline $100 \%$ & $0 \%$ & $90 \%$ & $0 \%$ & $0 \%$ & $0 \%$ & $10 \%$ \\
\hline $75 \%$ & $0 \%$ & $75 \%$ & $0 \%$ & $0 \%$ & $0 \%$ & $0 \%$ \\
\hline $0 \%$ & $0 \%$ & $0 \%$ & $0 \%$ & $0 \%$ & $0 \%$ & $0 \%$ \\
\hline $100 \%$ & $0 \%$ & $100 \%$ & $0 \%$ & $0 \%$ & $0 \%$ & $0 \%$ \\
\hline $100 \%$ & $0 \%$ & $100 \%$ & $0 \%$ & $0 \%$ & $0 \%$ & $0 \%$ \\
\hline $100 \%$ & $0 \%$ & $0 \%$ & $90 \%$ & $0 \%$ & $0 \%$ & $10 \%$ \\
\hline $100 \%$ & $0 \%$ & $90 \%$ & $0 \%$ & $0 \%$ & $0 \%$ & $10 \%$ \\
\hline $30 \%$ & $0 \%$ & $30 \%$ & $0 \%$ & $0 \%$ & $0 \%$ & $0 \%$ \\
\hline $100 \%$ & $0 \%$ & $0 \%$ & $0 \%$ & $90 \%$ & $10 \%$ & $0 \%$ \\
\hline $0 \%$ & $0 \%$ & $0 \%$ & $0 \%$ & $0 \%$ & $0 \%$ & $0 \%$ \\
\hline $0 \%$ & $0 \%$ & $0 \%$ & $0 \%$ & $0 \%$ & $0 \%$ & $0 \%$ \\
\hline $0 \%$ & $0 \%$ & $0 \%$ & $0 \%$ & $0 \%$ & $0 \%$ & $0 \%$ \\
\hline $0 \%$ & $0 \%$ & $0 \%$ & $0 \%$ & $0 \%$ & $0 \%$ & $0 \%$ \\
\hline 17.37 & 1.15 & 8.97 & 2.32 & 4.17 & 0.30 & 0.46 \\
\hline
\end{tabular}


DOE PRIME CONTRACT \# DE-AC02-78ET-51013 : B\&R \# AT-10-10-14F

DETAIL OF MAN-YEARS

ENGINEERS

S. Andreyev

W. Beck

V. Bertolino

J. Bosco

W. Burke

W. Byford

E. Byrne

R. Childs

J. Daigle

S. Fairfax

E. Fitzgerald

M. Fridberg

D. Gwinn

A. Helander

I. Mastovsky

J. Paranay

C. Park

W. Parkin

N. Pierce

R. Pillsbury

C. Reddy

J. Rosati

F. Sabelli

F. Silva

F. Tambini

E. Thibeault

$X$. Zhong

Now - RF

New - Cryo

TOTAL ENGINEERS

COMPUTER STAFF

H. Bergler

T. Fredlan

F. Kreisel

D. Nelson

J. Stillerman

New

TOTAL COMPUTER STAFF

\begin{tabular}{|c|c|c|c|c|c|c|}
\hline $\begin{array}{r}\text { TOTAL } \\
\text { FY } 96 \\
\end{array}$ & $\begin{array}{r}\text { Operations } \\
\text { FY } 96 \\
\end{array}$ & $\begin{array}{r}\text { Experiment } \\
\text { FY } 96 \\
\end{array}$ & $\begin{array}{c}\text { RF } \\
\text { FY } 96\end{array}$ & $\begin{array}{r}\text { Plasma } \\
\text { FY } 96 \\
\end{array}$ & $\begin{array}{r}\text { Division } \\
\text { FY } 96 \\
\end{array}$ & $\begin{array}{r}\text { Collaboration } \\
\text { FY } 96 \\
\end{array}$ \\
\hline $25 \%$ & $25 \%$ & $0 \%$ & $0 \%$ & $0 \%$ & $0 \%$ & $0 \%$ \\
\hline $100 \%$ & $20 \%$ & $0 \%$ & $60 \%$ & $0 \%$ & $0 \%$ & $20 \%$ \\
\hline $100 \%$ & $100 \%$ & $0 \%$ & $0 \%$ & $0 \%$ & $0 \%$ & $0 \%$ \\
\hline $100 \%$ & $15 \%$ & $0 \%$ & $0 \%$ & $75 \%$ & $0 \%$ & $10 \%$ \\
\hline $100 \%$ & $100 \%$ & $0 \%$ & $0 \%$ & $0 \%$ & $0 \%$ & $0 \%$ \\
\hline $41 \%$ & $41 \%$ & $0 \%$ & $0 \%$ & $0 \%$ & $0 \%$ & $0 \%$ \\
\hline $0 \%$ & $0 \%$ & $0 \%$ & $0 \%$ & $0 \%$ & $0 \%$ & $0 \%$ \\
\hline $100 \%$ & $70 \%$ & $20 \%$ & $10 \%$ & $0 \%$ & $0 \%$ & $0 \%$ \\
\hline $100 \%$ & $60 \%$ & $0 \%$ & $20 \%$ & $20 \%$ & $0 \%$ & $0 \%$ \\
\hline $0 \%$ & $0 \%$ & $0 \%$ & $0 \%$ & $0 \%$ & $0 \%$ & $0 \%$ \\
\hline $100 \%$ & $90 \%$ & $0 \%$ & $10 \%$ & $0 \%$ & $0 \%$ & $0 \%$ \\
\hline $100 \%$ & $20 \%$ & $0 \%$ & $70 \%$ & $0 \%$ & $0 \%$ & $10 \%$ \\
\hline $64 \%$ & $54 \%$ & $0 \%$ & $0 \%$ & $0 \%$ & $10 \%$ & $0 \%$ \\
\hline $11 \%$ & $9 \%$ & $0 \%$ & $2 \%$ & $0 \%$ & $0 \%$ & $0 \%$ \\
\hline $50 \%$ & $0 \%$ & $0 \%$ & $50 \%$ & $0 \%$ & $0 \%$ & $0 \%$ \\
\hline $21 \%$ & $17 \%$ & $0 \%$ & $4 \%$ & $0 \%$ & $0 \%$ & $0 \%$ \\
\hline $50 \%$ & $38 \%$ & $12 \%$ & $0 \%$ & $0 \%$ & $0 \%$ & $0 \%$ \\
\hline $100 \%$ & $50 \%$ & $20 \%$ & $10 \%$ & $20 \%$ & $0 \%$ & $0 \%$ \\
\hline $0 \%$ & $0 \%$ & $0 \%$ & $0 \%$ & $0 \%$ & $0 \%$ & $0 \%$ \\
\hline $0 \%$ & $0 \%$ & $0 \%$ & $0 \%$ & $0 \%$ & $0 \%$ & $0 \%$ \\
\hline $100 \%$ & $0 \%$ & $0 \%$ & $0 \%$ & $100 \%$ & $0 \%$ & $0 \%$ \\
\hline $64 \%$ & $64 \%$ & $0 \%$ & $0 \%$ & $0 \%$ & $0 \%$ & $0 \%$ \\
\hline $9 \%$ & $9 \%$ & $0 \%$ & $0 \%$ & $0 \%$ & $0 \%$ & $0 \%$ \\
\hline $100 \%$ & $90 \%$ & $0 \%$ & $0 \%$ & $0 \%$ & $0 \%$ & $10 \%$ \\
\hline $95 \%$ & $50 \%$ & $45 \%$ & $0 \%$ & $0 \%$ & $0 \%$ & $0 \%$ \\
\hline $73 \%$ & $33 \%$ & $20 \%$ & $0 \%$ & $20 \%$ & $0 \%$ & $0 \%$ \\
\hline $9 \%$ & $9 \%$ & $0 \%$ & $0 \%$ & $0 \%$ & $0 \%$ & $0 \%$ \\
\hline $0 \%$ & $0 \%$ & $0 \%$ & $0 \%$ & $0 \%$ & $0 \%$ & $0 \%$ \\
\hline $0 \%$ & $0 \%$ & $0 \%$ & $0 \%$ & $0 \%$ & $0 \%$ & $0 \%$ \\
\hline 16.12 & 9.64 & 1.17 & 2.36 & 2.35 & 0.10 & 0.50 \\
\hline
\end{tabular}

\begin{tabular}{rrrrrrr}
$50 \%$ & $0 \%$ & $0 \%$ & $0 \%$ & $50 \%$ & $0 \%$ & $0 \%$ \\
$100 \%$ & $0 \%$ & $0 \%$ & $0 \%$ & $90 \%$ & $0 \%$ & $10 \%$ \\
$100 \%$ & $0 \%$ & $0 \%$ & $0 \%$ & $100 \%$ & $0 \%$ & $0 \%$ \\
$50 \%$ & $0 \%$ & $0 \%$ & $0 \%$ & $50 \%$ & $0 \%$ & $0 \%$ \\
$100 \%$ & $0 \%$ & $0 \%$ & $0 \%$ & $90 \%$ & $0 \%$ & $10 \%$ \\
\hline $0 \%$ & $0 \%$ & $0 \%$ & $0 \%$ & $0 \%$ & $0 \%$ & $0 \%$ \\
\hline 4.00 & 0.00 & 0.00 & 0.00 & 3.80 & 0.00 & 0.20 \\
\hline
\end{tabular}


DOE PRIME CONTRACT \# DE-AC02-78ET-51013 : B\&R \# AT-10-10-14F

DETAIL OF MAN-YEARS

TECHNICIANS

D. Arsenault

J. Chicarello

W. Cochran

R. Danforth

G. Dekow

J. Gerolamo

R. Griffith

M. Iverson

H. Lander

T. Lloyd

J. Moscaritolo

R. Murray

J. Nickerson

J. Orvosh

A. Pfeiffer

S. Plerson

W. Pina

K. Rettman

M. Rioux

E. Rollins

M. Rowell

F. Shefton

R. St. Jean

R. Sylvia

S. Tambini

P. Telesmanick

T. Toland

Northeastern Coop

New/Temporary

Overtime

TOTAL TECHNICIANS

\section{DRAFTERS}

A. DiClaccio

M. Keniston

S. Kochan

New

TOTAL DRAFTERS

\begin{tabular}{|c|c|c|c|c|c|c|}
\hline $\begin{array}{r}\text { TOTAL } \\
\text { FY } 96 \\
\end{array}$ & $\begin{array}{r}\text { Operations } \\
\text { FY } 96 \\
\end{array}$ & $\begin{array}{r}\text { Experiment } \\
\text { FY } 96 \\
\end{array}$ & $\begin{array}{c}\text { RF } \\
\text { FY } 96\end{array}$ & $\begin{array}{r}\text { Plasma } \\
\text { FY } 96 \\
\end{array}$ & $\begin{array}{r}\text { Dlvision } \\
\text { FY } 96 \\
\end{array}$ & $\begin{array}{r}\text { Collaboration } \\
\text { FY } 96\end{array}$ \\
\hline 0.00 & 0.00 & 0.00 & 0.00 & 0.00 & 0.00 & 0.00 \\
\hline $60 \%$ & $60 \%$ & $0 \%$ & $0 \%$ & $0 \%$ & $0 \%$ & $0 \%$ \\
\hline $81 \%$ & $73 \%$ & $0 \%$ & $0 \%$ & $0 \%$ & $0 \%$ & $8 \%$ \\
\hline $93 \%$ & $46 \%$ & $0 \%$ & $19 \%$ & $28 \%$ & $0 \%$ & $0 \%$ \\
\hline $78 \%$ & $0 \%$ & $39 \%$ & $0 \%$ & $39 \%$ & $0 \%$ & $0 \%$ \\
\hline $81 \%$ & $72 \%$ & $0 \%$ & $0 \%$ & $0 \%$ & $0 \%$ & $9 \%$ \\
\hline $92 \%$ & $18 \%$ & $14 \%$ & $0 \%$ & $60 \%$ & $0 \%$ & $0 \%$ \\
\hline $94 \%$ & $85 \%$ & $0 \%$ & $0 \%$ & $0 \%$ & $0 \%$ & $9 \%$ \\
\hline $77 \%$ & $15 \%$ & $35 \%$ & $0 \%$ & $27 \%$ & $0 \%$ & $0 \%$ \\
\hline $90 \%$ & $90 \%$ & $0 \%$ & $0 \%$ & $0 \%$ & $0 \%$ & $0 \%$ \\
\hline $14 \%$ & $14 \%$ & $0 \%$ & $0 \%$ & $0 \%$ & $0 \%$ & $0 \%$ \\
\hline $17 \%$ & $17 \%$ & $0 \%$ & $0 \%$ & $0 \%$ & $0 \%$ & $0 \%$ \\
\hline $94 \%$ & $0 \%$ & $47 \%$ & $47 \%$ & $0 \%$ & $0 \%$ & $0 \%$ \\
\hline $82 \%$ & $37 \%$ & $0 \%$ & $33 \%$ & $0 \%$ & $0 \%$ & $12 \%$ \\
\hline $71 \%$ & $71 \%$ & $0 \%$ & $0 \%$ & $0 \%$ & $0 \%$ & $0 \%$ \\
\hline $100 \%$ & $0 \%$ & $0 \%$ & $85 \%$ & $0 \%$ & $0 \%$ & $15 \%$ \\
\hline $100 \%$ & $25 \%$ & $35 \%$ & $25 \%$ & $0 \%$ & $0 \%$ & $15 \%$ \\
\hline $86 \%$ & $43 \%$ & $0 \%$ & $0 \%$ & $43 \%$ & $0 \%$ & $0 \%$ \\
\hline $97 \%$ & $87 \%$ & $0 \%$ & $0 \%$ & $0 \%$ & $0 \%$ & $10 \%$ \\
\hline $12 \%$ & $12 \%$ & $0 \%$ & $0 \%$ & $0 \%$ & $0 \%$ & $0 \%$ \\
\hline $92 \%$ & $18 \%$ & $74 \%$ & $0 \%$ & $0 \%$ & $0 \%$ & $0 \%$ \\
\hline $100 \%$ & $80 \%$ & $0 \%$ & $20 \%$ & $0 \%$ & $0 \%$ & $0 \%$ \\
\hline $78 \%$ & $31 \%$ & $39 \%$ & $0 \%$ & $0 \%$ & $0 \%$ & $8 \%$ \\
\hline $3 \%$ & $3 \%$ & $0 \%$ & $0 \%$ & $0 \%$ & $0 \%$ & $0 \%$ \\
\hline $76 \%$ & $38 \%$ & $38 \%$ & $0 \%$ & $0 \%$ & $0 \%$ & $0 \%$ \\
\hline $76 \%$ & $38 \%$ & $38 \%$ & $0 \%$ & $0 \%$ & $0 \%$ & $0 \%$ \\
\hline $94 \%$ & $47 \%$ & $0 \%$ & $38 \%$ & $0 \%$ & $0 \%$ & $9 \%$ \\
\hline $94 \%$ & $38 \%$ & $28 \%$ & $0 \%$ & $28 \%$ & $0 \%$ & $0 \%$ \\
\hline $50 \%$ & $50 \%$ & $0 \%$ & $0 \%$ & $0 \%$ & $0 \%$ & $0 \%$ \\
\hline $0 \%$ & $0 \%$ & $0 \%$ & $0 \%$ & $0 \%$ & $0 \%$ & $0 \%$ \\
\hline $165 \%$ & $165 \%$ & $0 \%$ & $0 \%$ & $0 \%$ & $0 \%$ & $0 \%$ \\
\hline 22.47 & 12.73 & 3.87 & 2.67 & 2.25 & 0.00 & 0.95 \\
\hline
\end{tabular}

\begin{tabular}{rrrrrrr}
$100 \%$ & $70 \%$ & $0 \%$ & $30 \%$ & $0 \%$ & $0 \%$ & $0 \%$ \\
$3 \%$ & $1 \%$ & $0 \%$ & $0 \%$ & $0 \%$ & $0 \%$ & $2 \%$ \\
$100 \%$ & $10 \%$ & $10 \%$ & $0 \%$ & $0 \%$ & $0 \%$ & $80 \%$ \\
\hline $0 \%$ & $0 \%$ & $0 \%$ & $0 \%$ & $0 \%$ & $0 \%$ & $0 \%$ \\
\hline 2.03 & 0.81 & 0.10 & 0.30 & 0.00 & 0.00 & 0.82 \\
\hline
\end{tabular}


DOE PRIME CONTRACT \# DE-AC02-78ET-51013 : B\&R \# AT-10-10-14F

DETAIL OF MAN-YEARS

\begin{tabular}{ccccccr}
$\begin{array}{c}\text { TOTAL } \\
\text { FY 96 }\end{array}$ & $\begin{array}{r}\text { Operations } \\
\text { FY 96 }\end{array}$ & $\begin{aligned} \text { Experiment } \\
\text { FY 96 }\end{aligned}$ & $\begin{array}{c}\text { RF } \\
\text { FY 96 }\end{array}$ & $\begin{array}{r}\text { Plasma } \\
\text { FY 96 }\end{array}$ & $\begin{array}{r}\text { Division } \\
\text { FY 96 }\end{array}$ & $\begin{array}{r}\text { Collaboration } \\
\text { FY 96 }\end{array}$ \\
\hline 0.00 & 0.00 & 0.00 & 0.00 & 0.00 & 0.00 & 0.00
\end{tabular}

ADMINISTRATIVE STAFF

V. Censabella

New

TOTAL ADMINISTRATIVE STAFF

SUPPORT STAFF

New

K. Johnson

C. Arlington

TOTAL SUPPORT

\section{PFC COMPUTER SUPPORT}

M. Greenwald

M. London

TOTAL PFC COMPUTER SUPPORT

\begin{tabular}{rrrrrrrr}
$80 \%$ & $0 \%$ & $0 \%$ & $0 \%$ & $0 \%$ & $80 \%$ & $0 \%$ \\
\hline $0 \%$ & $0 \%$ & $0 \%$ & $0 \%$ & $0 \%$ & $0 \%$ & $0 \%$ \\
\hline 0.80 & 0.00 & 0.00 & 0.00 & 0.00 & 0.80 & 0.00 \\
\hline
\end{tabular}

\begin{tabular}{rrrrrrr}
$0 \%$ & $0 \%$ & $0 \%$ & $0 \%$ & $0 \%$ & $0 \%$ & $0 \%$ \\
$100 \%$ & $100 \%$ & $0 \%$ & $0 \%$ & $0 \%$ & $0 \%$ & $0 \%$ \\
\hline $0 \%$ & $0 \%$ & $0 \%$ & $0 \%$ & $0 \%$ & $0 \%$ & $0 \%$ \\
\hline 1.00 & 1.00 & 0.00 & 0.00 & 0.00 & 0.00 & 0.00 \\
\hline
\end{tabular}

\begin{tabular}{rrrrrrr}
$5 \%$ & $0 \%$ & $0 \%$ & $0 \%$ & $5 \%$ & $0 \%$ & $0 \%$ \\
$10 \%$ & $0 \%$ & $0 \%$ & $0 \%$ & $10 \%$ & $0 \%$ & $0 \%$ \\
\hline 0.15 & 0.00 & 0.00 & 0.00 & 0.15 & 0.00 & 0.00 \\
\hline
\end{tabular}


DOE PRIME CONTRACT \# DE-AC02-78ET-51013 : B\&R \# AT-10-10-14F

DETAIL OF MAN-YEARS

\begin{tabular}{|c|c|c|c|c|c|c|c|}
\hline & $\begin{array}{r}\text { TOTAL } \\
\text { FY } 96 \\
\end{array}$ & $\begin{array}{r}\text { Operations } \\
\text { FY } 96 \\
\end{array}$ & $\begin{array}{r}\text { Experiment } \\
\text { FY } 96 \\
\end{array}$ & $\begin{array}{c}\text { RF } \\
\text { FY } 96 \\
\end{array}$ & $\begin{array}{r}\text { Plasma } \\
\text { FY } 96 \\
\end{array}$ & $\begin{array}{r}\text { Division } \\
\text { FY } 96 \\
\end{array}$ & $\begin{array}{r}\text { Collaboration } \\
\text { FY } 96 \\
\end{array}$ \\
\hline \multicolumn{8}{|l|}{ RESEARCH ASSISTANTS } \\
\hline A. Allen & $100 \%$ & $0 \%$ & $100 \%$ & $0 \%$ & $0 \%$ & $0 \%$ & $0 \%$ \\
\hline V. Belevstev & $100 \%$ & $0 \%$ & $100 \%$ & $0 \%$ & $0 \%$ & $0 \%$ & $0 \%$ \\
\hline C. Christensen & $100 \%$ & $0 \%$ & $100 \%$ & $0 \%$ & $0 \%$ & $0 \%$ & $0 \%$ \\
\hline S. Gangadhara & $100 \%$ & $0 \%$ & $100 \%$ & $0 \%$ & $0 \%$ & $0 \%$ & $0 \%$ \\
\hline D. Garnier & $100 \%$ & $0 \%$ & $100 \%$ & $0 \%$ & $0 \%$ & $0 \%$ & $0 \%$ \\
\hline Y. In & $71 \%$ & $0 \%$ & $71 \%$ & $0 \%$ & $0 \%$ & $0 \%$ & $0 \%$ \\
\hline D. Jablonski & $100 \%$ & $0 \%$ & $100 \%$ & $0 \%$ & $0 \%$ & $0 \%$ & $0 \%$ \\
\hline M. Koltonyuk & $100 \%$ & $0 \%$ & $100 \%$ & $0 \%$ & $0 \%$ & $0 \%$ & $0 \%$ \\
\hline D. Lo & $100 \%$ & $0 \%$ & $100 \%$ & $0 \%$ & $0 \%$ & $0 \%$ & $0 \%$ \\
\hline D. Lumma & $29 \%$ & $0 \%$ & $29 \%$ & $0 \%$ & $0 \%$ & $0 \%$ & $0 \%$ \\
\hline A. Mazurenko & $100 \%$ & $0 \%$ & $0 \%$ & $100 \%$ & $0 \%$ & $0 \%$ & $0 \%$ \\
\hline R. Nachtrieb & $100 \%$ & $0 \%$ & $100 \%$ & $0 \%$ & $0 \%$ & $0 \%$ & $0 \%$ \\
\hline H. Ohkawa & $100 \%$ & $0 \%$ & $100 \%$ & $0 \%$ & $0 \%$ & $0 \%$ & $0 \%$ \\
\hline P. O'Shea & $100 \%$ & $0 \%$ & $0 \%$ & $0 \%$ & $100 \%$ & $0 \%$ & $0 \%$ \\
\hline D. Pappas & $100 \%$ & $0 \%$ & $100 \%$ & $0 \%$ & $0 \%$ & $0 \%$ & $0 \%$ \\
\hline J. Reardon & $100 \%$ & $0 \%$ & $0 \%$ & $100 \%$ & $0 \%$ & $0 \%$ & $0 \%$ \\
\hline J. Rost & $100 \%$ & $0 \%$ & $0 \%$ & $100 \%$ & $0 \%$ & $0 \%$ & $0 \%$ \\
\hline J. Schachter & $100 \%$ & $0 \%$ & $0 \%$ & $0 \%$ & $100 \%$ & $0 \%$ & $0 \%$ \\
\hline K. Shadman & $100 \%$ & $100 \%$ & $0 \%$ & $0 \%$ & $0 \%$ & $0 \%$ & $0 \%$ \\
\hline J. Sorci & $100 \%$ & $0 \%$ & $0 \%$ & $0 \%$ & $100 \%$ & $0 \%$ & $0 \%$ \\
\hline P. Stek & $100 \%$ & $0 \%$ & $100 \%$ & $0 \%$ & $0 \%$ & $0 \%$ & $0 \%$ \\
\hline M. Umansky & $100 \%$ & $0 \%$ & $0 \%$ & $0 \%$ & $100 \%$ & $0 \%$ & $0 \%$ \\
\hline Y. Wang & $100 \%$ & $0 \%$ & $100 \%$ & $0 \%$ & $0 \%$ & $0 \%$ & $0 \%$ \\
\hline New & $0 \%$ & $0 \%$ & $0 \%$ & $0 \%$ & $0 \%$ & $0 \%$ & $0 \%$ \\
\hline New & $0 \%$ & $0 \%$ & $0 \%$ & $0 \%$ & $0 \%$ & $0 \%$ & $0 \%$ \\
\hline TOTAL RESEARCH ASSISTANTS & 22.00 & 1.00 & 14.00 & 3.00 & 4.00 & 0.00 & 0.00 \\
\hline ADMINISTRATIVE LAB SUPPORT & & & & & & & \\
\hline Various & 8.71 & 3.78 & 1.96 & 0.85 & 1.60 & 0.23 & 0.29 \\
\hline TOTAL MAN-YEARS & 95.42 & 30.11 & 30.07 & 11.85 & 18.32 & 1.85 & 3.22 \\
\hline
\end{tabular}


DOE PRIME CONTRACT \# DE-AC02-78ET-51013 : B\&R \# AT-10-10-14F

TASK 01 : ALCATOR CMOD : FY96 GROUP BREAKDOWN

October 01, 1995 - September 30, 1996

Fiscal Year 1996 Budget

DETAIL OF MATERIALS \& SERVICES

Telephones

Catalogues, Journals, Books, etc.

Publications

Graphic Arts

Xerox Expense

Equipment Rental (no OH)

Office \& Drafting Supplies

Postage \& Shipping

Comp. Hardware Maintenance

Computer Software

Computer Supplies

PFC Computer Contribution

AIRCO ; LN2 (No Overhead)

Camb. Electric (No Overhead)

Industrial Subcontracts

Alternator Maintenance

Gases

TOTAL

FY 96

Radiology \& Safety

Machinists

Cryogenic Materials

Electrical/Electronic Components

7,000

3,400

11,500

1,100

8,500

20,100

18,300

7,500

23,500

33,000

14,500

12,900

Mechanical Components

0
0

optical Components

Vacuum Components

Raw Materials

Electronic Assemblies

Tools

Materials \& Services

Allocated Expense

12,500

25,000

11,500

37,500

2,200

171,426

116,160 
DOE PRIME CONTRACT \# DE-AC02-78ET-51013 : B\&R \# AT-10-10-14F

TASK 01 : ALCATOR CMOD : FY96 GROUP BREAKDOWN

October 01, 1995 - September 30, 1996

Fiscal Year 1996 Budget

DETAIL OF MATERIALS \& SERVICES

\section{UUSYSTEM FABSNUPGRADES (NO OH)}

X-ray Tomography System Fab

Magnetic Diagnostics Fab

First-Wall Upgrade

LHH/LHCD Fab

LH Antenna Fab

LH Instrumentation \& Control Fab

ICRF Tunable Transmitter Fab

Edge Thomson Scattering

EFC Magnet Power Supply Upgrade

Control System Upgrade

Cryopump Fab

Divertor Upgrade

ICRF Antenna

ICRF Matching System

ICRF Transmitter Upgrade

ICRF Instrumentation \& Control

LH Transmission Line Fab

ICRF Diagnostics

TOTAL

FY 96

0.00

$\begin{array}{r}\text { TOTAL } \\ \text { FY } 96 \\ \hline 0.00 \\ \\ 1,100 \\ 18,500 \\ 0 \\ 0 \\ 0 \\ 0 \\ 43,500 \\ 2,000 \\ 0 \\ 800 \\ 6,200 \\ 0 \\ 0 \\ 0 \\ 2,600 \\ 11,650 \\ 0 \\ 2,750 \\ \hline 821,686 \\ \hline \hline\end{array}$

TOTAL ESTIMATED M\&S 
DOE PRIME CONTRACT \# DE-AC02-78ET-51013 : B\&R \# AT-10-10-14F

TASK 01 : ALCATOR CMOD : FY96 GROUP BREAKDOWN

October 01, 1995 - September 30, 1996

Fiscal Year 1996 Budget

DETAIL OF ESTIMATED TRAVEL NEEDS

Washington D.C. (15 @ \$875)

Princeton, NJ (15 \$ \$853)

Texas (4@ $\$ 1,344)$

Sherwood Theory - Phila. ( $4 @ \$ 600$ )

California (8 @ \$1,504)

New Mexico ( 2 @ \$1,320)

Tennessee

RF/Diag Conference (4 @ \$1,657)

APS - Louisville

IEEE

Maryland ( 6 (a) \$750)

Canada ( $3 @ \$ 1,600$ )

TOTAL

FY 96

0.00

A. DOMESTIC:

Japan (4@3000)

England (3@2000)

Germany (2@2500)

Russia (1@3500)

13,125

12,795

5,376

1,200

12,032

2,640

6,628

22,000

Switzerland

Netherlands

IAEA

4,500

4,800

B. FOREIGN:

France EPS (3@3500)

12,000

6,000

5,000

3,500

0

0

0

Italy

10,500

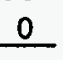

TOTAL ESTIMATED TRAVEL COSTS 
DOE PRIME CONTRACT \# DE-AC02-78ET-51013 : B\&A \# AT-10-10-14F

TASK 01 : ALCATOR CMOD : FY97 GROUP BREAKDOWN

October 01, 1996 - September 30, 1997

Fiscal Year 1997 Budget at \$15M SUMMARY OF COSTS

SALARIES \& WAGES

FACULTY \& RESEARCH STAFF

RESEARCH ASSISTANTS

COMPUTERSTAFF

ENGINEERS

TECHNICIANS

DRAFTERS

ADMINISTRATIVE STAFF

PROJECT SUPPORT STAFF PFC COMP SUPPORT

ADMINISTRATIVE SUPPORT

SUBTOTAL SALARIES \& WAGES

EMPLOYEE BENEFITS ( $46.5 \%$ S\&W)

OFF CAMPUS EB (\% S\&W)

ON CAMPUS TRAVEL (See attached)

OFF CAMPUS TRAVEL

RASTIPENDS

RA TUITION

M\&S (See altached)

TOTAL DIRECT COSTS

"OVERHEAD: \% of OFF CAMPUS

- OVERHEAD: $57.75 \%$ of MTDC Base

TOTAL EST. OPERATIONS

CAPITAL EQUIPMENT (See Attached)

TOTAL ESTIMATED COSTS

\begin{tabular}{|c|c|c|c|c|c|}
\hline $\begin{array}{l}\text { TOTAL } \\
\text { FY } 97 \\
\end{array}$ & $\begin{array}{c}\text { Operations } \\
\text { FY } 97\end{array}$ & $\begin{array}{l}\text { Experiment } \\
\text { FY } 97\end{array}$ & $\begin{array}{l}\text { RF } \\
\text { FY } 97\end{array}$ & $\begin{array}{l}\text { Plasma } \\
\text { FY } 97\end{array}$ & $\begin{array}{l}\text { Division } \\
\text { FY } 97\end{array}$ \\
\hline$\$ 1,336,512$ & $\$ 88,993$ & $\$ 600,410$ & $\$ 223,058$ & $\$ 354,072$ & $\$ 69,979$ \\
\hline 364,848 & 0 & 231,521 & 48,659 & 84,668 & 0 \\
\hline 249,347 & 0 & 0 & 0 & 249,347 & 0 \\
\hline $1,027,040$ & 632,071 & 53,002 & 206,411 & 126,314 & 9,242 \\
\hline $\begin{array}{r}1,166,217 \\
83,013\end{array}$ & $\begin{array}{r}735,740 \\
53,621\end{array}$ & $\begin{array}{r}200,805 \\
17,952\end{array}$ & $\begin{array}{r}120,236 \\
11,440\end{array}$ & $\begin{array}{r}109,436 \\
0\end{array}$ & $\begin{array}{l}0 \\
0\end{array}$ \\
\hline 32,486 & 0 & 0 & 0 & 0 & 32,486 \\
\hline $\begin{array}{r}29,136 \\
9,966\end{array}$ & $\begin{array}{r}29,136 \\
0\end{array}$ & $\begin{array}{l}0 \\
0\end{array}$ & $\begin{array}{l}0 \\
0\end{array}$ & $\begin{array}{r}0 \\
9,966\end{array}$ & $\begin{array}{l}0 \\
0\end{array}$ \\
\hline 456,092 & 238,130 & 87,192 & 48,175 & 73,770 & 8,825 \\
\hline $\begin{array}{r}\$ 4,754,657 \\
2,210,914\end{array}$ & $\begin{array}{r}\$ 1,777,691 \\
826,626\end{array}$ & $\begin{array}{r}\$ 1,190,882 \\
553,760\end{array}$ & $\begin{array}{r}\$ 657,979 \\
305,960\end{array}$ & $\begin{array}{r}\$ 1,007,573 \\
468,521\end{array}$ & $\begin{array}{r}\$ 120,532 \\
56,047\end{array}$ \\
\hline 0 & 0 & 0 & 0 & 0 & $\begin{array}{r}0,01 \\
0\end{array}$ \\
\hline 163,151 & 163,151 & 0 & 0 & 0 & 0 \\
\hline 0 & 0 & 0 & 0 & 0 & 0 \\
\hline 0 & 0 & 0 & 0 & 0 & 0 \\
\hline 0 & 0 & 0 & 0 & 0 & 0 \\
\hline $2,697,868$ & $2,697,868$ & 0 & 0 & 0 & 0 \\
\hline$\$ 9,826,590$ & $\$ 5,465,336$ & $\$ 1,744,642$ & $\$ 963,939$ & $\$ 1,476,094$ & $\$ 176,579$ \\
\hline 0 & 0 & 0 & 0 & 0 & 0 \\
\hline $4,488,410$ & $2,197,209$ & 916,554 & 506,409 & 775,472 & 92,766 \\
\hline$\$ 14,315,000$ & $\$ 7,662,545$ & $\$ 2,661,196$ & $\$ 1,470,348$ & $\$ 2,251,566$ & $\$ 269,345$ \\
\hline 685,000 & 210,000 & 315,000 & 60,000 & 100,000 & 0 \\
\hline$\$ 15,000,000$ & $\$ 7,872,545$ & $\$ 2,976,196$ & $\$ 1,530,348$ & $\$ 2,351,566$ & $\$ 269,345$ \\
\hline
\end{tabular}


- A Composite Overhead Rate of $46.50 \%$ (See "EB and OH Rates" Page attached to the Budget) is applied to the Modifled Total Direct Costs (MTDC) Base which is comprised of Total Direct Costs less the following items, some of which are included in the M\&S Amount above and itemized on attached pages.

Administrative Support

$\mathrm{EB}$ on Administrative Support

Allocated Expense

RA Tuition

Equipment Rental

Subcontracts $>\$ 25 \mathrm{~K}$

Cambridge Electric, Airco (BOC)

Fabrications/Upgrades

\begin{tabular}{rrrrrr}
$\$ 456,092$ & $\$ 238,130$ & $\$ 87,192$ & $\$ 48,175$ & $\$ 73,770$ & $\$ 8,825$ \\
212,082 & 110,730 & 40,544 & 22,401 & 34,303 & 4,104 \\
155,880 & 81,386 & 29,800 & 16,465 & 25,213 & 3,016 \\
0 & 0 & 0 & 0 & 0 & 0 \\
35,400 & 35,400 & 0 & 0 & 0 & 0 \\
200,000 & 200,000 & 0 & 0 & 0 & 0 \\
400,000 & 400,000 & 0 & 0 & 0 & 0 \\
595,000 & 595,000 & 0 & 0 & 0 & 0 \\
\hline$\$ 2,054,454$ & $\$ 1,660,646$ & $\$ 157,536$ & $\$ 87,041$ & $\$ 133,286$ & $\$ 15,945$ \\
\hline \hline
\end{tabular}


DOE PRIME CONTRACT \# DE-AC02-78ET-51013 : B\&R \# AT-10-10-14F

TASK 01 : ALCATOR CMOD : FY97 GROUP BREAKDOWN

October 01, 1996 - September 30, 1997

Fiscal Year 1997 - $\$ 15$ Million Proposal SUMMARY OF MAN-YEARS

\begin{tabular}{rrrrrr} 
TOTAL & Operations & Experiment & RF & Plasma & Division \\
FY 97 & FY 97 & FY 97 & FY 97 & FY 97 & FY 97 \\
\hline
\end{tabular}

SCIENTIFIC

FACULTY

OTHER ACADEMIC STAFF

SCIENTIFIC RESEARCHSTAFF

RESEARCHASSISTANTS

SUBTOTAL SCIENTIFIC

TECHNICAL \& ENGINEEAING

COMPUTERSTAFF

ENGINEERING RESEARCHSTAFF

TECHNICIANS

DRAFTERS

SUBTOTAL ENGINEERING \& TECH.

OTHER SUPPORT

ADMINISTRATIVE STAFF

PROJECT SUPPORT STAFF

PFC COMP SUPPORT

ADMINISTRATIVE SUPPORT

SUBTOTAL OTHER

\begin{tabular}{rrrrrr}
0.74 & 0.00 & 0.00 & 0.35 & 0.00 & 0.39 \\
1.36 & 0.00 & 0.90 & 0.00 & 0.36 & 0.10 \\
18.40 & 1.15 & 8.89 & 3.50 & 4.66 & 0.20 \\
22.00 & 0.00 & 14.00 & 3.00 & 5.00 & 0.00 \\
\hline & & & & & \\
42.50 & 1.15 & 23.79 & 6.85 & 10.02 & 0.69 \\
\hline
\end{tabular}

\begin{tabular}{rrrrrr} 
& & & & & \\
4.00 & 0.00 & 0.00 & 0.00 & 4.00 & 0.00 \\
18.35 & 10.65 & 1.05 & 4.10 & 2.45 & 0.10 \\
26.95 & 16.60 & 4.80 & 2.95 & 2.60 & 0.00 \\
2.00 & 1.30 & 0.40 & 0.30 & 0.00 & 0.00 \\
\hline 51.30 & 28.55 & 6.25 & 7.35 & 9.05 & 0.10 \\
\hline
\end{tabular}

\begin{tabular}{rrrrrr} 
& & & & & \\
0.80 & 0.00 & 0.00 & 0.00 & 0.00 & 0.80 \\
1.00 & 1.00 & 0.00 & 0.00 & 0.00 & 0.00 \\
0.15 & 0.00 & 0.00 & 0.00 & 0.15 & 0.00 \\
11.26 & 5.88 & 2.15 & 1.19 & 1.82 & 0.22 \\
\hline 13.21 & 6.88 & 2.15 & 1.19 & 1.97 & 1.02 \\
\hline
\end{tabular}

TOTAL MAN-YEARS

36.58

15.39

21.04

1.81 
DOE PRIME CONTRACT \# DE-AC02-78ET-51013 : B\&R \# AT-10-10-14F

DETAIL OF MAN-YEARS

FACULTY

I. Hutchinson

M. Porkolab (N/C eff. 2/1)

A. Bers

TOTAL FACULTY

\section{RESEARCH STAFF - OTHER ACADEMIC}

E. Marmar

J. Kesner

D. Sigmar

SCIENTIFIC RESEARCH STAFF

R. Boivin

P. Bonoli

C. Fiore

J. Goetz

S. Golovato

R. Granetz

M. Greenwald

S. Horne

A. Hubbard

J. Irby

B. LaBombard

P. Linsay

B. Lipschuitz

G. McCracken

A. Ram

J. Rice

J. Snipes

Y. Takase

J. Terry

R. Watterson

S. Wolle

Divertor

Thomson Scattering

MSE

TOTAL SCIENTIFIC RES. STAFF

\begin{tabular}{rrrrrr}
$\begin{array}{r}\text { TOTAL } \\
\text { FY 97 }\end{array}$ & $\begin{array}{r}\text { Operations } \\
\text { FY 97 }\end{array}$ & $\begin{array}{r}\text { Experiment } \\
\text { FY 97 }\end{array}$ & $\begin{array}{r}\text { RF } \\
\text { FY 97 }\end{array}$ & $\begin{array}{r}\text { Plasma } \\
\text { FY 97 }\end{array}$ & $\begin{array}{r}\text { Division } \\
\text { FY 97 }\end{array}$ \\
& & & & & \\
$39 \%$ & $0 \%$ & $0 \%$ & $0 \%$ & $0 \%$ & $39 \%$ \\
$35 \%$ & $0 \%$ & $0 \%$ & $35 \%$ & $0 \%$ & $0 \%$ \\
$0 \%$ & $0 \%$ & $0 \%$ & $0 \%$ & $0 \%$ & $0 \%$ \\
\hline & & & & & \\
\hline & 0.74 & 0.00 & 0.35 & 0.00 & 0.39 \\
\hline
\end{tabular}

\begin{tabular}{|c|c|c|c|c|c|}
\hline $100 \%$ & $0 \%$ & $90 \%$ & $0 \%$ & $0 \%$ & $10 \%$ \\
\hline $36 \%$ & $0 \%$ & $0 \%$ & $0 \%$ & $36 \%$ & $0 \%$ \\
\hline $0 \%$ & $0 \%$ & $0 \%$ & $0 \%$ & $0 \%$ & $0 \%$ \\
\hline $100 \%$ & $0 \%$ & $100 \%$ & $0 \%$ & $0 \%$ & $0 \%$ \\
\hline $100 \%$ & $0 \%$ & $0 \%$ & $100 \%$ & $0 \%$ & $0 \%$ \\
\hline $50 \%$ & $25 \%$ & $25 \%$ & $0 \%$ & $0 \%$ & $0 \%$ \\
\hline $100 \%$ & $0 \%$ & $64 \%$ & $0 \%$ & $36 \%$ & $0 \%$ \\
\hline $0 \%$ & $0 \%$ & $0 \%$ & $0 \%$ & $0 \%$ & $0 \%$ \\
\hline $100 \%$ & $0 \%$ & $0 \%$ & $0 \%$ & $100 \%$ & $0 \%$ \\
\hline $90 \%$ & $0 \%$ & $0 \%$ & $0 \%$ & $90 \%$ & $0 \%$ \\
\hline $0 \%$ & $0 \%$ & $0 \%$ & $0 \%$ & $0 \%$ & $0 \%$ \\
\hline $100 \%$ & $0 \%$ & $0 \%$ & $50 \%$ & $50 \%$ & $0 \%$ \\
\hline $100 \%$ & $90 \%$ & $0 \%$ & $0 \%$ & $0 \%$ & $10 \%$ \\
\hline $100 \%$ & $0 \%$ & $100 \%$ & $0 \%$ & $0 \%$ & $0 \%$ \\
\hline $0 \%$ & $0 \%$ & $0 \%$ & $0 \%$ & $0 \%$ & $0 \%$ \\
\hline $100 \%$ & $0 \%$ & $100 \%$ & $0 \%$ & $0 \%$ & $0 \%$ \\
\hline $0 \%$ & $0 \%$ & $0 \%$ & $0 \%$ & $0 \%$ & $0 \%$ \\
\hline $0 \%$ & $0 \%$ & $0 \%$ & $0 \%$ & $0 \%$ & $0 \%$ \\
\hline $100 \%$. & $0 \%$ & $100 \%$ & $0 \%$ & $0 \%$ & $0 \%$ \\
\hline $100 \%$ & $0 \%$ & $100 \%$ & $0 \%$ & $0 \%$ & $0 \%$ \\
\hline $100 \%$ & $0 \%$ & $0 \%$ & $100 \%$ & $0 \%$ & $0 \%$ \\
\hline $100 \%$ & $0 \%$ & $100 \%$ & $0 \%$ & $0 \%$ & $0 \%$ \\
\hline $0 \%$ & $0 \%$ & $0 \%$ & $0 \%$ & $0 \%$ & $0 \%$ \\
\hline $100 \%$ & $0 \%$ & $0 \%$ & $0 \%$ & $90 \%$ & $10 \%$ \\
\hline $100 \%$ & $0 \%$ & $100 \%$ & $0 \%$ & $0 \%$ & $0 \%$ \\
\hline $100 \%$ & $0 \%$ & $0 \%$ & $0 \%$ & $100 \%$ & $0 \%$ \\
\hline $100 \%$ & $0 \%$ & $100 \%$ & $0 \%$ & $0 \%$ & $0 \%$ \\
\hline $100 \%$ & $0 \%$ & $0 \%$ & $100 \%$ & $0 \%$ & $0 \%$ \\
\hline 19.76 & 1.15 & 9.79 & 3.50 & 5.02 & 0.30 \\
\hline
\end{tabular}


DOE PRIME CONTRACT \# DE-AC02-78ET-51013 : B\&R \# AT-10-10-14F

DETAIL OF MAN-YEARS

\section{ENGINEERS}

S. Andreyev

W. Beck

V. Bertolino

J. Bosco

W. Burke

W. Byford

E. Byrne

R. Childs

J. Daigle

S. Fairfax

E. Fitzgerald

M. Fridberg

D. Gwinn

A. Helander

I. Mastovsky

J. Paranay

C. Park

W. Parkin

N. Plerce

R. Pillsbury

C. Reddy

J. Rosati

F. Sabell

F. Silva

F. Tambini

E. Thibeault

$X$. Zhong

Now - RF

New - Cryo

TOTAL ENGINEERS

COMPUTER STAFF

H. Bergler

T. Fredian

F. Kreisel

D. Nelson

J. Stillerman

New

TOTAL COMPUTER STAFF

\begin{tabular}{|c|c|c|c|c|c|}
\hline $\begin{array}{r}\text { TOTAL } \\
\text { FY } 97 \\
\end{array}$ & $\begin{array}{r}\text { Operations } \\
\text { FY } 97 \\
\end{array}$ & $\begin{array}{r}\text { Experiment } \\
\text { FY } 97 \\
\end{array}$ & $\begin{array}{c}\text { RF } \\
\text { FY } 97\end{array}$ & $\begin{array}{r}\text { Plasma } \\
\text { FY } 97 \\
\end{array}$ & $\begin{array}{r}\text { Division } \\
\text { FY } 97 \\
\end{array}$ \\
\hline $0 \%$ & $0 \%$ & $0 \%$ & $0 \%$ & $0 \%$ & $0 \%$ \\
\hline $100 \%$ & $20 \%$ & $0 \%$ & $80 \%$ & $0 \%$ & $0 \%$ \\
\hline $100 \%$ & $100 \%$ & $0 \%$ & $0 \%$ & $0 \%$ & $0 \%$ \\
\hline $100 \%$ & $15 \%$ & $0 \%$ & $0 \%$ & $85 \%$ & $0 \%$ \\
\hline $100 \%$ & $100 \%$ & $0 \%$ & $0 \%$ & $0 \%$ & $0 \%$ \\
\hline $50 \%$ & $50 \%$ & $0 \%$ & $0 \%$ & $0 \%$ & $0 \%$ \\
\hline $0 \%$ & $0 \%$ & $0 \%$ & $0 \%$ & $0 \%$ & $0 \%$ \\
\hline $100 \%$ & $70 \%$ & $20 \%$ & $10 \%$ & $0 \%$ & $0 \%$ \\
\hline $100 \%$ & $60 \%$ & $0 \%$ & $20 \%$ & $20 \%$ & $0 \%$ \\
\hline $0 \%$ & $0 \%$ & $0 \%$ & $0 \%$ & $0 \%$ & $0 \%$ \\
\hline $90 \%$ & $80 \%$ & $0 \%$ & $10 \%$ & $0 \%$ & $0 \%$ \\
\hline $100 \%$ & $20 \%$ & $0 \%$ & $80 \%$ & $0 \%$ & $0 \%$ \\
\hline $100 \%$ & $90 \%$ & $0 \%$ & $0 \%$ & $0 \%$ & $10 \%$ \\
\hline $0 \%$ & $0 \%$ & $0 \%$ & $0 \%$ & $0 \%$ & $0 \%$ \\
\hline $100 \%$ & $0 \%$ & $0 \%$ & $100 \%$ & $0 \%$ & $0 \%$ \\
\hline $0 \%$ & $0 \%$ & $0 \%$ & $0 \%$ & $0 \%$ & $0 \%$ \\
\hline $0 \%$ & $0 \%$ & $0 \%$ & $0 \%$ & $0 \%$ & $0 \%$ \\
\hline $100 \%$ & $50 \%$ & $20 \%$ & $10 \%$ & $20 \%$ & $0 \%$ \\
\hline $0 \%$ & $0 \%$ & $0 \%$ & $0 \%$ & $0 \%$ & $0 \%$ \\
\hline $0 \%$ & $0 \%$ & $0 \%$ & $0 \%$ & $0 \%$ & $0 \%$ \\
\hline $100 \%$ & $0 \%$ & $0 \%$ & $0 \%$ & $100 \%$ & $0 \%$ \\
\hline $100 \%$ & $100 \%$ & $0 \%$ & $0 \%$ & $0 \%$ & $0 \%$ \\
\hline $0 \%$ & $0 \%$ & $0 \%$ & $0 \%$ & $0 \%$ & $0 \%$ \\
\hline $100 \%$ & $100 \%$ & $0 \%$ & $0 \%$ & $0 \%$ & $0 \%$ \\
\hline $95 \%$ & $50 \%$ & $45 \%$ & $0 \%$ & $0 \%$ & $0 \%$ \\
\hline $100 \%$ & $60 \%$ & $20 \%$ & $0 \%$ & $20 \%$ & $0 \%$ \\
\hline $0 \%$ & $0 \%$ & $0 \%$ & $0 \%$ & $0 \%$ & $0 \%$ \\
\hline $100 \%$ & $0 \%$ & $0 \%$ & $100 \%$ & $0 \%$ & $0 \%$ \\
\hline $100 \%$ & $100 \%$ & $0 \%$ & $0 \%$ & $0 \%$ & $0 \%$ \\
\hline 18.35 & 10.65 & 1.05 & 4.10 & 2.45 & 0.10 \\
\hline $50 \%$ & $0 \%$ & $0 \%$ & $0 \%$ & $50 \%$ & $0 \%$ \\
\hline $100 \%$ & $0 \%$ & $0 \%$ & $0 \%$ & $100 \%$ & $0 \%$ \\
\hline $100 \%$ & $0 \%$ & $0 \%$ & $0 \%$ & $100 \%$ & $0 \%$ \\
\hline $50 \%$ & $0 \%$ & $0 \%$ & $0 \%$ & $50 \%$ & $0 \%$ \\
\hline $100 \%$ & $0 \%$ & $0 \%$ & $0 \%$ & $100 \%$ & $0 \%$ \\
\hline $0 \%$ & $0 \%$ & $0 \%$ & $0 \%$ & $0 \%$ & $0 \%$ \\
\hline 4.00 & 0.00 & 0.00 & 0.00 & 4.00 & 0.00 \\
\hline
\end{tabular}


DOE PRIME CONTRACT \# DE-AC02-78ET-51013 : B\&R \# AT-10-10-14F

DETAIL OF MAN-YEARS

\begin{tabular}{|c|c|c|c|c|c|}
\hline $\begin{array}{r}\text { TOTAL } \\
\text { FY } 97 \\
\end{array}$ & $\begin{array}{r}\text { Operations } \\
\text { FY } 97\end{array}$ & $\begin{array}{r}\text { Experiment } \\
\text { FY } 97 \\
\end{array}$ & $\begin{array}{c}\text { RF } \\
\text { FY } 97 \\
\end{array}$ & $\begin{array}{r}\text { Plasma } \\
\text { FY } 97 \\
\end{array}$ & $\begin{array}{r}\text { Division } \\
\text { FY } 97 \\
\end{array}$ \\
\hline $100 \%$ & $100 \%$ & $0 \%$ & $0 \%$ & $0 \%$ & $0 \%$ \\
\hline $100 \%$ & $100 \%$ & $0 \%$ & $0 \%$ & $0 \%$ & $0 \%$ \\
\hline $100 \%$ & $50 \%$ & $0 \%$ & $20 \%$ & $30 \%$ & $0 \%$ \\
\hline $100 \%$ & $0 \%$ & $50 \%$ & $0 \%$ & $50 \%$ & $0 \%$ \\
\hline $100 \%$ & $100 \%$ & $0 \%$ & $0 \%$ & $0 \%$ & $0 \%$ \\
\hline $100 \%$ & $20 \%$ & $15 \%$ & $0 \%$ & $65 \%$ & $0 \%$ \\
\hline $100 \%$ & $100 \%$ & $0 \%$ & $0 \%$ & $0 \%$ & $0 \%$ \\
\hline $100 \%$ & $20 \%$ & $45 \%$ & $0 \%$ & $35 \%$ & $0 \%$ \\
\hline $100 \%$ & $100 \%$ & $0 \%$ & $0 \%$ & $0 \%$ & $0 \%$ \\
\hline $0 \%$ & $0 \%$ & $0 \%$ & $0 \%$ & $0 \%$ & $0 \%$ \\
\hline $0 \%$ & $0 \%$ & $0 \%$ & $0 \%$ & $0 \%$ & $0 \%$ \\
\hline $100 \%$ & $0 \%$ & $50 \%$ & $50 \%$ & $0 \%$ & $0 \%$ \\
\hline $100 \%$ & $60 \%$ & $0 \%$ & $40 \%$ & $0 \%$ & $0 \%$ \\
\hline $100 \%$ & $100 \%$ & $0 \%$ & $0 \%$ & $0 \%$ & $0 \%$ \\
\hline $100 \%$ & $0 \%$ & $0 \%$ & $100 \%$ & $0 \%$ & $0 \%$ \\
\hline $100 \%$ & $25 \%$ & $50 \%$ & $25 \%$ & $0 \%$ & $0 \%$ \\
\hline $100 \%$ & $50 \%$ & $0 \%$ & $0 \%$ & $50 \%$ & $0 \%$ \\
\hline $100 \%$ & $100 \%$ & $0 \%$ & $0 \%$ & $0 \%$ & $0 \%$ \\
\hline $0 \%$ & $0 \%$ & $0 \%$ & $0 \%$ & $0 \%$ & $0 \%$ \\
\hline $100 \%$ & $20 \%$ & $80 \%$ & $0 \%$ & $0 \%$ & $0 \%$ \\
\hline $100 \%$ & $80 \%$ & $0 \%$ & $20 \%$ & $0 \%$ & $0 \%$ \\
\hline $100 \%$ & $40 \%$ & $60 \%$ & $0 \%$ & $0 \%$ & $0 \%$ \\
\hline $0 \%$ & $0 \%$ & $0 \%$ & $0 \%$ & $0 \%$ & $0 \%$ \\
\hline $100 \%$ & $50 \%$ & $50 \%$ & $0 \%$ & $0 \%$ & $0 \%$ \\
\hline $100 \%$ & $50 \%$ & $50 \%$ & $0 \%$ & $0 \%$ & $0 \%$ \\
\hline $100 \%$ & $60 \%$ & $0 \%$ & $40 \%$ & $0 \%$ & $0 \%$ \\
\hline $100 \%$ & $40 \%$ & $30 \%$ & $0 \%$ & $30 \%$ & $0 \%$ \\
\hline $50 \%$ & $50 \%$ & $0 \%$ & $0 \%$ & $0 \%$ & $0 \%$ \\
\hline $0 \%$ & $0 \%$ & $0 \%$ & $0 \%$ & $0 \%$ & $0 \%$ \\
\hline $345 \%$ & $345 \%$ & $0 \%$ & $0 \%$ & $0 \%$ & $0 \%$ \\
\hline 26.95 & 16.60 & 4.80 & 2.95 & 2.60 & 0.00 \\
\hline
\end{tabular}

DRAFTERS

D. Arsenault

J. Chicarello

W. Cochran

R. Danforth

G. Dekow

J. Gerolamo

R. Griffith

M. Iverson

H. Lander

T. Lloyd

J. Moscaritolo

R. Murray

J. Nickerson

J. Orvosh

A. Pleiffer

S. Pierson

W. Pina

K. Rettman

M. Rioux

E. Rollins

M. Rowell

F. Shefton

New/Temporary

R. Sylvia

S. Tambini

P. Telesmanick

T. Toland

Northeastern Coop

New/Temporary

Overtime

TOTAL TECHNICIANS

A. DiCiaccio

M. Keniston

S. Kochan

New

TOTAL DRAFTERS

\begin{tabular}{rrrrrr}
$100 \%$ & $70 \%$ & $0 \%$ & $30 \%$ & $0 \%$ & $0 \%$ \\
$0 \%$ & $0 \%$ & $0 \%$ & $0 \%$ & $0 \%$ & $0 \%$ \\
$100 \%$ & $60 \%$ & $40 \%$ & $0 \%$ & $0 \%$ & $0 \%$ \\
\hline $0 \%$ & $0 \%$ & $0 \%$ & $0 \%$ & $0 \%$ & $0 \%$ \\
\hline 2.00 & 1.30 & 0.40 & 0.30 & 0.00 & 0.00 \\
\hline
\end{tabular}


DOE PRIME CONTRACT \# DE-AC02-78ET-51013 : B\&R \# AT-10-10-14F

DETAIL OF MAN-YEARS

\begin{tabular}{rrrrrr} 
TOTAL & Operations & Experiment & RF & Plasma & Division \\
FY 97 & FY 97 & FY 97 & FY 97 & FY 97 & FY 97 \\
\hline
\end{tabular}

ADMINISTRATIVE STAFF

New V. Censabella

TOTAL ADMINISTRATIVE STAFF

SUPPORT STAFF

New

C. Arlington

K. Johnson

TOTAL SUPPORT

PFC COMPUTER SUPPORT

M. Greenwald

M. London

TOTAL PFC COMPUTER SUPPORT

\begin{tabular}{rrrrrr}
$80 \%$ & $0 \%$ & $0 \%$ & $0 \%$ & $0 \%$ & $80 \%$ \\
\hline $0 \%$ & $0 \%$ & $0 \%$ & $0 \%$ & $0 \%$ & $0 \%$ \\
\hline 0.80 & 0.00 & 0.00 & 0.00 & 0.00 & 0.80 \\
\hline
\end{tabular}

\begin{tabular}{rrrrrr}
$0 \%$ & $0 \%$ & $0 \%$ & $0 \%$ & $0 \%$ & $0 \%$ \\
$100 \%$ & $100 \%$ & $0 \%$ & $0 \%$ & $0 \%$ & $0 \%$ \\
\hline $0 \%$ & $0 \%$ & $0 \%$ & $0 \%$ & $0 \%$ & $0 \%$ \\
\hline 1.00 & 1.00 & 0.00 & 0.00 & 0.00 & 0.00 \\
\hline
\end{tabular}

\begin{tabular}{rrrrrr}
$5 \%$ & $0 \%$ & $0 \%$ & $0 \%$ & $5 \%$ & $0 \%$ \\
$10 \%$ & $0 \%$ & $0 \%$ & $0 \%$ & $10 \%$ & $0 \%$ \\
\hline 0.15 & 0.00 & 0.00 & 0.00 & 0.15 & 0.00 \\
\hline
\end{tabular}


DOE PRIME CONTRACT \# DE-AC02-78ET-51013 : B\&A \# AT-10-10-14F

DETAIL OF MAN-YEARS

\begin{tabular}{|c|c|c|c|c|c|}
\hline $\begin{array}{r}\text { TOTAL } \\
\text { FY } 97 \\
\end{array}$ & 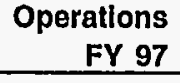 & $\begin{array}{r}\text { Experiment } \\
\text { FY } 97 \\
\end{array}$ & $\begin{array}{c}\text { RF } \\
\text { FY } 97 \\
\end{array}$ & $\begin{array}{r}\text { Plasma } \\
\text { FY } 97 \\
\end{array}$ & $\begin{array}{r}\text { Division } \\
\text { FY } 97 \\
\end{array}$ \\
\hline $100 \%$ & $0 \%$ & $100 \%$ & $0 \%$ & $0 \%$ & $0 \%$ \\
\hline $100 \%$ & $0 \%$ & $100 \%$ & $0 \%$ & $0 \%$ & $0 \%$ \\
\hline $100 \%$ & $0 \%$ & $100 \%$ & $0 \%$ & $0 \%$ & $0 \%$ \\
\hline $100 \%$ & $0 \%$ & $100 \%$ & $0 \%$ & $0 \%$ & $0 \%$ \\
\hline $100 \%$ & $0 \%$ & $100 \%$ & $0 \%$ & $0 \%$ & $0 \%$ \\
\hline $100 \%$ & $0 \%$ & $100 \%$ & $0 \%$ & $0 \%$ & $0 \%$ \\
\hline $100 \%$ & $0 \%$ & $100 \%$ & $0 \%$ & $0 \%$ & $0 \%$ \\
\hline $100 \%$ & $0 \%$ & $100 \%$ & $0 \%$ & $0 \%$ & $0 \%$ \\
\hline $100 \%$ & $0 \%$ & $100 \%$ & $0 \%$ & $0 \%$ & $0 \%$ \\
\hline $0 \%$ & $0 \%$ & $0 \%$ & $0 \%$ & $0 \%$ & $0 \%$ \\
\hline $100 \%$ & $0 \%$ & $0 \%$ & $100 \%$ & $0 \%$ & $0 \%$ \\
\hline $100 \%$ & $0 \%$ & $100 \%$ & $0 \%$ & $0 \%$ & $0 \%$ \\
\hline $100 \%$ & $0 \%$ & $100 \%$ & $0 \%$ & $0 \%$ & $0 \%$ \\
\hline $100 \%$ & $0 \%$ & $0 \%$ & $0 \%$ & $100 \%$ & $0 \%$ \\
\hline $100 \%$ & $0 \%$ & $100 \%$ & $0 \%$ & $0 \%$ & $0 \%$ \\
\hline $100 \%$ & $0 \%$ & $0 \%$ & $100 \%$ & $0 \%$ & $0 \%$ \\
\hline $100 \%$ & $0 \%$ & $0 \%$ & $100 \%$ & $0 \%$ & $0 \%$ \\
\hline $100 \%$ & $0 \%$ & $0 \%$ & $0 \%$ & $100 \%$ & $0 \%$ \\
\hline $0 \%$ & $0 \%$ & $0 \%$ & $0 \%$ & $0 \%$ & $0 \%$ \\
\hline $100 \%$ & $0 \%$ & $0 \%$ & $0 \%$ & $100 \%$ & $0 \%$ \\
\hline $100 \%$ & $0 \%$ & $100 \%$ & $0 \%$ & $0 \%$ & $0 \%$ \\
\hline $100 \%$ & $0 \%$ & $0 \%$ & $0 \%$ & $100 \%$ & $0 \%$ \\
\hline $0 \%$ & $0 \%$ & $0 \%$ & $0 \%$ & $0 \%$ & $0 \%$ \\
\hline $100 \%$ & $0 \%$ & $0 \%$ & $0 \%$ & $100 \%$ & $0 \%$ \\
\hline $100 \%$ & $0 \%$ & $100 \%$ & $0 \%$ & $0 \%$ & $0 \%$ \\
\hline 22.00 & 0.00 & 14.00 & 3.00 & 5.00 & 0.00 \\
\hline 11.26 & 5.88 & 2.15 & 1.19 & 1.82 & 0.22 \\
\hline 107.01 & 36.58 & 32.19 & 15.39 & 21.04 & 1.81 \\
\hline
\end{tabular}

TOTAL MAN-YEARS

A. Allen

V. Belevstev

C. Christensen

S. Gangadhara

D. Garnier

Y. In

D. Jablonski

M. Koltonyuk

D. Lo

D. Lumma

A. Mazurenko

R. Nachtrieb

H. Ohkawa

P. O'Shea

D. Pappas

J. Reardon

. Rost

J. Schachter

K. Shadman

J. Sorci

P. Stek

M. Umansky

Y. Wang

New

New

TOTAL RESEARCH ASSISTANTS

ADMINISTRATIVE LAB SUPPORT

Various 
DOE PRIME CONTRACT \# DE-AC02-78ET-51013 : B\&R \# AT-10-10-14F

TASK 01 : ALCATOR CMOD : FY97 GROUP BREAKDOWN

October 01, 1996 - September 30, 1997

Fiscal Year 1997 Budget at \$15M

DETAIL OF MATERIALS \& SERVICES

Telephones

Catalogues, Journals, Books, etc.

Publications

Graphic Arts

Xerox Expense

Equipment Rental (no OH)

Office \& Drafting Supplies

Postage \& Shipping

Comp. Hardware Maintenance

Computer Software

Computer Supplies

PFC Computer Contribution

AIRCO; LN2 (No Overhead)

Camb. Electric (No Overhead)

Industrial Subcontracts

Alternator Maintenance

Geses

Radiology \& Safety

Machinists

Cryogenic Materials

Electrical/Electronic Components

Mechanical Components

Optical Components

Vacuum Components

Raw Materials

Electronic Assemblies

Tools

Materials \& Services

Allocated Expense

TOTAL

FY 97

0.00

\begin{tabular}{r} 
FY 97 \\
\hline 0.00 \\
29,350 \\
2,500 \\
13,200 \\
1,700 \\
11,000 \\
35,400 \\
25,450 \\
11,400 \\
44,530 \\
56,090 \\
26,120 \\
23,260 \\
300,000 \\
100,000 \\
200,000 \\
0 \\
28,780 \\
40,955 \\
23,850 \\
11,840 \\
278,470 \\
144,740 \\
27,775 \\
69,645 \\
26,295 \\
112,320 \\
5,465 \\
371,348 \\
155,880 \\
\end{tabular}


DOE PRIME CONTRACT \# DE-AC02-78ET-51013 : B\&R \# AT-10-10-14F TASK 01 : ALCATOR CMOD : FY97 GROUP BREAKDOWN

October 01, 1996 - September 30, 1997

Fiscal Year 1997 Budget at $\$ 15 M$

DETAIL OF MATERIALS \& SERVICES

TOTAL

FY 97

SUBSYSTEM FABS/UPGRADES (NO OH)

$X$-ray Tomography System Fab

Magnetic Diagnostics Fab

First-Wall Upgrade

LHH/LHCD Fab

LH Antenna Fab

LH Instrumentation \& Control Fab

ICRF Tunable Transmitter Fab

Edge Thomson Scattering

EFC Magnet Power Supply Upgrade

Control System Upgrade

Cryopump Fab

Divertor Upgrade

ICRF Antenna

ICRF Matching System

ICRF Transmitter Upgrade

ICRF Instrumentation \& Contro

LH Transmission Line Fab

ICAF Diagnostics

$\begin{array}{r}\text { TOTAL } \\ \text { FY 97 } \\ \hline \\ 0 \\ 0 \\ 150,000 \\ 50,000 \\ 0 \\ 0 \\ 50,000 \\ 0 \\ 0 \\ 0 \\ 265,000 \\ 0 \\ 0 \\ 20,000 \\ 20,000 \\ 20,000 \\ 0 \\ 20,000 \\ \hline 2,772,363 \\ \hline \hline\end{array}$

TOTAL ESTIMATED M\&S 
DOE PRIME CONTRACT \# DE-AC02-78ET-51013 : B\&R \# AT-10-10-14F TASK 01 : ALCATOR CMOD : FY97 GROUP BREAKDOWN

October 01, 1996 - September 30, 1997

Fiscal Year 1997 Budget at $\$ 15 M$

DETAIL OF ESTIMATED TRAVEL NEEDS

TOTAL

FY 97

A. DOMESTIC:

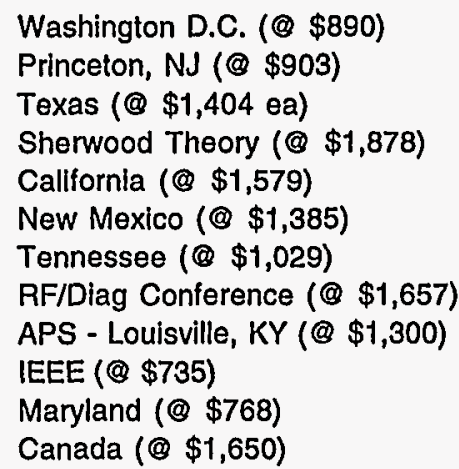

12,838

18,600

5,784

0

29,268

2,854

2,120

0

38,625

1,582

1,700

B. FOREIGN

$$
\begin{aligned}
& \text { Japan } \\
& \text { England } \\
& \text { Germany } \\
& \text { Russia } \\
& \text { Switzerland } \\
& \text { Netherlands } \\
& \text { IAEA } \\
& \text { PSI/EPS } \\
& \text { France (PSI) } \\
& \text { Italy }
\end{aligned}
$$

10,800

5,200

7,050

500

TOTAL ESTIMATED TRAVEL COSTS : 
DAC EQUIPMENT

Crates \& Controllers

Enhanced Highway Drivers

CAMAC U-ports

0

CAMAC Digitizers

3,000

CAMAC Timing Modules

20,000

CAMAC Diagnostic/Malnt. Module

5,000

CAMAC Modules: counters, TDC, Demod 10,000

CAMAC Prog. Amps.

PLCs

24,000

Mimic Panels, Displays

0

PLASMA CONTROL SYSTEM

Maintenance/Calibration Instr.

5,000

Hybrid Computer Upgrades

5,000

COMPUTER EQUIPMENT

Computer Peripherals

Computers, Personal

Computers, Workstations/Servers

10,000

Data Comm. Equipment

10,000

Data Terminals

Mass Storage, Magnetic

Mass Storage, Optical

Printers and Plotters

Network Test Equipment

15,000

10,000

10,000

10,000

5,000

10,000

FUELING/PELLET EQUIPMENT

\section{LPI}

DPI

Diagnostic Neutral Beam FAB

MHD DIAGNOSTICS EQUIPMENT

MHD Coils

VIS. \& UV SPECTROSCOPY

MSEFAB

BES FAB

60,000

CXRSFAB

13,000

12,000

LASER SCATTERING 
DOE PRIME CONTRACT \# DE-AC02-78ET-51013 : B\&R \# AT-10-10-14F

DETAIL OF CAPITAL EQUIPMENT NEEDS

\section{ALCATOR CMOD EQUIPMENT BREAKDOWN (continued)}

Calibration Source

LASER SCATTERING

TOTAL

FY 97

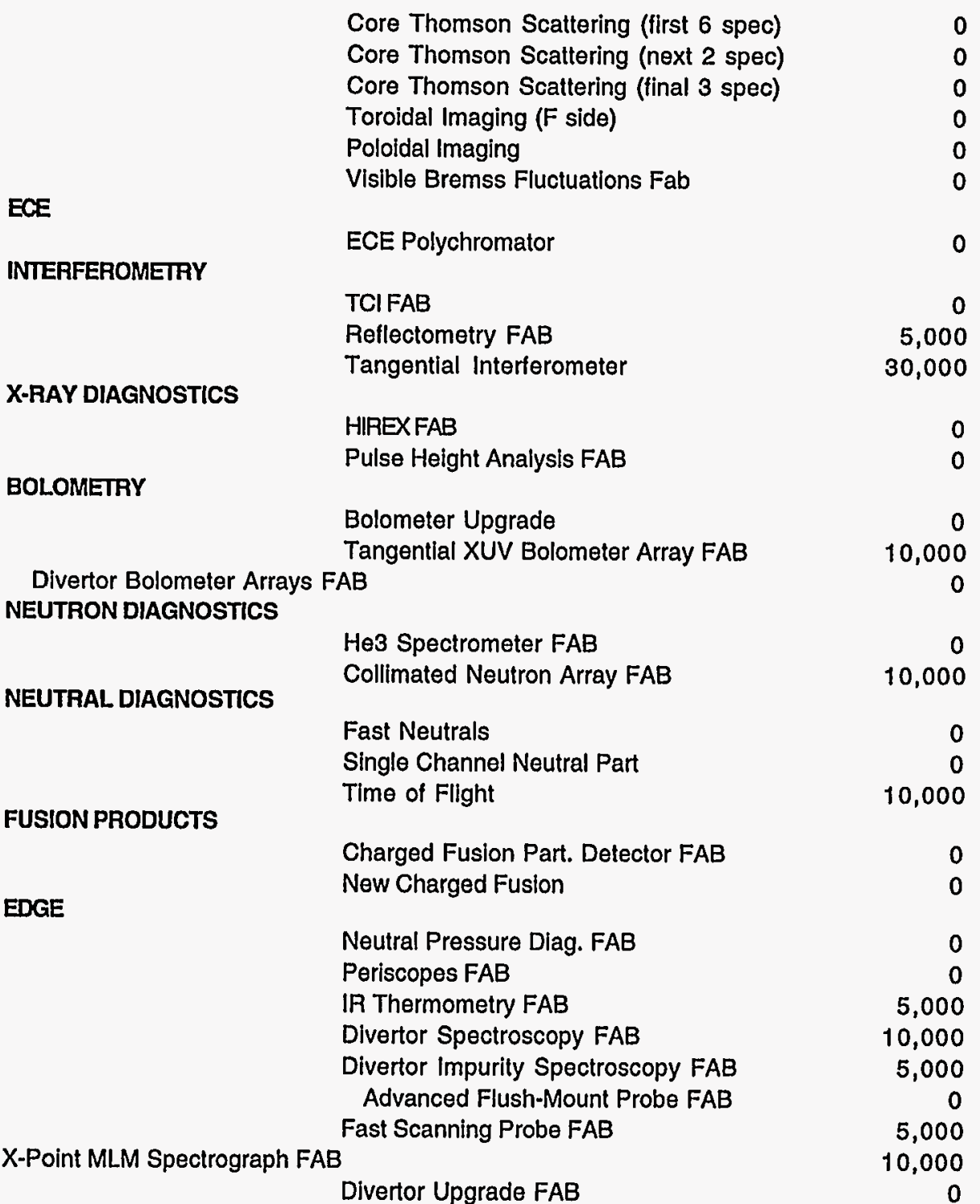


TOTAL

FY 97

ALCATOR CMOD EQUIPMENT BREAKDOWN (continued)

Omegatron Probes FAB

Edge Thomson Scattering FAB

0

Flat Plate Divertor Bolometer FAB

Flush Mount Probes in Flat Plate FAB

10,000

Vessel Inspection FAB

OTHER EQUIPMENT

RGADliferential Pumping

Vacuum \& Pumping Equipment

Video \& Optical Equipment and Instr.

ICRF

LH

Video Equipment

Power Amplifier

Fast Power Meter

Signal Generator

Digital Scopes

Tubes

Misc. RF Equipment

0

10,000

8,000

0

5,000

10,000

5,000

6,000

0
9,000

Measuring Equipment CO2 PHASE CONTRAST

Laser Power Attenuator

Function Generator

0

Acousto-Optic Modulator

Detector

Amplifiers

2,000

2,000

6,000

Programmable Controls FAB Cutting System

Flywheel FAB

Cryopump/Refrigerator $F A B$

CLIP

Electric Power Equip.

Electronic Equipment

Standby Power Equip.

Machine Tools

Safety Equipment

Fiberscope

TOTAL EQUIPMENT

Power Tools 
DOE PRIME CONTRACT \# DE-AC02-78ET-51013 : B\&R \# AT-10-10-14F

TASK 01 : ALCATOR CMOD : FY98 GROUP BREAKDOWN

October 01, 1997 - September 30, 1998

Fiscal Year 1998 Budget at \$16M

ESCALATED AT $105 \%$

SUMMARY OF COSTS

\begin{tabular}{|c|c|c|c|c|c|}
\hline $\begin{array}{l}\text { TOTAL } \\
\text { FY } 98 \\
\end{array}$ & $\begin{array}{c}\text { Operations } \\
\text { FY } 98\end{array}$ & $\begin{array}{c}\text { Experiment } \\
\text { FY } 98 \\
\end{array}$ & $\begin{array}{l}\text { RF } \\
\text { FY } 98 \\
\end{array}$ & $\begin{array}{c}\text { Plasma } \\
\text { FY } 98 \\
\end{array}$ & $\begin{array}{c}\text { Division } \\
\text { FY } 98 \\
\end{array}$ \\
\hline$\$ 1,389,974$ & $\$ 92,553$ & $\$ 624,427$ & $\$ 231,981$ & $\$ 368,235$ & $\$ 72,778$ \\
\hline 284,581 & 0 & 180,587 & 37,954 & 66,040 & 0 \\
\hline 259,320 & 0 & 0 & 0 & 259,320 & 0 \\
\hline $1,068,123$ & 657,354 & 55,122 & 214,668 & 131,367 & 9,612 \\
\hline $\begin{array}{r}1,218,697 \\
86,333\end{array}$ & $\begin{array}{r}768,848 \\
55,766\end{array}$ & $\begin{array}{r}209,841 \\
18,670\end{array}$ & $\begin{array}{r}125,647 \\
11,897\end{array}$ & $\begin{array}{r}114,361 \\
0\end{array}$ & $\begin{array}{l}0 \\
0\end{array}$ \\
\hline 33,786 & 0 & 0 & 0 & 0 & 33,786 \\
\hline $\begin{array}{l}30,418 \\
10,364\end{array}$ & $\begin{array}{r}30,418 \\
0\end{array}$ & $\begin{array}{l}0 \\
0\end{array}$ & $\begin{array}{l}0 \\
0\end{array}$ & $\begin{array}{r}0 \\
10,364\end{array}$ & $\begin{array}{l}0 \\
0\end{array}$ \\
\hline 468,769 & 249,413 & 86,003 & 49,150 & 75,025 & 9,178 \\
\hline $\begin{array}{r}\$ 4,850,365 \\
2,158,413\end{array}$ & $\begin{array}{r}\$ 1,854,352 \\
825,187\end{array}$ & $\begin{array}{r}\$ 1,174,650 \\
522.719\end{array}$ & $\begin{array}{r}\$ 671,297 \\
298,727\end{array}$ & $\begin{array}{r}\$ 1,024,712 \\
455,997\end{array}$ & $\begin{array}{r}\$ 125,354 \\
55,783\end{array}$ \\
\hline 0 & 0 & 0 & 0 & 0 & 0 \\
\hline 171,310 & 171,310 & 0 & 0 & 0 & 0 \\
\hline 0 & 0 & 0 & 0 & 0 & 0 \\
\hline 94,860 & 0 & 60,195 & 12,651 & 22,014 & 0 \\
\hline 98,956 & 0 & 62,972 & 13,494 & 22,490 & 0 \\
\hline $2,808,264$ & $2,808,264$ & 0 & 0 & 0 & 0 \\
\hline$\$ 10,182,168$ & $\$ 5,65 \dot{9}, 113$ & $\$ 1,820,536$ & $\$ 996,169$ & $\$ 1,525,213$ & $\$ 181,137$ \\
\hline 0 & 0 & 0 & 0 & 0 & 0 \\
\hline $4,972,832$ & $2,520,897$ & 945,890 & 554,933 & 845,877 & 105,235 \\
\hline$\$ 15,155,000$ & $\$ 8,180,010$ & $\$ 2,766,426$ & $\$ 1,551,102$ & $\$ 2,371,090$ & $\$ 286,372$ \\
\hline 845,000 & 230,000 & 190,000 & 125,000 & 300,000 & 0 \\
\hline
\end{tabular}

TOTAL ESTIMATED COSTS

\begin{tabular}{llllll}
$\$ 16,000,000$ & $\$ 8,410,010$ & $\$ 2,956,426$ & $\$ 1,676,102$ & $\$ 2,671,090$ & $\$ 286,372$ \\
\hline
\end{tabular}


" A Composite Overhead Rate of $44.50 \%$ (See "EB and OH Rates" Page attached to the Budget) is applled to the Modified Total Direct $C$ (MTDC) Base which is comprised of Total Direct Costs less the following items, some of which are included in the M\&S Amount above and itemized on attached pages.

Administrative Support
EB on Administrative Support
Allocated Expense
RA Tuition
Equipment Rental
Subcontracts $>\$ 25 \mathrm{~K}$
Cambridge Electric, Airco (BOC)
Fabrications/Upgrades

TOTAL EXCL. FROM MTDC BASE :

\begin{tabular}{rrrrrr}
$\$ 468,769$ & $\$ 249,413$ & $\$ 86,003$ & $\$ 49,150$ & $\$ 75,025$ & $\$ 9,178$ \\
208,602 & 110,989 & 38,271 & 21,872 & 33,386 & 4,084 \\
160,213 & 85,243 & 29,393 & 16,798 & 25,642 & 3,137 \\
98,956 & 0 & 62,972 & 13,494 & 22,490 & 0 \\
37,170 & 37,170 & 0 & 0 & 0 & 0 \\
210,000 & 210,000 & 0 & 0 & 0 & 0 \\
420,000 & 420,000 & 0 & 0 & 0 & 0 \\
600,000 & 600,000 & 0 & 0 & 0 & 0 \\
\hline & & & & & \\
$\$ 2,203,710$ & $\$ 1,712,815$ & $\$ 216,639$ & $\$ 101,314$ & $\$ 156,543$ & $\$ 16,399$ \\
\hline
\end{tabular}


DOE PRIME CONTRACT \# DE-AC02-78ET-51013 : B\&R \# AT-10-10-14F

TASK 01 : ALCATOR CMOD : FY98 GROUP BREAKDOWN

October 01, 1997 - September 30, 1998

Fiscal Year 1998 Budget at $\$ 16 \mathrm{M}$

SUMMARY OF MAN-YEARS

\begin{tabular}{rrrrrr} 
TOTAL & Operations & Experiment & AF & Plasma & Division \\
FY 98 & FY 98 & FY 98 & FY 98 & FY 98 & FY 98 \\
\hline
\end{tabular}

SCIENTIFIC

FACULTY

OTHER ACADEMIC STAFF

SCIENTIFIC RESEARCH STAFF

RESEARCH ASSISTANTS

\begin{tabular}{rrrrrr}
0.74 & 0.00 & 0.00 & 0.35 & 0.00 & 0.39 \\
1.36 & 0.00 & 0.90 & 0.00 & 0.36 & 0.10 \\
18.40 & 1.15 & 8.89 & 3.50 & 4.66 & 0.20 \\
22.00 & 0.00 & 14.00 & 3.00 & 5.00 & 0.00 \\
\hline & & & & & \\
42.50 & 1.15 & 23.79 & 6.85 & 10.02 & 0.69 \\
\hline
\end{tabular}

\section{SUBTOTAL SCIENTIFIC}

TECHNICAL \& ENGINEERING

COMPUTERSTAFF

ENGINEERING RESEARCH STAFF

TECHNICIANS

DRAFTERS

SUBTOTAL ENGINEERING \& TECH.

OTHER SUPPORT

ADMINISTRATIVE STAFF

PROUECT SUPPORT STAFF

PFC COMP SUPPORT

ADMINISTRATIVE SUPPORT

SUBTOTAL OTHER

\begin{tabular}{rrrrrr}
4.00 & & & & & \\
18.35 & 10.65 & 0.00 & 0.00 & 4.00 & 0.00 \\
26.95 & 16.60 & 1.05 & 4.10 & 2.45 & 0.10 \\
2.00 & 1.30 & 0.80 & 2.95 & 2.60 & 0.00 \\
& & 0.40 & 0.30 & 0.00 & 0.00 \\
\hline 51.30 & 28.55 & 6.25 & 7.35 & 9.05 & 0.10 \\
\hline
\end{tabular}

TOTAL MAN-YEARS

\begin{tabular}{rrrrrr}
0.80 & 0.00 & 0.00 & 0.00 & 0.00 & 0.80 \\
1.00 & 1.00 & 0.00 & 0.00 & 0.00 & 0.00 \\
0.15 & 0.00 & 0.00 & 0.00 & 0.15 & 0.00 \\
11.11 & 5.91 & 2.04 & 1.16 & 1.78 & 0.22 \\
\hline & & & & & \\
13.06 & 6.91 & 2.04 & 1.16 & 1.93 & 1.02 \\
\hline & & & & & \\
106.86 & 36.61 & 32.08 & 15.36 & 21.00 & 1.81 \\
\hline \hline
\end{tabular}


DOE PRIME CONTRACT \# DE-AC02-78ET-51013 : B\&R \# AT-10-10-14F

DETAIL OF MAN-YEARS

\begin{tabular}{|c|c|c|c|c|c|c|}
\hline & $\begin{array}{r}\text { TOTAL } \\
\text { FY } 98 \\
\end{array}$ & $\begin{array}{r}\text { Operations } \\
\text { FY } 98 \\
\end{array}$ & $\begin{array}{r}\text { Experiment } \\
\text { FY } 98 \\
\end{array}$ & $\begin{array}{c}\text { RF } \\
\text { FY } 98 \\
\end{array}$ & $\begin{array}{r}\text { Plasma } \\
\text { FY } 98 \\
\end{array}$ & $\begin{array}{r}\text { Division } \\
\text { FY } 98 \\
\end{array}$ \\
\hline \multicolumn{7}{|l|}{ FACULTY } \\
\hline 1. Hutchinson & $39 \%$ & $0 \%$ & $0 \%$ & $0 \%$ & $0 \%$ & $39 \%$ \\
\hline M. Porkolab (N/C eff. 2/1) & $35 \%$ & $0 \%$ & $0 \%$ & $35 \%$ & $0 \%$ & $0 \%$ \\
\hline A. Bers & $0 \%$ & $0 \%$ & $0 \%$ & $0 \%$ & $0 \%$ & $0 \%$ \\
\hline TOTAL FACULTY & 0.74 & 0.00 & 0.00 & 0.35 & 0.00 & 0.39 \\
\hline \multicolumn{7}{|c|}{ RESEARCH STAFF - OTHER ACADEMIC } \\
\hline E. Marmar & $100 \%$ & $0 \%$ & $90 \%$ & $0 \%$ & $0 \%$ & $10 \%$ \\
\hline J. Kesner & $36 \%$ & $0 \%$ & $0 \%$ & $0 \%$ & $36 \%$ & $0 \%$ \\
\hline D. Sigmar & $0 \%$ & $0 \%$ & $0 \%$ & $0 \%$ & $0 \%$ & $0 \%$ \\
\hline \multicolumn{7}{|l|}{ SCIENTIFIC RESEARCH STAFF } \\
\hline R. Boivin & $100 \%$ & $0 \%$ & $100 \%$ & $0 \%$ & $0 \%$ & $0 \%$ \\
\hline P. Bonoli & $100 \%$ & $0 \%$ & $0 \%$ & $100 \%$ & $0 \%$ & $0 \%$ \\
\hline C. Fiore & $50 \%$ & $25 \%$ & $25 \%$ & $0 \%$ & $0 \%$ & $0 \%$ \\
\hline J. Goetz & $100 \%$ & $0 \%$ & $64 \%$ & $0 \%$ & $36 \%$ & $0 \%$ \\
\hline S. Golovato & $0 \%$ & $0 \%$ & $0 \%$ & $0 \%$ & $0 \%$ & $0 \%$ \\
\hline R. Granetz & $100 \%$ & $0 \%$ & $0 \%$ & $0 \%$ & $100 \%$ & $0 \%$ \\
\hline M. Greenwald & $90 \%$ & $0 \%$ & $0 \%$ & $0 \%$ & $90 \%$ & $0 \%$ \\
\hline S. Horne & $0 \%$ & $0 \%$ & $0 \%$ & $0 \%$ & $0 \%$ & $0 \%$ \\
\hline A. Hubbard & $100 \%$ & $0 \%$ & $0 \%$ & $50 \%$ & $50 \%$ & $0 \%$ \\
\hline J. Irby & $100 \%$ & $90 \%$ & $0 \%$ & $0 \%$ & $0 \%$ & $10 \%$ \\
\hline B. LaBombard & $100 \%$ & $0 \%$ & $100 \%$ & $0 \%$ & $0 \%$ & $0 \%$ \\
\hline P. Linsay & $0 \%$ & $0 \%$ & $0 \%$ & $0 \%$ & $0 \%$ & $0 \%$ \\
\hline B. Lipschultz & $100 \%$ & $0 \%$ & $100 \%$ & $0 \%$ & $0 \%$ & $0 \%$ \\
\hline G. McCracken & $0 \%$ & $0 \%$ & $0 \%$ & $0 \%$ & $0 \%$ & $0 \%$ \\
\hline A. Ram & $0 \%$ & $0 \%$ & $0 \%$ & $0 \%$ & $0 \%$ & $0 \%$ \\
\hline J. Rice & $100 \%$ & - $0 \%$ & $100 \%$ & $0 \%$ & $0 \%$ & $0 \%$ \\
\hline J. Snipes & $100 \%$ & $0 \%$ & $100 \%$ & $0 \%$ & $0 \%$ & $0 \%$ \\
\hline Y. Takase & $100 \%$ & $0 \%$ & $0 \%$ & $100 \%$ & $0 \%$ & $0 \%$ \\
\hline J. Terry & $100 \%$ & $0 \%$ & $100 \%$ & $0 \%$ & $0 \%$ & $0 \%$ \\
\hline R. Watterson & $0 \%$ & $0 \%$ & $0 \%$ & $0 \%$ & $0 \%$ & $0 \%$ \\
\hline S. Wolfe & $100 \%$ & $0 \%$ & $0 \%$ & $0 \%$ & $90 \%$ & $10 \%$ \\
\hline Divertor & $100 \%$ & $0 \%$ & $100 \%$ & $0 \%$ & $0 \%$ & $0 \%$ \\
\hline Thomson Scattering & $100 \%$ & $0 \%$ & $0 \%$ & $0 \%$ & $100 \%$ & $0 \%$ \\
\hline MSE & $100 \%$ & $0 \%$ & $100 \%$ & $0 \%$ & $0 \%$ & $0 \%$ \\
\hline$\mp$ & $100 \%$ & $0 \%$ & $0 \%$ & $100 \%$ & $0 \%$ & $0 \%$ \\
\hline TOTAL SCIENTIFIC RES. STAFF & 19.76 & 1.15 & 9.79 & 3.50 & 5.02 & 0.30 \\
\hline
\end{tabular}


DOE PRIME CONTRACT \# DE-AC02-78ET-51013 : B\&R \# AT-10-10-14F

DETAIL OF MAN-YEARS

ENGINEERS

S. Andreyev

W. Beck

V. Bertolino

J. Bosco

W. Burke

W. Byford

E. Byrne

R. Childs

J. Daigle

S. Fairfax

E. Fitzgerald

M. Fridberg

D. Gwinn

A. Helander

I. Mastovsky

J. Paranay

C. Park

W. Parkin

N. Pierce

R. Pillsbury

C. Reddy

J. Rosati

F. Sabelli

F. Silva

F. Tambini

E. Thibeault

$X$. Zhong

New - RF

New - Cryo

TOTAL ENGINEERS

\section{COMPUTER STAFF}

$H$. Bergler

T. Fredian

F. Kreisel

D. Nelson

J. Stillerman

New

TOTAL COMPUTER STAFF

\begin{tabular}{|c|c|c|c|c|c|}
\hline $\begin{array}{r}\text { TOTAL } \\
\text { FY } 98 \\
\end{array}$ & $\begin{array}{r}\text { Operations } \\
\text { FY } 98 \\
\end{array}$ & $\begin{array}{r}\text { Experiment } \\
\text { FY } 98 \\
\end{array}$ & $\begin{array}{l}\text { RF } \\
\text { FY } 98 \\
\end{array}$ & $\begin{array}{r}\text { Plasma } \\
\text { FY } 98 \\
\end{array}$ & $\begin{array}{r}\text { Division } \\
\text { FY } 98 \\
\end{array}$ \\
\hline $0 \%$ & $0 \%$ & $0 \%$ & $0 \%$ & $0 \%$ & $0 \%$ \\
\hline $100 \%$ & $20 \%$ & $0 \%$ & $80 \%$ & $0 \%$ & $0 \%$ \\
\hline $100 \%$ & $100 \%$ & $0 \%$ & $0 \%$ & $0 \%$ & $0 \%$ \\
\hline $100 \%$ & $15 \%$ & $0 \%$ & $0 \%$ & $85 \%$ & $0 \%$ \\
\hline $100 \%$ & $100 \%$ & $0 \%$ & $0 \%$ & $0 \%$ & $0 \%$ \\
\hline $50 \%$ & $50 \%$ & $0 \%$ & $0 \%$ & $0 \%$ & $0 \%$ \\
\hline $0 \%$ & $0 \%$ & $0 \%$ & $0 \%$ & $0 \%$ & $0 \%$ \\
\hline $100 \%$ & $70 \%$ & $20 \%$ & $10 \%$ & $0 \%$ & $0 \%$ \\
\hline $100 \%$ & $60 \%$ & $0 \%$ & $20 \%$ & $20 \%$ & $0 \%$ \\
\hline $0 \%$ & $0 \%$ & $0 \%$ & $0 \%$ & $0 \%$ & $0 \%$ \\
\hline $90 \%$ & $80 \%$ & $0 \%$ & $10 \%$ & $0 \%$ & $0 \%$ \\
\hline $100 \%$ & $20 \%$ & $0 \%$ & $80 \%$ & $0 \%$ & $0 \%$ \\
\hline $100 \%$ & $90 \%$ & $0 \%$ & $0 \%$ & $0 \%$ & $10 \%$ \\
\hline $0 \%$ & $0 \%$ & $0 \%$ & $0 \%$ & $0 \%$ & $0 \%$ \\
\hline $100 \%$ & $0 \%$ & $0 \%$ & $100 \%$ & $0 \%$ & $0 \%$ \\
\hline $0 \%$ & $0 \%$ & $0 \%$ & $0 \%$ & $0 \%$ & $0 \%$ \\
\hline $0 \%$ & $0 \%$ & $0 \%$ & $0 \%$ & $0 \%$ & $0 \%$ \\
\hline $100 \%$ & $50 \%$ & $20 \%$ & $10 \%$ & $20 \%$ & $0 \%$ \\
\hline $0 \%$ & $0 \%$ & $0 \%$ & $0 \%$ & $0 \%$ & $0 \%$ \\
\hline $0 \%$ & $0 \%$ & $0 \%$ & $0 \%$ & $0 \%$ & $0 \%$ \\
\hline $100 \%$ & $0 \%$ & $0 \%$ & $0 \%$ & $100 \%$ & $0 \%$ \\
\hline $100 \%$ & $100 \%$ & $0 \%$ & $0 \%$ & $0 \%$ & $0 \%$ \\
\hline $0 \%$ & $0 \%$ & $0 \%$ & $0 \%$ & $0 \%$ & $0 \%$ \\
\hline $100 \%$ & $100 \%$ & $0 \%$ & $0 \%$ & $0 \%$ & $0 \%$ \\
\hline $95 \%$ & $50 \%$ & $45 \%$ & $0 \%$ & $0 \%$ & $0 \%$ \\
\hline $100 \%$ & $60 \%$ & $20 \%$ & $0 \%$ & $20 \%$ & $0 \%$ \\
\hline $0 \%$ & $0 \%$ & $0 \%$ & $0 \%$ & $0 \%$ & $0 \%$ \\
\hline $100 \%$ & $0 \%$ & $0 \%$ & $100 \%$ & $0 \%$ & $0 \%$ \\
\hline $100 \%$ & $100 \%$ & $0 \%$ & $0 \%$ & $0 \%$ & $0 \%$ \\
\hline 18.35 & 10.65 & 1.05 & 4.10 & 2.45 & 0.10 \\
\hline
\end{tabular}

\begin{tabular}{rrrrrr}
$50 \%$ & $0 \%$ & $0 \%$ & $0 \%$ & $50 \%$ & $0 \%$ \\
$100 \%$ & $0 \%$ & $0 \%$ & $0 \%$ & $100 \%$ & $0 \%$ \\
$100 \%$ & $0 \%$ & $0 \%$ & $0 \%$ & $100 \%$ & $0 \%$ \\
$50 \%$ & $0 \%$ & $0 \%$ & $0 \%$ & $50 \%$ & $0 \%$ \\
$100 \%$ & $0 \%$ & $0 \%$ & $0 \%$ & $100 \%$ & $0 \%$ \\
\hline $0 \%$ & $0 \%$ & $0 \%$ & $0 \%$ & $0 \%$ & $0 \%$ \\
\hline 4.00 & 0.00 & 0.00 & 0.00 & 4.00 & 0.00 \\
\hline
\end{tabular}


DOE PRIME CONTRACT \# DE-AC02-78ET-51013 : B\&R \# AT-10-10-14F DETAIL OFMAN-YEARS

\begin{tabular}{|c|c|c|c|c|c|}
\hline $\begin{array}{r}\text { TOTAL } \\
\text { FY } 98 \\
\end{array}$ & $\begin{array}{r}\text { Operatlons } \\
\text { FY } 98 \\
\end{array}$ & $\begin{array}{r}\text { Experiment } \\
\text { FY } 98 \\
\end{array}$ & $\begin{array}{c}\text { RF } \\
\text { FY } 98 \\
\end{array}$ & $\begin{array}{r}\text { Plasma } \\
\text { FY } 98 \\
\end{array}$ & $\begin{array}{r}\text { Division } \\
\text { FY } 98 \\
\end{array}$ \\
\hline $100 \%$ & $100 \%$ & $0 \%$ & $0 \%$ & $0 \%$ & $0 \%$ \\
\hline $100 \%$ & $100 \%$ & $0 \%$ & $0 \%$ & $0 \%$ & $0 \%$ \\
\hline $100 \%$ & $50 \%$ & $0 \%$ & $20 \%$ & $30 \%$ & $0 \%$ \\
\hline $100 \%$ & $0 \%$ & $50 \%$ & $0 \%$ & $50 \%$ & $0 \%$ \\
\hline $100 \%$ & $100 \%$ & $0 \%$ & $0 \%$ & $0 \%$ & $0 \%$ \\
\hline $100 \%$ & $20 \%$ & $15 \%$ & $0 \%$ & $65 \%$ & $0 \%$ \\
\hline $100 \%$ & $100 \%$ & $0 \%$ & $0 \%$ & $0 \%$ & $0 \%$ \\
\hline $100 \%$ & $20 \%$ & $45 \%$ & $0 \%$ & $35 \%$ & $0 \%$ \\
\hline $100 \%$ & $100 \%$ & $0 \%$ & $0 \%$ & $0 \%$ & $0 \%$ \\
\hline $0 \%$ & $0 \%$ & $0 \%$ & $0 \%$ & $0 \%$ & $0 \%$ \\
\hline $0 \%$ & $0 \%$ & $0 \%$ & $0 \%$ & $0 \%$ & $0 \%$ \\
\hline $100 \%$ & $0 \%$ & $50 \%$ & $50 \%$ & $0 \%$ & $0 \%$ \\
\hline $100 \%$ & $60 \%$ & $0 \%$ & $40 \%$ & $0 \%$ & $0 \%$ \\
\hline $100 \%$ & $100 \%$ & $0 \%$ & $0 \%$ & $0 \%$ & $0 \%$ \\
\hline $100 \%$ & $0 \%$ & $0 \%$ & $100 \%$ & $0 \%$ & $0 \%$ \\
\hline $100 \%$ & $25 \%$ & $50 \%$ & $25 \%$ & $0 \%$ & $0 \%$ \\
\hline $100 \%$ & $50 \%$ & $0 \%$ & $0 \%$ & $50 \%$ & $0 \%$ \\
\hline $100 \%$ & $100 \%$ & $0 \%$ & $0 \%$ & $0 \%$ & $0 \%$ \\
\hline $0 \%$ & $0 \%$ & $0 \%$ & $0 \%$ & $0 \%$ & $0 \%$ \\
\hline $100 \%$ & $20 \%$ & $80 \%$ & $0 \%$ & $0 \%$ & $0 \%$ \\
\hline $100 \%$ & $80 \%$ & $0 \%$ & $20 \%$ & $0 \%$ & $0 \%$ \\
\hline $100 \%$ & $40 \%$ & $60 \%$ & $0 \%$ & $0 \%$ & $0 \%$ \\
\hline $0 \%$ & $0 \%$ & $0 \%$ & $0 \%$ & $0 \%$ & $0 \%$ \\
\hline $100 \%$ & $50 \%$ & $50 \%$ & $0 \%$ & $0 \%$ & $0 \%$ \\
\hline $100 \%$ & $50 \%$ & $50 \%$ & $0 \%$ & $0 \%$ & $0 \%$ \\
\hline $100 \%$ & $60 \%$ & $0 \%$ & $40 \%$ & $0 \%$ & $0 \%$ \\
\hline $100 \%$ & $40 \%$ & $30 \%$ & $0 \%$ & $30 \%$ & $0 \%$ \\
\hline $50 \%$ & $50 \%$ & $0 \%$ & $0 \%$ & $0 \%$ & $0 \%$ \\
\hline $0 \%$ & $0 \%$ & $0 \%$ & $0 \%$ & $0 \%$ & $0 \%$ \\
\hline $345 \%$ & $345 \%$ & $0 \%$ & $0 \%$ & $0 \%$ & $0 \%$ \\
\hline 26.95 & 16.60 & 4.80 & 2.95 & 2.60 & 0.00 \\
\hline
\end{tabular}

\section{DRAFTERS \\ A. DiCiaccio \\ M. Keniston \\ S. Kochan \\ New \\ TOTAL DRAFTERS}

\begin{tabular}{rrrrrr}
$100 \%$ & $70 \%$ & $0 \%$ & $30 \%$ & $0 \%$ & $0 \%$ \\
$0 \%$ & $0 \%$ & $0 \%$ & $0 \%$ & $0 \%$ & $0 \%$ \\
$100 \%$ & $60 \%$ & $40 \%$ & $0 \%$ & $0 \%$ & $0 \%$ \\
\hline $0 \%$ & $0 \%$ & $0 \%$ & $0 \%$ & $0 \%$ & $0 \%$ \\
\hline 2.00 & 1.30 & 0.40 & 0.30 & 0.00 & 0.00 \\
\hline
\end{tabular}


DOE PRIME CONTRACT \# DE-AC02-78ET-51013 : B\&R \# AT-10-10-14F DETAIL OFMAN-YEARS

\begin{tabular}{rrrrrr} 
TOTAL & Operations & Experiment & RF & Plasma & Division \\
FY 98 & FY 98 & FY 98 & FY 98 & FY 98 & FY 98 \\
\hline
\end{tabular}

\section{ADMINISTRATIVE STAFF \\ V. Censabella \\ New}

TOTAL ADMINISTRATIVE STAFF

SUPPORT STAFF

Now

K. Johnson

C. Arlington

TOTAL SUPPORT

PFC COMPUTER SUPPORT

M. Greenwald

M. London

TOTAL PFC COMPUTER SUPPORT

\begin{tabular}{|c|c|c|c|c|c|}
\hline $80 \%$ & $0 \%$ & $0 \%$ & $0 \%$ & $0 \%$ & $80 \%$ \\
\hline $0 \%$ & $0 \%$ & $0 \%$ & $0 \%$ & $0 \%$ & $0 \%$ \\
\hline 0.80 & 0.00 & 0.00 & 0.00 & 0.00 & 0.80 \\
\hline $0 \%$ & $0 \%$ & $0 \%$ & $0 \%$ & $0 \%$ & $0 \%$ \\
\hline $100 \%$ & $100 \%$ & $0 \%$ & $0 \%$ & $0 \%$ & $0 \%$ \\
\hline $0 \%$ & $0 \%$ & $0 \%$ & $0 \%$ & $0 \%$ & $0 \%$ \\
\hline 1.00 & 1.00 & 0.00 & 0.00 & 0.00 & 0.00 \\
\hline $5 \%$ & $0 \%$ & $0 \%$ & $0 \%$ & $5 \%$ & $0 \%$ \\
\hline $10 \%$ & $0 \%$ & $0 \%$ & $0 \%$ & $10 \%$ & $0 \%$ \\
\hline 0.15 & 0.00 & 0.00 & 0.00 & 0.15 & 0.00 \\
\hline
\end{tabular}


DOE PRIME CONTRACT \# DE-AC02-78ET-51013 : B\&R \# AT-10-10-14F DETAIL OFMAN-YEARS

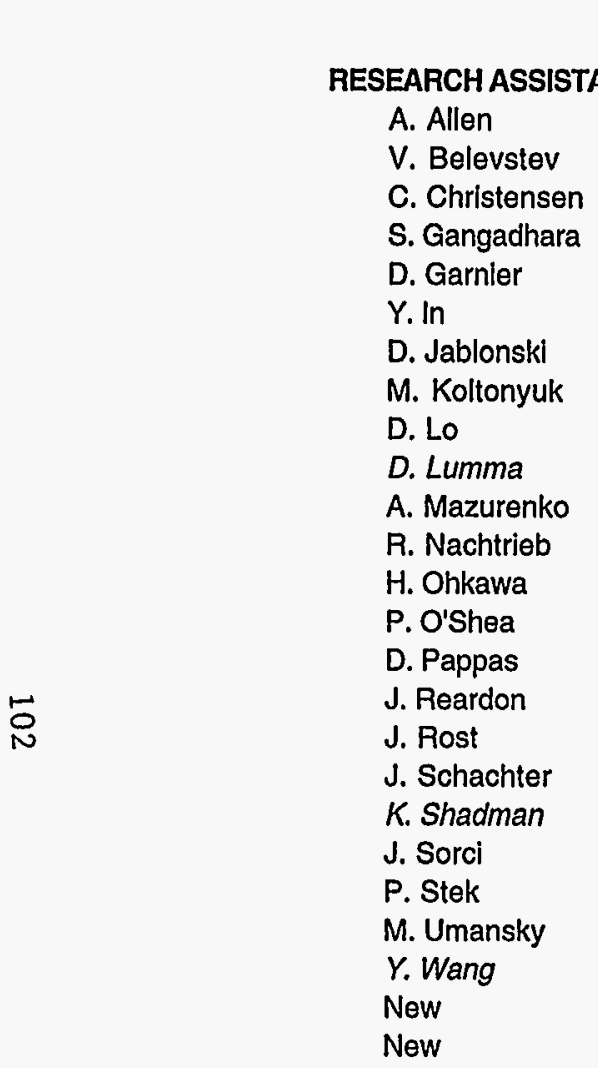

TOTAL RESEARCH ASSISTANTS

ADMINISTRATIVE LAB SUPPORT Various

TOTAL MAN-YEARS

\begin{tabular}{rrrrrr} 
TOTAL & Operations & Experiment & RF & Plasma & Divislon \\
FY 98 & FY 98 & FY 98 & FY 98 & FY 98 & FY 98 \\
\hline
\end{tabular}

\begin{tabular}{rrrrrr} 
& & & & \\
$100 \%$ & $0 \%$ & $100 \%$ & $0 \%$ & $0 \%$ & $0 \%$ \\
$100 \%$ & $0 \%$ & $100 \%$ & $0 \%$ & $0 \%$ & $0 \%$ \\
$100 \%$ & $0 \%$ & $100 \%$ & $0 \%$ & $0 \%$ & $0 \%$ \\
$100 \%$ & $0 \%$ & $100 \%$ & $0 \%$ & $0 \%$ & $0 \%$ \\
$100 \%$ & $0 \%$ & $100 \%$ & $0 \%$ & $0 \%$ & $0 \%$ \\
$100 \%$ & $0 \%$ & $100 \%$ & $0 \%$ & $0 \%$ & $0 \%$ \\
$100 \%$ & $0 \%$ & $100 \%$ & $0 \%$ & $0 \%$ & $0 \%$ \\
$100 \%$ & $0 \%$ & $100 \%$ & $0 \%$ & $0 \%$ & $0 \%$ \\
$100 \%$ & $0 \%$ & $100 \%$ & $0 \%$ & $0 \%$ & $0 \%$ \\
$0 \%$ & $0 \%$ & $0 \%$ & $0 \%$ & $0 \%$ & $0 \%$ \\
$100 \%$ & $0 \%$ & $0 \%$ & $100 \%$ & $0 \%$ & $0 \%$ \\
$100 \%$ & $0 \%$ & $100 \%$ & $0 \%$ & $0 \%$ & $0 \%$ \\
$100 \%$ & $0 \%$ & $100 \%$ & $0 \%$ & $0 \%$ & $0 \%$ \\
$100 \%$ & $0 \%$ & $0 \%$ & $0 \%$ & $100 \%$ & $0 \%$ \\
$100 \%$ & $0 \%$ & $100 \%$ & $0 \%$ & $0 \%$ & $0 \%$ \\
$100 \%$ & $0 \%$ & $0 \%$ & $100 \%$ & $0 \%$ & $0 \%$ \\
$100 \%$ & $0 \%$ & $0 \%$ & $100 \%$ & $0 \%$ & $0 \%$ \\
$100 \%$ & $0 \%$ & $0 \%$ & $0 \%$ & $100 \%$ & $0 \%$ \\
$0 \%$ & $0 \%$ & $0 \%$ & $0 \%$ & $0 \%$ & $0 \%$ \\
$100 \%$ & $0 \%$ & $0 \%$ & $0 \%$ & $100 \%$ & $0 \%$ \\
$100 \%$ & $0 \%$ & $100 \%$ & $0 \%$ & $0 \%$ & $0 \%$ \\
$100 \%$ & $0 \%$ & $0 \%$ & $0 \%$ & $100 \%$ & $0 \%$ \\
$0 \%$ & $0 \%$ & $0 \%$ & $0 \%$ & $0 \%$ & $0 \%$ \\
\hline $100 \%$ & $0 \%$ & $0 \%$ & $0 \%$ & $100 \%$ & $0 \%$ \\
$100 \%$ & $0 \%$ & $100 \%$ & $0 \%$ & $0 \%$ & $0 \%$ \\
\hline 22.00 & 0.00 & 14.00 & 3.00 & 5.00 & 0.00 \\
\hline
\end{tabular}

$\begin{array}{rrrrrr}11.11 & 5.91 & & & & \\ & & & & \\ \end{array}$

\begin{tabular}{lllllll}
106.86 & 36.61 & 32.08 & 15.36 & 21.00 & 1.81 \\
\hline \hline
\end{tabular}


"RA effort (man-years) reflects the entire year. However, salary is for the period 1 January - 30 June; effective 1 July, RA stipends and tuition are included in operating expenses and shown below:

\section{DETAIL OF RESEARCH ASSISTANT COSTS}

For the 6 Months Subsequent to July 1, 1998

Prior to July 1,1998 the tuition of graduate research assistants was charged to the employee benefits pool. At the request of the federa government, effective July 1, 1998 RA tuition will be charged direclly to the research project on which the RA works. The following assumptions were used in calculating the anticipated changes to the budget:

No EB on RA Stipends. Stipends will be subject to $\mathrm{OH}$.

No $\mathrm{OH}$ on Tuition.

$55 \%$ of RA tuition will be charged to the research accounts; MIT will subsidize the remaining $45 \%$.

EB drops 8 points.

RA Summer appointments span the period June-August. Therefore, June RA salary is shown in the salary portion of the budget, while the stipends and tuition for July forward are reflected in the figures below. However, for clarity, RA effort (man-years) for the full year is recorded above.

\begin{tabular}{rrrrrr}
$\begin{array}{r}\text { FY 98 } \\
\text { TOTAL }\end{array}$ & $\begin{array}{r}\text { FY 98 } \\
\text { Operations }\end{array}$ & $\begin{array}{r}\text { FY 98 } \\
\text { Experiment }\end{array}$ & $\begin{array}{c}\text { FY 98 } \\
\text { RF }\end{array}$ & $\begin{array}{r}\text { FY 98 } \\
\text { Plasma }\end{array}$ & $\begin{array}{r}\text { FY 98 } \\
\text { Divlsion }\end{array}$ \\
\hline 94,860 & 0 & 60,195 & 12,651 & 22,014 & 0 \\
& 0 & & & & \\
98,956 & 0 & 62,972 & 13,494 & 22,490 & 0 \\
\hline 193,816 & 0 & 123,167 & 26,145 & 44,504 & 0 \\
\hline
\end{tabular}

\author{
TUITION \\ No overhead \\ TOTAL RA COSTS
}


DOE PRIME CONTRACT \# DE-AC02-78ET-51013 : B\&R \# AT-10-10-14F

TASK 01 : ALCATOR CMOD : FY98 GROUP BREAKDOWN

October 01, 1997 - Seplember 30, 1998

Fiscal Year 1998 Budget at $\$ 16 M$

DETAIL OF MATERIALS \& SERVICES

Telephones

Catalogues, Journals, Books, etc.

Publications

Graphic Arts

Xerox Expense

Equipment Rental (no $\mathrm{OH}$ )

Office \& Drafting Supplies

Postage \& Shipping

Comp. Hardware Maintenance

Computer Software

Computer Supplies

PFC Computer Contribution

AlRCO ; LN2 (No Overhead)

Camb. Electric (No Overhead)

Industrial Subcontracts

Alternator Maintenance

Gases

Radiology \& Safety

Machinists

Cryogenic Materials

Electrical/Electronic Components

Mechanical Components

TOTAL

FY 98

0.00

Optical Components

Vacuum Components

Raw Materials

30,820

2,630

13,860

1,790

11,550

37,170

26,720

11,970

46,760

58,890

27,430

24,420

315,000

105,000

210,000

(assemblies

0
41,810

59,490

34,650

17,200

304,510

210,260

40,350

101,180

38,210

163,160

Tools

7,940

Materials \& Services

180,251

Allocated Expense

160,213 
DOE PRIME CONTRACT \# DE-AC02-78ET-51013 : B\&R \# AT-10-10-14F

TASK 01 : ALCATOR CMOD : FY98 GROUP BREAKDOWN

October 01, 1997 - September 30, 1998

Fiscal Year 1998 Budget at $\$ 16 M$

DETAIL OF MATERIALS \& SERVICES

TOTAL

FY 98

SUBSYSTEM FABS/UPGRADES (NO OH)

$X$-ray Tomography System Fab

Magnetic Diagnostics Fab

First-Wall Upgrade

LHH/LHCD Fab

LH Antenna Fab

LH Instrumentation \& Control Fab

ICRF Tunable Transmitter Fab

Edge Thomson Scattering

EFC Magnet Power Supply Upgrade

Control System Upgrade

Cryopump Fab

Divertor Upgrade

ICAF Antenna

ICRF Matching System

ICRF Transmilter Upgrade

ICRF Instrumentation \& Control

LH Transmission Line Fab

ICRF Diagnostics

0

000

200,000

0

20,000

0

0

TOTAL ESTIMATED M\&S 
DOE PRIME CONTAACT \# DE-AC02-78ET-51013 : B\&R \# AT-10-10-14F

TASK 01 : ALCATOR CMOD : FY98 GROUP BREAKDOWN

October 01, 1997 - September 30, 1998

Fiscal Year 1998 Budget at \$16M

DETAIL OF ESTIMATED TRAVEL NEEDS

TOTAL

FY 98

A. DOMESTIC:

Washington D.C. (@ \$917)

13,482

Princeton, NJ (@ \$930)

Texas (@ \$1,446 ea)

Sherwood Theory (@\$1,934)

California (@ $\$ 1,626)$

New Mexico (@ \$1,427)

Tennessee (@ \$1,060)

RF/Diag Conference (@ \$1,707)

APS - Denver, Co (@ $\$ 1,500)$

IEEE (@ \$757)

Maryland (@ \$791)

Canada (@ \$1,700)

19,540

6,072

0

30,726

2,996

2,226

$$
0
$$

Japan
England
Germany
Russia
Switzerland
Netherlands (EC-10)
IAEA
EPS
France
Italy

40,550

B. FOREIGN:

Italy

11,340

5,460

7,404

0

2,552

0
7,875

7,875

14,700

2,940

TOTAL ESTIMATED TRAVEL COSTS : 
DOE PRIME CONTRACT \# DE-AC02-78ET-51013 : B\&R \# AT-10-10-14F DETAIL OF CAPITAL EQUIPMENT NEEDS

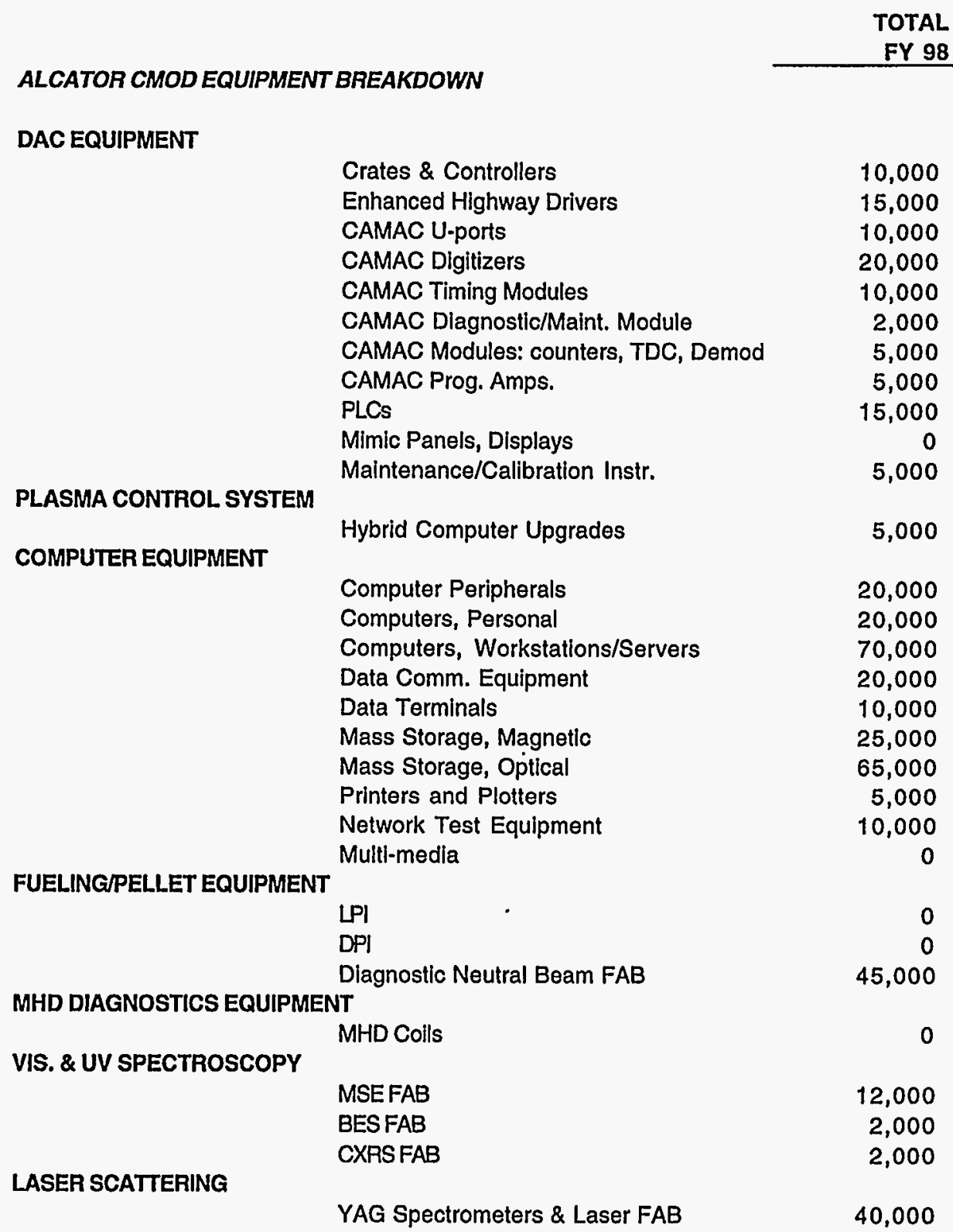


DOE PRIME CONTAACT \# DE-AC02-78ET-51013 : B\&R \# AT-10-10-14F DETAIL OF CAPITAL EQUIPMENT NEEDS

\section{ALCATOR CMOD EQUIPMENT BREAKDOWN (continued)}

Calibration Source

LASER SCATTERING

Core Thomson Scattering (first 6 spec)

Core Thomson Scattering (next 2 spec)

Core Thomson Scattering (final 3 spec)

Toroidal Imaging ( $F$ side)

Poloidal Imaging

ECE

Visible Bremss Fluctuations Fab

FY 98

INTERFEROMETRY

ECE Polychromator

TCIFAB

Reflectometry $\mathrm{FAB}$

Tangential Interferometer

X-RAY DIAGNOSTICS

\section{HIREXFAB}

Pulse Height Analysis FAB

BOLOMETRY

Bolometer Upgrade

Tangential XUV Bolometer Array FAB

Divertor Bolometer Arrays FAB NEUTRON DIAGNOSTICS

He3 Spectrometer FAB

Collimated Neutron Array FAB

NEUTRAL DIAGNOSTICS

Fast Neutrals

Single Channel Neutral Part

Time of Flight

FUSION PRODUCTS

Charged Fusion Part. Detector FAB

New Charged Fusion

Neutral Pressure Diag. FAB

Periscopes FAB

IR Thermometry FAB

Divertor Spectroscopy $F A B$

Divertor Impurity Spectroscopy FAB

Advanced Flush-Mount Probe FAB

X-Point MLM Spectrograph FAB Fast Scanning Probe FAB

40,000

Divertor Upgrade FAB 
DOE PRIME CONTRACT \# DE-AC02-78ET-51013 : B\&R \# AT-10-10-14F

DETAIL OF CAPITAL EQUIPMENT NEEDS

ALCATOR CMOD EQUIPMENT BREAKDOWN (continued)

TOTAL

FY 98

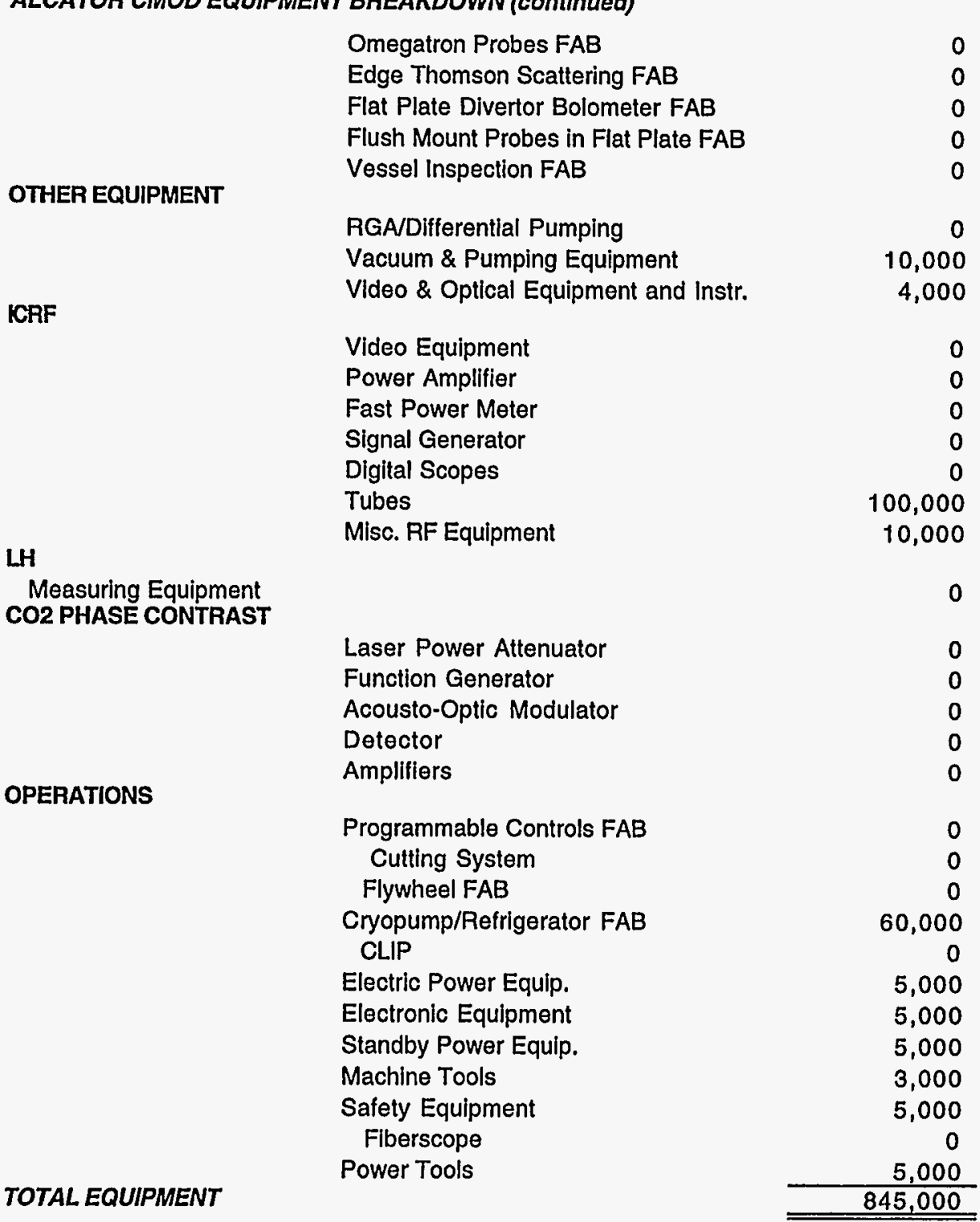


DOE PRIME CONTRACT \# DE-AC02-78ET-51013 : B\&R \# AT-10-10-14F

TASK 01: ALCATOR CMOD : FY97 GROUP BREAKDOWN

October 01, 1996 - September 30, 1997

Fiscal Year 1997 ALTERNATE BUDGET AT \$13M

SUMMARY OF COSTS

\begin{tabular}{|c|c|c|c|c|c|}
\hline $\begin{array}{l}\text { TOTAL } \\
\text { FY } 97\end{array}$ & $\begin{array}{l}\text { Operations } \\
\text { FY } 97\end{array}$ & $\begin{array}{l}\text { Experiment } \\
\text { FY } 97\end{array}$ & $\begin{array}{l}\text { RF } \\
\text { FY } 97\end{array}$ & $\begin{array}{l}\text { Plasma } \\
\text { FY } 97\end{array}$ & $\begin{array}{l}\text { Division } \\
\text { FY } 97\end{array}$ \\
\hline$\$ 1,276,828$ & $\$ 88,993$ & $\$ 540,726$ & $\$ 223,058$ & $\$ 354,072$ & $\$ 69,979$ \\
\hline 364,848 & 0 & 231,521 & 48,659 & 84,668 & 0 \\
\hline 249,347 & 0 & 0 & 0 & 249,347 & 0 \\
\hline 888,935 & 530,161 & 53,002 & 180,456 & 116,074 & 9,242 \\
\hline $\begin{array}{r}952,216 \\
83,013\end{array}$ & $\begin{array}{r}521,739 \\
53,621\end{array}$ & $\begin{array}{r}200,805 \\
17,952\end{array}$ & $\begin{array}{r}120,236 \\
11,440\end{array}$ & $\begin{array}{r}109,436 \\
0\end{array}$ & $\begin{array}{l}0 \\
0\end{array}$ \\
\hline 32,486 & 0 & 0 & 0 & 0 & 32,486 \\
\hline $\begin{array}{r}29,136 \\
9,966\end{array}$ & $\begin{array}{r}29,136 \\
0\end{array}$ & $\begin{array}{l}0 \\
0\end{array}$ & $\begin{array}{l}0 \\
0\end{array}$ & $\begin{array}{r}0 \\
9,966\end{array}$ & $\begin{array}{l}0 \\
0\end{array}$ \\
\hline 416,507 & 206,121 & 82,476 & 46,124 & 72,961 & 8,825 \\
\hline $\begin{array}{r}\$ 4,303,282 \\
2,001,026\end{array}$ & $\begin{array}{r}\$ 1,429,771 \\
664,844\end{array}$ & $\begin{array}{r}\$ 1,126,482 \\
523,814\end{array}$ & $\begin{array}{r}\$ 629,973 \\
292,937\end{array}$ & $\begin{array}{r}\$ 996,524 \\
463,384\end{array}$ & $\begin{array}{r}\$ 120,532 \\
56,047\end{array}$ \\
\hline 0 & 0 & 0 & 0 & 0 & 0 \\
\hline 141,086 & 141,086 & 0 & 0 & 0 & 0 \\
\hline 0 & 0 & 0 & 0 & 0 & 0 \\
\hline 0 & 0 & 0 & 0 & 0 & 0 \\
\hline 0 & 0 & 0 & 0 & 0 & 0 \\
\hline $2,202,139$ & $2,202,139$ & 0 & 0 & 0 & 0 \\
\hline$\$ 8,647,533$ & $\$ 4,437,840$ & $\$ 1,650,296$ & $\$ 922,910$ & $\$ 1,459,908$ & $\$ 176,579$ \\
\hline 0 & 0 & 0 & 0 & 0 & 0 \\
\hline $4,088,467$ & $1,876,888$ & 866,990 & 484,854 & 766,969 & 92,766 \\
\hline$\$ 12,736,000$ & $\$ 6,314,728$ & $\$ 2,517,286$ & $\$ 1,407,764$ & $\$ 2,226,877$ & $\$ 269,345$ \\
\hline 264,000 & 41,000 & 128,000 & 60,000 & 35,000 & 0 \\
\hline$\$ 13,000,000$ & $\$ 6,355,728$ & $\$ 2,645,286$ & $\$ 1,467,764$ & $\$ 2,261,877$ & $\$ 269,345$ \\
\hline
\end{tabular}


- A Composite Overhead Rate of $46.50 \%$ (See "EB and OH Rates" Page altached to the Budget) is applied to the Modifled Total Direct $C$ (MTDC) Base which is comprised of Total Direct Costs less the following items, some of which are included in the M\&S Amount above and itemized on attached pages.

Administrative Support

EB on Administrative Support

Allocated Expense

RA Tuition

Equipment Rental

Subcontracts $>\$ 25 \mathrm{~K}$

Cambridge Electric, Airco (BOC)

Fabrications/Upgrades

TOTAL EXCL. FROM MTDC BASE :

\begin{tabular}{rrrrrr}
$\$ 416,507$ & $\$ 206,121$ & $\$ 82,476$ & $\$ 46,124$ & $\$ 72,961$ & $\$ 8,825$ \\
193,676 & 95,846 & 38,351 & 21,448 & 33,927 & 4,104 \\
142,350 & 70,446 & 28,188 & 15,764 & 24,936 & 3,016 \\
0 & 0 & 0 & 0 & 0 & 0 \\
35,400 & 35,400 & 0 & 0 & 0 & 0 \\
200,000 & 200,000 & 0 & 0 & 0 & 0 \\
270,000 & 270,000 & 0 & 0 & 0 & 0 \\
310,000 & 310,000 & 0 & 0 & 0 & 0 \\
\hline
\end{tabular}


DOE PRIME CONTRACT \# DE-AC02-78ET-51013 : B\&R \# AT-10-10-14F

TASK 01 : ALCATOR CMOD : FY97 GROUP BREAKDOWN

October 01, 1996 - September 30, 1997

Fiscal Year 1997 ALTERNATE BUDGET AT \$13M SUMMARY OF MAN-YEARS

\begin{tabular}{rrrrrr} 
TOTAL & Operations & Experiment & RF & Plasma & Division \\
FY 97 & FY 97 & FY 97 & FY 97 & FY 97 & FY 97 \\
\hline
\end{tabular}

\section{SCIENTIFIC \\ FACULTY \\ OTHER ACADEMIC STAFF \\ SCIENTIFIC RESEARCH STAFF \\ RESEARCH ASSISTANTS
SUBTOTAL SCIENTIFIC
TECHNICAL \& ENGINEERING COMPUTERSTAFF
ENGINEERING RESEARCHSTAFF
TECHNICIANS
DRAFTERS

SUBTOTAL ENGINEERING \& TECH.

OTHER SUPPORT

ADMINISTRATIVE STAFF

PROJECT SUPPORT STAFF

PFCCOMP SUPPORT

ADMINISTRATIVE SUPPORT

\section{SUBTOTAL OTHER}

TOTAL MAN-YEARS

\begin{tabular}{rrrrrr}
0.74 & 0.00 & 0.00 & 0.35 & 0.00 & 0.39 \\
1.36 & 0.00 & 0.90 & 0.00 & 0.36 & 0.10 \\
17.40 & 1.15 & 7.89 & 3.50 & 4.66 & 0.20 \\
22.00 & 0.00 & 14.00 & 3.00 & 5.00 & 0.00 \\
\hline 41.50 & 1.15 & 22.79 & 6.85 & 10.02 & 0.69 \\
\hline
\end{tabular}

\begin{tabular}{rrrrrr}
4.00 & 0.00 & 0.00 & 0.00 & 4.00 & 0.00 \\
15.96 & 8.96 & 1.05 & 3.60 & 2.25 & 0.10 \\
23.50 & 13.15 & 4.80 & 2.95 & 2.60 & 0.00 \\
2.00 & 1.30 & 0.40 & 0.30 & 0.00 & 0.00 \\
\hline & & & & & \\
45.46 & 23.41 & 6.25 & 6.85 & 8.85 & 0.10 \\
\hline
\end{tabular}

\begin{tabular}{rrrrrr}
0.80 & 0.00 & 0.00 & 0.00 & 0.00 & 0.80 \\
1.00 & 1.00 & 0.00 & 0.00 & 0.00 & 0.00 \\
0.15 & 0.00 & 0.00 & 0.00 & 0.15 & 0.00 \\
10.29 & 5.09 & 2.04 & 1.14 & 1.80 & 0.22 \\
\hline 12.24 & 6.09 & 2.04 & 1.14 & 1.95 & 1.02 \\
\hline
\end{tabular}

99.20

31.08

14.84

20.82 
DOE PRIME CONTRACT \# DE-AC02-78ET-51013 : B\&R \# AT-10-10-14F DETAIL OF MAN-YEARS

\section{FACULTY}

I. Hutchinson

M. Porkolab (N/C eff. 2/1)

A. Bers

\section{TOTAL FACULTY}

RESEARCH STAFF - OTHER ACADEMIC

\section{E. Marmar}

J. Kesner

D. Sigmar

SCIENTIFIC RESEARCH STAFF
R. Boivin
P. Bonoli
C. Fiore
J. Goetz
S. Golovato
R. Granetz
M. Greenwald
S. Horne
A. Hubbard
J. Irby
B. LaBombard
P. Linsay
B. Lipschultz
G. McCracken
A. Ram
J. Rice
J. Snipes
Y. Takase
J. Terry
R. Watterson
S. Wolfe
Divertor
Thomson Scattering
MSE
RF

TOTAL SCIENTIFIC RES. STAFF

\begin{tabular}{rrrrrr}
$\begin{array}{r}\text { TOTAL } \\
\text { FY 97 }\end{array}$ & $\begin{array}{r}\text { Operations } \\
\text { FY 97 }\end{array}$ & $\begin{array}{r}\text { Experiment } \\
\text { FY 97 }\end{array}$ & $\begin{array}{c}\text { RF } \\
\text { FY 97 }\end{array}$ & $\begin{array}{r}\text { Plasma } \\
\text { FY 97 }\end{array}$ & $\begin{array}{r}\text { Division } \\
\text { FY 97 }\end{array}$ \\
\hline & & & & & \\
$39 \%$ & $0 \%$ & $0 \%$ & $0 \%$ & $0 \%$ & $39 \%$ \\
$35 \%$ & $0 \%$ & $0 \%$ & $35 \%$ & $0 \%$ & $0 \%$ \\
$0 \%$ & $0 \%$ & $0 \%$ & $0 \%$ & $0 \%$ & $0 \%$ \\
\hline & 0 & & & & \\
\hline & & & & & \\
\hline
\end{tabular}

\begin{tabular}{|c|c|c|c|c|c|}
\hline $100 \%$ & $0 \%$ & $90 \%$ & $0 \%$ & $0 \%$ & $10 \%$ \\
\hline $36 \%$ & $0 \%$ & $0 \%$ & $0 \%$ & $36 \%$ & $0 \%$ \\
\hline $0 \%$ & $0 \%$ & $0 \%$ & $0 \%$ & $0 \%$ & $0 \%$ \\
\hline $100 \%$ & $0 \%$ & $100 \%$ & $0 \%$ & $0 \%$ & $0 \%$ \\
\hline $100 \%$ & $0 \%$ & $0 \%$ & $100 \%$ & $0 \%$ & $0 \%$ \\
\hline $50 \%$ & $25 \%$ & $25 \%$ & $0 \%$ & $0 \%$ & $0 \%$ \\
\hline $100 \%$ & $0 \%$ & $64 \%$ & $0 \%$ & $36 \%$ & $0 \%$ \\
\hline $0 \%$ & $0 \%$ & $0 \%$ & $0 \%$ & $0 \%$ & $0 \%$ \\
\hline $100 \%$ & $0 \%$ & $0 \%$ & $0 \%$ & $100 \%$ & $0 \%$ \\
\hline $90 \%$ & $0 \%$ & $0 \%$ & $0 \%$ & $90 \%$ & $0 \%$ \\
\hline $0 \%$ & $0 \%$ & $0 \%$ & $0 \%$ & $0 \%$ & $0 \%$ \\
\hline $100 \%$ & $0 \%$ & $0 \%$ & $50 \%$ & $50 \%$ & $0 \%$ \\
\hline $100 \%$ & $90 \%$ & $0 \%$ & $0 \%$ & $0 \%$ & $10 \%$ \\
\hline $100 \%$ & $0 \%$ & $100 \%$ & $0 \%$ & $0 \%$ & $0 \%$ \\
\hline $0 \%$ & $0 \%$ & $0 \%$ & $0 \%$ & $0 \%$ & $0 \%$ \\
\hline $100 \%$ & $0 \%$ & $100 \%$ & $0 \%$ & $0 \%$ & $0 \%$ \\
\hline $0 \%$ & $0 \%$ & $0 \%$ & $0 \%$ & $0 \%$ & $0 \%$ \\
\hline $0 \%$ & $0 \%$ & $0 \%$ & $0 \%$ & $0 \%$ & $0 \%$ \\
\hline $100 \%$ & $0 \%$ & $100 \%$ & $0 \%$ & $0 \%$ & $0 \%$ \\
\hline $100 \%$ & $0 \%$ & $100 \%$ & $0 \%$ & $0 \%$ & $0 \%$ \\
\hline $100 \%$ & $0 \%$ & $0 \%$ & $100 \%$ & $0 \%$ & $0 \%$ \\
\hline $100 \%$ & $0 \%$ & $100 \%$ & $0 \%$ & $0 \%$ & $0 \%$ \\
\hline $0 \%$ & $0 \%$ & $0 \%$ & $0 \%$ & $0 \%$ & $0 \%$ \\
\hline $100 \%$ & $0 \%$ & $0 \%$ & $0 \%$ & $90 \%$ & $10 \%$ \\
\hline $100 \%$ & $0 \%$ & $100 \%$ & $0 \%$ & $0 \%$ & $0 \%$ \\
\hline $100 \%$ & $0 \%$ & $0 \%$ & $0 \%$ & $100 \%$ & $0 \%$ \\
\hline $0 \%$ & $0 \%$ & $0 \%$ & $0 \%$ & $0 \%$ & $0 \%$ \\
\hline $100 \%$ & $0 \%$ & $0 \%$ & $100 \%$ & $0 \%$ & $0 \%$ \\
\hline 18.76 & 1.15 & 8.79 & 3.50 & 5.02 & 0.30 \\
\hline
\end{tabular}


DOE PRIME CONTRACT \# DE-AC02-78ET-51013 : B\&R \# AT-10-10-14F DETAIL OF MAN-YEARS

ENGINEERS
S. Andreyev
W. Beck
V. Bertolino
J. Bosco
W. Burke
W. Byford
E. Byrne
R. Childs
J. Daigle
S. Fairfax
E. Fitzgerald
M. Fridberg
D. Gwinn
A. Helander
I. Mastovsky
J. Paranay
C. Park
W. Parkin
N. Plerce
R. Pillsbury
C. Reddy
J. Rosati
F. Sabelli
F. Silva
F. Tambini
E. Thibeault
X. Zhong
New - RF
New - Cryo
TOTAL ENGINEERS
COMPUTER STAFF
H. Bergler
T. Fredian
F. Kreisel
D. Nelson
J. Stillerman
TOT. CoMPUTER STAFF

\begin{tabular}{|c|c|c|c|c|c|}
\hline $\begin{array}{l}\text { TOTAL } \\
\text { FY } 97 \\
\end{array}$ & $\begin{array}{r}\text { Operations } \\
\text { FY } 97 \\
\end{array}$ & $\begin{array}{r}\text { Experlment } \\
\text { FY } 97 \\
\end{array}$ & $\begin{array}{c}\text { RF } \\
\text { FY } 97\end{array}$ & $\begin{array}{r}\text { Plasma } \\
\text { FY } 97 \\
\end{array}$ & $\begin{array}{r}\text { Division } \\
\text { FY } 97 \\
\end{array}$ \\
\hline $0 \%$ & $0 \%$ & $0 \%$ & $0 \%$ & $0 \%$ & $0 \%$ \\
\hline $100 \%$ & $20 \%$ & $0 \%$ & $80 \%$ & $0 \%$ & $0 \%$ \\
\hline $100 \%$ & $100 \%$ & $0 \%$ & $0 \%$ & $0 \%$ & $0 \%$ \\
\hline $100 \%$ & $15 \%$ & $0 \%$ & $0 \%$ & $85 \%$ & $0 \%$ \\
\hline $100 \%$ & $100 \%$ & $0 \%$ & $0 \%$ & $0 \%$ & $0 \%$ \\
\hline $50 \%$ & $50 \%$ & $0 \%$ & $0 \%$ & $0 \%$ & $0 \%$ \\
\hline $0 \%$ & $0 \%$ & $0 \%$ & $0 \%$ & $0 \%$ & $0 \%$ \\
\hline $100 \%$ & $70 \%$ & $20 \%$ & $10 \%$ & $0 \%$ & $0 \%$ \\
\hline $100 \%$ & $60 \%$ & $0 \%$ & $20 \%$ & $20 \%$ & $0 \%$ \\
\hline $0 \%$ & $0 \%$ & $0 \%$ & $0 \%$ & $0 \%$ & $0 \%$ \\
\hline $100 \%$ & $90 \%$ & $0 \%$ & $10 \%$ & $0 \%$ & $0 \%$ \\
\hline $100 \%$ & $20 \%$ & $0 \%$ & $80 \%$ & $0 \%$ & $0 \%$ \\
\hline $64 \%$ & $54 \%$ & $0 \%$ & $0 \%$ & $0 \%$ & $10 \%$ \\
\hline $0 \%$ & $0 \%$ & $0 \%$ & $0 \%$ & $0 \%$ & $0 \%$ \\
\hline $50 \%$ & $0 \%$ & $0 \%$ & $50 \%$ & $0 \%$ & $0 \%$ \\
\hline $0 \%$ & $0 \%$ & $0 \%$ & $0 \%$ & $0 \%$ & $0 \%$ \\
\hline $0 \%$ & $0 \%$ & $0 \%$ & $0 \%$ & $0 \%$ & $0 \%$ \\
\hline $100 \%$ & $50 \%$ & $20 \%$ & $10 \%$ & $20 \%$ & $0 \%$ \\
\hline $0 \%$ & $0 \%$ & $0 \%$ & $0 \%$ & $0 \%$ & $0 \%$ \\
\hline $0 \%$ & $0 \%$ & $0 \%$ & $0 \%$ & $0 \%$ & $0 \%$ \\
\hline $100 \%$ & $0 \%$ & $0 \%$ & $0 \%$ & $100 \%$ & $0 \%$ \\
\hline $64 \%$ & $64 \%$ & $0 \%$ & $0 \%$ & $0 \%$ & $0 \%$ \\
\hline $0 \%$ & $0 \%$ & $0 \%$ & $0 \%$ & $0 \%$ & $0 \%$ \\
\hline $100 \%$ & $100 \%$ & $0 \%$ & $0 \%$ & $0 \%$ & $0 \%$ \\
\hline $95 \%$ & $50 \%$ & $45 \%$ & $0 \%$ & $0 \%$ & $0 \%$ \\
\hline $73 \%$ & $53 \%$ & $20 \%$ & $0 \%$ & $0 \%$ & $0 \%$ \\
\hline $0 \%$ & $0 \%$ & $0 \%$ & $0 \%$ & $0 \%$ & $0 \%$ \\
\hline $100 \%$ & $0 \%$ & $0 \%$ & $100 \%$ & $0 \%$ & $0 \%$ \\
\hline $0 \%$ & $0 \%$ & $0 \%$ & $0 \%$ & $0 \%$ & $0 \%$ \\
\hline 15.96 & 8.96 & 1.05 & 3.60 & 2.25 & 0.10 \\
\hline $50 \%$ & $0 \%$ & $0 \%$ & $0 \%$ & $50 \%$ & $0 \%$ \\
\hline $100 \%$ & $0 \%$ & $0 \%$ & $0 \%$ & $100 \%$ & $0 \%$ \\
\hline $100 \%$ & $0 \%$ & $0 \%$ & $0 \%$ & $100 \%$ & $0 \%$ \\
\hline $50 \%$ & $0 \%$ & $0 \%$ & $0 \%$ & $50 \%$ & $0 \%$ \\
\hline $100 \%$ & $0 \%$ & $0 \%$ & $0 \%$ & $100 \%$ & $0 \%$ \\
\hline $0 \%$ & $0 \%$ & $0 \%$ & $0 \%$ & $0 \%$ & $0 \%$ \\
\hline 4.00 & 0.00 & 0.00 & 0.00 & 4.00 & 0.00 \\
\hline
\end{tabular}


DOE PRIME CONTRACT \# DE-AC02-78ET-51013 : B\&R \# AT-10-10-14F DETAIL OF MAN-YEARS

\begin{tabular}{|c|c|c|c|c|c|}
\hline $\begin{array}{r}\text { TOTAL } \\
\text { FY } 97 \\
\end{array}$ & $\begin{array}{r}\text { Operations } \\
\text { FY } 97 \\
\end{array}$ & $\begin{array}{r}\text { Experiment } \\
\text { FY } 97 \\
\end{array}$ & $\begin{array}{c}\text { RF } \\
\text { FY } 97 \\
\end{array}$ & $\begin{array}{r}\text { Plasma } \\
\text { FY } 97 \\
\end{array}$ & $\begin{array}{r}\text { Division } \\
\text { FY } 97 \\
\end{array}$ \\
\hline $100 \%$ & $100 \%$ & $0 \%$ & $0 \%$ & $0 \%$ & $0 \%$ \\
\hline $100 \%$ & $100 \%$ & $0 \%$ & $0 \%$ & $0 \%$ & $0 \%$ \\
\hline $100 \%$ & $50 \%$ & $0 \%$ & $20 \%$ & $30 \%$ & $0 \%$ \\
\hline $100 \%$ & $0 \%$ & $50 \%$ & $0 \%$ & $50 \%$ & $0 \%$ \\
\hline $100 \%$ & $100 \%$ & $0 \%$ & $0 \%$ & $0 \%$ & $0 \%$ \\
\hline $100 \%$ & $20 \%$ & $15 \%$ & $0 \%$ & $65 \%$ & $0 \%$ \\
\hline $100 \%$ & $100 \%$ & $0 \%$ & $0 \%$ & $0 \%$ & $0 \%$ \\
\hline $100 \%$ & $20 \%$ & $45 \%$ & $0 \%$ & $35 \%$ & $0 \%$ \\
\hline $100 \%$ & $100 \%$ & $0 \%$ & $0 \%$ & $0 \%$ & $0 \%$ \\
\hline $0 \%$ & $0 \%$ & $0 \%$ & $0 \%$ & $0 \%$ & $0 \%$ \\
\hline $0 \%$ & $0 \%$ & $0 \%$ & $0 \%$ & $0 \%$ & $0 \%$ \\
\hline $100 \%$ & $0 \%$ & $50 \%$ & $50 \%$ & $0 \%$ & $0 \%$ \\
\hline $100 \%$ & $60 \%$ & $0 \%$ & $40 \%$ & $0 \%$ & $0 \%$ \\
\hline $100 \%$ & $100 \%$ & $0 \%$ & $0 \%$ & $0 \%$ & $0 \%$ \\
\hline $100 \%$ & $0 \%$ & $0 \%$ & $100 \%$ & $0 \%$ & $0 \%$ \\
\hline $100 \%$ & $25 \%$ & $50 \%$ & $25 \%$ & $0 \%$ & $0 \%$ \\
\hline $100 \%$ & $50 \%$ & $0 \%$ & $0 \%$ & $50 \%$ & $0 \%$ \\
\hline $100 \%$ & $100 \%$ & $0 \%$ & $0 \%$ & $0 \%$ & $0 \%$ \\
\hline $0 \%$ & $0 \%$ & $0 \%$ & $0 \%$ & $0 \%$ & $0 \%$ \\
\hline $100 \%$ & $20 \%$ & $80 \%$ & $0 \%$ & $0 \%$ & $0 \%$ \\
\hline $100 \%$ & $80 \%$ & $0 \%$ & $20 \%$ & $0 \%$ & $0 \%$ \\
\hline $100 \%$ & $40 \%$ & $60 \%$ & $0 \%$ & $0 \%$ & $0 \%$ \\
\hline $0 \%$ & $0 \%$ & $0 \%$ & $0 \%$ & $0 \%$ & $0 \%$ \\
\hline $100 \%$ & $50 \%$ & $50 \%$ & $0 \%$ & $0 \%$ & $0 \%$ \\
\hline $100 \%$ & $50 \%$ & $50 \%$ & $0 \%$ & $0 \%$ & $0 \%$ \\
\hline $100 \%$ & $60 \%$ & $0 \%$ & $40 \%$ & $0 \%$ & $0 \%$ \\
\hline $100 \%$ & $40 \%$ & $30 \%$ & $0 \%$ & $30 \%$ & $0 \%$ \\
\hline $50 \%$ & $50 \%$ & $0 \%$ & $0 \%$ & $0 \%$ & $0 \%$ \\
\hline $0 \%$ & $0 \%$ & $0 \%$ & $0 \%$ & $0 \%$ & $0 \%$ \\
\hline $0 \%$ & $0 \%$ & $0 \%$ & $0 \%$ & $0 \%$ & $0 \%$ \\
\hline 23.50 & 13.15 & 4.80 & 2.95 & 2.60 & 0.00 \\
\hline
\end{tabular}

\section{DRAFTERS \\ A. DiCiaccio \\ M. Keniston \\ S. Kochan \\ New \\ TOTAL DRAFTERS}

\begin{tabular}{rrrrrr}
$100 \%$ & $70 \%$ & $0 \%$ & $30 \%$ & $0 \%$ & $0 \%$ \\
$0 \%$ & $0 \%$ & $0 \%$ & $0 \%$ & $0 \%$ & $0 \%$ \\
$100 \%$ & $60 \%$ & $40 \%$ & $0 \%$ & $0 \%$ & $0 \%$ \\
\hline $0 \%$ & $0 \%$ & $0 \%$ & $0 \%$ & $0 \%$ & $0 \%$ \\
\hline 2.00 & 1.30 & 0.40 & 0.30 & 0.00 & 0.00 \\
\hline
\end{tabular}


DOE PRIME CONTRACT \# DE-AC02-78ET-51013 : B\&R \# AT-10-10-14F

DETAIL OF MAN-YEARS

\begin{tabular}{rrrrrr} 
TOTAL & Operations & Experiment & RF & Plasma & Division \\
FY 97 & FY 97 & FY 97 & FY 97 & FY 97 & FY 97 \\
\hline
\end{tabular}

ADMINISTRATIVE STAFF

V. Censabella

New

\begin{tabular}{rrrrrr}
$80 \%$ & $0 \%$ & $0 \%$ & $0 \%$ & $0 \%$ & $80 \%$ \\
\hline $0 \%$ & $0 \%$ & $0 \%$ & $0 \%$ & $0 \%$ & $0 \%$ \\
\hline 0.80 & 0.00 & 0.00 & 0.00 & 0.00 & 0.80 \\
\hline
\end{tabular}

TOTAL ADMINISTRATIVE STAFF

SUPPORT STAFF

Now

K. Johnson

C. Arlington

TOTAL SUPPORT

PFC COMPUTER SUPPORT

M. Greenwald

M. London

TOTAL PFC COMPUTEA SUPPORT

\begin{tabular}{rrrrrr}
$0 \%$ & $0 \%$ & $0 \%$ & $0 \%$ & $0 \%$ & $0 \%$ \\
$100 \%$ & $100 \%$ & $0 \%$ & $0 \%$ & $0 \%$ & $0 \%$ \\
\hline $0 \%$ & $0 \%$ & $0 \%$ & $0 \%$ & $0 \%$ & $0 \%$ \\
\hline 1.00 & 1.00 & 0.00 & 0.00 & 0.00 & 0.00 \\
\hline $5 \%$ & $0 \%$ & $0 \%$ & $0 \%$ & $5 \%$ & $0 \%$ \\
$10 \%$ & $0 \%$ & $0 \%$ & $0 \%$ & $10 \%$ & $0 \%$ \\
\hline 0.15 & 0.00 & 0.00 & 0.00 & 0.15 & 0.00 \\
\hline
\end{tabular}


DOE PRIME CONTRACT \# DE-AC02-78ET-51013 : B\&R \# AT-10-10-14F DETAIL OFMAN-YEARS

\begin{tabular}{|c|c|c|c|c|c|c|}
\hline & $\begin{array}{r}\text { TOTAL } \\
\text { FY } 97 \\
\end{array}$ & $\begin{array}{r}\text { Operations } \\
\text { FY } 97 \\
\end{array}$ & $\begin{array}{r}\text { Experiment } \\
\text { FY } 97 \\
\end{array}$ & $\begin{array}{c}\text { RF } \\
\text { FY } 97 \\
\end{array}$ & $\begin{array}{r}\text { Plasma } \\
\text { FY } 97 \\
\end{array}$ & $\begin{array}{r}\text { Division } \\
\text { FY } 97 \\
\end{array}$ \\
\hline \multicolumn{7}{|l|}{ RESEARCH ASSISTANTS } \\
\hline A. Allen & $100 \%$ & $0 \%$ & $100 \%$ & $0 \%$ & $0 \%$ & $0 \%$ \\
\hline V. Belevstev & $100 \%$ & $0 \%$ & $100 \%$ & $0 \%$ & $0 \%$ & $0 \%$ \\
\hline C. Christensen & $100 \%$ & $0 \%$ & $100 \%$ & $0 \%$ & $0 \%$ & $0 \%$ \\
\hline S. Gangadhara & $100 \%$ & $0 \%$ & $100 \%$ & $0 \%$ & $0 \%$ & $0 \%$ \\
\hline D. Garnier & $100 \%$ & $0 \%$ & $100 \%$ & $0 \%$ & $0 \%$ & $0 \%$ \\
\hline Y. In & $100 \%$ & $0 \%$ & $100 \%$ & $0 \%$ & $0 \%$ & $0 \%$ \\
\hline D. Jablonski & $100 \%$ & $0 \%$ & $100 \%$ & $0 \%$ & $0 \%$ & $0 \%$ \\
\hline M. Koltonyuk & $100 \%$ & $0 \%$ & $100 \%$ & $0 \%$ & $0 \%$ & $0 \%$ \\
\hline D. Lo & $100 \%$ & $0 \%$ & $100 \%$ & $0 \%$ & $0 \%$ & $0 \%$ \\
\hline D. Lumma & $0 \%$ & $0 \%$ & $0 \%$ & $0 \%$ & $0 \%$ & $0 \%$ \\
\hline A. Mazurenko & $100 \%$ & $0 \%$ & $0 \%$ & $100 \%$ & $0 \%$ & $0 \%$ \\
\hline R. Nachtrieb & $100 \%$ & $0 \%$ & $100 \%$ & $0 \%$ & $0 \%$ & $0 \%$ \\
\hline H. Ohkawa & $100 \%$ & $0 \%$ & $100 \%$ & $0 \%$ & $0 \%$ & $0 \%$ \\
\hline P. O'Shea & $100 \%$ & $0 \%$ & $0 \%$ & $0 \%$ & $100 \%$ & $0 \%$ \\
\hline D. Pappas & $100 \%$ & $0 \%$ & $100 \%$ & $0 \%$ & $0 \%$ & $0 \%$ \\
\hline J. Reardon & $100 \%$ & $0 \%$ & $0 \%$ & $100 \%$ & $0 \%$ & $0 \%$ \\
\hline J. Rost & $100 \%$ & $0 \%$ & $0 \%$ & $100 \%$ & $0 \%$ & $0 \%$ \\
\hline J. Schachter & $100 \%$ & $0 \%$ & $0 \%$ & $0 \%$ & $100 \%$ & $0 \%$ \\
\hline K. Shadman & $0 \%$ & $0 \%$ & $0 \%$ & $0 \%$ & $0 \%$ & $0 \%$ \\
\hline J. Sorci & $100 \%$ & $0 \%$ & $0 \%$ & $0 \%$ & $100 \%$ & $0 \%$ \\
\hline P. Stek & $100 \%$ & $0 \%$ & $100 \%$ & $0 \%$ & $0 \%$ & $0 \%$ \\
\hline M. Umansky & $100 \%$ & $0 \%$ & $0 \%$ & $0 \%$ & $100 \%$ & $0 \%$ \\
\hline Y. Wang & $0 \%$ & $0 \%$ & $0 \%$ & $0 \%$ & $0 \%$ & $0 \%$ \\
\hline New & $100 \%$ & $0 \%$ & $0 \%$ & $0 \%$ & $100 \%$ & $0 \%$ \\
\hline New & $100 \%$ & $0 \%$ & $100 \%$ & $0 \%$ & $0 \%$ & $0 \%$ \\
\hline TOTAL RESEARCH ASSISTANTS & 22.00 & 0.00 & 14.00 & 3.00 & 5.00 & 0.00 \\
\hline ADMINISTRATIVE LAB SUPPORT & & & & & & \\
\hline Various & 10.29 & 5.09 & 2.04 & 1.14 & 1.80 & 0.22 \\
\hline TOTAL MAN-YEARS & 99.20 & 30.65 & 31.08 & 14.84 & 20.82 & 1.81 \\
\hline
\end{tabular}


DOE PRIME CONTRACT \# DE-AC02-78ET-51013 : B\&R \# AT-10-10-14F

TASK 01 : ALCATOR CMOD : FY97 GROUP BREAKDOWN

October 01, 1996 - September 30, 1997

Fiscal Year 1997 ALTERNATE BUDGET AT \$13M

DETAIL OFMATERIALS \& SERVICES

Telephones

Catalogues, Journals, Books, etc.

Publications

Graphic Arts

Xerox Expense

Equipment Rental (no OH)

Office \& Drafting Supplies

Postage \& Shipping

Comp. Hardware Maintenance

Computer Software

Computer Supplies

PFC Computer Contribution

AIRCO ; LN2 (No Overhead)

Camb. Electric (No Overhead)

Industrial Subcontracts

Alternator Maintenance

Gases

Radiology \& Safety

Machinists

Cryogenic Materials

Electrical/Electronlc Components

TOTAL

FY 97

Mechanical Components

Optical Components

29,350

2,500

13,200

1,700

11,000

35,400

25,450

11,400

44,530

56,090

26,120

23,260

200,000

70,000

200,000

28,780

40,955

23,850

11,840

278,470

144,740

27,775

Vacuum Components

69,645

Raw Materials

26,295

Electronic Assemblies

112,320

Tools

5,465

Materials \& Services

301,557

Allocated Expense

142,350 
DOE PRIME CONTRACT \# DE-ACD2-78ET-51013 : B\&R \# AT-10-10-14F

TASK 01 : ALCATOR CMOD : FY97 GROUP BREAKDOWN

October 01, 1996 - September 30, 1997

Fiscal Year 1997 ALTERNATE BUDGET AT \$13M

DETAIL OF MATERIALS \& SERVICES

TOTAL

FY 97

SUBSYSTEM FABS/UPGRADES (NO OH)

X-ray Tomography System Fab

Magnetic Diagnostics Fab

First-Wall Upgrade

LHH/LHCD Fab

LH Antenna Fab

LH Instrumentation \& Control Fab

ICRF Tunable Transmitter Fab

Edge Thomson Scattering

EFC Magnet Power Supply Upgrade

Control System Upgrade

Cryopump Fab

Divertor Upgrade

ICRF Antenna

ICRF Matching System

ICRF Transmitter Upgrade

ICRF Instrumentation \& Control

LH Transmission Line Fab

ICRF Diagnostics

0

150,000

000
0

0

50,000

0

0

0
000

30,000

0

20,000

20,000

20,000

20,000

TOTAL ESTIMATED M\&S 
DOE PRIME CONTRACT \# DE-AC02-78ET-51013 : B\&R \# AT-10-10-14F

TASK 01 : ALCATOR CMOD : FY97 GROUP BREAKDOWN

October 01, 1996 - September 30, 1997

\section{Fiscal Year 1997 ALTERNATE BUDGET AT \$13M} DETAIL OF ESTIMATED TRAVEL NEEDS

TOTAL

FY 97

A. DOMESTIC:

Washington D.C. (@ \$890)
Princeton, NJ (@ \$903)
Texas (@ \$1,404 ea)
Sherwood Theory (@ \$1,878)
California (@ $\$ 1,579)$
New Mexico $(@ \$ 1,385)$
Tennessee $(@ \$ 1,029)$
RF/Dlag Conference $(@ \$ 1,657)$
APS - Louisville, KY $(@ \$ 1,300)$
IEEE (@ \$735)
Maryland $(@ \$ 768)$
Canada (@ $\$ 1,650)$

10,087

14,880

4,338

24,390

2,854

2,120

0
9,355

1,582

1,700

B. FOREIGN:

Japan
England
Germany
Russia
Switzerland
Netherlands
IAEA
EPS
France (PSI)
Italy

10,800

5,200

7,050

0
2,430

0

7,500

14,000

2,800

TOTAL ESTIMATED TRAVEL COSTS : 
DOE PRIME CONTRACT \# DE-AC02-78ET-51013 : B\&R \# AT-10-10-14F DETAIL OF CAPITAL EQUIPMENT NEEDS

TOTAL

FY 97

ALCATOR CMOD EQUIPMENT BREAKDOWN

DAC EQUIPMENT

\begin{tabular}{|c|c|c|}
\hline & Crates \& Controllers & 0 \\
\hline & Enhanced Highway Drivers & 0 \\
\hline & CAMAC U-ports & 0 \\
\hline & CAMAC Digitizers & 10,000 \\
\hline & CAMAC Timing Modules & 0 \\
\hline & CAMAC Diagnostic/Maint. Module & 2,000 \\
\hline & CAMAC Modules: counters, TDC, Demod & 5,000 \\
\hline & CAMAC Prog. Amps. & 3,000 \\
\hline & PLCs & 15,000 \\
\hline & Mimic Panels, Displays & 0 \\
\hline & Maintenance/Calibration Instr. & 5,000 \\
\hline \multicolumn{3}{|l|}{ PLASMA CONTROL SYSTEM } \\
\hline & Hybrid Computer Upgrades & 5,000 \\
\hline \multicolumn{3}{|l|}{ COMPUTER EQUIPMENT } \\
\hline & Computer Peripherals & 2,000 \\
\hline & Computers, Personal & 5,000 \\
\hline & Computers, Workstations/Servers & 0 \\
\hline & Data Comm. Equipment & 10,000 \\
\hline & Data Terminals & 5,000 \\
\hline & Mass Storage, Magnetlc & 5,000 \\
\hline & Mass Storage, Optical & 0 \\
\hline & Printers and Plotters & 0 \\
\hline & Network Test Equipment & 3,000 \\
\hline & Multi-media & 0 \\
\hline \multicolumn{3}{|l|}{ FUELING/PELLET EQUIPMENT } \\
\hline & LPI & 0 \\
\hline & DPI & 0 \\
\hline & Diagnostic Neutral Beam FAB & 40,000 \\
\hline \multicolumn{3}{|c|}{ MHD DIAGNOSTICS EQUIPMENT } \\
\hline & MHD Coils & 0 \\
\hline \multicolumn{3}{|l|}{ VIS. \& UV SPECTROSCOPY } \\
\hline & MSEFAB & 5,000 \\
\hline & BESFAB & 2,000 \\
\hline & CXRS FAB & 2,000 \\
\hline
\end{tabular}

YAG Spectrometers \& Laser FAB $\quad 10,000$ 
DOE PRIME CONTRACT \# DE-AC02-78ET-51013 : B\&R \# AT-10-10-14F DETAIL OF CAPITAL EQUIPMENT NEEDS

\begin{tabular}{|c|c|c|}
\hline & & $\begin{array}{l}\text { TOTAL } \\
\text { FY } 97 \\
\end{array}$ \\
\hline $\begin{array}{c}\text { ALCATOR CMOD EQ } \\
\text { Calibration Source }\end{array}$ & BREAKDOWN (continued) & 0 \\
\hline LASER SCATTERING & & \\
\hline & Core Thomson Scattering (first $6 \mathrm{spec}$ ) & 0 \\
\hline & Core Thomson Scattering (next 2 spec) & 0 \\
\hline & Core Thomson Scattering (final 3 spec) & 0 \\
\hline & Toroidal Imaging (F side) & 0 \\
\hline & Poloidal Imaging & 0 \\
\hline & Visible Bremss Fluctuations Fab & 0 \\
\hline ECE & & \\
\hline & ECE Polychromator & 0 \\
\hline INTERFEROMETRY & & \\
\hline & TCIFAB & 0 \\
\hline & Reflectometry FAB & 5,000 \\
\hline & Tangential Interferometer & 5,000 \\
\hline X-RAY DIAGNOSTICS & & \\
\hline & HIREXFAB & 0 \\
\hline & Pulse Height Analysis FAB & 0 \\
\hline BOLOMEIRY & & \\
\hline & Bolometer Upgrade & 0 \\
\hline & Tangential XUV Bolometer Array FAB & 0 \\
\hline Divertor Bolometer & & 0 \\
\hline NEUTRON DIAGNOST & & \\
\hline & He3 Spectrometer FAB & 0 \\
\hline & Collimated Neutron Array FAB & 0 \\
\hline NEUTRAL DIAGNOST & & \\
\hline & Fast Neutrals & 0 \\
\hline & Single Channel Neutral Part & 0 \\
\hline & Time of Flight & 10,000 \\
\hline FUSION PRODUCTS & & \\
\hline & Charged Fusion Part. Detector FAB & 0 \\
\hline & New Charged Fusion & 0 \\
\hline EDGE & & \\
\hline & Neutral Pressure Diag. FAB & 0 \\
\hline & Periscopes FAB & 0 \\
\hline & IR Thermometry FAB & 5,000 \\
\hline & Divertor Spectroscopy FAB & 1,000 \\
\hline & Divertor Impurity Spectroscopy FAB & 1,000 \\
\hline & Advanced Flush-Mount Probe FAB & 0 \\
\hline & Fast Scanning Probe FAB & 0 \\
\hline X-Point MLM Spectr & & 10,000 \\
\hline
\end{tabular}


DOE PRIME CONTRACT \# DE-AC02-78ET-51013 : B\&R \# AT-10-10-14F DETAIL OF CAPITAL EQUIPMENT NEEDS

TOTAL

ALCATOR CMOD EQUIPMENT BREAKDOWN (continuEd)

Omegatron Probes FAB

Edge Thomson Scattering FAB

Flat Plate Divertor Bolometer FAB

Flush Mount Probes in Flat Plate FAB

Vessel Inspection FAB

OTHER EQUIPMENT

KAF

Measuring Equipment

RGA/Differential Pumping

Vacuum \& Pumping Equipment

Video \& Optical Equipment and Instr.

0

10,000

0

0

2,000

2,000

Vldeo Equipment

Power Amplifier

Fast Power Meter

0

5,000

10,000

Signal Generator

5,000

Digital Scopes

6,000

Misc. RF Equipment

, 000

CO2 PHASE CONTRAST

Laser Power Altenuator

Function Generator

Acousto-Optic Modulator

Detector

Amplifiers

2,000

2,000

0

Programmable Controls FAB

Culting System

Flywheel FAB

Cryopump/Refrigerator $\mathrm{FAB}$

CLIP

Electric Power Equip.

Electronic Equipment

Standby Power Equip.

Machine Tools

Safety Equipment

Fiberscope

Power Tools

6,000

0

0

0

2,000

10,000

3,000

3,000

5,000

1,000

TOTAL EQUIPMENT 
DOE PRIME CONTRACT \# DE-AC02-78ET-51013 : B\&R \# AT-10-10-14F

TASK 01 : ALCATOR CMOD : FY98 GROUP BREAKDOWN

October 01, 1997 - September 30, 1998

ESCALATED AT $105 \%$

Fiscal Year 1998 ALTERNATE BUDGET AT \$13.6M

SUMMARY OF COSTS

SALARIES \& WAGES
FACULTY \& RESEARCH STAFF
RESEARCH ASSISTANTS
COMPUTERSTAFF
ENGINEERS
TECHNICIANS
DRAFTERS
ADMINISTRATIVE STAFF
PROIECT SUPPORT STAFF
PFCCOMPSUPPORT
ADMINISTRATIVE SUPPORT

SUBTOTAL SALARIES \& WAGES

EMPLOYEE BENEFITS ( $44.5 \%$ S\&W)

OFF CAMPUS EB (\% S\&W)

ON CAMPUS TRAVEL (See attached) OFF CAMPUS TRAVEL

RASTIPENDS

RA TUITION

M\&S (See attached)

TOTAL DIRECT COSTS

* OVERHEAD: $\%$ of OFF CAMPUS

* OVERHEAD: $63.88 \%$ of MTDC Base

TOTAL EST. OPERATIONS

CAPITAL EQUIPMENT (See Attached)

\begin{tabular}{|c|c|c|c|c|c|}
\hline $\begin{array}{l}\text { TOTAL } \\
\text { FY } 98 \\
\end{array}$ & $\begin{array}{c}\text { Operatlons } \\
\text { FY } 98 \\
\end{array}$ & $\begin{array}{l}\text { Experiment } \\
\text { FY } 98\end{array}$ & $\begin{array}{l}\text { RF } \\
\text { FY } 98 \\
\end{array}$ & $\begin{array}{l}\text { Plasma } \\
\text { FY } 98\end{array}$ & $\begin{array}{l}\text { Division } \\
\text { FY } 98\end{array}$ \\
\hline$\$ 1,327,902$ & $\$ 92,553$ & $\$ 501,202$ & $\$ 231,981$ & $\$ 429,388$ & $\$ 72,778$ \\
\hline 284,581 & 0 & 180,587 & 37,954 & 66,040 & 0 \\
\hline 259,320 & 0 & 0 & 0 & 259,320 & 0 \\
\hline 924,492 & 551,367 & 55,122 & 187,674 & 120,717 & 9,612 \\
\hline $\begin{array}{r}995,066 \\
86,333\end{array}$ & $\begin{array}{r}545,217 \\
55,766\end{array}$ & $\begin{array}{r}209,841 \\
18,670\end{array}$ & $\begin{array}{r}125,647 \\
11,897\end{array}$ & $\begin{array}{r}114,361 \\
0\end{array}$ & $\begin{array}{l}0 \\
0\end{array}$ \\
\hline 33,786 & 0 & 0 & 0 & 0 & 33,786 \\
\hline $\begin{array}{l}30,418 \\
10,364\end{array}$ & $\begin{array}{r}30,418 \\
0\end{array}$ & $\begin{array}{l}0 \\
0\end{array}$ & $\begin{array}{l}0 \\
0\end{array}$ & $\begin{array}{r}0 \\
10,364\end{array}$ & $\begin{array}{l}0 \\
0\end{array}$ \\
\hline 417,111 & 205,633 & 76,268 & 47,017 & 79,015 & 9,178 \\
\hline$\$ 4,369,373$ & $\$ 1,480,954$ & $\$ 1,041,690$ & $\$ 642,170$ & $\$ 1,079,205$ & $\$ 125,354$ \\
\hline $1,944,372$ & 659,025 & 463,552 & 285,766 & 480,246 & 55,783 \\
\hline 0 & 0 & 0 & 0 & 0 & 0 \\
\hline 148,142 & 148,142 & 0 & 0 & 0 & 0 \\
\hline 0 & 0 & 0 & 0 & 0 & 0 \\
\hline 94,860 & 0 & 60,195 & 12,651 & 22,014 & 0 \\
\hline 98,956 & 0 & 62,972 & 13,494 & 22,490 & 0 \\
\hline $2,239,218$ & $2,239,218$ & 0 & 0 & 0 & 0 \\
\hline$\$ 8,894,921$ & $\$ 4,527,339$ & $\$ 1,628,409$ & $\$ 954,081$ & $\$ 1,603,955$ & $\$ 181,137$ \\
\hline 0 & 0 & 0 & 0 & 0 & 0 \\
\hline $4,433,079$ & $2,071,467$ & 834,271 & 530,482 & 891,624 & 105,235 \\
\hline$\$ 13,328,000$ & $\$ 6,598,806$ & $\$ 2,462,680$ & $\$ 1,484,563$ & $\$ 2,495,579$ & $\$ 286,372$ \\
\hline 322,000 & 152,000 & 100,000 & 25,000 & 45,000 & 0 \\
\hline$\$ 13,650,000$ & $\$ 6,750,806$ & $\$ 2,562,680$ & $\$ 1,509,563$ & $\$ 2,540,579$ & $\$ 286,372$ \\
\hline
\end{tabular}

TOTAL ESTIMATED COSTS 
- A Composite Overhead Rate of $44.50 \%$ (See "EB and OH Rates" Page attached to the Budget) is applied to the Modlfied Total Direct Costs (MTDC) Base which is comprised of Total Direct Costs less the following items, some of which are included in the M\&S Amount above and itemized on attached pages.

Administrative Support

EB on Administrative Support

Allocated Expense

RA Tuition

Equipment Rental

Subcontracts $>\$ 25 \mathrm{~K}$

Cambridge Electric, Airco (BOC)

Fabrications/Upgrades

$\$ 417,111$

185,615

142,557

98,956

37,170

210,000

270,000

400,000

TOTAL EXCL. FROM MTDC BASE :

\begin{tabular}{rrrrr}
$\$ 205,633$ & $\$ 76,268$ & $\$ 47,017$ & $\$ 79,015$ & $\$ 9,178$ \\
91,507 & 33,939 & 20,923 & 35,162 & 4,084 \\
70,280 & 26,066 & 16,069 & 27,005 & 3,137 \\
0 & 62,972 & 13,494 & 22,490 & 0 \\
37,170 & 0 & 0 & 0 & 0 \\
210,000 & 0 & 0 & 0 & 0 \\
270,000 & 0 & 0 & 0 & 0 \\
400,000 & 0 & 0 & 0 & 0 \\
\hline
\end{tabular}


DOE PRIME CONTRACT \# DE-AC02-78ET-51013 : B\&R \# AT-10-10-14F

TASK 01 : ALCATOR CMOD : FY98 GROUP BREAKDOWN

October 01, 1997 - September 30, 1998

Fiscal Year 1998 ALTERNATE BUDGET AT \$13.6M

SUMMARY OF MAN-YEARS

\begin{tabular}{rrrrrr} 
TOTAL & Operations & Experiment & RF & Plasma & Division \\
FY 98 & FY 98 & FY 98 & FY 98 & FY 98 & FY 98 \\
\hline
\end{tabular}

\section{SCIENTIFIC \\ FACULTY \\ OTHER ACADEMIC STAFF \\ SCIENTIFIC RESEARCH STAFF \\ RESEARCH ASSISTANTS \\ SUBTOTAL SCIENTIFIC \\ TECHNICAL \& ENGINEERING \\ COMPUTERSTAFF \\ ENGINEERING RESEARCHSTAFF \\ TECHNICIANS \\ DRAFTERS}

SUBTOTAL ENGINEERING \& TECH.

\section{OTHER SUPPORT}

ADMINISTRATIVE STAFF

PROJECT SUPPORT STAFF

PFC COMP SUPPORT

ADMINISTRATIVE SUPPORT

SUBTOTAL OTHER

TOTAL MAN-YEARS

\begin{tabular}{rrrrrr}
0.74 & 0.00 & 0.00 & 0.35 & 0.00 & 0.39 \\
1.36 & 0.00 & 0.90 & 0.00 & 0.36 & 0.10 \\
17.40 & 1.15 & 6.89 & 3.50 & 5.66 & 0.20 \\
22.00 & 0.00 & 14.00 & 3.00 & 5.00 & 0.00 \\
\hline & & & & & \\
41.50 & 1.15 & 21.79 & 6.85 & 11.02 & 0.69 \\
\hline
\end{tabular}

\begin{tabular}{rrrrrr}
4.00 & 0.00 & 0.00 & 0.00 & 4.00 & 0.00 \\
15.96 & 8.96 & 1.05 & 3.60 & 2.25 & 0.10 \\
23.50 & 13.15 & 4.80 & 2.95 & 2.60 & 0.00 \\
2.00 & 1.30 & 0.40 & 0.30 & 0.00 & 0.00 \\
\hline & & & & & \\
45.46 & 23.41 & 6.25 & 6.85 & 8.85 & 0.10 \\
\hline
\end{tabular}

\begin{tabular}{llllll}
0.80 & 0.00 & 0.00 & 0.00 & 0.00 & 0.80 \\
1.00 & 1.00 & 0.00 & 0.00 & 0.00 & 0.00 \\
0.15 & 0.00 & 0.00 & 0.00 & 0.15 & 0.00 \\
9.88 & 4.87 & 1.81 & 1.11 & 1.87 & 0.22 \\
\hline & & & & & \\
11.83 & 5.87 & 1.81 & 1.11 & 2.02 & 1.02 \\
\hline
\end{tabular}

98.79

30.43

29.85

14.81

21.89

1.81 
DOE PRIME CONTRACT \# DE-AC02-78ET-51013 : B\&R \# AT-10-10-14F DETAIL OF MAN-YEARS

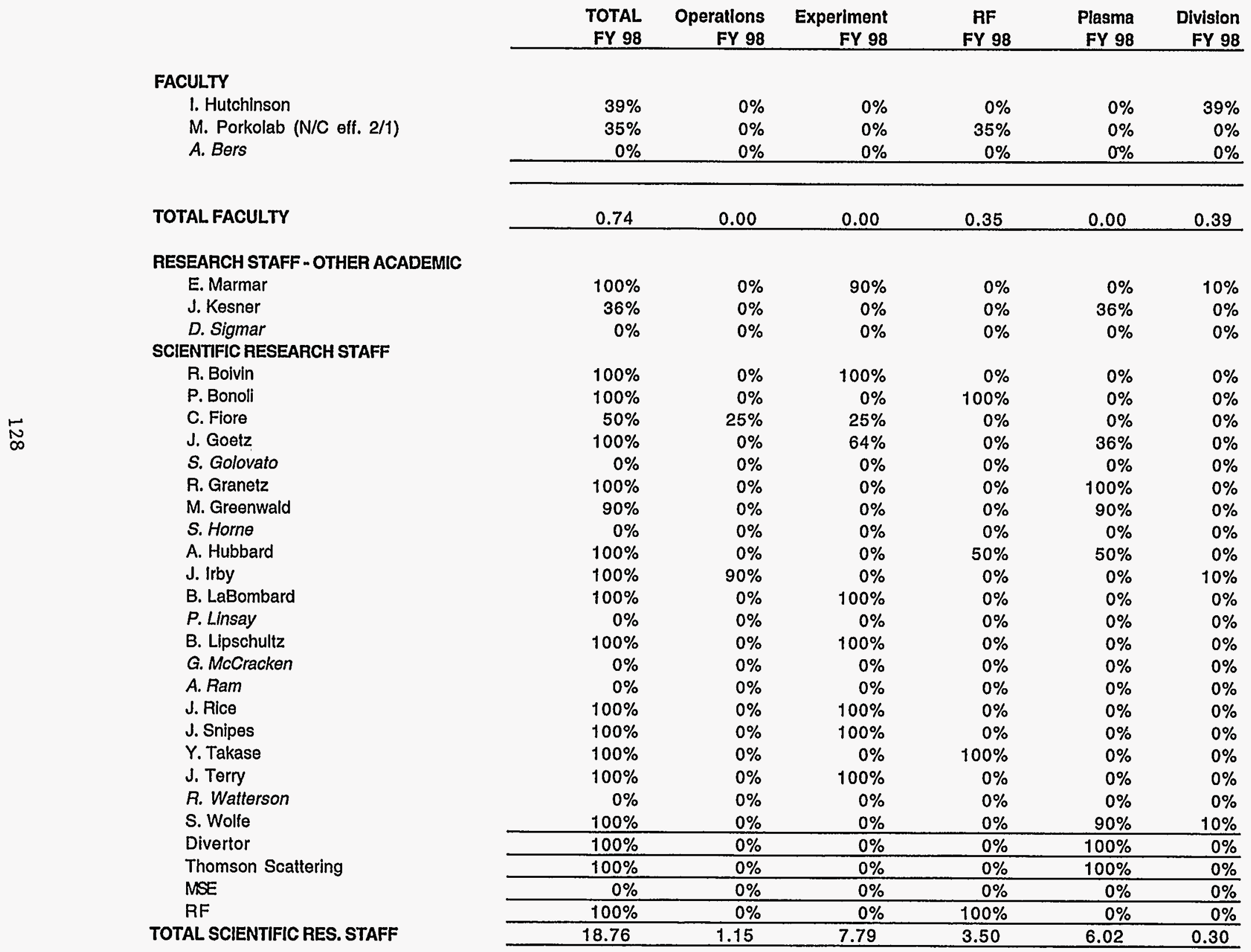


DOE PRIME CONTRACT \# DE-AC02-78ET-51013 ; B\&R \# AT-10-10-14F DETAIL OF MAN-YEARS

ENGINEERS
S. Andreyev
W. Beck
V. Bertolino
J. Bosco
W. Burke
W. Byford
E. Byrne
R. Childs
J. Daigle
S. Fairfax
E. Fitzgerald
M. Fridberg
D. Gwinn
A. Helander
I. Mastovsky
J. Paranay
C. Park
W. Parkin
N. Pierce
R. Pillsbury
C. Reddy
J. Rosati
F. Sabelli
F. Silva
F. Tambinl
E. Thibeault
X. Zhong
New - RF
New - Cryo
TOTAL ENGINEERS
T.
COMPUTER STAFF
H. Bergler
T. Fredian
F. Krelsel
D. Nelson
J. Stillerman
New
TOTAL CompUTER STAFF

\begin{tabular}{|c|c|c|c|c|c|}
\hline $\begin{array}{r}\text { TOTAL } \\
\text { FY } 98 \\
\end{array}$ & $\begin{array}{r}\text { Operatlons } \\
\text { FY } 98 \\
\end{array}$ & $\begin{array}{r}\text { Experiment } \\
\text { FY } 98 \\
\end{array}$ & $\begin{array}{c}\text { RF } \\
\text { FY } 98 \\
\end{array}$ & $\begin{array}{r}\text { Plasma } \\
\text { FY } 98 \\
\end{array}$ & $\begin{array}{r}\text { Division } \\
\text { FY } 98 \\
\end{array}$ \\
\hline $0 \%$ & $0 \%$ & $0 \%$ & $0 \%$ & $0 \%$ & $0 \%$ \\
\hline $100 \%$ & $20 \%$ & $0 \%$ & $80 \%$ & $0 \%$ & $0 \%$ \\
\hline $100 \%$ & $100 \%$ & $0 \%$ & $0 \%$ & $0 \%$ & $0 \%$ \\
\hline $100 \%$ & $15 \%$ & $0 \%$ & $0 \%$ & $85 \%$ & $0 \%$ \\
\hline $100 \%$ & $100 \%$ & $0 \%$ & $0 \%$ & $0 \%$ & $0 \%$ \\
\hline $50 \%$ & $50 \%$ & $0 \%$ & $0 \%$ & $0 \%$ & $0 \%$ \\
\hline $0 \%$ & $0 \%$ & $0 \%$ & $0 \%$ & $0 \%$ & $0 \%$ \\
\hline $100 \%$ & $70 \%$ & $20 \%$ & $10 \%$ & $0 \%$ & $0 \%$ \\
\hline $100 \%$ & $60 \%$ & $0 \%$ & $20 \%$ & $20 \%$ & $0 \%$ \\
\hline $0 \%$ & $0 \%$ & $0 \%$ & $0 \%$ & $0 \%$ & $0 \%$ \\
\hline $100 \%$ & $90 \%$ & $0 \%$ & $10 \%$ & $0 \%$ & $0 \%$ \\
\hline $100 \%$ & $20 \%$ & $0 \%$ & $80 \%$ & $0 \%$ & $0 \%$ \\
\hline $64 \%$ & $54 \%$ & $0 \%$ & $0 \%$ & $0 \%$ & $10 \%$ \\
\hline $0 \%$ & $0 \%$ & $0 \%$ & $0 \%$ & $0 \%$ & $0 \%$ \\
\hline $50 \%$ & $0 \%$ & $0 \%$ & $50 \%$ & $0 \%$ & $0 \%$ \\
\hline $0 \%$ & $0 \%$ & $0 \%$ & $0 \%$ & $0 \%$ & $0 \%$ \\
\hline $0 \%$ & $0 \%$ & $0 \%$ & $0 \%$ & $0 \%$ & $0 \%$ \\
\hline $100 \%$ & $50 \%$ & $20 \%$ & $10 \%$ & $20 \%$ & $0 \%$ \\
\hline $0 \%$ & $0 \%$ & $0 \%$ & $0 \%$ & $0 \%$ & $0 \%$ \\
\hline $0 \%$ & $0 \%$ & $0 \%$ & $0 \%$ & $0 \%$ & $0 \%$ \\
\hline $100 \%$ & $0 \%$ & $0 \%$ & $0 \%$ & $100 \%$ & $0 \%$ \\
\hline $64 \%$ & $64 \%$ & $0 \%$ & $0 \%$ & $0 \%$ & $0 \%$ \\
\hline $0 \%$ & $0 \%$ & $0 \%$ & $0 \%$ & $0 \%$ & $0 \%$ \\
\hline $100 \%$ & $100 \%$ & $0 \%$ & $0 \%$ & $0 \%$ & $0 \%$ \\
\hline $95 \%$ & $50 \%$ & $45 \%$ & $0 \%$ & $0 \%$ & $0 \%$ \\
\hline $73 \%$ & $53 \%$ & $20 \%$ & $0 \%$ & $0 \%$ & $0 \%$ \\
\hline $0 \%$ & $0 \%$ & $0 \%$ & $0 \%$ & $0 \%$ & $0 \%$ \\
\hline $100 \%$ & $0 \%$ & $0 \%$ & $100 \%$ & $0 \%$ & $0 \%$ \\
\hline $0 \%$ & $0 \%$ & $0 \%$ & $0 \%$ & $0 \%$ & $0 \%$ \\
\hline 15.96 & 8.96 & 1.05 & 3.60 & 2.25 & 0.10 \\
\hline $50 \%$ & $0 \%$ & $0 \%$ & $0 \%$ & $50 \%$ & $0 \%$ \\
\hline $100 \%$ & $0 \%$ & $0 \%$ & $0 \%$ & $100 \%$ & $0 \%$ \\
\hline $100 \%$ & $0 \%$ & $0 \%$ & $0 \%$ & $100 \%$ & $0 \%$ \\
\hline $50 \%$ & $0 \%$ & $0 \%$ & $0 \%$ & $50 \%$ & $0 \%$ \\
\hline $100 \%$ & $0 \%$ & $0 \%$ & $0 \%$ & $100 \%$ & $0 \%$ \\
\hline $0 \%$ & $0 \%$ & $0 \%$ & $0 \%$ & $0 \%$ & $0 \%$ \\
\hline 4.00 & 0.00 & 0.00 & 0.00 & 4.00 & 0.00 \\
\hline
\end{tabular}


DOE PRIME CONTRACT \# DE-AC02-78ET-51013 : B\&R \# AT-10-10-14F DETAIL OF MAN-YEARS

TECHNICIANS

D. Arsenault

J. Chicarello

W. Cochran

R. Danforth

G. Dekow

J. Gerolamo

R. Griffith

M. Iverson

H. Lander

T. Lloyd

J. Moscaritolo

R. Murray

J. Nickerson

J. Orvosh

A. Pfeiffer

S. Pierson

W. Pina

K. Rettman

M. Aioux

E. Rollins

M. Rowell

F. Shefton

New/Temporary

R. Sylvia

S. Tambini

P. Telesmanick

T. Toland

Northeastern Coop

New/Temporary

Overtime

TOTAL TECHNICIANS

\section{DRAFTERS}

A. DiCiaccio

M. Keniston

S. Kochan

New

TOTAL DRAFTERS

\begin{tabular}{rrrrrr} 
TOTAL & Operations & Experiment & RF & Plasma & Division \\
FY 98 & FY 98 & FY 98 & FY 98 & FY 98 & FY 98 \\
\hline
\end{tabular}

\begin{tabular}{|c|c|c|c|c|c|}
\hline $100 \%$ & $100 \%$ & $0 \%$ & $0 \%$ & $0 \%$ & $0 \%$ \\
\hline $100 \%$ & $100 \%$ & $0 \%$ & $0 \%$ & $0 \%$ & $0 \%$ \\
\hline $100 \%$ & $50 \%$ & $0 \%$ & $20 \%$ & $30 \%$ & $0 \%$ \\
\hline $100 \%$ & $0 \%$ & $50 \%$ & $0 \%$ & $50 \%$ & $0 \%$ \\
\hline $100 \%$ & $100 \%$ & $0 \%$ & $0 \%$ & $0 \%$ & $0 \%$ \\
\hline $100 \%$ & $20 \%$ & $15 \%$ & $0 \%$ & $65 \%$ & $0 \%$ \\
\hline $100 \%$ & $100 \%$ & $0 \%$ & $0 \%$ & $0 \%$ & $0 \%$ \\
\hline $100 \%$ & $20 \%$ & $45 \%$ & $0 \%$ & $35 \%$ & $0 \%$ \\
\hline $100 \%$ & $100 \%$ & $0 \%$ & $0 \%$ & $0 \%$ & $0 \%$ \\
\hline $0 \%$ & $0 \%$ & $0 \%$ & $0 \%$ & $0 \%$ & $0 \%$ \\
\hline $0 \%$ & $0 \%$ & $0 \%$ & $0 \%$ & $0 \%$ & $0 \%$ \\
\hline $100 \%$ & $0 \%$ & $50 \%$ & $50 \%$ & $0 \%$ & $0 \%$ \\
\hline $100 \%$ & $60 \%$ & $0 \%$ & $40 \%$ & $0 \%$ & $0 \%$ \\
\hline $100 \%$ & $100 \%$ & $0 \%$ & $0 \%$ & $0 \%$ & $0 \%$ \\
\hline $100 \%$ & $0 \%$ & $0 \%$ & $100 \%$ & $0 \%$ & $0 \%$ \\
\hline $100 \%$ & $25 \%$ & $50 \%$ & $25 \%$ & $0 \%$ & $0 \%$ \\
\hline $100 \%$ & $50 \%$ & $0 \%$ & $0 \%$ & $50 \%$ & $0 \%$ \\
\hline $100 \%$ & $100 \%$ & $0 \%$ & $0 \%$ & $0 \%$ & $0 \%$ \\
\hline $0 \%$ & $0 \%$ & $0 \%$ & $0 \%$ & $0 \%$ & $0 \%$ \\
\hline $100 \%$ & $20 \%$ & $80 \%$ & $0 \%$ & $0 \%$ & $0 \%$ \\
\hline $100 \%$ & $80 \%$ & $0 \%$ & $20 \%$ & $0 \%$ & $0 \%$ \\
\hline $100 \%$ & $40 \%$ & $60 \%$ & $0 \%$ & $0 \%$ & $0 \%$ \\
\hline $0 \%$ & $0 \%$ & $0 \%$ & $0 \%$ & $0 \%$ & $0 \%$ \\
\hline $100 \%$ & $50 \%$ & $50 \%$ & $0 \%$ & $0 \%$ & $0 \%$ \\
\hline $100 \%$ & $50 \%$ & $50 \%$ & $0 \%$ & $0 \%$ & $0 \%$ \\
\hline $100 \%$ & $60 \%$ & $0 \%$ & $40 \%$ & $0 \%$ & $0 \%$ \\
\hline $100 \%$ & $40 \%$ & $30 \%$ & $0 \%$ & $30 \%$ & $0 \%$ \\
\hline $50 \%$ & $50 \%$ & $0 \%$ & $0 \%$ & $0 \%$ & $0 \%$ \\
\hline $0 \%$ & $0 \%$ & $0 \%$ & $0 \%$ & $0 \%$ & $0 \%$ \\
\hline $0 \%$ & $0 \%$ & $0 \%$ & $0 \%$ & $0 \%$ & $0 \%$ \\
\hline 23.50 & 13.15 & 4.80 & 2.95 & 2.60 & 0.00 \\
\hline
\end{tabular}

\begin{tabular}{rrrrrr}
$100 \%$ & $70 \%$ & $0 \%$ & $30 \%$ & $0 \%$ & $0 \%$ \\
$0 \%$ & $0 \%$ & $0 \%$ & $0 \%$ & $0 \%$ & $0 \%$ \\
$100 \%$ & $60 \%$ & $40 \%$ & $0 \%$ & $0 \%$ & $0 \%$ \\
\hline $0 \%$ & $0 \%$ & $0 \%$ & $0 \%$ & $0 \%$ & $0 \%$ \\
\hline 2.00 & 1.30 & 0.40 & 0.30 & 0.00 & 0.00 \\
\hline
\end{tabular}


DOE PRIME CONTRACT \# DE-AC02-78ET-51013 : B\&R \# AT-10-10-14F DETAIL OF MAN-YEARS

ADMINISTRATIVE STAFF

V. Censabella

New

TOTAL ADMINISTRATIVE STAFF

SUPPORT STAFF

New

K. Johnson

C. Arlington

TOTAL SUPPORT

PFC COMPUTER SUPPORT

M. Greenwald

M. London

TOTAL PFC COMPUTER SUPPORT

\begin{tabular}{rrrrrr} 
TOTAL & Operations & Experiment & RF & Plasma & Division \\
FY 98 & FY 98 & FY 98 & FY 98 & FY 98 & FY 98 \\
\hline
\end{tabular}

\begin{tabular}{rrrrrr}
$80 \%$ & $0 \%$ & $0 \%$ & $0 \%$ & $0 \%$ & $80 \%$ \\
\hline $0 \%$ & $0 \%$ & $0 \%$ & $0 \%$ & $0 \%$ & $0 \%$ \\
\hline 0.80 & 0.00 & 0.00 & 0.00 & 0.00 & 0.80 \\
\hline
\end{tabular}

\begin{tabular}{rrrrrr}
0.80 & 0.00 & 0.00 & 0.00 & 0.00 & 0.80 \\
\hline $0 \%$ & & & & & \\
$100 \%$ & $100 \%$ & $0 \%$ & $0 \%$ & $0 \%$ & $0 \%$ \\
\hline $0 \%$ & $0 \%$ & $0 \%$ & $0 \%$ & $0 \%$ & $0 \%$ \\
\hline 1.00 & 1.00 & 0.00 & $0 \%$ & $0 \%$ & $0 \%$ \\
\hline & & & 0.00 & 0.00 & 0.00 \\
\hline $10 \%$ & $0 \%$ & $0 \%$ & $0 \%$ & $5 \%$ & $0 \%$ \\
0.15 & $0 \%$ & $0 \%$ & $0 \%$ & $10 \%$ & $0 \%$ \\
\hline & 0.00 & 0.00 & 0.00 & 0.15 & 0.00 \\
\hline
\end{tabular}




\begin{tabular}{|c|c|c|c|c|c|}
\hline $\begin{array}{r}\text { TOTAL } \\
\text { FY } 98 \\
\end{array}$ & $\begin{array}{r}\text { Operatlons } \\
\text { FY } 98 \\
\end{array}$ & $\begin{array}{r}\text { Experiment } \\
\text { FY } 98 \\
\end{array}$ & $\begin{array}{c}\text { RF } \\
\text { FY } 98 \\
\end{array}$ & $\begin{array}{r}\text { Plasma } \\
\text { FY } 98 \\
\end{array}$ & $\begin{array}{r}\text { Division } \\
\text { FY } 98 \\
\end{array}$ \\
\hline $100 \%$ & $0 \%$ & $100 \%$ & $0 \%$ & $0 \%$ & $0 \%$ \\
\hline $100 \%$ & $0 \%$ & $100 \%$ & $0 \%$ & $0 \%$ & $0 \%$ \\
\hline $100 \%$ & $0 \%$ & $100 \%$ & $0 \%$ & $0 \%$ & $0 \%$ \\
\hline $100 \%$ & $0 \%$ & $100 \%$ & $0 \%$ & $0 \%$ & $0 \%$ \\
\hline $100 \%$ & $0 \%$ & $100 \%$ & $0 \%$ & $0 \%$ & $0 \%$ \\
\hline $100 \%$ & $0 \%$ & $100 \%$ & $0 \%$ & $0 \%$ & $0 \%$ \\
\hline $100 \%$ & $0 \%$ & $100 \%$ & $0 \%$ & $0 \%$ & $0 \%$ \\
\hline $100 \%$ & $0 \%$ & $100 \%$ & $0 \%$ & $0 \%$ & $0 \%$ \\
\hline $100 \%$ & $0 \%$ & $100 \%$ & $0 \%$ & $0 \%$ & $0 \%$ \\
\hline $0 \%$ & $0 \%$ & $0 \%$ & $0 \%$ & $0 \%$ & $0 \%$ \\
\hline $100 \%$ & $0 \%$ & $0 \%$ & $100 \%$ & $0 \%$ & $0 \%$ \\
\hline $100 \%$ & $0 \%$ & $100 \%$ & $0 \%$ & $0 \%$ & $0 \%$ \\
\hline $100 \%$ & $0 \%$ & $100 \%$ & $0 \%$ & $0 \%$ & $0 \%$ \\
\hline $100 \%$ & $0 \%$ & $0 \%$ & $0 \%$ & $100 \%$ & $0 \%$ \\
\hline $100 \%$ & $0 \%$ & $100 \%$ & $0 \%$ & $0 \%$ & $0 \%$ \\
\hline $100 \%$ & $0 \%$ & $0 \%$ & $100 \%$ & $0 \%$ & $0 \%$ \\
\hline $100 \%$ & $0 \%$ & $0 \%$ & $100 \%$ & $0 \%$ & $0 \%$ \\
\hline $100 \%$ & $0 \%$ & $0 \%$ & $0 \%$ & $100 \%$ & $0 \%$ \\
\hline $0 \%$ & $0 \%$ & $0 \%$ & $0 \%$ & $0 \%$ & $0 \%$ \\
\hline $100 \%$ & $0 \%$ & $0 \%$ & $0 \%$ & $100 \%$ & $0 \%$ \\
\hline $100 \%$ & $0 \%$ & $100 \%$ & $0 \%$ & $0 \%$ & $0 \%$ \\
\hline $100 \%$ & $0 \%$ & $0 \%$ & $0 \%$ & $100 \%$ & $0 \%$ \\
\hline $0 \%$ & $0 \%$ & $0 \%$ & $0 \%$ & $0 \%$ & $0 \%$ \\
\hline $100 \%$ & $0 \%$ & $0 \%$ & $0 \%$ & $100 \%$ & $0 \%$ \\
\hline $100 \%$ & $0 \%$ & $100 \%$ & $0 \%$ & $0 \%$ & $0 \%$ \\
\hline 22.00 & 0.00 & 14.00 & 3.00 & 5.00 & 0.00 \\
\hline 9.88 & 4.87 & 1.81 & 1.11 & 1.87 & 0.22 \\
\hline 98.79 & 30.43 & 29.85 & 14.81 & 21.89 & 1.81 \\
\hline
\end{tabular}
A. Allen
V. Belevstev
C. Christensen
S. Gangadhara
D. Garnier
Y. In
D. Jablonski
M. Koltonyuk
D. Lo
D. Lumma
A. Mazurenko
R. Nachtrieb
H. Ohkawa
P. O'Shea
D. Pappas
J. Reardon
J. Rost
J. Schachter
K. Shadman
J. Sorci
P. Stek
M. Umansky
Y. Wang
New
New

TOTAL RESEARCH ASSISTANTS

ADMINISTRATIVE LAB SUPPORT Various

TOTAL MAN-YEARS
DOE PRIME CONTRACT \# DE-AC02-78ET-51013 : B\&R \# AT-10-10-14F DETAIL OFMAN-YEARS

\section{STANTS}

-

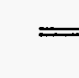


"RA effort (man-years) reflects the entire year. However, salary is for the period 1 January - 30 June; effective 1 July, RA stipends and tuition are included in operating expenses and shown below:

\section{DETAIL OF RESEARCH ASSISTANT COSTS}

For the 6 Months Subsequent to July 1, 1998

Prior to July 1,1998 the tuition of graduate research assistants was charged to the employee benefits pool. At the request of the federal government, effective July 1, 1998 RA tuition will be charged directly to the research project on which the RA works. The following assumptions were used in calculating the anticipated changes to the budget:

No EB on RA Stipends. Stipends will be subject to $\mathrm{OH}$.

No OH on Tuition.

$55 \%$ of RA tuition will be charged to the research accounts; MIT will subsidize the remaining $45 \%$.

EB drops 8 points.

RA Summer appointments span the period June-August. Therefore, June RA salary is shown in the salary portion of the budget, while the stipends and tuition for July forward are reflected in the figures below. However, for clarity, RA effort (man-years) for the full year is recorded above.

\begin{tabular}{rrrrrr}
$\begin{array}{r}\text { FY 98 } \\
\text { TOTAL }\end{array}$ & $\begin{array}{r}\text { FY 98 } \\
\text { Operations }\end{array}$ & $\begin{array}{r}\text { FY 98 } \\
\text { Experiment }\end{array}$ & $\begin{array}{c}\text { FY 98 } \\
\text { RF }\end{array}$ & $\begin{array}{r}\text { FY 98 } \\
\text { Plasma }\end{array}$ & $\begin{array}{r}\text { FY 98 } \\
\text { Divislon }\end{array}$ \\
\hline 94,860 & 0 & 60,195 & 12,651 & 22,014 & 0 \\
& & & & & \\
98,956 & 0 & 62,972 & 13,494 & 22,490 & 0 \\
\hline & & & & & \\
193,816 & 0 & 123,167 & 26,145 & 44,504 & 0 \\
\hline
\end{tabular}

TOTAL AA COSTS 
DOE PRIME CONTRACT \# DE-AC02-78ET-51013 : B\&R \# AT-10-10-14F

TASK 01 : ALCATOR CMOD : FY98 GROUP BREAKDOWN

October 01, 1997 - September 30, 1998

\section{Flscal Year 1998 ALTERNATE BUDGET AT \$13.6M}

DETAIL OF MATERIALS \& SERVICES

TOTAL

FY 98

Telephones

30,820

Catalogues, Journals, Books, etc.

2,630

Publications

Graphic Arts

Xerox Expense

Equipment Rental (no $\mathrm{OH}$ )

13,860

1,790

11,550

37,170

Office \& Drafting Supplies

26,720

Postage \& Shipping

11,970

46,760

58,890

Computer Software

27,430

Computer Supplies

24,420

Computer Contribution

AIRCO ; LN2 (No Overhead)

200,000

Camb. Electric (No Overhead)

70,000

Industrial Subcontracts

210,000

Alternator Maintenance

Gases

Radiology \& Safety

30,220

43,000

Machinists

Cryogenic Materials

25,040

12,430

Electrical/Electronic Components

292,390

Mechanical Components

151,980

Optical Components

29,160

Vacuum Components

73,130

Raw Materials

27,610

117,940

Tools

5,740

Materials \& Services

Allocated Expense

142,557 
DOE PRIME CONTRACT \# DE-AC02-78ET-51013 : B\&R \# AT-10-10-14F

TASK 01 : ALCATOR CMOD : FY98 GROUP BREAKDOWN

October 01, 1997 - September 30, 1998

Fiscal Year 1998 ALTERNATE BUDGET AT \$13.6M DETAIL OF MATERIALS \& SERVICES

TOTAL

FY 98

\section{SUBSYSTEM FABS/UPGRADES (NO OH)}

X-ray Tomography System Fab

Magnetic Diagnostics Fab

First-Wall Upgrade

LHH/LHCD Fab

0

LH Antenna Fab

LH Instrumentation \& Control Fab

ICRF Tunable Transmitter Fab

Edge Thomson Scattering

EFC Magnet Power Supply Upgrade

Control System Upgrade

Cryopump Fab

Divertor Upgrade

ICRF Antenna

ICRF Matching System

ICRF Transmitter Upgrade

ICRF Instrumentation \& Control

LH Transmission Line Fab

ICRF Dlagnostics

$\begin{array}{r}0 \\ 0 \\ 0 \\ 200,000 \\ 0 \\ 0 \\ 20,000 \\ 0 \\ 0 \\ 0 \\ 50,000 \\ 0 \\ 0 \\ 30,000 \\ 10,000 \\ 20,000 \\ 50,000 \\ 20,000 \\ \hline 2,311,495 \\ \hline \hline\end{array}$

TOTAL ESTIMATED M\&S 
DOE PAIME CONTRACT \# DE-AC02-78ET-51013 : B\&R \# AT-10-10-14F

TASK 01 : ALCATOR CMOD : FY98 GROUP BREAKDOWN

October 01, 1997 - September 30, 1998

Fiscal Year 1998 ALTERNATE BUDGET AT \$13.6M

DETAIL OFESTIMATED TRAVEL NEEDS

TOTAL

FY 98

A. DOMESTIC:

Washington D.C. (@ \$917)

Princeton, NJ (@ \$930)

Texas (@ $\$ 1,446$ ea)

Sherwood Theory (@ \$1,934)

California (@ \$1,626)

New Mexico (@ \$1,427)

Tennessee (@ $\$ 1,060$ )

RF/Diag Conference (@ \$1,707)

APS - Denver, Co $(@ \$ 1,500)$

IEEE (@ \$757)

Maryland (@ \$791)

Canada (@ $\$ 1,700)$

10,593

15,632

4,554

0
5,605

2,996

2,226

0

30,818

0
662

1,785

B. FOREIGN:

Japan

England

11,340

5,460

Germany

7,404

Russia

Switzerland

Netherlands (EC-10)

IAEA

EPS

France

Italy

7,404
0

2,552

0
7,875

14,700

2,940

TOTAL ESTIMATED TRAVEL COSTS : 
DOE PRIME CONTRACT \# DE-AC02-78ET-51013 : B\&R \# AT-10-10-14F

DETAIL OF CAPITAL EQUIPMENT NEEDS

\section{ALCATOR CMOD EQUIPMENT BREAKDOWN}

TOTA

FY 98

DAC EQUIPMENT

Crates \& Controllers

Enhanced Highway Drivers

CAMAC U-ports

CAMAC Digitizers

CAMAC Timing Modules

CAMAC Diagnostic/Maint. Module

CAMAC Modules: counters, TDC, Demod

CAMAC Prog. Amps.

PLCs

Mimic Panels, Displays

Maintenance/Calibration Instr.

Hybrid Computer Upgrades

Computer Peripherals

Computers, Personal

Computers, Workstations/Servers

Data Comm. Equipment

Data Terminals

Mass Storage, Magnetic

Mass Storage, Optical

Printers and Plotters

Network Test Equipment

Multi-media

5,000

4,000

2,000

2,000

5,000

10,000

4,000

2,000

5,000

5,000

15,000

4,000

5,000

5,000

0

0
4,000

FUELING/PELLET EQUIPMENT

LPI

DPI

0

Diagnostic Neutral Beam FAB

0

MHD DIAGNOSTICS EQUIPMENT

MHD Coils

MSEFAB

BESFAB

CXRSFAB

10,000

10,000

LASER SCATTERING

YAG Spectrometers \& Laser FAB

10,000 
DOE PRIME CONTRACT \# DE-AC02-78ET-51013 : B\&R \# AT-10-10-14F DETAIL OF CAPITAL EQUIPMENT NEEDS

TOTAL

FY 98

ALCATOR CMOD EQUIPMENT BREAKDOWN (continued)

Calibration Source

LASER SCATTERING

Core Thomson Scattering (first 6 spec)

Core Thomson Scattering (next 2 spec)

Core Thomson Scattering (final 3 spec)

Toroidal Imaging (F side)

Poloidal Imaging

ECE

Visible Bremss Fluctuations Fab

ECE Polychromator

TCIFAB

Reflectometry FAB

Tangential Interferometer

X-RAY DIAGNOSTICS

\section{HIREXFAB}

Pulse Height Analysis FAB

BOLOMETRY

Bolometer Upgrade

Tangential XUV Bolometer Array FAB

Divertor Bolometer Arrays FAB NEUTRON DIAGNOSTICS

He3 Spectrometer FAB

Collimated Neutron Array FAB

NEUTRAL DIAGNOSTICS

Fast Neutrals

Single Channel Neutral Part

Time of Flight

FUSION PRODUCTS

Charged Fusion Part. Detector FAB

New Charged Fusion

Neutral Pressure Diag. FAB

Periscopes FAB

IR Thermometry FAB

Divertor Spectroscopy $F A B$

Divertor Impurity Spectroscopy FAB

Advanced Flush-Mount Probe FAB

Fast Scanning Probe FAB 
DOE PRIME CONTRACT \# DE-AC02-78ET-51013 : B\&R \# AT-10-10-14F DETAIL OF CAPITAL EQUIPMENT NEEDS

TOTAL

FY 98

ALCATOR CMOD EQUIPMENT BREAKDOWN (continued)

Omegatron Probes FAB

0

dge Thomson Scattering FAB

Flat Plate Divertor Bolometer FAB

Flush Mount Probes in Flat Plate FAB

1,000

Vessel Inspection FAB

0

OTHER EQUIPMENT

RGA/Differential Pumping

Vacuum \& Pumping Equipment

Video \& Optical Equipment and Instr.

ICAF

Video Equipment

Power Amplifler

Fast Power Meter

Signal Generator

Digital Scopes

Tubes

Misc. RF Equipment

2,000

4,000

LH

Measuring Equipment

CO2 PHASE CONTRAST

Laser Power Attenuator

Function Generator

Acousto-Optic Modulator

Detector

Amplifiers

OPERATIONS

Programmable Controls FAB

Cutting System

Flywheel FAB

Cryopump/Refrigerator $F A B$

$$
\text { CLIP }
$$

Electric Power Equip.

Electronic Equipment

Standby Power Equip.

Machine Tools

Safety Equipment

Fiberscope

Power Tools

0

0

0

0

25,000

0

0

0

0

0

120,000

0

2,000

6,000

3,000

1,000

3,000

0

1,000 
EMPLOYEE BENEFITS AND OVERHEAD RATES

\begin{tabular}{|c|c|c|c|}
\hline & $\begin{array}{l}\text { OCT } 01- \\
\text { JUN } 30 \\
\text { (9 MOS) }\end{array}$ & $\begin{array}{c}\text { JUL 01- } \\
\text { SEP } 30 \\
\text { (3 MOS) }\end{array}$ & $\begin{array}{l}\text { FISCAL } \\
\text { YEAR' } \\
\text { COMPOSITE }\end{array}$ \\
\hline \multicolumn{4}{|l|}{ EMPLOYEE BENEFITS } \\
\hline FY $96-10 / 01 / 95-09 / 30 / 96:$ & $44.50 \%$ & $46.50 \%$ & $45.00 \%$ \\
\hline FY $97-10 / 01 / 96-09 / 30 / 97:$ & $46.50 \%$ & $46.50 \%$ & $46.50 \%$ \\
\hline FY $98-10 / 01 / 97-09 / 30 / 98:$ & $46.50 \%$ & $38.50 \%$ & $44.50 \%$ \\
\hline \multicolumn{4}{|l|}{ OVERHEAD } \\
\hline FY $96-10 / 01 / 95-09 / 30 / 96:$ & $54.50 \%$ & $56.00 \%$ & $54.88 \%$ \\
\hline FY $97-10 / 01 / 96-09 / 30 / 97:$ & $56.00 \%$ & $63.00 \%$ & $57.75 \%$ \\
\hline FY $98-10 / 01 / 97-09 / 30 / 98:$ & $63.00 \%$ & $66.50 \%$ & $63.88 \%$ \\
\hline \multicolumn{4}{|l|}{ TECH/ADMIN } \\
\hline FY $96-10 / 01 / 95-09 / 30 / 96:$ & $7.90 \%$ & $7.90 \%$ & $7.90 \%$ \\
\hline FY $97-10 / 01 / 96-09 / 30 / 97:$ & $7.90 \%$ & $7.90 \%$ & $7.90 \%$ \\
\hline FY $98-10 / 01 / 97-09 / 30 / 98:$ & $7.90 \%$ & $7.90 \%$ & $7.90 \%$ \\
\hline \multicolumn{4}{|l|}{ ALLOCATED EXPENSE } \\
\hline FY $96-10 / 01 / 95-09 / 30 / 96:$ & $2.70 \%$ & $2.70 \%$ & $2.70 \%$ \\
\hline FY $97-10 / 01 / 96-09 / 30 / 97:$ & $2.70 \%$ & $2.70 \%$ & $2.70 \%$ \\
\hline FY $98-10 / 01 / 97-09 / 30 / 98:$ & $2.70 \%$ & $2.70 \%$ & $2.70 \%$ \\
\hline
\end{tabular}




\section{Appendix A}

\section{Alcator Publications}

\section{Papers Published in Refereed Journals}

Fuchs, V., Bonoli, P.T., Shkarofsky, I.P., Cote, A., Demers, Y., Janicki, C., "Simulations of Current Density Profile Control Using Lower Hybrid Current Drive in the TdeV Tokamak", Nuclear Fusion 35, (1995) 1.

Goetz, J.A., Lipschultz, B., Graf, M.A., et al., "Power Balance and Scaling of the Radiated Power in the Divertor and Main Plasma of Alcator C-Mod," Jour. of Nucl. Materials 220222, (1995), 971-975.

Hutchinson, I.H., LaBombard, B., Goetz, J.A., et al., "The Effects of Field Reversal on the Alcator C-Mod Divertor," Plasma Phys. and Controlled Fusion 37, (1995), 1389.

Hutchinson, I.H., "The Magnetic Presheath Boundary Condition with E $\times$ B Drifts," Phys. Plasmas 3, (1996), 6.

Kinsey, J., Kritz, A. Bonoli, P. Porkolab, M., "Time-Dependent Scenario Modeling of the Tokamak Physics Experiment Using a Theory-Based Transport Model", Physics of Plasmas 3, (1996) 1064.

LaBombard, B., Jablonski, D., Lipschultz, B., McCracken, G., Goetz, J., "Scaling of Plasma Parameters in the SOL and Divertor for Alcator C-Mod," Jour. of Nucl. Materials 220-222, (1995), 976-981.

May, M.J., Finkenthal, M., Regan, S.P., ... Terry, J.L., Graf, M.A., et al., "Measurements of Molybdenum Radiation in Alcator C-Mod Tokamak using a Multilayer Mirror Soft X-ray Polychromator," Rev. Sci. Instrum., 66, (Jan. 1995) 561.

McCracken, G.M., Bombarda, F., Graf, M., Goetz, J.A., et al., "Impurity Transport in the Divertor of the Alcator C-Mod Tokamak," Jour. of Nucl. Materials, 220-222, (1995), $264-268$.

Rice. J.E., Fournier, K.B., Graf, M.A., Terry, J.L., et al., "X-ray Observations of 21 - nl' Transitions in $\mathrm{Mo}^{30+}-\mathrm{Mo}^{33+}$ from Tokamak Plasmas," Phys. Rev. A 513551 (1995).

Rice, J.E., Graf, M.A., Terry, J.L., Marmar, E.S., et al., "X-ray Observations of Helium-like Scandium from the Alcator C-Mod Tokamak," J. Phys. B 28, 893 (1995). 
Takase Y., Golovato, S.N., Porkolab, M., Bonoli, P.T., Alcator Group, "Initial ICRF Coupling and Heating Experiments on Alcator C-Mod," Fusion Engineering and Design 26, 89 (1995).

Vahala, L., Vahala, G., Bonoli, P., Effects of Large Aspect Ratios and Fluctuations on Hard X-Ray Detection in Lower Hybrid Driven Divertor Tokamaks", Review of Scientific Instruments, 66, (1995) 838.

\section{Papers Submitted for Publication in Refereed Journals}

Bonoli, P.T., Porkolab, M. Ramos, J., "Negative Magnetic Shear Modes of Operation in the Alcator C-Mod Tokamak Near the Beta Limit", submitted to Plasma Physics and Controlled Fusion.

Niemczewski, A., Hutchinson, I.H., LaBombard, B., et al., "Neutral Particle Dynamics in the Alcator C-Mod Tokamak," submitted to Nuclear Fusion.

Snipes, J.A., Hubbard, A.E., Garnier, D.T., et al., "H-modes on Alcator C-Mod," submitted to Plasma Phys. and Control. Fusion.

Takase, Y, Boivin, R.L., Bombarda, F., et al., "Survey of ICRF heating experiments and enhanced performance modes in Alcator C-Mod," submitted to Plasma Physics and Controlled Fusion (1996).

\section{Papers to be Published in Refereed Journals}

Borras, M.C., Granetz, R.S., "Discrepancies Between Soft X-ray Emissivity Contours and Magnetic Flux Surfaces in Alcator C-Mod," to be published in Plasma Phys. and Controlled Fusion.

Goetz, J.A., Kurz, C., LaBombard, B., et al., "Comparison of Detracted and Radiative Divertor Operation in Alcator C-Mod," to be published in Phys. of Plasmas, June 1996.

Granetz, R.S., Hutchinson, I.H., Sorci, J., et al., "Disruptions and Halo Currents in Alcator C-Mod," to be published in Nuclear Fusion.

Granetz, R.S., Borras, M.C., "Is X-ray Emissivity Constant on Magnetic Flux Surfaces?" to be published in Fusion Eng. and Design. 
Rice, J.E., Bombarda, F., Graf, M.A., et al., "Multiple Plasma Diagnostics from a Five Chord High Energy Resolution X-ray Spectrometer Array," to be published in Fusion Engineering and Design.

Rice, J.E., Fournier, K.B., Terry, J.L., et al., "X-ray Observations of 21-nl' Transitions from Zr, Nb, Mo and Pd in Near Neonlike Charge States," to be published in Phys. Rev. A.

Rice, J.E., Terry, J.L., Fournier, K.B., Graf, M.A., et al., "X-ray and VUV Observations of $\mathrm{Mo}^{23+}-\mathrm{Mo}^{33+}$ Brightness Profiles from Alcator C-Mod Plasmas," to be published in J. Phys. B.

Snipes, J.A., "Characteristics of H-Modes on Alcator C-Mod," to be published in Phys. of Plasmas.

\section{MIT Plasma Fusion Center Research Reports (including theses)}

Borras, M.C., Granetz, R.S., "A Comparison of Soft X-ray Emissivity Contours with Magnetic Flux Surfaces in Alcator C-Mod," PFC/JA-95-12, May 1995.

Goetz, J.A., Kurz, C., LaBombard, L., et al., "Comparison of Detached and Radiative Divertor Operation in Alcator C-Mod," PFC/JA-95-44, Nov. 1995.

Graf, M.A., Rice, J.E., Terry, J.L., "Spectroscopic Measurement of Impurity Transport Coefficients and Penetration Efficiencies in Alcator C-Mod Plasmas," PFC/JA-95-1, Jan. 1995.

Graf, M.A., "Impurity Injection Experiments on the Alcator C-Mod Tokamak," PFC/RR95-6, June 1995.

Granetz, R.S., Hutchinson, I.H., Sorci, J., et al., "Disruptions and Halo Currents in Alcator C-Mod," PFC/JA-95-15, July 1995.

Hubbard,A.E., Hsu, T.C., O'Shea, P.J., and the Alcator C-Mod Group, "Alcator C-Mod Papers Presented at the 9th Joint Workshop on Electron Cyclotron Emission and Electron Cyclotron Resonance Heating," PFC/JA-95-11, April 1995.

Horne, S., Bertolino, V., Daigle, J., Fredian, T., et al., "First Demonstration of Remote Tokamak Control Operation of Alcator C-Mod from LLNL," PFC/JA-95-27, Aug. 1995. 
Hutchinson, I.H., Horne, S., Tinios, G., Wolfe, S.M., Granetz, R.S., "Plasma Shape Control: A General Approach and its Application to Alcator C-Mod," PFC/JA-95-4, Feb. 1995.

Hutchinson, I.H., LaBombard, B., Goetz, J., et al., "The Effects of Field Reversal on the Alcator C-Mod Divertor," PFC/JA-95-31, Aug. 1995.

Hutchinson, I.H., "The Magnetic Presheath Boundary Condition with E $\times$ B Drifts," PFC/JA-95-32, Aug. 1995.

Hutchinson, I.H., LaBombard, B., Lipschultz, B., "Experimental Divertor Similarity Database Parameters," PFC/RR-95-12, Dec. 1995.

Kurz, C., "Tomography of Light Emission from the Plasma Edge of Alcator C-Mod," PFC/RR-95-5, May 1995.

Marmar, E.S., "Active Spectroscopic Diagnostics for ITER Utilizing Neutral Beams," PFC/JA-95-33, Sept. 1995.

Niemczewski, A., "Neutral Particle Dynamics in the Alcator C-Mod Tokamak," PFC/RR95-8, Aug. 1995.

Porkolab, M., "Edge Turbulence Measurements During the $\mathrm{L}$ - to $\mathrm{H}$-mode Transition by Phase Contrast Imaging on DIII-D," PFC/JA-95-28, Aug. 1995.

Porkolab, M., Bonoli, P.T., Chiu, S.C., "Collisional Damping of the Fast Magnetosonic Wave in the Tokamak Edge Plasma," PFC/JA-95-29, Aug. 1995.

Rice, J.E., Fournier, K.B., Terry, J.L., et al., "X-ray Observations of $2 l-n l$ ' Transitions from Zr, Nb, Mo and Pd in Near Neonlike Charge States," PFC/JA-95-45, Nov. 1995.

Rice, J.E., Bombarda, F., Graf, M.A., Marmar, E.S., Terry, J.L., Wang, Y., "Multiple Plasma Diagnosis from a Five Chord High Energy Resolution X-ray Spectrometer Array," PFC/JA-95-46, Nov. 1995.

Snipes, J.A., Hubbard, A.E., Garnier, D.T., et al., "H-Modes on Alcator C-Mod," PFC/JA95-47, Nov. 1995.

Terry, J.L., Snipes, J.A., Kurz, C., "The Visible, Imaging Diode Arrays on Alcator CMod," PFC/JA-95-2, Jan. 1995. 
Tinios, G., "Axisymmetric Control in Alcator C-Mod," PFC/RR-95-2, Jan. 1995.

\section{Conferences}

22nd European Physical Society Conference

on Controlled Fusion and Plasma Physics

Bournemouth, 3-7 July 1995

(Eur. Phys. Soc., Geneva, Switzerland, 1995)

Bonoli, P.T., Porkolab, M., Hubbard, A., Sugiyama, L., Batchelor, D.B., Kessel, C., Nevins, W.M., "Simulations of Current Drive and Current Profile Control in the Tokamak Physics Experiment (TPX)", Vol. 19C, p. IV-121.

Lipschultz, B., Goetz, J.A., Hutchinson, I.H., et al., "An Investigation of the Extent of Divertor Detachment in Alcator C-Mod," Vol. 19C, p. II-325.

McCracken, G.M., Lipschultz, B., LaBombard, B., et al., "Impurity Screening in Alcator C-Mod," Vol. 19C, p. II-313.

Takase, Y., Boivin, R., Bombarda, F., et al., "ICRF Heating and Enhanced Confinement Modes in Alcator C-Mod," Vol. 19C, p. II-341.

11th Topical Conference on Radio Frequency Power in Plasmas

Palm Springs, CA 1995

AIP Conf. Proc. 355 ed R. Prater and V.S. Chan (AIP, NY, 1996)

Bonoli, P.T., Porkolab, M., Sugiyama, L., Kessel, C., "Current Drive and Current Profile Control in the Tokamak Physics Experiment (TPX)", p. 213

Golovato, S.N., Porkolab, M., Takase, Y., et al., "ICRF Heating in the Alcator C-Mod Tokamak," p. 23.

Porkolab, M., Bonoli, P.T., Golovato, S., et al., "Advanced Tokamak Physics Scenarios in Alcator C-Mod," p. 345.

Porkolab, M. Bonoli, P.T., "Collisional Damping of the Fast Magnetosonic Wave in the Tokamak Edge Plasma", p. 213. 
Takase, Y., Golovato, S., Porkolab, M., et al., "ICRF Heated Enhanced Performance Modes and Direct Electron Heating in Alcator C-Mod," p. 75.

Wright, J.C.,.Phillips, C.K., Bonoli, P.T., "Direct Calculation of Current Drive Efficiency in FISIC Code", p. 321.

\section{APS Abstracts}

36th Annual Meeting - Division of Plasma Physics of the American Physical Society,

Louisville, KY, Nov. 6-10, 1995.

Abstracts Published in Bull. Am. Phys. Soc., 40, 1995

Batishcheva, A., Batishchev, O., Krasheninnikov, S., et al., "Kinetic Simulation of Electron Transport in C-Mod SOL Plasmas with Fokker-Planck ALLA Code."

Boivin, R.L., Rost, J.C., and the ALcator Group, "Confinement Studies using CX Diagnostics in Alcator C-Mod."

Bombarda, F., Coppi, B., Fiore, C., et al., "Transport Regimes in High Density Plasmas Produced by Alcator C-Mod."

Bonoli, P.T., Porkolab, M., Sugiyama, L., Kessel, C., "Simulations of MHD Stable Operating Scenarios in the Tokamak Physics Experiment".

Bretz, N., Jobes, F., Grek, B., Irby, J., "Design of a Second Harmonic Tangential Array Interferometer for C-Mod."

Daughton, M., Coppi, B., Sugiyama, L., et al., "Transport Simulations of Alcator C-Mod ICRF Plasmas."

Fiore, C., Boivin, R.L., "Neutron Measurements from Alcator C-Mod."

Fournier, K.B., Goldstein, W.H., May, M.J., ..., Terry, J.L., Rice, J.E., et al., "CollisionalRadiative Modeling of Core Impurity Ions in Tokamak Plasmas.

Goetz, J.A., LaBombard, B., Lipschultz, B., et al., "Comparison of Detached and Radiative Divertor Operation in Alcator C-Mod."

Greenwald, M., Schachter, J., and the Alcator Group, "Transport Studies on Alcator CMod." 
Horne, S.F., Fredian, T.W., Stillerman, J.A., et al., "First Control of a Tokamak from a Remote Site."

Horne, S.F., Fredian, T.W., Stillerman, J.A., et al., "First Control of a Tokamak from a Remote Site." "TSC Plasma Halo Simulation of an Alcator C-Mode Disruption."

Hosea, J.C., Bonanos, P., Gereg, L., "Final Design and Analysis of the PPPL-MIT Four Strap Antenna for Alcator C-Mod."

Hubbard, A.E., Irby, J., O'Shea, P.J., et al., "Electron Temperature Profiles During L and H-mode on Alcator C-Mod."

Hutchinson, I.H., Goetz, J., Kurz, C., et al., "Effects of Field Direction on Divertor Assymetry in Alcator C-Mod."

Johnson, D., Grek, B., Palladino, R., et al., "The C-Mod Divertor Thomson Scattering System."

Kurz, C., LaBombard, B., Lipschultz, B., et al., Measurements of Neutral Density Beam on $\mathrm{H}_{\alpha}$ Emissivity in the Alcator C-Mod Divertor."

LaBombard, B., Jablonski, D., Kurz, C., et al., "Evidence of Strong Plasma-Neutral Momentum Coupling in the Alcator C-Mod Divertor."

Ma, C.H., Hutchinson, D.P., Richards, R.K., Irby, J., "A Feasibility Study of an Infrared Tangential Viewing Polarimeter for Measurement of the Electron Density Profile in ITER."

Marmar, E.S., Garnier, D.T., Terry, J.L., et al., "q Profile Measurements using Lithium Pellets on Alcator C-Mod."

May, M.J., Regan, S.P., Finkenthal, M., et al., "Molybdenum Impurity Concentrations and Their Associated Radiative Power Losses in Ohmic and ICRF-heated Alcator C-Mod Plasmas."

Porkolab, M., Bonoli, P.T., Golovato, S., et al., "Advanced Tokamak Physics Scenarios in Alcator C-Mod."

Qu, Y.L., Rice, J.E., Marmar, E.S., Bombarda, F., "X-ray Observations of Toroidal Rotation in Alcator C-Mod Plasmas." 
Ramos, J.J., Bonoli, P.T., "Reverse Shear Operating Modes in ITER".

Regan, S.P., May, M.J., Finkenthal, M., et al., "Design of a Multilayer Mirror Divertor Diagnostic for Emissions from Low and High Z Impurities in Alcator C-Mod."

Reardon, J., Boivin, R., Golovato, S.N., et al., "Evidence of Parametric Decay Instabilities During ICRF Heating on Alcator C-Mod."

Rice, J.E., Terry, J.L., Marmar, E.S., Bombarda, F., "X-ray Observations of Up-Down Impurity Density Asymmetries in Alcator C-Mod Plasmas."

Richards, R.K., Hutchinson, D.P., Ma, C.H., Takase, Y., "A Co-2-Laser Thomson Scattering Diagnostic for Ion-Tail Measurements."

Rost, J.C., Boivin, R.L., Bonoli, P., et al., "Charge Exchange Flux from the Edge during ICRF Heating on Alcator C-Mod."

Sayer, R.O., Jardin, S.C., Wolfe, S.M., Granetz, R.S.,

Schachter, J., Greenwald, M., and the Alcator Group, "Local Transport Analysis for Alcator C-Mod."

Snipes, J.A., Christensen, C., Fiore, C., et al., Characteristics of H-Modes in Alcator C-Mod."

Sorci, J., Granetz, R.S., Hutchinson, I.H., et al., "Disruptions and Halo Currents in Alcator C-Mod."

Stek, P., Irby, J., Christensen, C., et al., "Edge Electron Density Studies Using Reflectometry on Alcator C-Mod."

Takase, Y., Bonoli, P., Garnier, D., et al., "High Power ICRF Heating in Alcator C-Mod."

Vesey, R.A., Stotler, D.P., Snipes, J.A., et al., "Neutral Particle Modeling of Alcator CMod Divertor Plasmas."

Wang, Y., Rice, J., Bombarda, F., et al., Impurity Screening Study of Various Alcator C-Mod Plasmas."

Watterson, R., Casey, J.A., Hubbard, A., et al., "Operation of the Alcator C-Mod YAG 
Thomson Scattering Diagnostic."

Welch, B.L., Griem, H.R., Weaver, J.L., "Divertor and Plasma Edge Parameters of Alcator C-Mod from Visible and Ultraviolet Emissions."

Wolfe, S.M., Hutchinson, I.H., Horne, S.F., et al., "Quasi-orthogonal Plasma Shape Control on Alcator C-Mod."

\section{APS Orals}

36th Annual Meeting - Division of Plasma Physics of the American Physical Society

Louisville, KY, Nov. 6-10, 1995.

Abstracts Published in Bull. Am. Phys. Soc., 40, 1995

Christensen, C., Marmar, E., Hubbard, A., et al., "Particle Transport Measurements from Visible Contiuum Profiles on Alcator C-Mod."

Garnier, D.T., Marmar, E.S., Takase, Y., et al., "Lithium Pellet Enhanced Performance Discharges on Alcator C-Mod."

Golovato, S., Bonoli, P., Porkolab, M., et al., "Heating and Confinement in the ICRFheated Alcator C-Mod Tokamak."

Granetz, R.S., Garnier, D., Marmar, E.S., Terry, J.L., "Killer Pellet Experiments on Alcator C-Mod."

Irby, J., Hutchinson, I.H., and the Alcator Group, Alcator C-Mod Tokamak Operation and Experimental Development."

Jablonski, D., LaBombard, B., Lipschultz, B., McCracken, G.M., Terry, J., "Observation of Impurity Injection Plumes in the Scrape-Off Layer of the Alcator C-Mod Tokamak."

Knoll, D., Mchugh, P., Krasheninnikov, S., et al., Characterization of C-Mod Like Detached Divertor Plasmas."

McCracken, G.M., Terry, J., Granetz, R.S., et al., "Screening of Non-Recycling Impurities in Alcator C-Mod."

O'Shea, P., Takase, Y., Bonoli, P., et al., "Deposition and Transport Measurements During 
First Wave Mode-Conversion Heating on Alcator C-Mod."

Terry, J.I., Goetz, J.A., Lipschultz, B., et al., "Investigation of the X-point Region in Alcator C-Mod Plasmas."

International Sherwood Fusion Theory Conference

Incline Village, NV, April 3-5, 1995

Bonoli, P.T., Porkolab, M., Kessel, C., "Analysis of Self-Consistent MHD Stable Operating Scenarios in the Tokamak Physics Experiment", Paper 1D42.

McCracken, G.M., and the Alcator Group, "Experimental Data for the Edge Model Validation," (invited paper).

\section{Invited Papers}

Goetz, J.A. "Comparison of Radiative Divertor Characteristics in Alcator C-Mod with Detached and Attached Divertor Operation," presented at APS, Nov. 6-10, 1995, Louisville, KY.

Granetz, R.S., "Disruptions and Halo Currents in Alcator C-Mod," presented at APS, Nov. 6-10, 1995, Louisville, KY.

Marmar, E.S., "Active Spectroscopic Diagnostics for ITER Utilizing Neutral Beams," presented at the International School of Plasma Physics "Piero Caldirola" workshop on Diagnostics for ITER,"' Varenna, Italy, Aug. 28 - Sept. 1, 1995.

Rice, J.E., "X-ray Observations of 21-nl' Transitions from Zr, Nb, Mo and Pd in Near Neonlike Charge States," presented at the $10^{\text {th }}$ APS Topical Conference on Atomic Processes in Plasmas, Jan. 15, 1996, San Francisco, CA.

Snipes, J.A., "H-Modes on Alcator C-Mod," presented at APS, Nov. 6-10, 1995, Louisville, KY. 


\section{Workshop Presentations}

Workshop on Plasma Edge and Divertor Physics

Garching, Germany, May 16-17, 1995

Hutchinson, I.H., for the Alcator Group, "Overview of Alcator C-Mod Divertor Research."

LaBombard, B., for the Alcator Group, "Scrape-off Layer and Divertor Transport on Alcator C-Mod."

LaBombard, B., for the Alcator Group, "Divertor Detachment and 'Death-Rays' on Alcator C-Mod."

9th Joint Workshop on Electron Cyclotron Emission

Borrego Springs, CA, Jan. 22-26, 1995

Hubbard, A.E., Hsu, T.C., O'Shea, P.J., "Michelson Interferometer for $\mathrm{T}_{e}$ Profile Measurements on Alcator C-Mod."

O'Shea, P.J., Hubbard, A.E., and the Alcator C-Mod Group, "Nine Channel Polychromator for Fast $T_{e}$ Measurements on Alcator C-Mod."

\section{Other Workshops}

Bonoli, P.T., Porkolab, M., Kessel, C., Nevins, W.M., "Heating and Current Drive Scenario Modelling in TPX", TPX Physics Meeting, General Atomics, San Diego, CA, Jan. 26-27, 1995.

Bonoli, P.T., Porkolab, M., Kessel, C., "Current Drive and Heating Scenarios in TPX", TPX Physics Meeting, Massachusetts Institute of Technology, Cambridge, MA, May 4-5, 1995.

Granetz. R.S., "Disruptions and Halo Currents in Alcator C-Mod," ITER Disruptions Workshop, Garching, Germany, Feb. 14, 1995.

McCracken, G.M., for the Alcator Group, "First Wall Studies in Alcator C-Mod," presented at Plasma Facing Materials and Components Task Group Meeting, Pleasanton, CA, Sept. 19-21, 1995. 
Takase, Y., "Mode Conversion Electron Heating in Alcator C-Mod," presented at the Mode Conversion Current Drive Meeting, Louisville, KY, 5 November 1995.

Takase, Y., "Transport and Transport Barriers on Alcator C-Mod," presented at the Transport and Transport Barriers Workshop, Austin, TX, 8-11 January 1996.

\section{Other Presentations}

Boivin, R.L., "Ion Temperature Measurements in Alcator C-Mod," Centre Canadien de Fusion Magnetique (CCFM) seminar, Varennes, Canada, Dec. 19, 1995.

Granetz, R.S., "Tokamaks: Where We Are and Where We Have to Go," Distinguished Lecture Series at Lincoln Labs, Jan. 11, 1995.

Granetz, R.S., "Disruptions and Halo Currents in Alcator C-Mod," invited seminar at Columbia University, April 7, 1995.

Greenwald, M., "Recent Highlights from the Alcator C-Mod Program," PPPL colloquium, Jan. 1996.

Greenwald, M., "Transport Program in Alcator C-Mod," New York Univ. Courant Institute Seminar, May 1995.

Hutchinson, I.H., "Recent Results from Alcator C-Mod," PPPL colloquium, Jan. 25, 1995.

Hutchinson, I.H., "The Alcator C-Mod Program, Recent Achievements," briefing at Office of Fusion Energy, Feb. 22, 1995.

Hutchinson, I.H., "Thermonuclear Fusion," Electrochemical Society, N.E. Division, April 11, 1995.

Hutchinson, I.H., "Recent Results from Alcator C-Mod," Colloquium at University of Stuttgart, May 15, 1995.

Hutchinson, ,I.H., "Recent Results from Alcator C-Mod of Particular Interest to ITER," Seminar at ITER JCT, San Diego, May 25, 1995.

Hutchinson, I.H., "Alcator C-Mod Accomplishments and Plans," FPA Annual Meeting, Montreal, Sept. 7, 1995. 
Rice. J.E., "X-ray Observations of 21-nl' Transitions in $\mathrm{Mo}^{30+}-\mathrm{Mo}^{33+}$," $11^{\text {th }}$ International Colloquium on UV and X-ray Spectroscopy of Astrophysical and Laboratory Plasmas, May 29 - June 2, 1995, Nagoya, Japan.

Rice, J.E., "Multiple Plasma Diagnosis from a 5 Chord,, High Energy Resolution X-ray Spectrometer Array," 7th International Toki Conference on Plasma Physics and Controlled Nuclear Fusion, Nov. 28 - Dec. 1, 1995, Toki, Japan.

Takase, Y., "Recent ICRF Results on Alcator C-Mod," presented at Max-Planck-Institut für Plasmaphysik, Garching, Germany, 17 July 1995.

Takase, Y., "High Power ICRF Heating in Alcator C-Mod," presented at Columbia University, New York, NY, 17 November 1995.

Wolfe, S.M., "The Alcator C-Mod Tokamak Program: Highlights of Recent Achievements and Prospects for the Future," Plasma Fusion Center IAP Seminar, Jan. 17, 1996. 



\section{Appendix B \\ Collaborations}

Collaborations form an integral and increasingly important part of the Alcator C-Mod program. Because of the knowledge and skills which they bring to these efforts, there are many contributions which collaborators make to strengthen our program. Collaborations allow us to utilize outside expertise to solve those problems which we cannot staff. They help to maximize the utilization of C-Mod in the context of the decreasing number of major facilities in the US program. They promote a broader perspective for our program within the context of the world fusion and plasma physics efforts. As we are a relatively small group (among the major US facilities), collaborations provide a high leverage avenue to increase our productivity, and many scientific opportunities exist in our program for outside participation. It must also be recognized that increased collaborations require resources at MIT, to provide scientific, engineering and computing infrastructure. In addition, each collaboration requires a level of direct MIT scientific staff involvement, for coordination and integration.

Table B.I lists recent and ongoing collaborations. Two major collaborative efforts are planned; the first, with PPPL on ICRF and diagnostics, began in FY94, and is envisioned to grow in scope during FY97 and FY98; the second is a new effort, in conjunction with the University of Texas, to bring to C-Mod diagnostic hardware, including a diagnostic neutral beam and associated spectroscopy, along with science, engineering and technical effort. Details of these two collaborations, along with highlights from some of the other projects, are described in the following sections.

\section{B.1 PPPL Collaborations}

The most ambitious component of the MIT-PPPL collaboration is in the ICRF area. Cavities for four MW of tunable ( 40 to $80 \mathrm{MHz}$ ) source power transmitters will be transferred from TFTR to C-Mod. We at MIT are bringing up two of our FMIT sources for this system, and once commisioned, it will be connected to our existing 2 two-strap antennas, which can be operated in current drive phasing. In parallel, Princeton is designing and will build a 4-strap antenna, which when installed will allow us to couple all of the available transmitters, bringing our total ICRF source capability to $8 \mathrm{MW}$. This will enable us to reach our divertor power loading design values, significantly enhancing our ITERrelevant dissipative divertor studies. Current drive and heating experiments, including the investigation of advanced mode-conversion schemes, will also be undertaken. Princeton personnel, including physicists and engineers, are contributing to this program, both in 
the design, construction and installation phases, as well as through the operations phase. The schedule of this effort is being driven by budget limitations. Assuming the PPPL construction is completed in time, the new antenna will be installed in C-Mod early in FY98.

Under an SBIR Grant with DoE, Princeton Scientific Instruments(PSI) has designed a Thomson scattering system for the Alcator C-Mod divertor region, to measure temperature and density profiles in the vicinity of the last closed flux surface, near the $\mathrm{x}$-point. PSI has designed and built the optical systems to couple the laser light in and the scattered light out of the tokamak, along with spectrometers and detectors to analyze the scattered light. PPPL is providing the laser, data acquisition hardware, and manpower to operate the experiment and analyze the results. MIT is providing interface hardware, as well as local infrastructure support necessary to implement the system. Work on this project began in FY94. The in-vessel optical system was installed in the machine in FY95, and installation of the laser and spectrometers is planned for the spring of 1996. First measurements should be available during the summer run campaign.

\section{B.2 FRC-Texas Collaboration}

The Fusion Research Center at the University of Texas has proposed a major collaboration on C-Mod with an overall theme of studying turbulence and transport. They propose to ship the TEXT diagnostic neutral beam (DNB) and associated hardware to C-Mod. They will also take primary responsibility for providing spectroscopic diagnostics to view the beam, including systems for charge exchange recombination spectroscopy (CXRS), and beam emission spectroscopy (BES). CXRS will increase our measurement capabilities (spatial and temporal resolution) for ion temperature profiles, rotation profiles (both poloidal and toroidal) and low $\mathrm{Z}$ impurity density evolution, including helium, boron and carbon. The BES system will allow us to diagnose density fluctuation profiles well into the core of the plasma. MIT will take responsibility for implementing a motional stark effect (MSE) system, to measure current density profiles. The MSE measurements, which also rely on the DNB, will be particularly valuable when we begin current density profile modification experiments with current drive, first with the fast-wave system and later with lower hybrid. Texas will also add a radiometer detection system to our existing ECE collection optics, to measure electron temperature fluctuations.

\section{B.3 Highlights of Other Diagnostic Collaborations}

\section{B.3.1 Los Alamos National Laboratory}

Collaboration with the fusion diagnostic group at Ios Alamos was begun in FY95. 
Due to funding constraints, this effort will be relatively limited in scope during FY96. Concentration has been on the testing of a high speed imaging CCD camera, which has been used to observe various plasma wall interaction phenomena, including the results of disruptions. Near term plans include the installation of IR imaging system to measure the surface temperature rise of plasma facing components, both during normal operation and after major disruptions.

\section{B.3.2 University of Maryland}

An ongoing collaboration with Ben Welch is focussed on visible/UV imaging spectroscopy, to measure impurity influxes, isotope ratios, and edge/divertor density and ion temperature. A two-dimensional imaging system was installed, and is now operational, enhancing the diagnostic, adding flow velocity measurements to the other capabilities.

\section{B.3.3 Johns Hopkins University}

Collaboration with Michael Finkenthal and coworkers at JHU involves a Multi-LayerMirror based polychromator system which is used primarily to monitor molybdenum dynamics in the confined plasma. In addition, with co-workers from Lawrence Livermore and Hebrew University, detailed calculations related to the atomic physics of highly ionized molybdenum are being carried out by the Hopkins group, in order to allow very detailed interpretation of the EUV and x-ray measurements from these species, and relate them directly to the plasma parameters of interest (molybdenum density, and electron temperature and density). A new system aimed at enhancing our divertor diagnostics, also based on MLM technology, is presently being designed and will be implemented on C-Mod. This system will, at first, be aimed at measurements of nitrogen near the X-Point, and should be particularly useful for dissipative divertor studies.

\section{B.3.4 Science Research Laboratory}

Steve Fulghum, from Science Research Laboratory, is developing a visible imaging fluctuation diagnostic for implementation on C-Mod. Funded by a Phase II SBIR grant, this project is aimed at developing a diagnostic which can be used to measure the $\omega$ and $k$ spectra of the broad band turbulent fluctuations. Initial measurements, which were undertaken in FY94, using $\mathrm{H}_{\alpha}$ emission and a prototype detector system, were very promising, and extension of the technique to use bremsstrahlung emission, in order to measure more deeply into the core plasma, is under investigation. The second generation imaging system will be installed on C-Mod during the spring of 1996.

B.4 Transport and Modeling

B.4.1 Dimensionless Scaling Studies 
Alcator C-Mod can be run in regimes which are equivalent in dimensionless parameters to a number of other tokamaks, including DIIID, JET, ASDEX-U, JT60-U and COMPASS, but with very different dimensional parameters from all of these. One of the crucial issues which impacts the predictions of ITER operation is the extrapolation of confinement results from presently operating experiments, and C-Mod provides extremely important information about this extrapolation. Experiments have already begun in this area, in concert with DIIID and ASDEX-U. $\rho^{*}$ scaling comparisons with JET, JT60-U, DIIID, ASDEX-U and COMPASS will commence on C-Mod after the PPPL tunable ICRF system comes into operation.

\section{B.4.2 Modeling}

MHD stability modeling of C-Mod discharges is an ongoing collaborative effort with Ramos and coworkers at MIT, as well as with Glasser at LANL, whose DCON code is being used to examine stability of PEP-mode and H-Mode discharges. Coppi and coworkers from MIT, with Francesca Bombarda from Frascati, are looking at a variety of transport modeling and theory issues. Bill Dorland, from the IFS at U. Texas has recently begun analyzing C-Mod transport results using the IFS-PPPL model.

Edge/Divertor modeling of C-Mod discharges is primarily accomplished through collaboration. Dana Knoll, of INEL, working with Frederick Wising (MIT/Sweden), uses the UEDGE code to investigate divertor plasma dynamics of our discharges. Peter Stangeby and his group at the University of Toronto are using their 2-D impurity Monte Carlo code, DIVIMP, in the analysis of C-MOD edge and divertor data, with particular emphasis on impurity flows and shielding. Batishev and Krasheninnikov, at MIT, are involved in parallel transport kinetic modeling for the divertor and edge, along with investigations into the possible roles that molecules may play in divertor dynamics. Loarte, at JET, is using the EDGE2D code to model C-Mod data and together with Vlases, comparing C-Mod and JET divertor results.

\section{B.5 Remote operation of C-Mod}

As the national and international fusion programs move in the direction of large, multiinstitution facilities, the ability to provide fully functional off-site control rooms will play an extremely important role in helping to maximize the efficient utilization of these facilities. In collaboration with Lawrence Livermore National Laboratory, we operated C-Mod from Livermore. In this 2 day demonstration, The physics operator and session leader were located at Livermore. Shot choices were controlled over the network, through our Plasma Control System (PCS) interface. Other CAMAC controlled parameters, including the 
timing and power level for the ICRF auxiliary heating systems and some diagnostics, were also controlled from Livermore. Engineering control, through our PLC network, remained on-site at MIT. Computerized real-time audio and video links were provided between our control room and the Livermore site, which facilitated between-shot communications. 
Table B.1 Recent and Ongoing Collaborations Divertor/Edge

- PPPL/PSI - Divertor Thomson Scattering (D. Johnson, Dimock)

- PPPL - High Resolution Spectroscopy (Skinner)

- U. Md. - High Resolution Spectroscopy (Welch)

- U. Toronto - Edge Modeling - DIVIMP (Stangeby)

- JET - EDGE2D Modeling - (Loarte)

- INEL \& MIT/Sweden - UEDGE Modeling - (Knoll \& Wising)

- PPPL - DEGAS II Edge Modeling

- MIT - Parallel Transport Kinetic Modeling (Batishev, et al.)

- JET - Divertor Similarity Studies (Vlases)

- LLNL/DIII-D - Coordinated Divertor Studies (Allen, Hill)

- LANL - Visible/IR Imaging (Wurden)

- Johns Hopkins U. - Divertor Soft X-Ray Diag. (Finkenthal, May) RF/Advanced Tokamak

- PPPL - Sources, Antennas (Wilson, et al.)

- Max-Planck - RF Modeling (Brambilla)

- PPPL - Experiments (Majeski)

- GA - Experiments (Pinsker)

- JAERI - Experiments (Kimura)

- MIT/PPPL - PEST (Kessel, Ramos)

Transport/Stability

- DIII-D - Dimensionless Scaling (DeBoo, et al.)

- ASDEX-UG - Dimensionless Scaling (Noterdaeme, et al.)

- PPPL - TRANSP (McCune, et al.)

- LLNL/JHU - High Z Atomic Physics (Fournier, et al.)

- Frascati/MIT - Modeling, Theory (Bombarda, Coppi, Migliuolo)

- Science Research Lab. - Fluctuation Diagnostics (Fulghum)

- U. Illinois/Lehigh U. - Transport Modeling (Singer, Kinsey)

- LANL - DCON MHD Stability (Glasser)

- IFS-Texas - Transport modeling (Bill Dorland) 
Table B.1 Recent and Ongoing Collaborations (continued)

Wall Conditioning

- KFA Julich - Boronization (Esser, Winter)

General Diagnostics

- JHU - Core Molybdenum Diagnostics (Finkenthal, May)

- ORNL - $\mathrm{CO}_{2}$ Scattering (Richards)

Personnel Exchanges with:

- FTU - Bombarda, Kroegler, Giovannozzi

- JT60-U - Takase, Golovato, Moriyama, Kimura

- NIFS/LHD - Kondo, Mizuuchi, Sudo

- Nagoya U. - Sugai

- ASDEX-U - Takase, Snipes, Hartmann

- TCV (Lausanne) - Lister, Snipes, Greenwald

- JET - Hutchinson, Loarte

Plasma Physics "Community"

- ITER Database and Experts Participation

- Disruptions, H-Mode, Diagnostics, Confinement, Divertor

- LLNL - Remote Control Room (Casper, et al.)

- NIST - Atomic Physics (Sugar, et al.)

- TCV - Hybrid Computer (completed)

- Padua/LANL - Data Acquisition and Analysis Software (completed)

Planned Major Collaboration with U. Texas

- Diagnostic Neutral Beam

- Associated Diagnostics (CXRS, BES, MSE)

- ECE Temperature Fluctuations

- Probes

- Participation of 4 FTE Scientists and 4 Students 
